FABIÁN NÚÑEZ LARROTTA

ESTUDO E IMPLEMENTAÇÃO DE SINAIS DE EXCITAÇÃO APLICADOS EM IDENTIFICAÇÃO DE SISTEMAS MULTIVARIÁVEIS 


\section{ESTUDO E IMPLEMENTAÇÃO DE SINAIS DE EXCITAÇÃO APLICADOS EM IDENTIFICAÇÃO DE SISTEMAS MULTIVARIÁVEIS}

Dissertação apresentada à Escola Politécnica da Universidade de São Paulo para obtenção do título de Mestre em Ciências. 


\section{ESTUDO E IMPLEMENTAÇÃO DE SINAIS DE EXCITAÇÃO APLICADOS EM IDENTIFICAÇÃO DE SISTEMAS MULTIVARIÁVEIS}

Dissertação apresentada à Escola Politécnica da Universidade de São Paulo para obtenção do título de Mestre em Ciências.

Área de Concentração:

Engenharia de Sistemas

Orientador: Prof. Dr. Claudio Garcia 


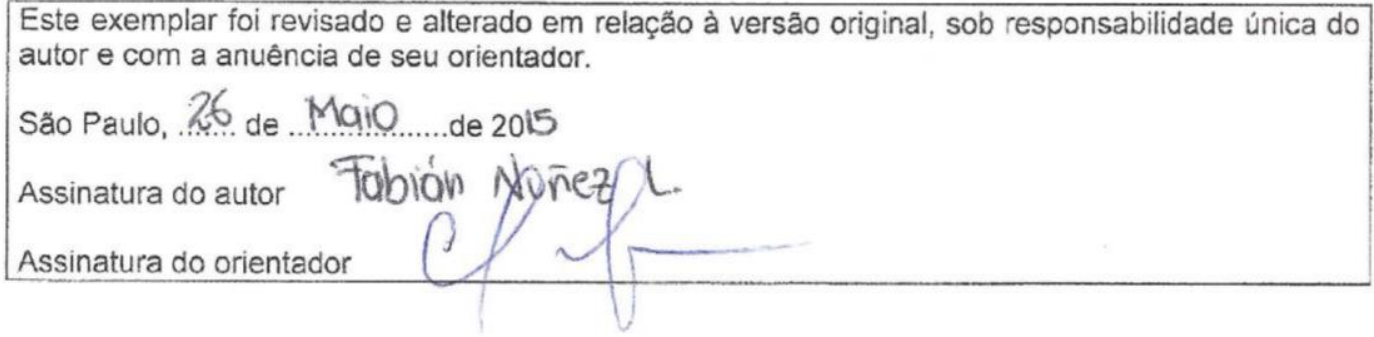

\section{Catalogação-na-publicação}

Larrotta, Fabián Núñez

Estudo e Implementação de Sinais de Excitação Aplicados em Identificação de Sistemas Multivariáveis / F. N. Larrotta -- versão corr. -- São Paulo, 2015. $126 \mathrm{p}$.

Dissertação (Mestrado) - Escola Politécnica da Universidade de São Paulo. Departamento de Engenharia de Telecomunicações e Controle.

1.Identificação de Sistemas 2.Sinal PRBS 3.Sinal GBN 4.Correlação Cruzada 5.Identificação MIMO I.Universidade de São Paulo. Escola Politécnica. Departamento de Engenharia de Telecomunicações e Controle II.t. 
Dedicado a

minha família 


\section{Agradecimentos}

Meus sinceros agradecimentos ao professor Dr. Claudio Garcia pela grande oportunidade, orientação e apoio constante para a realização deste trabalho.

Aos colegas do grupo de pesquisa pelo conhecimento compartilhado. Aos meus amigos e companheiros do caminho Roy Daniel Aguirre, Mariana Inglez, Marcela Hernández, Laura Lima, Carolina Manchola, Jennifer Salguero e Juan Guillermo Ladino por fazerem parte da minha vida e estiverem ao meu lado sempre.

Agradeço aos meus pais Fidel e Edilma por muito me influenciar com seus exemplos de dedicação, por seus conselhos, por ser o meu grande apoio e meu combustível. Aos meus irmãos por sempre me animarem e darem forças para continuar. A Vanessa Tarazona pela paciência e pelo seu amor, principalmente nos momentos difíceis.

Ao LAC - Laboratório de Automação e Controle da Escola Politécnica de USP e ao CETAI - Centro de Excelência em Tecnologia de Automação Industrial da PETROBRAS pela disponibilização dos recursos físicos.

À CAPES pelo apoio financeiro 


\section{Resumo}

Devido à crescente implementação do Controle Preditivo baseado em Modelo (MPC) em outros processos além de refino e plantas petroquímicas, que geralmente possuem múltiplas entradas e saídas, tem-se um aumento na demanda de modelos gerados por identificação de sistemas.

Identificar modelos que representem fielmente a dinâmica do processo depende em grande medida das características dos sinais de excitação dos processos. Assim, o foco deste trabalho é realizar um estudo dos sinais típicos usados em identificação de sistemas, PRBS e GBN, em uma abordagem multivariável. O estudo feito neste trabalho parte das características da geração dos sinais individualmente, depois é feita uma análise de correlação cruzada dos sinais de entrada, observando a influência desta sobre os resultados de identificação. Evitar uma alta correlação entre os sinais de entrada permite determinar o efeito de cada entrada sobre a saída no processo de identificação.

Um ponto importante no projeto de sinais de identificação de sistemas multivariáveis é a frequência dos mesmos para conseguir excitar os processos nas regiões de frequência de operação normal e assim extrair a maior informação dinâmica possível do processo.

As características estudadas são avaliadas por meio de testes em três plantas simuladas diferentes, categorizadas como mal, medianamente e bem condicionadas. Estas implementações foram feitas usando sinais GBN e PRBS de diferentes frequências. Expressões para a caracterização dos sinais de excitação foram avaliadas identificando os processos em malha aberta e malha fechada. Para as plantas mal condicionadas foram implementados sinais compostos por uma parte completamente correlacionada e uma parte não-correlacionada, conhecido como método de dois passos.

Finalmente são realizados experimentos de identificação em uma aplicação em tempo real de uma planta piloto de neutralização de $\mathrm{pH}$. Os testes realizados na planta foram feitos visando avaliar os estudos de frequência e correlação em uma aplicação real. Os resultados mostram que a condição de sinais completamente descorrelacionados não deve ser cumprida para ter bons resultados nos modelos identificados. Isto permite ter mais flexibilidade na geração do conjunto de sinais de excitação.

Palavras-chave: Identificação de sistemas, Sinal PRBS, Sinal GBN, Correlação cruzada, Identificação MIMO. 


\section{Abstract}

Due to the Predictive Control based on Model (MPC) rising in other process beyond refining and petrochemical plants, which in general have multiple inputs and outputs, there have been an increase in demand of models generated by system identification.

Identify models that accurately represent the dynamics of the process depends largely on the characteristics of the processes excitation signals. Thus, the focus of this work is to perform a study of the typical signals used in identification systems, PRBS and GBN, in a multivariable approach. The study carried out in this work begins on the individual generation characteristics of the signals, and then an analysis is made of input signals cross-correlation, by observing the influence of this on the identification results. Avoid a high correlation among the input signals allows to determine the effect of each input on the output of the identification process.

An important point in the signals design for multivariable system identification is its frequency to get excite the processes in the normal operation frequency regions and thus extract the maximum dynamic information possible of the process.

The studied characteristics are evaluated by testing three different simulated plants, categorized as well, medium and ill conditioned. These implementations were made using GBN and PRBS signals of different frequencies. Expressions to characterize the excitation signals were evaluated identifying the processes in open and closed-loop. For ill-conditioned plants were implemented signals composed by a fully correlated part and a non-correlated part, known as two-step method.

Finally, identification experiments are performed on a real time application in a pilot $\mathrm{pH}$ neutralization plant. The tests were made in the plant in order to evaluate the frequency and correlation studies in a real application. The results show that the completely uncorrelated signals condition must not be satisfied to have good results on the identified models, which besides allows greater flexibility in the generation of the excitation signals set.

Keywords: Identification systems, PRBS signal, GBN signal, Cross-correlation, MIMO Identification. 


\section{Lista de Figuras}

2.1 Ciclo da Identificação de Sistemas. . . . . . . . . . . . . . . . p. 16

2.2 Estrutura de um modelo. . . . . . . . . . . . . . . . . . . . . p. 19

2.3 Estrutura de um modelo em malha fechada. . . . . . . . . . . . . p. 21

3.1 Registro de deslocamento com realimentação módulo 2. . . . . . . . . p. 25

3.2 Sinal PRBS de comprimento 63 e tempo de bit $4 \ldots \ldots$. . . . . . p. 27

3.3 Espectro de potência do sinal da Figura 3.2 . . . . . . . . . . p. 27

3.4 Função de autocorrelação dos primeiros 60 atrasos do sinal da Figura 3.2. p. 27

3.5 Sinal GBN de comprimento 50 e $p=0,7 \ldots \ldots \ldots$ p. 29

3.6 Espectro de potência de sinais GBN. . . . . . . . . . . . . . p. 29

3.7 Espectro de potência do sinal da Figura 3.5 . . . . . . . . . . . p. 30

3.8 Função de auto correlação do sinal da Figura 3.5. . . . . . . . . . . . p. 30

4.1 Diagrama de blocos relacionando as entradas e saídas do Reator. . . . . p. p.34

4.2 Diagrama de blocos do Reator de Polimerização em malha fechada. . . p. 34

4.3 Diagrama de blocos relacionando as entradas e saídas da coluna de destilação. . . . . . . . . . . . . . . . . p. . 36

4.4 Diagrama de blocos relacionando as entradas e saídas da Coluna de Destilação em malha fechada. . . . . . . . . . . . . . . . . . . . . p.37

4.5 Coluna de alta pureza. . . . . . . . . . . . . . . . p. 38

4.6 Plano de saídas $\left\{y_{1} ; y_{2}\right\}$ resultado de um teste com sinal GBN no modelo

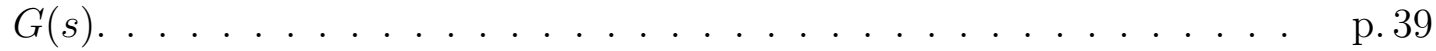

5.1 Função de correlação . . . . . . . . . . . . . . . . . . . . . . . p. 43

5.2 Correlações cruzadas entre sequências PRBS. . . . . . . . . . . . p. 44

5.3 Correlações cruzadas entre sequências GBN. . . . . . . . . . . . p. 45

5.4 Correlações cruzadas máximas entre três combinações de sequências PRBS. p. 46

5.5 Correlações cruzadas mínimas entre três combinações de sequências PRBS. p. 46

5.6 Correlações cruzadas máximas entre três combinações de sequências GBN. p. 47

5.7 Correlações cruzadas mínimas entre três combinações de sequências GBN. p. 47

5.8 Espectro de potência de sequências GBN com diferentes sementes e comprimento $N=1500, p=0,775 \ldots \ldots \ldots \ldots \ldots$ p. 50 
5.9 Espectro de potência de sequências GBN com diferentes sementes e comprimento $N=10000, p=0,775 \ldots \ldots \ldots \ldots$ p. . . . . . . . . . . .

5.10 Espectro de potência de sequências GBN com diferentes sementes e comprimento $N=1500, p=0,775 \ldots \ldots \ldots \ldots \ldots$ p. . . . . . . . . . . 51

5.11 Frequência de $3 \mathrm{~dB}$ para sinais GBN com comprimento $N=1500$. . . p. p. 51

5.12 Espectro de sequências PRBS com diferentes sementes, comprimento

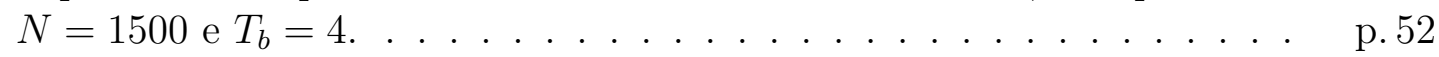

5.13 Espectro de sequências GBN com diferentes sementes, comprimento $N=$

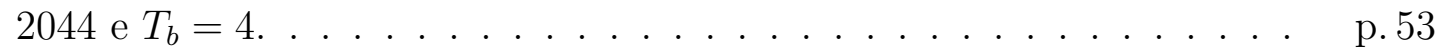

5.14 Frequência de $3 \mathrm{~dB}$ para sinais PRBS, comprimento $N=1500 \ldots \ldots$ p. . 53

6.1 Sinais GBN para identificaçao do reator. . . . . . . . . . . p. 57

6.2 Resposta do sistema usando o sinal GBN da Figura 6.1. . . . . . . . p. 57

6.3 Sinais GBN para identificaçao da coluna de destilação. . . . . . . . . p. 60

6.4 Resposta do sistema usando o sinal GBN da Figura 6.3 . . . . . . . . p. 60

6.5 Exemplo da resposta ao pulso de $y_{1} / u_{1}$ na coluna de destilação (fit=91,06\%). p. 64

$6.6 \overline{F I T}$ da validação cruzada das saídas $y_{1}$ e $y_{2}$ em função de $p_{1}$ e $p_{2}$. . . p. 64

6.7 Média geométrica, $\overline{F I T}_{y}$, entre as saídas $y_{1}$ e $y_{2} \ldots \ldots \ldots$. . . . . 65

6.8 Contorno da média geométrica $\overline{F I T}_{y} \ldots \ldots \ldots \ldots$ p. . . . . . . . . . . . .

$6.9 \overline{F I T}$ da resposta ao degrau de $y_{i} / u_{i}$ em função de $p_{1}$ e $p_{2}$. . . . . . . p 66

6.10 Superfície da média geométrica, $\overline{F I T}_{y / u}$ em função $p_{1}$ e $p_{2} \ldots \ldots$. . . . p. 66

6.11 Superfície da média geométrica total, $\overline{F I T}_{T} \ldots \ldots \ldots$ p. . . . . 67

6.12 Contorno da média geométrica $\overline{F I T}_{T}$ da Figura 6.11. . . . . . . p p. 67

$6.13 \overline{F I T}$ da validação cruzada das saídas $y_{1}$ e $y_{2}$ em função de $p_{1}$ e $p_{2} \ldots$. . p. 68

6.14 Contorno da média geométrica $\overline{F I T}_{y}$ das saídas $y_{1}$ e $y_{2} \ldots \ldots$. . . . p. 68

$6.15 \overline{\text { FIT }}$ das validações das respostas ao degrau de $y_{i} / u_{i} \ldots \ldots$. . . . . . . p. 69

6.16 Média geométrica $\overline{F I T}_{y / u} \ldots \ldots \ldots \ldots$. . . . . . . . . . . 69

6.17 Média geométrica entre os FIT das respostas ao degrau e validação cruzada, $\overline{F I T}_{T} \ldots \ldots \ldots \ldots \ldots \ldots \ldots$ p. . . . . . . . . . . . . . . . . . .

6.18 Contorno da superfície do $\overline{F I T}_{T}$ da Figura 6.17 . . . . . . . . . p. 70

$6.19 \overline{F I T}_{y_{i}}$ das validações cruzadas das saídas $y_{1}$ e $y_{2} \ldots \ldots \ldots$. . . . . . . p. 71

$6.20 \overline{F I T}_{y_{i} / u_{i}}$ da validação da resposta ao degrau. . . . . . . . . . . p. 71

6.21 Média geométrica $\overline{F I T}_{T} \ldots \ldots \ldots \ldots \ldots \ldots$ p. . . . . . . . . . . . . . .

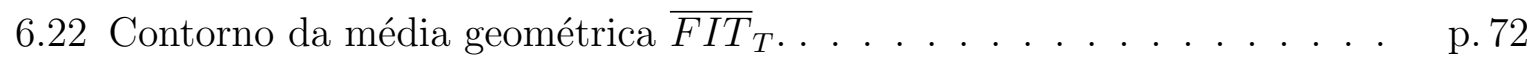

$6.23 \overline{F I T}$ das validações cruzadas dos saídas $y_{1}$ e $y_{2}$ em função de $T b_{1}$ e $T b_{2}$. p. 74 
6.24 Média geométrica $\overline{F I T}_{y}$ em função de $T b_{1}$ e $T b_{2}$. . . . . . . . . . p. 74

$6.25 \overline{F I T}$ da validação da resposta ao degrau de $y_{1} / u_{1}, y_{1} / u_{2}, y_{2} / u_{1}$ e $y_{2} / u_{2}$. $\quad$ p. 75

6.26 Média geométrica $\overline{F I T}_{y_{i} / u_{i}}$ em função de $T_{b 1}$ e $T_{b 2} \ldots \ldots$. . . . . . . p. 75

6.27 Média geométrica $\overline{F I T}_{T} \ldots \ldots \ldots \ldots \ldots \ldots$ p. . . . . . . . . . . . . . . . .

$6.28 \overline{F I T}$ da validação cruzada das saídas $y_{1}$ e $y_{2}$ mudando $T_{b 1}$ e $T_{b 2}$. . . . $\quad$ p.77

6.29 Contorno da média geométrica $\overline{F I T}_{y}$ entre as validações cruzadas das saídas $y_{1}$ e $y_{2} \ldots \ldots \ldots \ldots \ldots \ldots \ldots \ldots$ p. . . . . . . . . . . . . . . .

$6.30 \overline{F I T}$ da validação da resposta ao degrau de $y_{i} / S P_{i} \ldots \ldots$. . . . . . p. 78

6.31 Média geométrica $\overline{F I T}_{y_{i} / S P_{i}}$ das quatro validações ao degrau $y_{i} / S P_{i} . \quad$. $\quad$ p.78

6.32 Média geométrica $\overline{F I T}_{T} \ldots \ldots \ldots \ldots \ldots \ldots$ p. . . . . . . . . . . . . . . . .

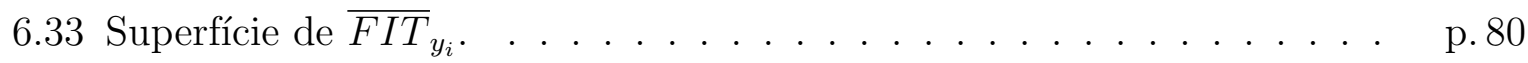

6.34 Superfície de $\overline{F I T}_{y_{i} / u_{i}} \ldots \ldots \ldots \ldots \ldots \ldots$ p. . . . . . . . . . . . . . . .

6.35 Média geométrica $\overline{F I T}_{T} \ldots \ldots \ldots \ldots \ldots \ldots$ p. . . . . . . . . . . . . .

6.36 Resultados da média geométrica dos índices FIT da validação cruzada das saídas. . . . . . . . . . . . . . . . . . . . p. 83

6.37 Resultados da média geométrica dos índices FIT das validações cruzadas nas saídas em malha fechada. . . . . . . . . . . . . p. 84

6.38 Resultados da média geométrica total em malha fechada usando sinais GBN. . . . . . . . . . . . . . . . . p. 85

6.39 Resultados da média geométrica dos índices FIT das saídas em malha fechada usando sinais GBN. . . . . . . . . . . . . . p. 85

6.40 Resultados da média geométrica total em malha fechada usando sinais GBN. . . . . . . . . . . . . . . . .

6.41 Resultados da média geométrica dos índices FIT das validações das saídas usando sinais PRBS. . . . . . . . . . . . . . . p. 88

6.42 Resultados da média geométrica dos índices FIT das validações das saídas em malha fechada.

6.43 Resultados da média geométrica total em malha fechada usando sinais PRBS. . . . . . . . . . . . . . . . . . . . .

6.44 Resultados da média geométrica dos índices $\overline{F I T}_{y}$ das saídas em malha fechada usando sinais PRBS. . . . . . . . . . . . .

6.45 Resultados da média geométrica total em malha fechada usando sinais PRBS. . . . . . . . . . . . . . . . . p p 90

6.46 Índices $\overline{F I T}$ da validação cruzada em função da correlação dos sinais de entrada. . . . . . . . . . . . . . . . p. 92

6.47 Índices $\overline{F I T}$ da validação da resposta ao degrau em função da correlação dos sinais de entrada. . . . . . . . . . . . . . . . p. . . . . . . . . 
6.48 Índices $\overline{F I T}$ da validação cruzada em função da correlação dos sinais de entrada. . . . . . . . . . . . . . . . . . p. 94

6.49 Índices $\overline{F I T}$ da validação da resposta ao degrau em função da correlação dos sinais de entrada. . . . . . . . . . . . . . . p. . 95

6.50 Exemplo de sinais utilizados no método de dois passos. . . . . . . . . . $\quad$ p.97

6.51 Plano de saídas $\left\{y_{1} ; y_{2}\right\}$ resultado de um teste com o método de dois passos no modelo $G(s) \ldots \ldots \ldots$. . . . . . . . . . . . . . . . . . .

7.1 Foto da planta piloto de neutralização de pH do LCPI. . . . . . . . . . p. 103

7.2 P\&ID da planta de neutralização de pH. . . . . . . . . . . . . . . . . . p. 104

7.3 Sinais deslocados para as entradas de nível e pH. . . . . . . . . . p. 105

7.4 Auto-validação do modelo BJ usando sinais GBN de baixa correlação. . p. 107

7.5 Validação cruzada do modelo BJ usando sinais GBN de baixa correlação. p. 108

7.6 Validação cruzada da resposta ao degrau do modelo BJ usando sinais GBN de baixa correlação. . . . . . . . . . . . . . . . . . p. 109

7.7 FCC dos sinais de SP e as saídas do controlador. . . . . . . . . . . . p.113 


\section{Lista de Tabelas}

2.1 Estruturas de modelos (LJUNG, 1999) . . . . . . . . . . . . p 19

3.1 Soma módulo 2 de duas variáveis binárias. . . . . . . . . . . . . . p. 25

3.2 Parametrização de um sinal PRBS. . . . . . . . . . . . . . p p. 26

3.3 Parametrização de um sinal GBN. . . . . . . . . . . . . . . . . . . p. p. 29

4.1 Parâmetros de sintonia para o Controle do Reator . . . . . . . . . . . . p. 34

4.2 Restrições do Sistema. . . . . . . . . . . . . . . . . . . . . . . . p. 35

4.3 Condições experimentais. . . . . . . . . . . . . . . p. 36

4.4 Parâmetros de sintonia para o Controle da Coluna de destilação . . . . $\quad$ p. 37

6.1 Sementes de geração e características de correlação cruzada das combianções de sinais GBN. . . . . . . . . . . . . . . p. 57

6.2 Sementes de geração e características de correlação cruzada das combianções de sinais PRBS. . . . . . . . . . . . . . . p. 57

6.3 Índices $\overline{F I T}$ obtidos da validação cruzada usando sinais GBN. . . . . . p. 58

6.4 Índices $\overline{F I T}$ obtidos da validação cruzada usando sinais PRBS. . . . . $\quad$ p. 58

6.5 Ordens utilizadas no modelo BJ para a identificação da coluna de destilação em malha fechada. . . . . . . . . . . . . . . . . p. p. 59

6.6 Sementes de geração e características de correlação cruzada das combianções de sinais GBN. . . . . . . . . . . . . . . . . . p.61

6.7 Sementes de geração e características de correlação cruzada das combianções de sinais PRBS. . . . . . . . . . . . . . . . . . p. 61

6.8 Resultados da validação cruzada usando sinais GBN. . . . . . . . . . . p. 62

6.9 Resultados da validação cruzada usando sinais PRBS. . . . . . . . . . p. 63

6.10 Maiores $p_{i}$ encontradas na média geométrica de $\overline{F I T}_{T}$ em malha aberta p. 84

6.11 Maiores $p_{i}$ encontradas na média geométrica de $y_{i}$ e $y_{i} / u_{i}$ em malha fechada - identificação direta. . . . . . . . . . . . . . p. 86

6.12 Valores de $\Gamma$ de acordo com $p$ e $T_{b} \ldots \ldots \ldots \ldots$ p. . . . . . . . . . . .

6.13 Resultados usando sinais GBN puros. . . . . . . . . . . . p. 98

6.14 Resultados usando sinais PRBS puros. . . . . . . . . . . . . . . . p. 99

6.15 Resultados usando sinais GBN mistos. . . . . . . . . . . . . . p. 100

6.16 Resultados usando sinais PRBS mistos. . . . . . . . . . . . p. 100 
6.17 Resultados da validação do modelo obtido com sinais GBN puros usando sinais GBN mistos. . . . . . . . . . . . . . . . . . p. 100

6.18 Resultados da validação do modelo obtido com sinais PRBS puros usando sinais PRBS mistos. . . . . . . . . . . . . . . . . . p. 101

7.1 Condições experimentais da planta de neutralização de pH. . . . . . . . p. 105

7.2 Características de geração dos sinais para a identificação da planta piloto.p. 106

7.3 Ordens das estruturas usadas para a identificação da malha de nível p. 106

7.4 Ordens das estruturas usadas para a identificação da da malha de pH . p. 106

7.5 Índice FIT (\%) da auto-validação para as três condições de correlação usando sinais GBN. . . . . . . . . . . . . . . . . . . p. 107

7.6 Índice FIT (\%) da auto-validação para as três condições de correlação usando sinais PRBS. . . . . . . . . . . . . . . . . p. 108

7.7 Índice FIT (\%) da validação cruzada para as três condições de correlação usando sinais GBN. . . . . . . . . . . . . . . . . . . p. 109

7.8 Índice FIT (\%) da validação cruzada para as três condições de correlação usando sinais PRBS. . . . . . . . . . . . . . . . . . p. 109

7.9 Índice FIT (\%) da validação cruzada da resposta ao degrau para as três condições de correlação usando sinais GBN. . . . . . . . . . . . . . p.110

7.10 Índice FIT (\%) da validação cruzada da resposta ao degrau para as três condições de correlação usando sinais PRBS. . . . . . . . . . . . . . . p.110

7.11 Ordens das estruturas usadas para a identificação da malha de nível . . p.111

7.12 Ordens das estruturas usadas para a identificação da da malha de pH · p.111

7.13 Índice FIT (\%) da auto-validação para as três condições de correlação usando sinais GBN. . . . . . . . . . . . . . . . . . p. 111

7.14 Índice FIT (\%) da auto-validação para as três condições de correlação usando sinais PRBS. . . . . . . . . . . . . . . . . . . p. 112

7.15 Índice FIT (\%) da validação cruzada para as três condições de correlação usando sinais GBN. . . . . . . . . . . . . . . . . . . p. 112

7.16 Índice FIT (\%) da validação cruzada para as três condições de correlação usando sinais PRBS. . . . . . . . . . . . . . . . . . . 


\section{Sumário}

\section{Lista de Abreviaturas e Siglas}

1 Introdução $\quad$ p. 11

1.1 Motivação . . . . . . . . . . . . . . . . . . . . . p. 11

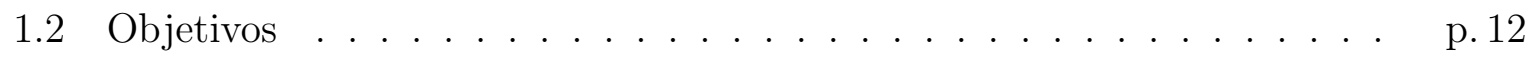

1.3 Revisão Bibliográfica . . . . . . . . . . . . . . . . . p. 12

1.4 Resumo .............................. p. 13

1.5 Estrutura do texto . . . . . . . . . . . . . p. 14

2 Identificação de Sistemas $\quad$ p. 15

2.1 Controle Multivariável . . . . . . . . . . . . . . p. 15

2.2 O Modelo . . . . . . . . . . . . . . . . . . p. 17

2.3 Estimação de Parâmetros . . . . . . . . . . . . . . . . . . . . . . p. 19

2.4 Identificação em malha fechada . . . . . . . . . . . . . p. p. 20

2.4.1 Descrição do sistema em malha fechada . . . . . . . . . . . p. 21

2.4.2 Abordagens para a identificação em malha fechada . . . . . . . p. 22

2.5 Resumo . . . . . . . . . . . . . . . . . . . p. 23

3 Sinais de Excitação $\quad$ p. 24

3.1 Sinal Binário Pseudo-aleatório (PRBS) . . . . . . . . . . p. 24

3.1.1 Propriedades das sequências binárias de máximo comprimento • p.26

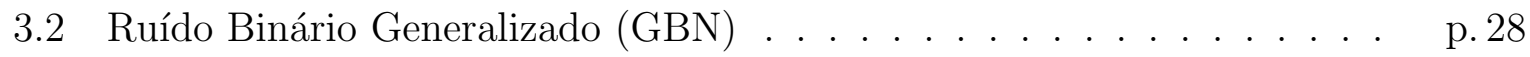

3.3 Resumo . . . . . . . . . . . . . . . . . p. 30

4 Seleção das Plantas Testadas p. 32

4.1 Análise do modelo . . . . . . . . . . . . . . . . p. 32

4.2 Reator de Polimerização $2 \mathrm{x} 2 \ldots \ldots$. . . . . . . . . . . . . 33

4.2.1 Planta em Malha Fechada . . . . . . . . . . . . . p. 34

4.3 Coluna de Destilação $3 \times 3 \ldots \ldots \ldots$. . . . . . . . . . . . . . . . . . . 
4.3.1 Planta em Malha Fechada . . . . . . . . . . . . p. 35

4.4 Plantas mal condicionadas . . . . . . . . . . . . . . . p. 38

4.5 Resumo . . . . . . . . . . . . . . . . . . . . . p. 39

5 Projeto de sinais de excitação $\quad$ p. 41

5.1 Estudo de correlações cruzadas . . . . . . . . . . . . . . p. 41

5.1 .1 Correlação Cruzada . . . . . . . . . . . . . . . p. 41

5.1.1.1 Significância do coeficiente de correlação . . . . . . . . p. 42

5.1 .2 Correlação de sinais de excitação . . . . . . . . . . . . . . p.43

5.2 Estudo de frequência . . . . . . . . . . . . . . p. 47

5.2.1 Frequência dos sinais de excitação . . . . . . . . . . . . . . . p.49

5.3 Resumo . . . . . . . . . . . . . . . . . p. 53

6 Estudo de casos $\quad$ p. 55

6.1 Testes de correlação e frequência conjuntos . . . . . . . . . . . . p. 55

6.1.1 Resultados do Reator de Polimerização 2x2 . . . . . . . . p. p.56

6.1.2 Resultados na Coluna de Destilação 3x3 . . . . . . . . . . . p. 59

6.2 Teste de frequências combinadas . . . . . . . . . . . . . p. 63

6.2.1 Reator de Polimerização $2 \times 2 \ldots$. . . . . . . . . . . p. 63

6.2.1.1 Resultados em Malha aberta - GBN . . . . . . . p. 64

6.2.1.2 Resultados em Malha Fechada-GBN . . . . . . p. 68

6.2.1.3 Forma analítica - GBN . . . . . . . . . . p. 73

6.2.1.4 Resultados em Malha aberta - PRBS . . . . . . . . p. 74

6.2.1.5 Resultados em Malha Fechada - PRBS . . . . . . . p. 76

6.2.1.6 Forma analítica - PRBS ........... . p. 81

6.2 .2 Coluna de Destilação . . . . . . . . . . . . . . . . . p. 83

6.2.2.1 Resultados em Malha aberta - GBN . . . . . . p. 83

6.2.2.2 Resultados em Malha fechada - GBN . . . . . . . . p. 84

6.2.2.3 Forma analítica - GBN . . . . . . . . . p. 86

6.2.2.4 Resultados em Malha aberta - PRBS . . . . . . . p. 87

6.2.2.5 Resultados em Malha fechada - PRBS . . . . . . . p. 88

6.2.2.6 Forma analítica - PRBS . . . . . . . . . p. 90

6.3 Testes de correlação . . . . . . . . . . . . . . . . . . . . . . p.91 
6.3.1 Resultados do Reator de Polimerização . . . . . . . . . . . . . . p. 92

6.3.2 Resultados da Coluna de Destilação . . . . . . . . . . . . . p. 94

6.4 Método de dois passos para a identificação de plantas mal condicionadas p. 96

6.4.1 Parametrização das simulações da Coluna de Alta Pureza . . . . p.96

6.4.2 Resultados usando Sinais Puros . . . . . . . . . . . p. 98

6.4.3 Resultados do Método de 2 passos . . . . . . . . . . . p. 99

6.5 Resumo . . . . . . . . . . . . . . . . . . . p. 101

7 Aplicação em tempo real: Planta piloto de neutralização de pH p.103

7.1 Descrição do processo . . . . . . . . . . . . . . . . . . . . p. 103

7.2 Identificação em malha fechada . . . . . . . . . . . . . . p. 105

7.2.1 Resultados - Auto-validação . . . . . . . . . . . . . . p. 107

7.2.2 Resultados - Validação cruzada . . . . . . . . . . . . p. 108

7.3 Identificação direta da planta em malha fechada . . . . . . . . . . . p. 110

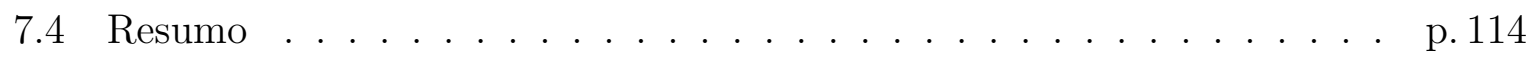

8 Conclusões $\quad$ p. 115

8.1 Principais Conclusões . . . . . . . . . . . . . . . . p. 115

8.2 Recomendações e trabalhos futuros . . . . . . . . . . . . . p. 116

$\begin{array}{lr}\text { Referências Bibliográficas } & \text { p. } 118\end{array}$ 


\section{Lista de Abreviaturas e Siglas}

BJ modelo Box-Jenkins.

BN ruído binário (Binary Noise).

CV variável controlada (controlled variable).

FAC função de autocorrelação.

FCC função de correlação cruzada.

FIT índice de ajuste.

GBN ruído binário generalizado (generalized binary noise).

MIMO múltiplas entradas e múltiplas saídas (multiple inputs and multiple outputs).

MLS sequência de máximo comprimento (maximum length sequence).

MPC controle preditivo baseado em modelo (model predictive control).

MV variável manipulada (manipulated variable).

PDF função densidade de probabilidade (probability density function).

PID proporcional, integral e derivativo

PRBS sinal binário pseudo-aleatório (pseudo-random binary sequence).

RGA matriz de ganhos relativos (relative gain array).

SISO entrada única e saída única (single input and single output).

SNR relação sinal ruído (signal-to-noise ratio).

SVD descomposição em valores singulares (singular value decomposition). 


\section{Introdução}

\subsection{Motivação}

Nas últimas três décadas tem ocorrido um interesse especial por parte da indústria e da academia nos processos avançados de controle, onde tem-se visto uma grande evolução na tecnologia do Controle Preditivo baseado em Modelo (MPC), que se expandiu desde as refinarias e a indústria petroquímica até industrias menores (GOUGH, 2011; LITH, 2009). O uso do controle MPC gera um melhor rendimento do controle, que o obtido com enfoques e técnicas mais tradicionais, como o controle PID. Este tipo de controle encontra-se em uma camada superior à do controle regulatório, normalmente manipulando os setpoints da camada regulatória, a fim de manter as variáveis controladas em uma região ótima.

As técnicas usadas no controle preditivo baseado em modelo usam explicitamente um modelo matemático na forma de equações diferenciais ou de diferenças, que representa o processo a ser controlado para predizer os estados futuros e calcular as ações de controle ótimas. Portanto, a dinâmica dos modelos tem um papel central na tecnologia MPC e seu desempenho é fortemente dependente da precisão do modelo. Segundo Zhu (1998), o trabalho mais forte e que consome mais tempo durante o projeto de um MPC industrial é o modelamento e a identificação. Trabalhos mais antigos (ANDERSEN; KÜMMEL, 1992) afirmam que até $90 \%$ do custo e tempo de implantação são consumidos na identificação do modelo de processo, enquanto que em trabalhos mais recentes (DARBY; NIKOLAOU, 2012) se diz que mais do $50 \%$ do tempo de projeto é consumido nesta fase.

Segundo Seborg (1999) e Zhu (1998), os modelos para MPC são tradicionalmente obtidos a partir de uma série de testes experimentais em malha aberta, aplicando degraus em cada variável de entrada e esperando todas as saídas estabilizarem em seu novo ponto de equilíbrio, antes de excitar outra entrada.

Como as plantas industriais são normalmente multivariáveis, isto é, com múltiplas entradas e múltiplas saídas, é mais vantajoso realizar uma identificação multivariável, isto é, excitando diversas entradas simultaneamente.

Tanto na identificação em malha aberta como em malha fechada, uma das preocupações é excitar adequadamente a planta, e portanto devem-se gerar os sinais de excitação para a obtenção de modelos identificados que se aproximem da realidade. 


\subsection{Objetivos}

Os objetivos principais deste trabalho são avaliar a construção dos sinais de excitação GBN e PRBS para identificação multivariável e propor a caracterização dos conjuntos de sinais de excitação, dadas as características da planta conhecidas previamente (informações a priori), conforme o conceito de identificação plant-friendliness (RIVERA et al., 2003).

Para atingir os objetivos propostos, são feitos:

- Estudo da geração dos sinais de excitação para realizar comparações das características dos sinais gerados (período do sinal, amplitude, forma do espectro de potência, propriedades de correlação cruzada e autocorrelação, etc).

- Realizar um estudo de correlação cruzada e de frequência dos sinais de excitação, para a parametrização de sinais de excitação eficientes em identificação de sistemas multivariáveis.

- Implementação de códigos em software MATLABß para a geração dos sinais de excitação GBN e PRBS.

- Avaliação dos sinais GBN e PRBS por meio de simulações de identificação de plantas petroquímicas. Os testes permitem também avaliar o efeito da correlação cruzada dos sinais de excitação e o efeito da frequência no processo de identificação. Foram escolhidos três tipos de plantas, um reator de polimerização 2x2 (CHIEN; HUANG; YANG, 1999), um modelo de uma coluna de destilação binária 3x3 (OGUNNAIKE et al., 1983) e um modelo de uma coluna de alta pureza (SKOGESTAD; MORARI; DOYLE, 1988), altamente mal condicionado.

- Implementação de sinais gerados pelo método de dois passos (ZHU, 2001) no modelo da coluna de alta pureza (SKOGESTAD; MORARI; DOYLE, 1988).

- Avaliação dos sinais GBN e PRBS por meio de uma aplicação de identificação em tempo real. Os experimentos de identificação foram levados a cabo na Planta Piloto de Neutralização de pH localizada no Laboratório de Controle de Processos Industriais da Escola Politécnica da USP.

\subsection{Revisão Bibliográfica}

O campo da Identificação de Sistemas foi desenvolvido ao redor dos anos 60, especialmente nas áreas do controle e as comunicações. A identificação de sistemas baseia-se na teoria de sistemas, na teoria de sinais, na teoria de controle e na teoria da estimação estatística (ISERMANN; MÜNCHHOFF, 2011). O problema da Identificação de Sistemas é a descrição matemática do comportamento de fenômenos físicos, econômicos, etc., através de modelos. Comumente estes modelos são obtidos através do ajuste de dados que provêm de um experimento, a modelos com uma estrutura pré-definida. As diferentes técnicas e procedimentos empregados neste processo são estudados por muitos autores a fim de realizar estimativas que descrevam os fenômenos o mais próximo da realidade. 
Em (SöDERSTRöM; STOICA, 1988) e (LJUNG, 1999) são apresentadas as bases da Identificação de Sistemas, os métodos usados, a determinação da estrutura dos modelos e os métodos de validação. O enfoque dominante nestes trabalhos são os métodos de identificação direta baseados no método clássico do erro de predição (PEM).

Uma parte vital do ciclo da identificação de sistemas é o projeto dos sinais de excitação. Em (ZHU, 2001) são tratados e implementados 4 tipos de sinais usados normalmente na indústria para a identificação de processos, dentre os quais são encontradas as sequências binárias (pseudo) aleatórias ou ruído binário. Em (BIRDSALL; RISTENBAT, 1958) e (GOLOMB, 1965) foram estudados os fundamentos da geração e propriedades de sequências pseudoaleatórias a partir de registros de deslocamentos conhecidas como sequências binárias pseudo-aleatórias (Pseudo-Random Binary Sequence, PRBS) . Tulleken (1990) apresentou o sinal GBN (Generalized Binary Noise), que consiste em um sinal estocástico que possui chaveamentos aleatórios entre dois níveis fixos do sinal a cada tempo de amostragem.

Caracterizar os sinais de excitação a fim de extrair a informação de interesse dos processos tem sido um tema estudado por vários autores. Em (AGUIRRE, 2007) é proposto um método heurístico para a escolha dos parâmetros de geração dos sinais PRBS. Em (RIVERA et al., 2003) se usa informação a priori do processo como as constantes de tempo dominantes em malha aberta para o projeto de sinais PRBS. Em (CHEN; YU, 1997) são calculadas expressões a fim de parametrizar dos sinais GBN a partir de um intervalo de frequências desejado.

Em processos industriais normalmente existem interações entre as entradas e as saídas, isto devido ao carácter multivariável dos mesmos. Gevers et al. (2006) estuda a identificação de sistemas com múltiplas entradas examinando o efeito de entradas adicionais nos parâmetros estimados.

Os processos que possuem interações fortes entre as saídas são conhecidos como processos mal condicionados. Em (BRISTOL, 1966) é definido um método para medir o nível de interação das saídas em um processo usando a matriz de ganhos relativos. Enquanto, em (ZHU; STEC, 2006) é proposto um método para identificar uma classe de processos mal condicionados usando sinais que possuem uma parte altamente correlacionada para excitar a direcionalidade de baixo ganho. Em (VAILLANT; KURAMOTO; GARCIA, 2013) é feita uma comparação da efetividade de cinco métodos de geração de sinais de entrada para a identificação de plantas mal condicionadas, os métodos foram avaliados em um modelo de uma coluna de destilação de alta pureza.

A identificação em malha fechada tem sido a miúdo sugerida como uma ferramenta para a identificação de sistemas que são instáveis em malha aberta, ou que, por especificações dos produtos devem ser mantidos em uma faixa de operação. Em (FORSSELL; LJUNG, 1999) são analisados propriedades estatísticas dos métodos de identificação em malha fechada e é proposto um método ótimo para o projeto de experimentos em malha fechada.

Em (MORALES, 2013) é realizada a identificação e o desenvolvimento do sistema de controle para uma planta piloto de neutralização de pH, localizada na Escola Politécnica da USP. 


\subsection{Resumo}

Experimentos de identificação de sistemas executados tanto em malha aberta como fechada permitem a obtenção de modelos nominais que sejam adequados para o projeto de sistemas de controle avançado. Por sua vez, a eficiência do controle depende da qualidade do modelo identificado. Isto é, quanto mais aproximado o modelo identificado descreva o comportamento do processo real, melhor será o desempenho do controle. Para a obtenção de modelos identificados aproximados da realidade é necessário projetar adequadamente o experimento, uma parte primordial é a escolha dos sinais de excitação e as suas características.

O presente trabalho aborda esse problema ao estudar os dois tipos de sinais mais usados para excitar processos em experimentos de identificação, PRBS e GBN. Estes sinais serão estudados tanto em malha aberta como em malha fechada, em várias condições de ruído, correlação e frequência, e finalmente, testados em plantas simuladas e em uma aplicação em tempo real.

\subsection{Estrutura do texto}

Este trabalho está organizado em 8 capítulos. Neste primeiro capítulo é apresentada a motivação do projeto junto com os objetivos propostos e a revisão bibliográfica, que conduzem ao desenvolvimento do mesmo.

No Capítulo 2 são apresentados os conceitos preliminares da área do modelamento de processos, conhecida como identificação de sistemas, os seus passos básicos, a estimação de parâmetros e a identificação em malha fechada, fatores que vão fazer parte da análise dos sinais gerados.

O Capítulo 3 aborda os conceitos e as características dos sinais GBN e PRBS, suas formas de geração, suas características em frequência e funções de autocorrelação.

No Capítulo 4 são expostas as plantas a serem simuladas, os seus respectivos modelos, a forma dos controladores em malha fechada e as condições de operação das mesmas.

No Capítulo 5 são estudadas as características de correlação cruzada e frequência de sinais GBN e PRBS gerados a partir da implementação de códigos em software MATLABß).

O Capítulo 6 está composto por várias seções correspondentes aos diferentes estudos de simulação realizados nas plantas apresentadas no Capítulo 4, onde são analisadas as características de correlação e frequência dos sinais em cada caso testado.

No Capítulo 7 é apresentada a aplicação dos sinais de identificação em uma planta piloto de neutralização de $\mathrm{pH}$, a descrição do processo e as formas de identificação do mesmo.

Finalmente, no Capítulo 8 são sintetizadas as principais conclusões deste trabalho. E são feitas propostas para continuidade deste trabalho. 


\section{Identificação de Sistemas}

Modelos matemáticos de sistemas na vida real são fundamentais em todos os campos científicos e em aplicações de engenharia. Com modelos precisos, podem-se analisar sistemas e predizer seu comportamento. Os modelos podem ser construídos a partir de leis e princípios físicos. Porém, em uma situação quando existe um pequeno conhecimento do sistema ou quando o modelamento físico consome muito tempo, um modelo do sistema pode ser identificado a partir de dados experimentais. Este é o enfoque deste trabalho. Este capítulo apresenta alguns conceitos básicos de Identificação de Sistemas e as etapas envolvidas neste processo.

A Identificação de Sistemas ou de processos é a área do modelamento matemático de sistemas a partir de dados experimentais, que são normalmente coletados em um teste de identificação ou de um experimento, projetado para tornar os dados medidos o mais informativo possível das propriedades do sistema (ZHU, 2001).

Em termos gerais, um experimento de identificação é feito excitando o sistema, observando e armazenando os dados, tanto da sua entrada como da saída, em um intervalo de tempo (SöDERSTRöM; STOICA, 1988). O primeiro passo é determinar uma forma adequada do modelo (tipicamente uma equação em diferenças de uma ordem certa). Como segundo passo, um método é usado para estimar os parâmetros desconhecidos do modelo proposto. Na prática, as estimativas da estrutura e os parâmetros são com frequência obtidos iterativamente. Isto quer dizer que uma tentativa da estrutura é escolhida e os parâmetros correspondentes são estimados. Assim, o modelo obtido é testado para observar se é uma representação apropriada do sistema. Se o modelo não apresenta o rendimento esperado, isto é, não consegue representar a dinâmica do processo dentro dos critérios adotados, deve-se reiniciar o procedimento utilizando outro modelo. O procedimento é ilustrado na Figura 2.1.

Este trabalho tem um foco nos dois primeiros passos, planejamento de medições e geração de sinais, onde são usados modelos de múltiplas entradas e múltiplas saídas (MIMO) lineares, invariantes no tempo e de dimensão finita, que representam processos petroquímicos.

\subsection{Controle Multivariável}

Antes de entrar nos tópicos de identificação e geração de sinais, é necessário familiarizarse com o ambiente onde os modelos identificados são usados. Geralmente, o uso de modelos lineares para o controle de processos contínuos apresenta um bom rendimento, pelo menos ao redor do ponto de operação onde os dados são coletados. Isto é porque as funções não 
Figura 2.1: Ciclo da Identificação de Sistemas.

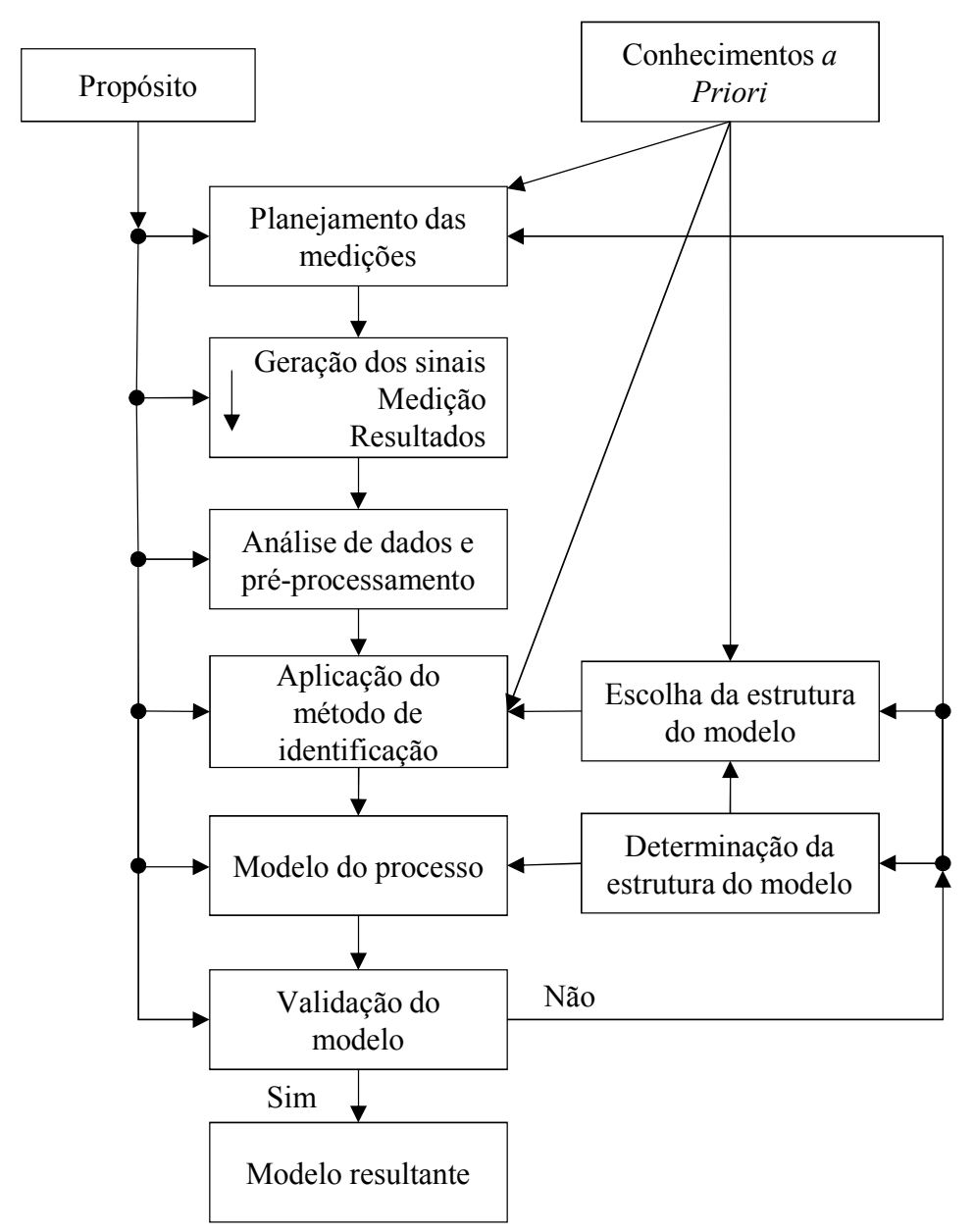

Fonte: Ljung (1999)

lineares podem ser aproximadas por uma função linear em torno de um ponto de equilíbrio, pois dentro de certos limites os processos normalmente têm um comportamento quase linear, o que explica o sucesso das tecnologias de controle baseadas em modelos lineares para processos contínuos. A área onde os modelos lineares são menos efetivos é durante o processo de partida e parada das plantas, em que o comportamento não linear do processo chega a ser dominante (ZHU, 2001).

O MPC nasceu na indústria do petróleo e vem sendo expandido e utilizado em outras indústrias, diferenciando-se do controle clássico porque além de atuar em mais de uma variável manipulada ao mesmo tempo, tem a capacidade de incluir restrições do processo (DARBY; NIKOLAOU, 2012).

O controle preditivo baseado em modelo (MPC) é um método de controle moderno, baseado na solução de um problema de controle ótimo, cujo fim é a seleção do sinal de controle minimizando uma função objetivo. A função objetivo é definida em termos das variáveis presentes e preditas, sendo avaliadas usando um modelo para predizer as futuras saídas do processo.

Basicamente, um controlador MPC trabalha da seguinte maneira: no momento atual, $t$, o comportamento do processo sobre um horizonte de tempo é considerado. Usando 
um modelo, a resposta do modelo às mudanças nas entradas manipuladas é predita. Os movimentos futuros das entradas manipuladas são escolhidos, tais que a resposta coincida com os objetivos do controle. Só o primeiro movimento computado das entradas manipuladas é implementado. No seguinte intervalo de tempo, a computação é repetida com o horizonte de predição movimentado em 1. Na maioria dos controladores MPC, o desempenho desejado é alcançado pela minimização de uma função de perda quadrática do erro entre o setpoint e a saída predita, mais um termo de penalização para as ações de controle. Esta otimização respeita todas as restrições requeridas na operação do processo, como são os limite superior e inferior das válvulas ou temperaturas limites dentro do processo. Quando uma restrição de uma variável controlada é violada, o algoritmo automaticamente ajusta todas as outras variáveis manipuladas para satisfazer os objetivos do controle (ZHU, 2001).

Os objetivos de controle associados com as variáveis controladas podem ser atribuídos com prioridades e são tratados de acordo com isto. O controle realimentado está incluso no MPC. A capacidade de manipular restrições é o fator diferenciador deste tipo de controle, que faz dele um controle um pouco mais flexível.

\subsection{O Modelo}

Neste trabalho são considerados modelos lineares invariantes no tempo (LTI) e em tempo discreto com sinal de entrada $u(t)$ e sinal de saída $y(t)$. A relação entre a entrada e a saída de um sistema no projeto de um controlador MPC pode ser representada mediante uma equação linear de diferenças:

$$
y(t)+a_{1} y(t-1)+\ldots+a_{n} y(t-n)=b_{1} u(t-1)+\ldots+b_{m} u(t-m)
$$

Um modo útil de ver a Equação (2.1) é na forma de cálculo do seguinte valor de saída dado por observações do passado:

$$
y(t)=-a_{1} y(t-1)-\ldots-a_{n} y(t-n)+b_{1} u(t-1)+\ldots+b_{m} u(t-m)
$$

E para uma notação mais compacta são introduzidos os vetores:

$$
\begin{gathered}
\theta=\left[\begin{array}{llllll}
a_{1} & \ldots & a_{n} & b_{1} & \ldots & b_{n}
\end{array}\right]^{T} \\
\varphi^{T}(t)=\left[\begin{array}{llllll}
-y(t-1) & \ldots & -y(t-n) & u(t-1) & \ldots & u(t-n)
\end{array}\right]
\end{gathered}
$$

Assim, (2.2) pode ser escrita:

$$
y(t)=\varphi^{T}(t) \theta
$$

Levando estas equações para a descrição de sistemas MIMO com $l$ entradas e $p$ saídas, se tem: 


$$
y(t)+A_{1} y(t-1)+\ldots+A_{n} y(t-n)=B_{1} u(t-1)+\ldots+B_{m} u(t-m)
$$

onde $A_{1}(p \times p), \ldots, A_{n}(p \times p), B_{0}(l \times p), B_{1}(l \times p), \ldots, B_{n}(l \times p)$ são matrizes constantes. Usando o operador de atraso $q^{-1}$, a Equação (2.6) pode ser escrita:

$$
A(q) y(t)=B(q) u(t)
$$

onde $A(q)$ e $B(q)$ são matrizes polinomiais:

$$
A(q)=I+A_{1} q^{-1}+\ldots+A_{n} q^{-n} ; \quad B(q)=B_{0}+B_{1} q^{-1}+\ldots+B_{m} q^{-m}
$$

Chegando-se assim a,

$$
y(t)=G(q) u(t) ; \quad G(q)=A^{-1}(q) B(q)
$$

Devido às diferentes formas de representações que podem ser dadas a um sistema MIMO, é adotada uma forma canônica simples, a forma diagonal de uma Descrição Matricial Fracionária (matriz fraction description - MFD). A forma diagonal MFD de uma dada $G(q)$ é:

$$
A(q)=\left[\begin{array}{cccc}
A_{11}(q) & 0 & \cdots & 0 \\
0 & A_{22}(q) & & \vdots \\
\vdots & & \ddots & 0 \\
0 & \cdots & 0 & A_{p p}(q)
\end{array}\right] ; \quad B(q)=\left[\begin{array}{ccc}
B_{11}(q) & \cdots & B_{1 l}(q) \\
\vdots & \ddots & \vdots \\
B_{p 1}(q) & \cdots & B_{p l}(q)
\end{array}\right]
$$

onde $A_{11}(q), \ldots, A_{p p}(q)$ são polinômios mônicos, e os graus de $B_{i 1}(q), \ldots, B_{i l}(q)$ são iguais ou menores que os de $A_{i i}(q)$. Desta maneira, as relações entre uma entrada $l$ e uma saída $p$ são desacopladas em subprocessos independentes:

$$
\begin{aligned}
& A_{11} y_{1}(t)=B_{11} u_{1}(t)+\cdots+B_{1 l}(q) u_{l}(t) \\
& A_{p p} y_{p}(t)=B_{p 1} u_{1}(t)+\cdots+B_{p l}(q) u_{l}(t)
\end{aligned}
$$

Um modelo linear completo é representado na Figura 2.2, onde as funções de transferência $G\left(q, \theta_{n}\right)$ e $H\left(q, \theta_{n}\right)$ são parametrizados pelo vetor $\theta_{n} \in \mathbf{R}^{n}$, o qual é estimado (LJUNG, 1999). Sinais não medidos que afetem o sistema são modelados pela perturbação estocástica aditiva $v(t)$ na saída. Além disso, $e(t)$ é considerado ruído branco estacionário de média zero. As correspondentes equações do modelo são: 


$$
\begin{aligned}
& y(t)=G\left(q, \theta_{n}\right) u(t)+v(t), \\
& v(t)=H\left(q, \theta_{n}\right) e(t) .
\end{aligned}
$$

Figura 2.2: Estrutura de um modelo.

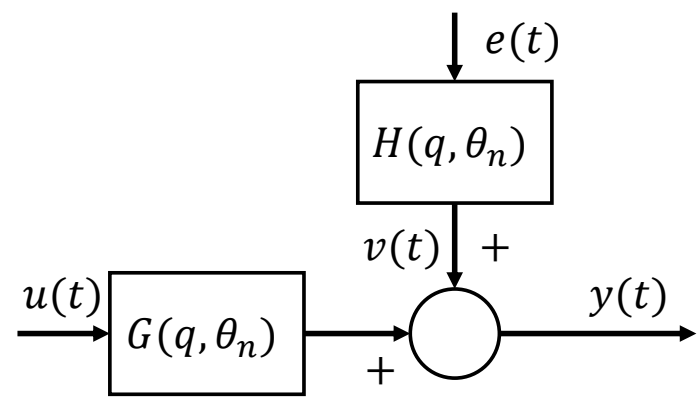

Autor: Ljung (1999).

Asume-se que $H\left(q, \theta_{n}\right)$ é mônico e que $H\left(q, \theta_{n}\right)^{-1} H\left(q, \theta_{n}\right)$ e $H^{-1}\left(q, \theta_{n}\right)$ são estáveis.

Partindo de (2.12) considera-se a estrutura de modelo generalizada (LJUNG, 1999):

$$
A(q) y(t)=\frac{B(q)}{F(q)} u(t)+\frac{C(q)}{D(q)} e(t)
$$

onde $C(q)$ e $D(q)$ são polinômios similares a $A(q)$ e $B(q)$ definidos na Equação (2.7). Este tipo de descrição do sistema apresenta uma vantagem, possui maior liberdade na descrição das propriedades dos termos dos distúrbios. A introdução do polinômio $C(q)$ introduz essa flexibilidade descrevendo a equação do erro como uma média móvel (moving average - MA) do ruído branco.

A Tabela (2.1) apresenta as diferentes estruturas baseadas nas combinações dos polinômios usados.

Tabela 2.1: Estruturas de modelos (LJUNG, 1999)

\begin{tabular}{cc}
\hline Polinômios Usados na Eq. (2.13) & Estrutura do Modelo \\
\hline B & FIR (resposta finita ao impulso) \\
AB & ARX \\
ABC & ARMAX \\
AC & ARMA \\
ABD & ARARX \\
ABCD & ARARMAX \\
BF & OE (output error) \\
BFCD & BJ (box-jenkins) \\
\hline
\end{tabular}




\subsection{Estimação de Parâmetros}

As representações de um sistema através de um número finito de coeficientes permitem ter uma aproximação dos fenômenos que ocorrem na realidade. Frequentemente não é possível determinar estes coeficientes com conhecimentos a priori ou por interpretações físicas dos mecanismos que governam a dinâmica do sistema (LJUNG, 1999). A determinação do valor destes parâmetros pode ser feita através de um procedimento de estimação.

Deste modo, chega-se na situação de selecionar uma certa estrutura de modelo $\boldsymbol{M}$, com modelos particulares $\boldsymbol{M}(\theta)$ parametrizados usando o vetor de parâmetros $\theta \epsilon D_{M} \subset \mathbf{R}^{d}$. O vetor de parâmetros $\theta$ varia ao longo de um subconjunto de $\mathbf{R}^{d}$, onde $d$ é a dimensão de $\theta$.

Neste trabalho consideram-se os métodos de identificação de erro de predição (prediction error identification method - PEM) (LJUNG, 1999; SöDERSTRöM; STOICA, 1988). Este método minimiza a função de predição do erro $\varepsilon_{F}(t, \theta)$

$$
V_{N}\left(\theta, Z^{N}\right)=\frac{1}{2 N} \sum_{t=1}^{N} \epsilon_{F}^{2}(t, \theta)
$$

onde $Z^{N}$ é o vetor que contém os dados entrada-saída coletados, isto é:

$$
Z^{N}=[y(1), u(1), y(2), u(2), \ldots, y(N), u(N)]
$$

O erro de predição é definido como $\varepsilon_{F}(t, \theta)=y(t, \theta)-\hat{y}(t, \theta)$.

$\mathrm{O}$ vetor de parâmetros estimados, $\hat{\theta}_{N}$, é escolhido minimizando a função (2.14):

$$
\hat{\theta}_{N}:=\underset{\theta}{\arg \min } \frac{1}{2 N} \sum_{t=1}^{N}(y(t, \theta)-\hat{y}(t, \theta))^{2}
$$

$\mathrm{Na}$ identificação de sistemas procuram-se testes nos quais diferentes modelos tenham a capacidade de descrever os dados observados. Um "bom" modelo é aquele que produz pequenos erros de predição quando validado com dados observados, tornando $\varepsilon(t, \theta) \approx 0$.

\subsection{Identificação em malha fechada}

Em certas aplicações, o processo unicamente pode ser identificado em malha fechada. Os testes industriais em malha aberta deixam a operação exposta a distúrbios no processo que podem afetar a qualidade dos produtos, ou fazer as saídas saírem das faixas de segurança, podendo colocar em risco a operação do sistema. Também, testes em malha aberta podem atingir zonas não lineares, o que pode afetar a identificação do modelo, tornando-o inadequado para a região normal de operação.

$\mathrm{Na}$ seção anterior foram apresentadas as bases e a teoria fundamental da Identificação de Sistemas. Esta seção estende esta teoria onde o conjunto de dados, $Z_{N}$, usado para 
gerar o vetor de parâmetros, $\widehat{\theta}_{N}$, é obtido em condições de malha fechada. Os problemas e as questões com a identificação em malha fechada são introduzidos ao longo do trabalho com as duas principais abordagens para uma satisfatória identificação a partir de dados em malha fechada.

\subsubsection{Descrição do sistema em malha fechada}

Um sistema em malha fechada, representado pela Figura 2.3, é um sistema que se encontra sob um controle realimentado. Neste trabalho, assume-se que o controlador seja linear e conhecido.

Figura 2.3: Estrutura de um modelo em malha fechada.

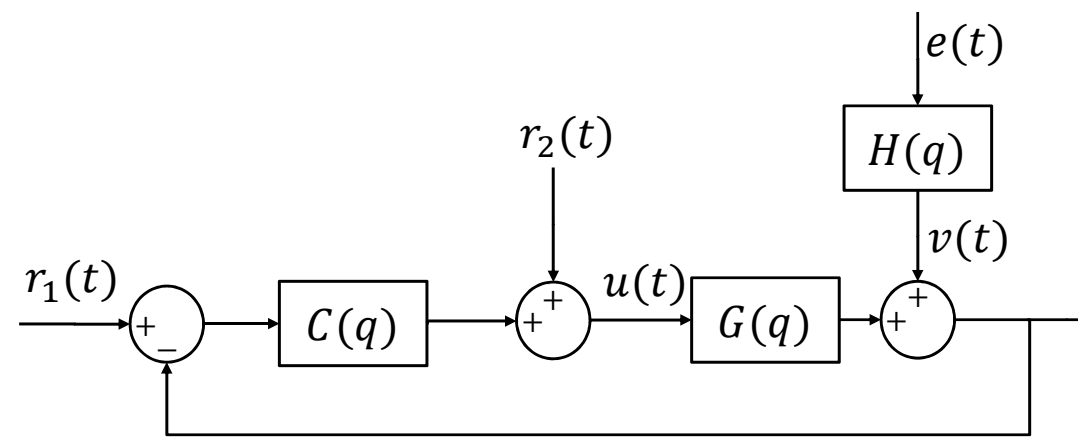

Autor: Isermann e Münchhoff (2011)

Lembrando a representação do sistema real expressada na Equação (2.12) e definindo o sinal de entrada como:

$$
u(t)=r_{2}(t)+C(q)\left(r_{1}(t)-y(t)\right)
$$

onde $r_{1}(t)$ é o sinal de referência e $r_{2}$ é considerado um sinal de excitação adicionado à ação de controle. Para os propósitos deste trabalho é suficiente considerar um sinal de referência definido como:

$$
r(t)=r_{2}(t)+C(q) r_{1}(t)
$$

assumindo $r(t)$ independente do ruído $e(t)$. O sinal de entrada pode ser redefinido agora como:

$$
u(t)=r(t)-C(q) y(t)
$$

Assim, a representação do sistema em malha fechada pode ser dada através da seguinte expressão:

$$
y(t)=G(q) S_{0}(q) r(t)+S_{0}(q) H(q) e(t)
$$


com $S_{0}(q)$ denominado a função de sensibilidade e definida por:

$$
S_{0}(q)=\frac{1}{1+C(q) G(q)}
$$

Pode-se definir a função de malha fechada como:

$$
\begin{aligned}
& G_{0}^{m f}(q)=G_{0}(q) S_{0}(q) \\
& H_{0}^{m f}(q)=S_{0}(q) H_{0}(q)
\end{aligned}
$$

isto permite rescrever a Equação (2.20):

$$
\begin{aligned}
y(t) & =G_{0}^{m f}(q) r(t)+v^{m f}(t) \\
& =G_{0}^{m f}(q) u(t)+H_{0}^{m f}(q) e(t)
\end{aligned}
$$

com a entrada definida,

$$
u(t)=S_{0}(q) r(t)-C(q) v^{m f}(t)
$$

Uma assunção na Identificação de Sistemas é que o conjunto de dados, $Z_{N}$, seja suficientemente rico para permitir as condições que tornam possível determinar os parâmetros certos do sistema. Entretanto, a identificação em malha fechada possui alguns problemas e restrições que aparecem devido ao fato de que um sistema operando em malha fechada é normalmente menos informativo que o caso em malha aberta. O objetivo do controle realimentado é justamente fazer com que o sistema se torne menos sensível às perturbações. Apesar disso, o principal problema ou dificuldade a vencer na identificação de sistemas em malha fechada é a correlação entre o ruído não medido e a entrada. Considerando a Figura 2.3 é claro que se o controlador, $C(q)$, não é zero, a entrada e o ruído estarão correlacionados. Esta correlação tipicamente resulta em uma estimativa tendenciosa (FORSSELL; LJUNG, 1999).

\subsubsection{Abordagens para a identificação em malha fechada}

Para a identificação em malha fechada, pode-se, em geral, distinguir dois casos (ISERMANN; MÜNCHHOFF, 2011):

- Caso 1. Identificação indireta do processo: a identificação é feita considerando o sinal de referência, $r_{1}(t)$, como a entrada do processo e fazendo $r_{2}(t)=0$. Assim, o conjunto de dados é $Z_{m f}^{N}=\left[y(1), r_{1}(1), y(2), r_{1}(2), \ldots, y(N), r_{1}(N)\right]$. O conjunto $Z_{m f}^{N}$ é calculado o modelo completo do sistema em malha fechada como primeiro passo. A partir do modelo obtido em malha fechada e com o conhecimento do controlador $C(q)$, finalmente se calcula o modelo da planta.

Este caso possui as seguintes características:

- requer o conhecimento do controlador,

- pode possuir uma alta complexidade na solução analítica, 
- não tem ordem do modelo pré-definida,

- não funciona se o controlador apresenta não linearidades, tal como a saturação.

- Caso 2. Identificação direta do processo: O processo é identificado diretamente, isto é, sem o passo intermediário da determinação do modelo em malha fechada. Neste caso é ignorada a realimentação e a planta é identificada usando as medições do sinal de controle $u(t)$ e da saída $y(t)$. O controlador, portanto, pode não ser conhecido, o que é uma vantagem quando controladores avançados estão atuando sobre o processo.

Este caso possui as seguintes características:

- funciona independentemente da natureza do controlador,

- não precisa de algoritmos adicionais como pode ser necessário no caso da identificação indireta,

- requer um modelo adequado do ruído para evitar bias no modelo da planta,

- sistemas instáveis ou com restrições podem ser tratados sem prejudicar a exatidão do modelo, isto se o sistema for estável em malha fechada.

\subsection{Resumo}

Neste capítulo foi discutida brevemente a teoria sobre a qual se baseia a Identificação de Sistemas e a sua aplicação em algoritmos de controle, principalmente no controle preditivo (MPC). Com mais ênfase foram apresentadas as expressões que governam os chamados Métodos de Erro de Predição e a descrição matemática dos seus modelos.

Foram introduzidos também os conceitos de identificação em malha aberta e malha fechada, suas vantagens, desvantagens e, as abordagens para a identificação em malha fechada. 


\section{Sinais de Excitação}

Nos projetos de identificação pode ocorrer que mesmo quando a estrutura de modelo for a certa para capturar a dinâmica verdadeira do sistema, o erro estimado não será zero, devido a que os dados no procedimento de identificação são finitos e corrompidos por ruído. O propósito do projeto das entradas é minimizar o erro estimado, minimizando a variância da estimativa dos parâmetros.

A informação obtida através de experimentos nos sistemas reais depende da excitação das entradas, as quais são amiúde limitadas por restrições de amplitude ou de potência. Por esta razão, é necessário um projeto de experimento para se obter a estimativa do sistema dentro de uma precisão desejada, economizando-se tempo e custos. A robustez do projeto das entradas para a identificação de sistemas é também um grande desafio, especialmente quando o modelo do sistema é usado para projetar seu sistema de controle.

O método de geração dos sinais abordado neste trabalho faz parte do grupo de sinais binários aleatórios, que têm sido amplamente utilizados na identificação de sistemas, devido à facilidade de geração e às suas funções de correlação.

Os sinais binários a serem empregados podem ser ajustados no seu espectro de potência para atingir regiões de frequência em que opera a planta. Suas amplitudes podem ser alteradas conforme os limites e restrições que possui o sistema. A seguir são apresentados dois tipos de sinais binários, o Sinal Binário Pseudo-aleatório (Pseudo-random Binary Sequence, PRBS) estudado amplamente em (SöDERSTRöM; STOICA, 1988) e o sinal de Ruído Binário Generalizado (Generalized Binary Noise, GBN) proposto em (TULLEKEN, 1990).

\subsection{Sinal Binário Pseudo-aleatório (PRBS)}

As sequências binárias pseudo-aleatórias (PRBS) são sinais de dois estados, os quais podem ser gerados usando um registro de deslocamento de ordem $n$, como se apresenta na Figura 3.1. Chegam a representar parcialmente o ruído branco (SöDERSTRöM; STOICA, 1988).

A Figura 3.1 representa um registro de deslocamento básico de $n$ etapas, no qual uma trajetória de realimentação é adicionada, como resultado da soma módulo 2 das etapas anteriores. A soma módulo 2, denotada por $\oplus$ na Figura 3.1, é definida na Tabela 3.1.

As variáveis de estado do registro são alimentadas com valores lógicos de um ou zero. Cada vetor inicial de estados é permitido, excetuando-se o estado zero em todas suas etapas. Quando o pulso do relógio é aplicado, o valor do $k$-ésimo estado é transferido 
Figura 3.1: Registro de deslocamento com realimentação módulo 2.

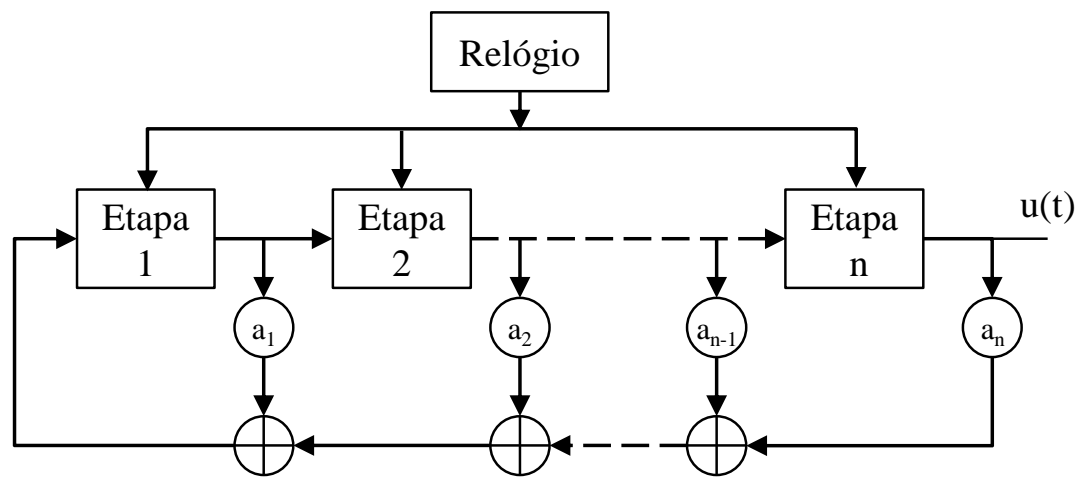

Fonte: Söderström e Stoica (1988).

Tabela 3.1: Soma módulo 2 de duas variáveis binárias.

\begin{tabular}{ccc}
\hline$u_{1}$ & $u_{2}$ & $u_{1}+u_{2}$ \\
\hline 0 & 0 & 0 \\
1 & 0 & 1 \\
0 & 1 & 1 \\
1 & 1 & 0 \\
\hline
\end{tabular}

para o $(k+1)$-ésimo estado e um novo valor é injetado no primeiro estado através da realimentação. Este sistema opera em tempo discreto e o tempo do relógio é igual ao tempo de amostragem.

Os coeficientes de realimentação $a_{1}, \ldots, a_{n}$, são um e zero, enquanto a sequência obtida de cada registo de deslocamento depende da conexão de realimentação e do estado inicial do registro. Para um número de etapas em um registro há um número máximo de dígitos, os quais ocorrem antes de que a sequência se repita. Isto é então uma sequência de máximo comprimento (MLS), a qual é o tipo de sequência de interesse na identificação de sistemas.

Para um registro de deslocamento com $n$ estados ou etapas, há um máximo período possível $M=2^{n}-1$, onde $n$ é a ordem ou o número de estados do registro de deslocamento.

A escolha do caminho de realimentação de um registro de deslocamento para gerar um sinal PRBS de máximo comprimento é expresso a partir da Equação (3.1), onde $q^{-1}$ é o operador de atraso.

$$
A\left(q^{-1}\right)=1 \oplus a_{1} q^{-1} \oplus a_{2} q^{-2} \oplus \ldots \oplus a_{n} q^{-n}
$$

Se o sinal PRBS $u(t)$ gerado possui máximo comprimento, então o polinômio $A\left(q^{-1}\right)$ que gera a sequência de máximo comprimento é chamado "Polinômio característico"'. $\mathrm{Na}$ literatura se encontram tabulados todos os polinômios irredutíveis de várias ordens e também é indicado que estes polinômios são primitivos (DAVIES, 1970). 


\subsubsection{Propriedades das sequências binárias de máximo compri- mento}

Segundo (BIRDSALL; RISTENBAT, 1958) os sinais PRBS de máximo comprimento possuem as seguintes características:

1. Para um registro de deslocamento de $n$ etapas, a sequência de máximo comprimento possui um comprimento $M=2^{n}-1$. Isto foi mostrado por (GOLOMB, 1965), sendo uma consequência do fato que o polinômio característico do registro de deslocamento é irredutível.

2. Uma sequência PRBS de máximo comprimento igual a $N$, possui $(N+1) / 2$ estados lógicos em um e $(N-1) / 2$ estados lógicos em zero.

3. Será assumido que os dois estados da sequência PRBS de máximo comprimento previamente definidos como estados lógicos um e zero, serão escolhidos para corresponder a níveis de voltagem ou amplitude de $+a$ e $-a$, respectivamente.

4. A função de autocorrelação de um sinal PRBS pode se assemelhar à função de autocorrelação de uma sequência de ruído branco. Sua função de autocorrelação é dada por:

$$
R_{x x}(\tau)=\left\{\begin{array}{cc}
a^{2}\left(1-\frac{N+1}{N} \frac{|\tau|}{\Delta t}\right) & -\Delta t<\tau<\Delta t \\
a^{2} / N & \Delta t \leq \tau \leq(N-1) \Delta t
\end{array}\right.
$$

Isto é, quando $N$ é suficientemente longo, na faixa $[0, N \Delta t], R_{x x}(\tau)$ pode ser tomado como uma função $\delta$.

Tabela 3.2: Parametrização de um sinal PRBS.

\begin{tabular}{cc}
\hline Parâmetro & Valor \\
\hline Tipo de sinal & PRBS \\
Comprimento do sinal & $N=63$ \\
Tempo de bit & $T_{b}=4$ \\
Período de amostragem & $\Delta t=1 \mathrm{~min}$ \\
Período do sinal & $T_{N}=63 * 4=252 \mathrm{~min}$ \\
\hline
\end{tabular}

As Figuras 3.2, 3.3 e 3.4 apresentam o sinal PRBS com as características apresentadas na Tabela (3.2), seu espectro e a sua função de autocorrelação, respectivamente.

Na Figura 3.3 consegue-se apreciar que o espectro do sinal PRBS tem pontos em que o sinal possui valores em zero, essa característica se apresenta ao redor das frequências $2 \pi / T_{b}, 4 \pi / T_{b}, 6 \pi / T_{b}$, etc. Esta característica dos sinais PRBS resulta em uma baixa relação sinal-ruído nessas faixas de frequência. 
Figura 3.2: Sinal PRBS de comprimento 63 e tempo de bit 4.

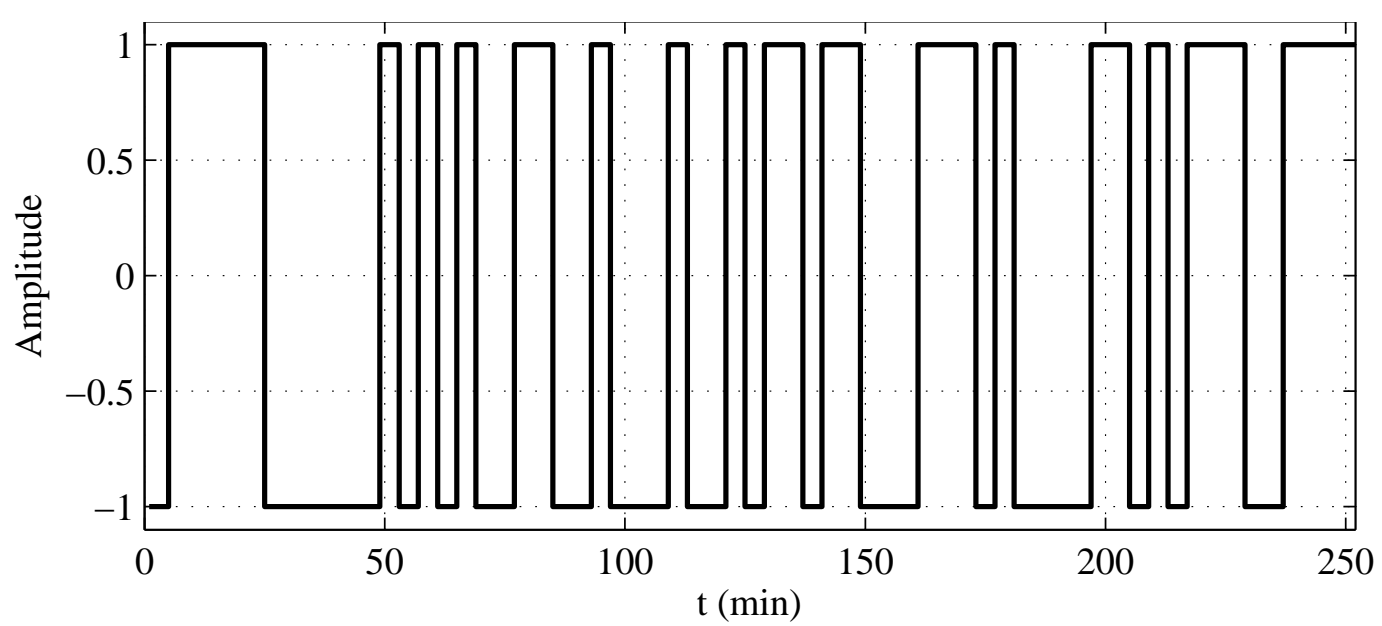

Fonte: Autor.

Figura 3.3: Espectro de potência do sinal da Figura 3.2.

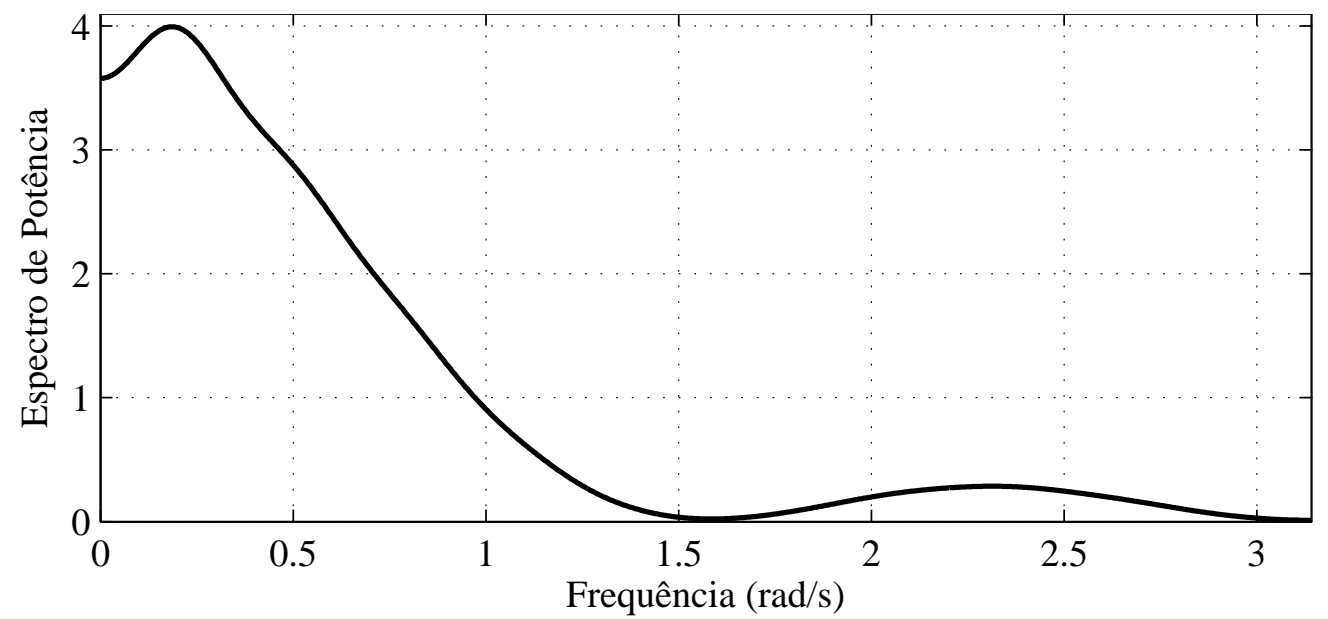

Fonte: Autor.

Figura 3.4: Função de autocorrelação dos primeiros 60 atrasos do sinal da Figura 3.2.

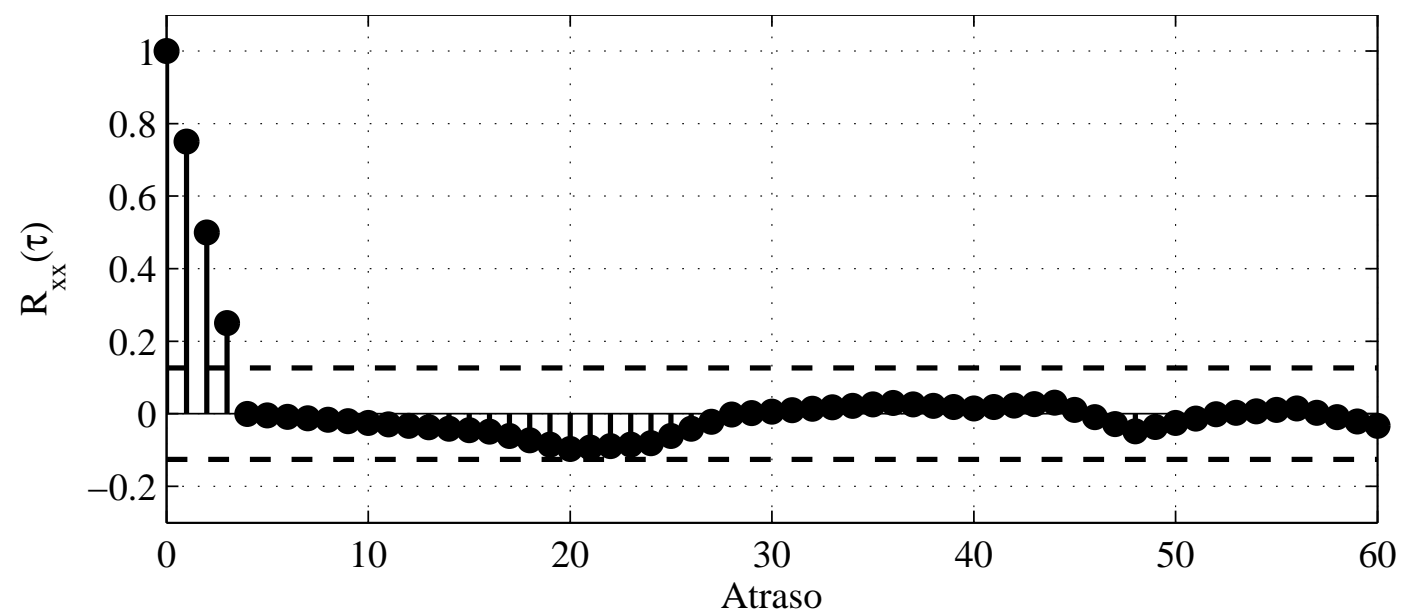

Fonte: Autor. 


\subsection{Ruído Binário Generalizado (GBN)}

Este tipo de sinal foi introduzido por Tulleken (1990), que aproveitando as características do ruído binário para a identificação de sistemas, apresentou um sinal que também possui características importantes a nível da frequência, cujo espectro pode ser modificado e levado às regiões de interesse. Particularmente, as regiões de baixa frequência são importantes nas dinâmicas das plantas petroquímicas, dado que possuem a maior informação do comportamento da planta.

Estes sinais nasceram como alternativa ao ruído binário $(\mathrm{BN})$, onde manipulando a probabilidade de chaveamento se faz mais flexível o sinal, chegando a modificar seu espectro de potência.

Um sinal GBN é um sinal binário e portanto tem dois valores de amplitude $+a$ e $-a$. Em cada intervalo de amostragem o seu chaveamento obedece as seguintes probabilidades:

$$
\begin{gathered}
P(u(t)=u(t-1))=p \\
P(u(t) \neq u(t-1))=1-p
\end{gathered}
$$

onde $p$ é a probabilidade de não-chaveamento e possui valores entre zero e um. Os eventos em pontos do tempo são independentes, assim, $P(u(t)=a)=P(u(t)=-a)=1 / 2$ e portanto o sinal tem média zero.

Observando-se a distribuição do tempo de chaveamento $T_{s w}$, se estabelece que:

$$
P\left(T_{s w}=k T\right)=p^{k-1}(1-p) ; k=1,2,3, \ldots
$$

desde que $k-1$ não-chaveamentos sejam seguidos por um chaveamento. Desta maneira se chega que $T_{s w} / T$ segue uma distribuição geométrica que depende de $p$, assim:

$$
E T_{s w}=\sum_{\infty}^{\infty}(k T) p^{k-1}(1-p)=\frac{T}{1-p}
$$

Por outro lado, o espectro de potência assintótico para os sinais GBN em tempo discreto é dado para todas as $\Omega \in[0, \pi / T]$ da seguinte maneira:

$$
\Phi_{p}^{d}(\Omega, q)=\frac{\left(1-q^{2}\right) T}{1-2 q \cos (\Omega T)+q^{2}}
$$

Na Figura 3.6 se apresenta o espectro de potência $\Phi_{p}^{d}(\Omega, q)$ de sinais GBN para diferentes valores de $q=2 p-1$, nela se observa a influência do parâmetro $p$ na forma do espectro.

As figuras 3.5, 3.7 e 3.8 apresentam as características do sinal GBN com os parâmetros da tabela 3.3, nas quais estão a forma do sinal de saída, o espectro de potência e a sua função de correlação.

Na figura 3.7 se apresenta o espetro de potência calculado analiticamente conforme (3.5) e calculando numericamente a média de 1000 espectros de potência de sinais GBN 
Tabela 3.3: Parametrização de um sinal GBN.

\begin{tabular}{cc}
\hline Parâmetro & Valor \\
\hline Tipo de sinal & GBN \\
Comprimento do sinal & $N=50$ \\
Probabilidade de não-chaveamento & $p=0,7$ \\
Período de amostragem & $\Delta t=1 \mathrm{~min}$ \\
Período do sinal & $T_{N}=50 \mathrm{~min}$ \\
\hline
\end{tabular}

construídos com os mesmos parâmetros, mas partindo de sementes diferentes. Se observa que o espectro de potência do sinal GBN não apresenta valores em zero, tal como se observou no sinal PRBS.

Figura 3.5: Sinal GBN de comprimento 50 e $p=0,7$.

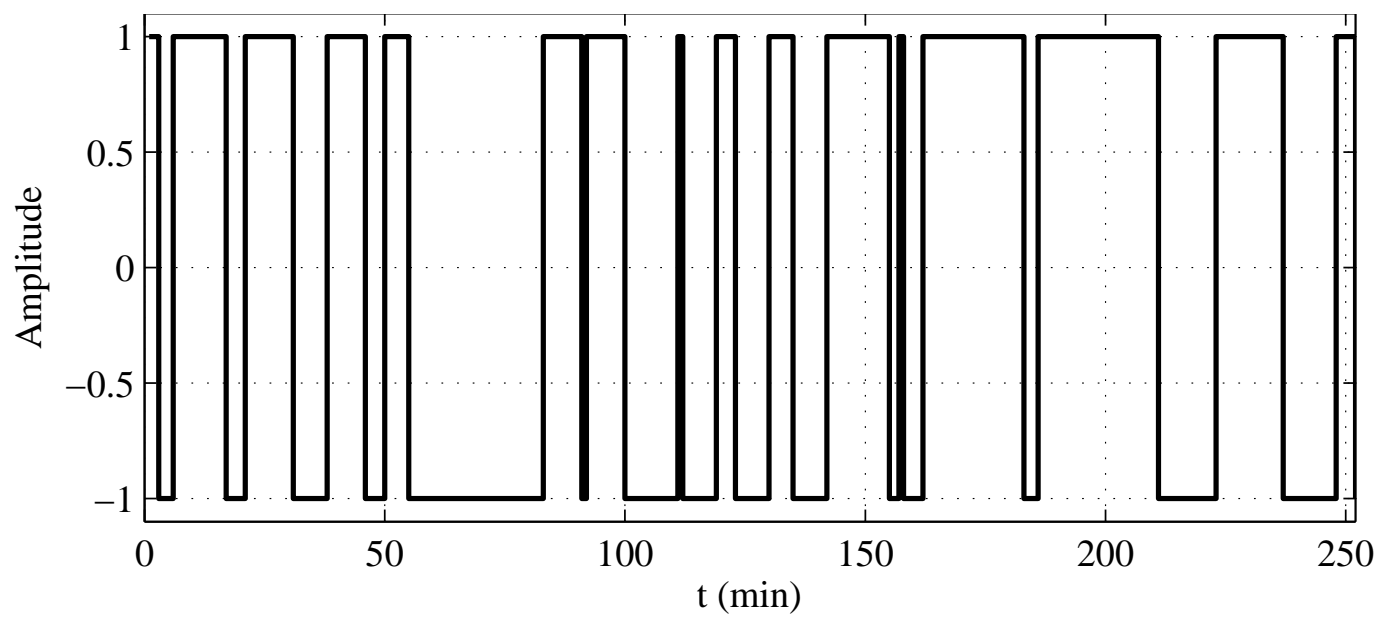

Fonte: Autor.

Figura 3.6: Espectro de potência de sinais GBN.

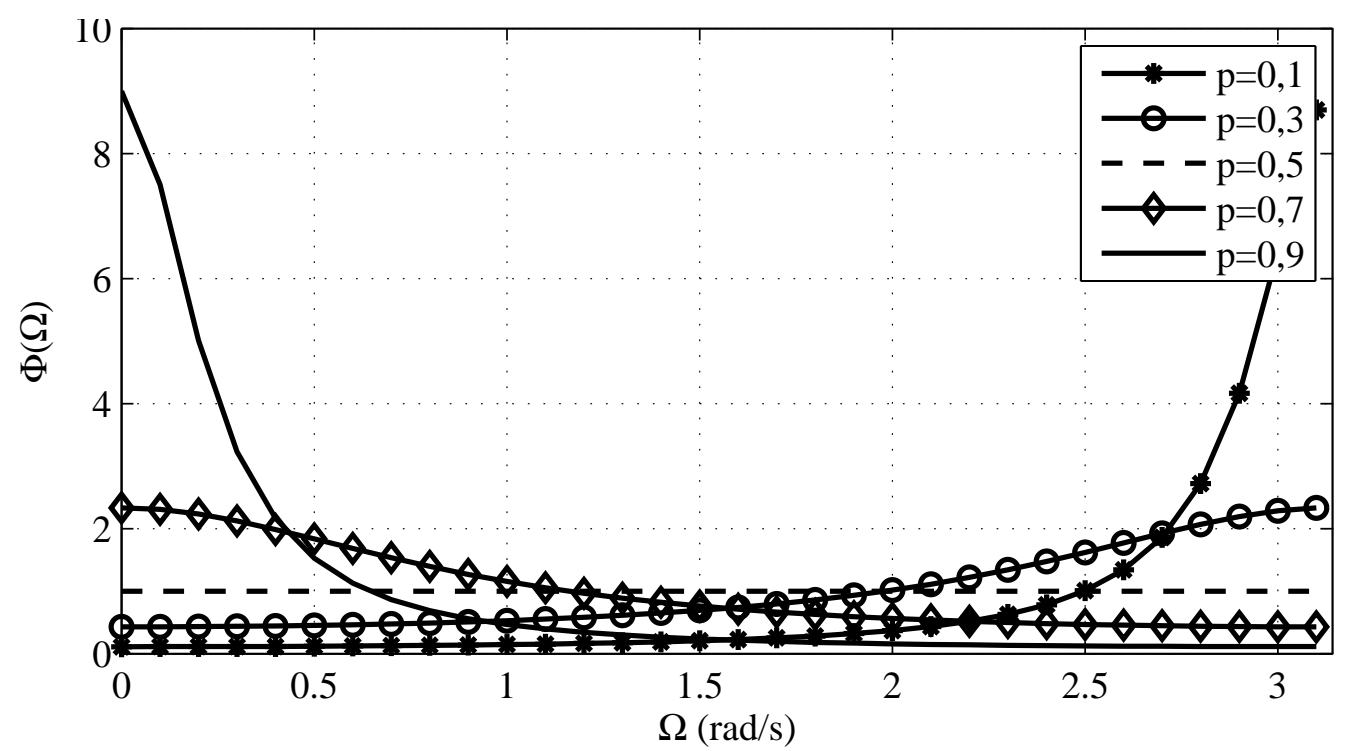

Fonte: Autor. 
Figura 3.7: Espectro de potência do sinal da Figura 3.5.

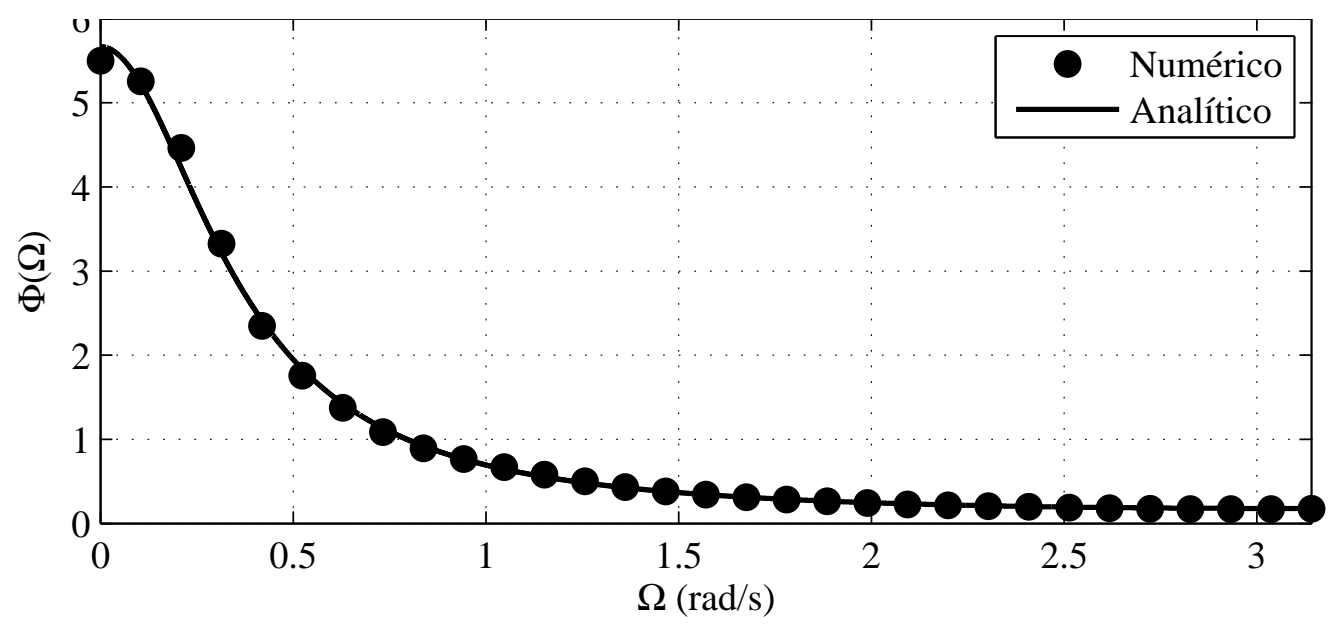

Fonte: Autor.

Figura 3.8: Função de auto correlação do sinal da Figura 3.5.

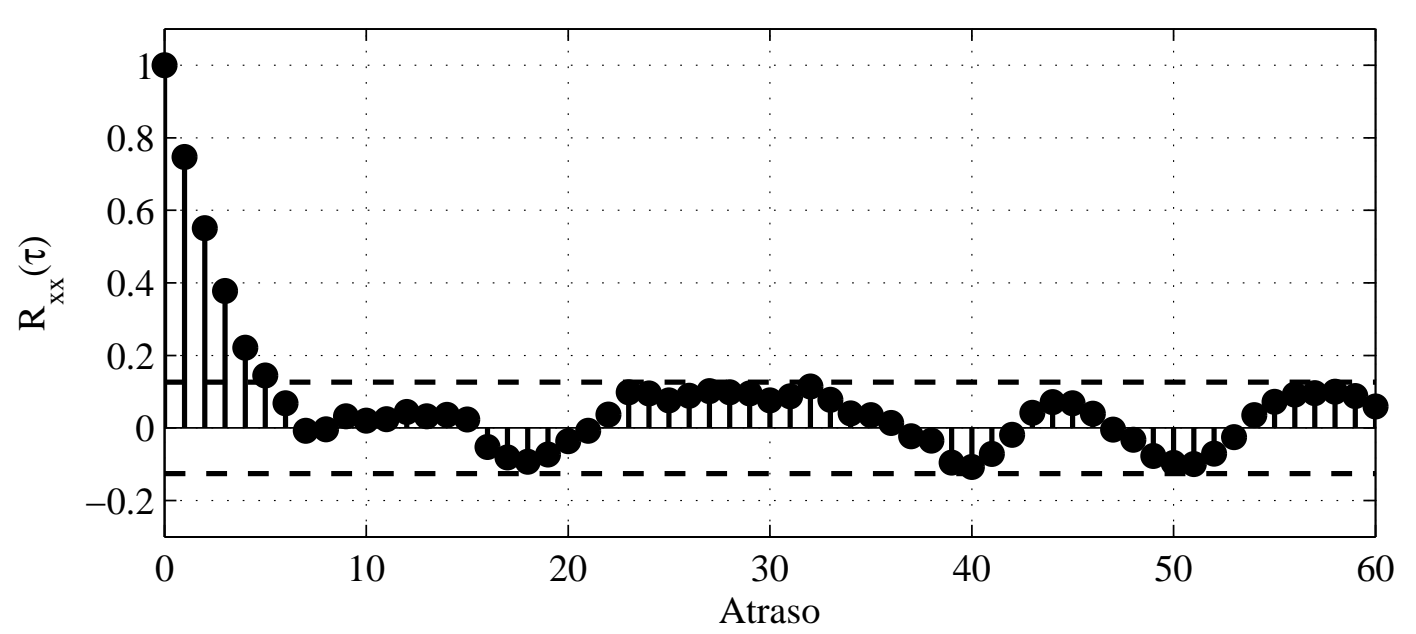

Fonte: Autor.

Um bom sinal para a identificação de sistemas apresenta uma característica de baixa frequência, este tipo de característica pode-se conseguir nos dois tipos de sinais. No sinal PRBS é possível concentrar a potência do sinal na faixa de baixas frequências aumentandose o tempo de bit, $T_{b}$. Enquanto no sinal GBN é possível ajustar o espectro de potência modificando-se a probabilidade de não-chaveamento, $p$, o que apresenta uma maior flexibilidade no ajuste da faixa de frequências sobre os sinais PRBS.

\subsection{Resumo}

Neste capítulo foram apresentados os sinais binários GBN e PRBS . Estes sinais podem ser facilmente modificados em amplitude e ajustados para que a potência esteja concentrada em uma faixa de frequências predefinida, estas características fazem deste tipo de sinais atrativos e os mais usados em experimentos industriais de identificação. 
Primeiro, foi apresentado o sinal PRBS e a forma em que este sinal é gerado a partir de um registro de deslocamento. Quando o sinal PRBS gerado possui $2^{n}-1$ pontos, sendo $n$ a ordem do registro de deslocamento, o sinal se considera de máximo comprimento possuindo características importantes, entre elas, a semelhança da sua função de autocorrelação com a de uma sequência de ruído branco. Por fim, um exemplo deste tipo de sinal foi apresentado.

Seguidamente, foi apresentado o sinal GBN junto com as equações envolvidas para sua geração. A partir das equações de geração é possível obter a expressão do espectro de potência. Uma vantagem deste tipo de sinal é a possibilidade de ajustar o seu espectro de potência de forma continua a partir do parâmetro $p$, que pode variar entre [0-1]. Finalmente foi apresentado um exemplo deste tipo de sinal e a influência da probabilidade de não-chaveamento sobre o espectro de potência dos sinais. 


\section{Seleção das Plantas Testadas}

Neste trabalho, as diferentes condições dos sinais de excitação são aplicadas para identificar algumas plantas bem, medianamente e mal condicionadas. As plantas selecionadas são: um reator de polimerização simulado de escala industrial $2 \mathrm{x} 2$ proposto por Chien, Huang e Yang (1999), considerada uma planta bem condicionada; o modelo da coluna de destilação binária 3x3 (OGUNNAIKE et al., 1983) medianamente mal condicionada e finalmente o modelo de uma coluna de destilação binária de alta pureza apresentado em (SKOGESTAD; MORARI; DOYLE, 1988), considerada mal condicionada.

\subsection{Análise do modelo}

Dada a matriz de ganhos estáticos $K$ de um sistema linear MIMO em malha aberta, a sua decomposição em valores singulares pode ser escrita como:

$$
K=W \Sigma V
$$

onde $W$ é a matriz singular unitária esquerda correspondendo às direções das saídas, $V$ é a matriz singular unitária direita, correspondendo às direções das entradas e $\Sigma$ é uma matriz diagonal de valores singulares reais e positivos em forma descendente.

A relação entre o máximo $\sigma_{M}$ e o mínimo valor $\sigma_{m}$ singular da matriz $\Sigma$ é conhecida como número de condição:

$$
\gamma=\frac{\sigma_{M}}{\sigma_{m}}
$$

Um processo é dito mal condicionado se $\sigma_{M}>>\sigma_{m}$, ou seja, $\gamma>>1$, indicando que as saídas do sistema são em grande medida dependentes da direção de suas entradas. Para obter resultados de acordo com a realidade devido ao uso das unidades de engenharia, o modelo pode ser normalizado, multiplicando-se as entradas e as saídas por um fator de escala.

Um método para medir o nível de interação em um processo independente da escala das suas variáveis é a matriz de ganhos relativos (relative gain array, RGA) (BRISTOL, 1966). A matriz RGA pode ser expressa como (ZHU; STEC, 2006):

$$
\Lambda=K \cdot *\left(K^{-1}\right)^{T}
$$


onde $\left(*^{*}\right)$ denota a multiplicação elemento a elemento da matriz.

Para um sistema MIMO de duas entradas e duas saídas (2x2):

$$
\Lambda=\left(\begin{array}{cc}
\lambda_{11} & \lambda_{12} \\
\lambda_{21} & \lambda_{22}
\end{array}\right)=\left(\begin{array}{cc}
\lambda & 1-\lambda \\
1-\lambda & \lambda
\end{array}\right) \text { e } \lambda=\frac{1}{1-\left(g_{12} g_{21} / g_{11} g_{22}\right)}
$$

onde $g_{i j}$ são os ganhos de malha aberta da $j$-ésima entrada sobre a $i$-ésima saída do processo.

Uma planta mal condicionada se caracteriza por ter um valor de $\lambda>>1$. As expressões (4.1) e (4.4) podem ser avaliadas no domínio da frequência.

Neste trabalho, os processos simulados para o estudo dos sinais GBN e PRBS foram caracterizados a partir do cálculo do $R G A$ :

- o reator de polimerização, bem condicionado com um $R G A\left(\lambda_{i j}\right)<1(\lambda=0,7087)$,

- a coluna de destilação binária 3x3, medianamente mal condicionada com $R G A\left(\lambda_{i j}\right) \approx$ 2 ,

- a coluna de destilação binária de alta pureza, mal condicionada com $R G A\left(\lambda_{i j}\right)=$ 35,068 .

\subsection{Reator de Polimerização 2x2}

O primeiro modelo testado é um reator de polimerização de escala industrial. Esta planta tem duas entradas e duas saídas e o modelo de processo é representado pela Equação (4.5), onde a escala de tempo é em horas, o que representa uma resposta dinâmica do processo muito lenta (CHIEN; HUANG; YANG, 1999).

As duas variáveis controladas são as duas medições representando a condição do reator e as duas variáveis manipuladas são os setpoints das malhas de alimentação da vazão do reator, tendo como distúrbio a vazão de purga do reator.

$$
\begin{gathered}
y(s)=G(s) u(s)+G_{d}(s) d(s) \\
G(s)=\left[\begin{array}{cc}
\frac{22,89 e^{-0,2 s}}{4,572 s+1} & \frac{-11,64 e^{-0,4 s}}{1,807 s+1} \\
\frac{4,689 e^{-0,2 s}}{2,174 s+1} & \frac{5,8 e^{-0,4 s}}{1,801 s+1}
\end{array}\right] ; \quad G_{d}(s)=\left[\begin{array}{c}
\frac{-4,243 e^{-0,4 s}}{3,445 s+1} \\
\frac{-0,601 e^{-0,4 s}}{1,982 s+1}
\end{array}\right]
\end{gathered}
$$

Às saídas $y_{1}$ e $y_{2}$ são adicionados ruído de medição $e_{1}$ e $e_{2}$ e perturbações não medidas $v_{1}$ e $v_{2}$. O ruído de medição é de tipo Gaussiano. As perturbações $v_{1}$ e $v_{2}$ são de tipo Gaussiano filtradas pela estrutura $G_{d}(s)$ apresentada na Equação $(4.5)$, com $d_{1}$ e $d_{2}$ variando a cada 0,4 horas (Figura 4.1). 
Figura 4.1: Diagrama de blocos relacionando as entradas e saídas do Reator.

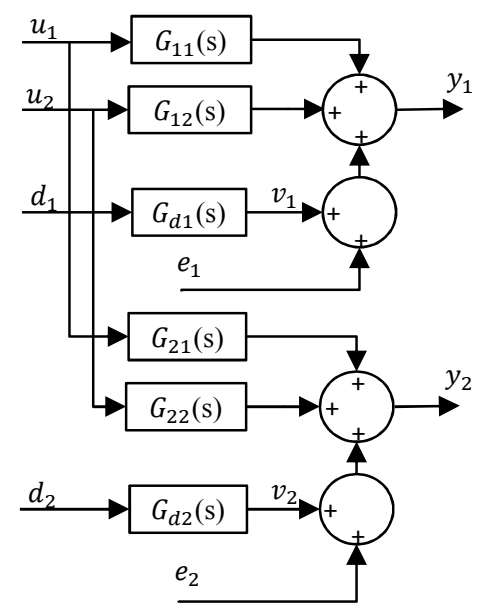

Fonte: Autor.

\subsubsection{Planta em Malha Fechada}

Em (CHIEN; HUANG; YANG, 1999) é proposto um método de sintonização multi-malha para controladores PID aplicados no Reator de Polimerização 2x2. O método é derivado de um método de síntese de controladores como uma especificação do rendimento de controle de $5 \%$ de sobressinal na resposta em modo servo. Os parâmetros do PI resultantes são apresentados na Tabela 4.1, e o sistema em malha fechada tem a configuração apresentada na Figura 4.2.

Tabela 4.1: Parâmetros de sintonia para o Controle do Reator

\begin{tabular}{cccc}
\hline$K_{c_{1}}$ & $\tau_{i_{1}}$ & $K_{c_{2}}$ & $\tau_{i_{2}}$ \\
\hline 0,263 & 1,42 & 0,163 & 1,77 \\
\hline
\end{tabular}

Figura 4.2: Diagrama de blocos do Reator de Polimerização em malha fechada.

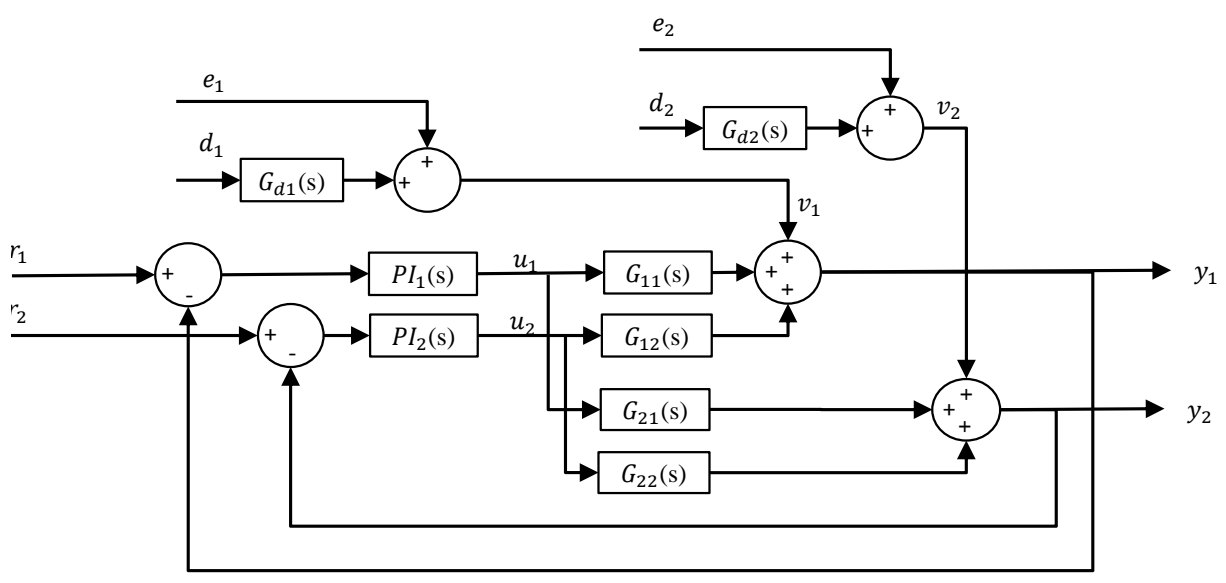

Fonte: Autor. 


\subsection{Coluna de Destilação $3 \times 3$}

A seguir, se considera para os próximos testes, o modelo de uma planta piloto que representa uma coluna de destilação binária de água-etanol, apresentada por Ogunnaike et al. (1983). O modelo do sistema apresenta-se na Equação (4.6), onde as constantes de tempo e os atrasos são dados em minutos. As saídas $y_{1}, y_{2}$ e $y_{3}$ correspondem à fração molar de etanol no topo, à fração molar de etanol na corrente secundária e à temperatura do prato \#19 $\left({ }^{\circ} \mathrm{C}\right)$, respectivamente.

As entradas $u_{1}, u_{2}$ e $u_{3}$ são a vazão de refluxo, a vazão na corrente secundária e a pressão da corrente do refervedor, respectivamente.

$$
\begin{gathered}
G(s)=\left[\begin{array}{ccc}
\frac{0,66 e^{-2,6 s}}{6,7 s+1} & \frac{-0,61 e^{-3,5 s}}{8,64 s+1} & \frac{-0,0049 e^{-s}}{9,06 s+1} \\
\frac{1,11 e^{-6,5 s}}{3,25 s+1} & \frac{-2,36 e^{-3 s}}{5 s+1} & \frac{-0,01 e^{-1,2 s}}{7,09 s+1} \\
\frac{-34,68 e^{-9,2 s}}{8,15 s+1} & \frac{46,3 e^{-9,4 s}}{10,9 s+1} & \frac{0,87(11,61 s+1) e^{-s}}{(3,89 s+1)(18,8 s+1)}
\end{array}\right] \\
G_{d}(s)=\left[\begin{array}{cc}
\frac{0,14 e^{-12 s}}{6,9 s+1} & \frac{-0,0011(26,32 s+1) e^{-2,66 s}}{(7,85 s+1)(14,63 s+1)} \\
\frac{0,53 e^{-10,5 s}}{6,9 s+1} & \frac{-0,0032(19,62 s+1) e^{-3,44 s}}{(7,29 s+1)(8,94 s+1)} \\
\frac{-11,54 e^{-0,6 s}}{7,01 s+1} & \frac{0,32 e^{-2,6 s}}{7,76 s+1}
\end{array}\right]
\end{gathered}
$$

Às saídas $y_{1}, y_{2}$ e $y_{3}$ são adicionados os ruídos de medição $e_{1}, e_{2}$ e $e_{3}$ e perturbações não medidas $v_{1}, v_{2}$ e $v_{3}$. Os ruídos de medição são de tipo Gaussiano. As perturbações $v_{1}, v_{2}$ e $v_{3}$ são de tipo Gaussiano filtradas pela estrutura $G_{d}(s)$ apresentada na Equação (4.6), com $d_{1}$ e $d_{2}$ variando a cada 2 e 10 minutos, respectivamente (Figura 4.3).

As condições operacionais e de perturbação da planta foram as mesmas usadas em Ogunnaike et al. (1983), apresentadas nas tabelas 4.2 e 4.3, onde os sinais de entrada tomam os valores de $\pm 4 \%, \pm 3 \%$ e $\pm 9 \%$ das restrições.

Tabela 4.2: Restrições do Sistema.

\begin{tabular}{lcc}
\hline Variável & Limite inferior & Limite Superior \\
\hline Vazão de refluxo & $0,068 \mathrm{gpm}$ & $0,245 \mathrm{gpm}$ \\
Vazão na corrente secundária & $0,00694 \mathrm{gpm}$ & $0,1 \mathrm{gpm}$ \\
Pressão da corrente do refervedor & $15,6 \mathrm{psig}$ & $34,0 \mathrm{psig}$ \\
\hline
\end{tabular}

\subsubsection{Planta em Malha Fechada}

Em (OGUNNAIKE et al., 1983) é apresentado um controlador multi-malha PI aplicado na Coluna de destilação. Também foi desenvolvido e implementado no processo real um controlador multivariável para sistemas que possuem múltiplos tempos mortos. O contro- 
Figura 4.3: Diagrama de blocos relacionando as entradas e saídas da coluna de destilação.

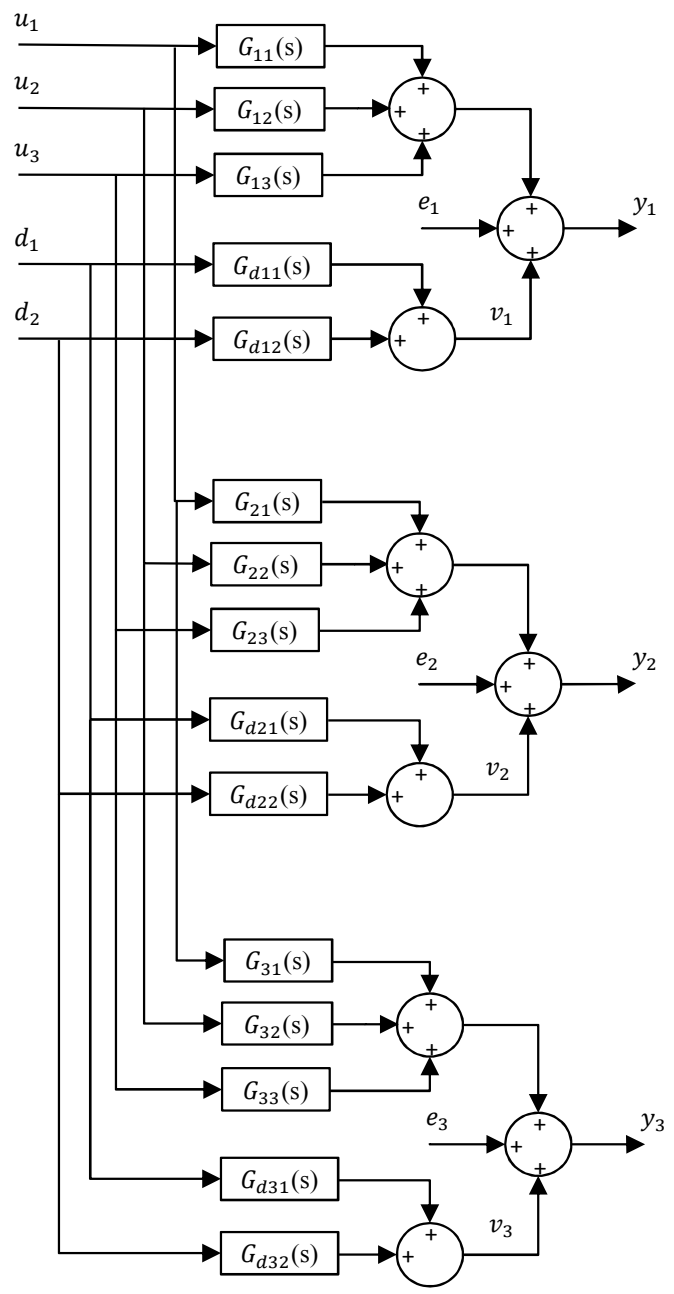

Fonte: Autor.

Tabela 4.3: Condições experimentais.

\begin{tabular}{lccc}
\hline Variável & setpoint & De & Até \\
\hline Fração molar etanol no topo & 0,7 & 0,7 & 0,65 \\
Fração molar etanol na corr. secund. & 0,52 & 0,53 & 0,45 \\
Temperatura do prato \#19 & $92{ }^{\circ} \mathrm{C}$ & $92^{\circ} \mathrm{C}$ & $97^{\circ} \mathrm{C}$ \\
Perturbação na vazão de alimentação & & $0,8 \mathrm{gpm}$ & $1,0 \mathrm{gpm}$ \\
Perturbação na temperatura & & $78^{\circ} \mathrm{C}$ & $58^{\circ} \mathrm{C}$ \\
\hline
\end{tabular}

lador consiste em um compensador de tempos mortos acoplado com um PI tradicional. No artigo são comparados os compensadores PI e PI+compensador de tempos mortos. Neste trabalho é considerado unicamente o controlador PI sem compensador de tempos mortos, sendo que os parâmetros dos PI resultantes são apresentados na Tabela 4.4.

O sistema em malha fechada tem a configuração apresentada na Figura 4.4. As respostas ao degrau no instante zero aplicados no setpoints com amplitude igual ao valor máximo das do sistema se apresentam na Figura ??. 
Tabela 4.4: Parâmetros de sintonia para o Controle da Coluna de destilação

\begin{tabular}{cccccc}
\hline$K_{c_{1}}$ & $\tau_{i_{1}}$ & $K_{c_{2}}$ & $\tau_{i_{2}}$ & $K_{c_{3}}$ & $\tau_{i_{3}}$ \\
\hline 01,2 & 5 & $-0,15$ & 10 & 0,6 & 4 \\
\hline
\end{tabular}

Figura 4.4: Diagrama de blocos relacionando as entradas e saídas da Coluna de Destilação em malha fechada.

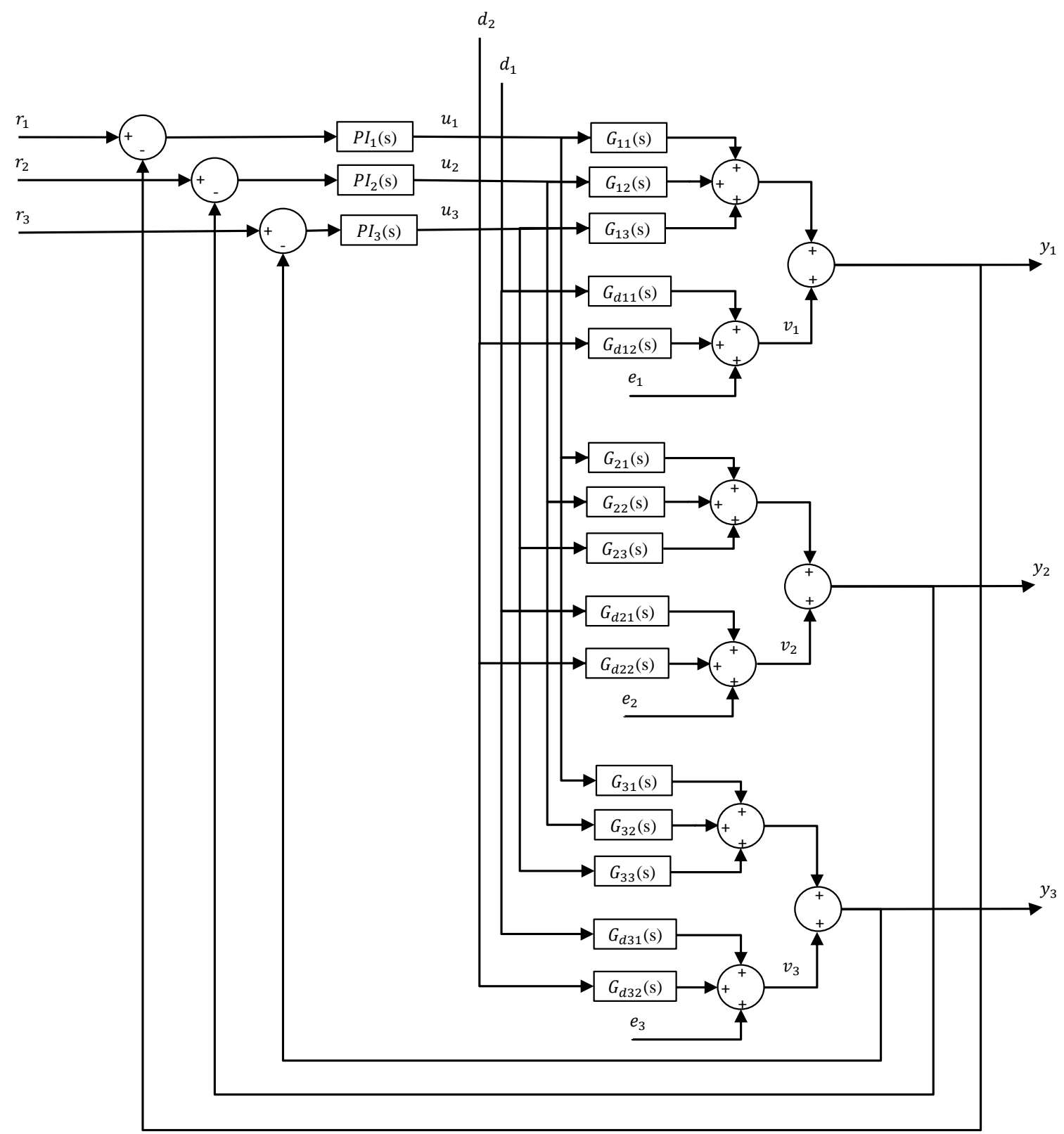

Fonte: Autor. 


\subsection{Plantas mal condicionadas}

Devido à natureza dos processos multivariáveis (MIMO), uma variável manipulada afeta mais de uma variável controlada. Esta característica é conhecida como interação e torna mais difícil o controle destes sistemas. Quando as interações entre algumas das saídas são muito fortes, o processo é chamado mal condicionado. Assim, dependendo da combinação das entradas, pode-se ter diferentes variações nas amplitudes das saídas do sistema, altas e baixas, conhecidas como direções de alto e baixo ganho (SEBORG, 1999).

Exemplos de plantas mal condicionadas mais conhecidas e estudadas na literatura são as colunas de alta pureza, empregadas na separação de produtos que possuem pontos de ebulição muito próximos. Skogestad, Morari e Doyle (1988) apresentam as características da natureza das colunas de destilação, a resposta das composições e os seus respectivos modelos analíticos. Além da dificuldade do controle deste tipo de plantas, o processo de identificação se vê fortemente afetado devido às interações e à direcionalidade do ganho presente nelas. Métodos clássicos de identificação têm dificuldades para representar completamente a dinâmica deste tipo de processo. Muitos trabalhos têm enfoques diferentes para melhorar a precisão dos modelos identificados, alguns desses enfoques são variações dos métodos clássicos (ZHU, 2001; MICCHI; PANNOCCHIA, 2008; RIVERA; JUN, 2000; SEBORG, 1999; VAILLANT; KURAMOTO; GARCIA, 2013).

O processo a ser identificado neste trabalho é uma coluna de destilação binária apresentada em (SKOGESTAD; MORARI; DOYLE, 1988), que se considera operando na configuração L-V. Nesta configuração, as entradas da planta (MV) L e V correspondem à vazão de refluxo e à vazão no refervedor, conforme mostrado na Figura 4.5.

Figura 4.5: Coluna de alta pureza.

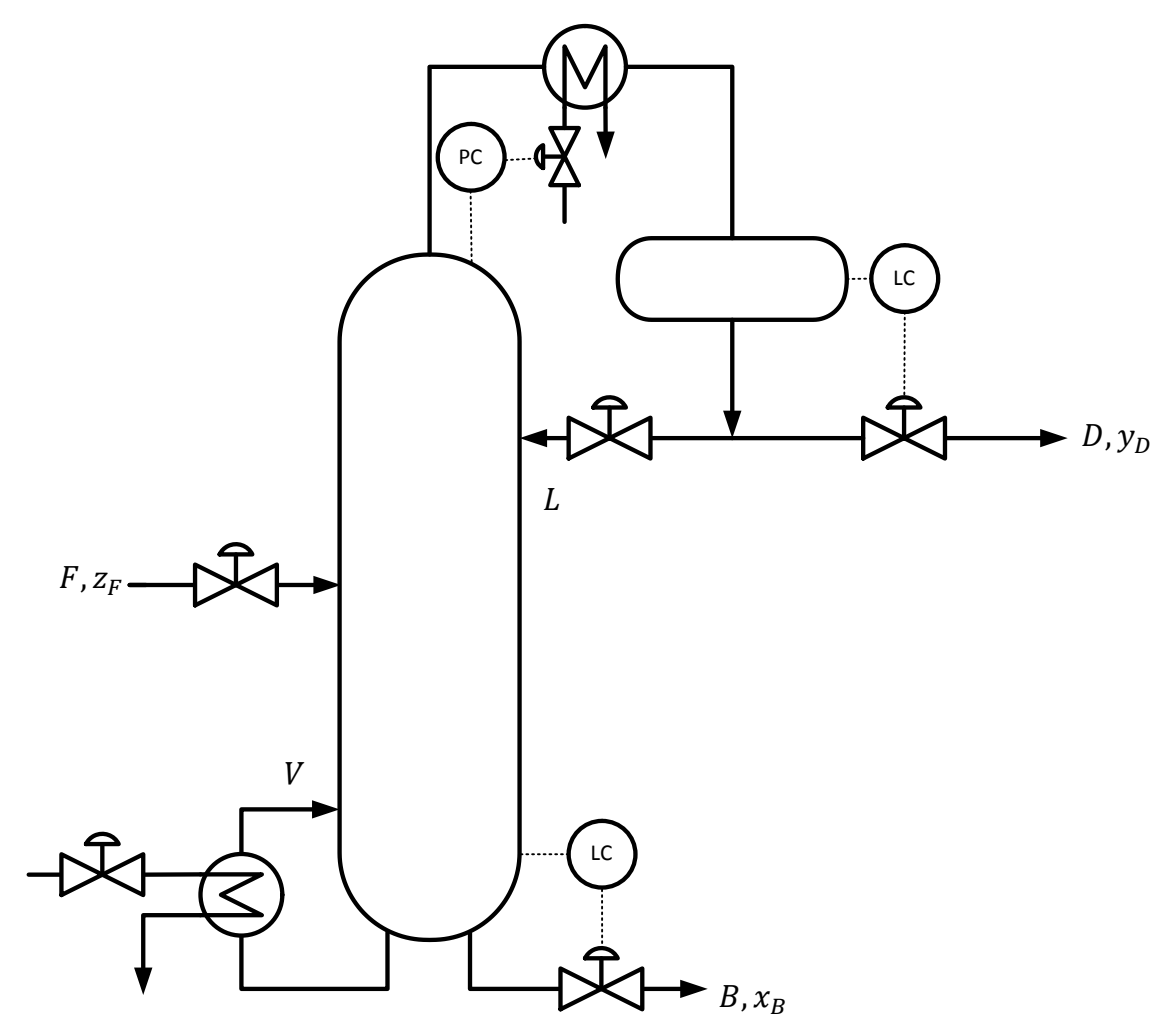

Fonte: Skogestad, Morari e Doyle (1988). 
As saídas $y_{D}$ e $x_{B}$ correspondem à composição do destilado e à composição do produto de fundo, respectivamente. As duas composições de saída são dadas como fração molar do produto leve. Neste trabalho são consideradas as entradas $u_{1}$ e $u_{2}$ da planta como a L/F e $\mathrm{V} / \mathrm{F}$, sendo $\mathrm{F}$ a vazão de carga da coluna. As saídas $y_{1}$ e $y_{2}$ são $y_{D}$ e $x_{B}$, respectivamente.

O modelo de segunda ordem que representa a dinâmica da coluna de alta pureza é apresentado em (4.7):

$$
G(s)=\left[\begin{array}{ll}
\frac{k_{11}}{1+\tau_{1} s} & \frac{k_{11}+k_{12}}{1+\tau_{2} s}-\frac{k_{11}}{1+\tau_{1} s} \\
\frac{k_{21}}{1+\tau_{1} s} & \frac{k_{21}+k_{22}}{1+\tau_{2} s}-\frac{k_{21}}{1+\tau_{1} s}
\end{array}\right]
$$

onde $\tau_{1}=194$ minutos, $\tau_{2}=15$ minutos, $k_{11}=87,8, k_{12}=-86,4, k_{21}=108,2 \mathrm{e}$ $k_{22}=-109,6$.

A planta $G(s)$ contém duas constantes de tempo, que correspondem às dinâmicas das direções de baixo e alto ganho. A direção de baixo ganho apresenta dinâmicas mais rápidas que a de alto ganho.

A característica da direcionalidade de alto e baixo ganho pode ser observada na Figura 4.6, plotando-se $x_{B}$ em função de $y_{D}$, onde se percebe a dependência linear das duas saídas. Os resultados foram obtidos de um teste usando um sinal GBN com $p=0,96$, amplitude igual a 0,00001 e $N=1500$.

Figura 4.6: Plano de saídas $\left\{y_{1} ; y_{2}\right\}$ resultado de um teste com sinal GBN no modelo $G(s)$.

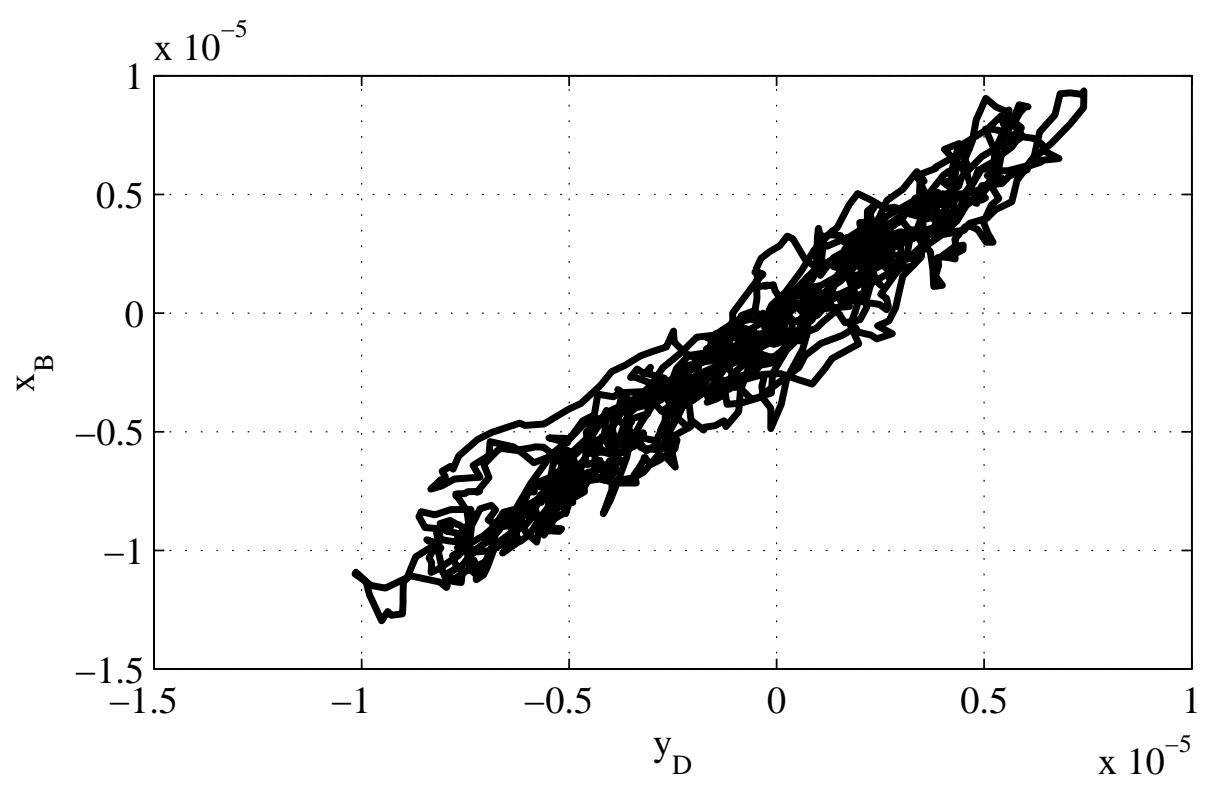

Fonte: Autor. 


\subsection{Resumo}

Neste capítulo foram apresentados dois métodos para medir a interação entre as variáveis dos processos a partir da matriz de ganhos estáticos em malha aberta: o número de condição (Equação (4.2)) e a matriz de ganhos relativos (Equação (4.3)). Mediante estas expressões é possível caracterizar a natureza dos processos como bem ou mal condicionados, o que representa um aspecto importante na hora de projetar o experimento de identificação e na implementação da lei de controle.

Foram descritos também os modelos de três plantas, o primeiro deles, um reator de polimerização de dimensões $2 \times 2$. Este processo é considerado bem condicionado com um $R G A\left(\lambda_{i j}\right)=0,7087$ e com dinâmicas lentas. Este processo também foi estudado em malha fechada usando controladores PI propostos em (CHIEN; HUANG; YANG, 1999). O segundo processo descrito foi o modelo de uma coluna de destilação de água-etanol de dimensões $3 \mathrm{x} 3$, este processo é considerado medianamente mal condicionada com $R G A\left(\lambda_{i j}\right) \approx 2$. Este processo também foi apresentado em malha fechada usando controladores PI propostos em (OGUNNAIKE et al., 1983).

Finalmente, foi apresentado o modelo de uma coluna de alta pureza de dimensões $2 \mathrm{x} 2$, este processo é considerado mal condicionada com $R G A\left(\lambda_{i j}\right)=35,068$. Esta coluna foi testada com um conjunto de sinais GBN de comprimento $N=1500$ e $p=0,96$ para observar a direcionalidade de alto e baixo ganho em um plano de saídas $\left\{y_{1} ; y_{2}\right\}$. 


\section{Projeto de sinais de excitação}

Caracterizar os sinais de excitação para a identificação de um sistema é uma tarefa decisiva para extrair informações de interesse para a aplicação do modelo identificado. A caracterização envolve o comprimento dos sinais, as suas características em frequência e correlação cruzada entre os múltiplos sinais, fatores importantes a serem escolhidos. Essa informação deve levar em conta as interações entre as entradas e as saídas. Neste capítulo são estudadas a correlação cruzada entre os sinais de excitação e a frequência dos mesmos. Os sinais GBN e PRBS testados são gerados a partir da implementação de códigos no software MATLABß.

\subsection{Estudo de correlações cruzadas}

Independente do sinal escolhido, a prática mais comum em identificação MIMO é projetar os sinais de entrada descorrelacionados (DAVIES, 1970; KOUNG; MACGREGOR, 1993).

Para evitar um tempo elevado dos testes de identificação em plantas com mais de uma entrada, injetam-se nas entradas múltiplos sinais de teste para fazer uma identificação simultânea (ISERMANN; MÜNCHHOFF, 2011). Além de reduzir o tempo total do experimento, Gevers et al. (2006) mostram que a melhoria da precisão da estimação dos parâmetros aumenta ao injetar novas entradas, concluindo finalmente que é melhor excitar todas as entradas simultaneamente. Entretanto, na hora de injetar todos os sinais ao mesmo tempo, existe um efeito cruzado entre os sinais de teste, que torna difícil identificar o efeito de diferentes entradas sobre a mesma saída. Na identificação simultânea de sistemas MIMO se requer uma especial atenção para se evitar a correlação cruzada entre as entradas (DAVIES, 1970; KOUNG; MACGREGOR, 1993; LJUNG, 1999; ISERMANN; MÜNCHHOFF, 2011).

\subsubsection{Correlação Cruzada}

A medida mais comum de dependência entre dois conjuntos de dados é o coeficiente de correlação de Pearson, normalmente chamado coeficiente de correlação. O coeficiente de correlação mede quão forte é a relação linear entre as variáveis $x$ e $y$. O valor numérico de $r_{x y}$ pode ser calculado através da Equação (5.1) e possui valores entre +1 e -1 . Se o coeficiente de correlação tem um valor perto de +1 , então existe uma forte relação linear positiva entre $x$ e $y$. Por outra parte, se $r_{x y}=-1$ existe uma forte relação linear negativa entre $x$ e $y$. Finalmente, quanto mais próximo de zero o coeficiente de correlação é, a 
relação linear entre $x$ e $y$ diminui, o que significa que os sinais estão mais perto de serem descorrelacionados.

$$
r_{x y}=\frac{\operatorname{cov}(x(t), y(t))}{\sigma_{x(t)} \sigma_{y(t)}}=\frac{E\left[\left(x(t)-\mu_{x(t)}\right)\left(y(t)-\mu_{y(t)}\right)\right]}{\sigma_{x} \sigma_{y}}
$$

$\mathrm{Na}$ análise de sinais no domínio do tempo, o coeficiente de Pearson deve ser calculado em diferentes pontos de deslocamento dos sinais, chamada função de correlação cruzada (FCC):

$$
R_{x y}(\tau)=r_{x(\tau) y(t-\tau)}=\frac{E\left[\left(x(t)-\mu_{x(t)}\right)\left(y(t-\tau)-\mu_{y(t-\tau)}\right)\right]}{\sigma_{x(t)} \sigma_{y(t-\tau)}}
$$

Finalmente, através da Equação (5.2) os sinais $x$ e $y$ são considerados ortogonais quando o valor de $r_{x y}(\tau)=0$ para $\tau=0$. Da mesma maneira, os sinais são considerados descorrelacionados quando $r_{x y}(\tau)=0$ para todo $\tau$.

\subsubsection{Significância do coeficiente de correlação}

Uma vez calculado o coeficiente de correlação de Pearson é necessário ter uma percepção da sua significância. Um coeficiente de correlação é mais significativo caso se possa afirmar, com uma certa probabilidade, que é diferente de zero. Em termos estatísticos, é necessário conhecer a probabilidade de que o coeficiente provenha de sinais descorrelacionados. Portanto existem duas hipóteses possíveis:

$$
\begin{aligned}
& \mathrm{H}_{0}: r_{x y}=0 \Rightarrow \text { Os sinais } x \text { e } y \text { são descorrelacionados. } \\
& \mathrm{H}_{1}: r_{x y} \neq 0 \Rightarrow \text { Os sinais } x \text { e } y \text { possuem alguma correlação. }
\end{aligned}
$$

Desde o suposto da Hipótese nula, $H_{0}$, a distribuição da FCC de dois sinais caracterizada por $r_{x y}=0$ segue uma lei de t-student com $N-2$ graus de liberdade. Em consequência, dado um certo coeficiente $r_{x y}$ é preciso comprovar se ele se encontra dentro da distribuição amostral especificada pela Hipótese nula. Para efeitos práticos, é usada a Equação (5.3) (KREMELBERG, 2010):

$$
t=\frac{r_{x y}-0}{\sqrt{\frac{1-r_{x y}^{2}}{N-2}}}
$$

e se compara o valor obtido com o existente nas tabelas para um certo nível de significância $\alpha$ e $N-2$ graus de liberdade, $t_{(\alpha, N-2)}$. Com isto, se:

$t>t_{(\alpha, N-2)} \Rightarrow$ Se rejeita a Hipótese nula. Portanto as variáveis estão relacionadas.

$t \leq t_{(\alpha, N-2)} \Rightarrow$ As duas variáveis são descorrelacionadas.

Considerando que os sinais de identificação usados na industria normalmente possuem comprimentos maiores que 100 pontos, podem ser calculados os limites que deve possuir a FCC para um nível de significância de $5 \%$, isto é, $\alpha=0,05$. O valor de $t_{(\alpha=0,05)}$ usado 
para graus de liberdade maiores que 100 é de $1,96 \approx 2$. Com isto e utilizando a Equação (5.3), os limites que deve possuir a FCC para considerar-se que dois sinais $x$ e $y$ sejam significativamente descorrelacionados se apresentam na Equação (5.4) (BROCKWELL; DAVIS, 1991).

$$
r_{\text {lim }}= \pm \frac{1,96}{\sqrt{N+2}} \approx \frac{2}{\sqrt{N}}
$$

A função crosscorr ( $\mathrm{x}, \mathrm{y}, \mathrm{nLags})$ do Matlab $($ ) calcula a FCC dos sinais $x$ e $y$, por exemplo, considerando $x$ e $y$ dois sinais GBN gerados com 900 pontos e $p=0,9$, a função crosscorr $(\mathrm{x}, \mathrm{y}, \mathrm{nLags})$ fornece como saída a Figura 5.1. Em vários pontos de atraso a FCC dos sinais $x$ e $y$ possui valores maiores que o limite $r_{\text {lim }}=2 / \sqrt{900}=0,0667$, nestes pontos de atraso os sinais possuem alguma correlação cruzada significativa.

Figura 5.1: Função de correlação .

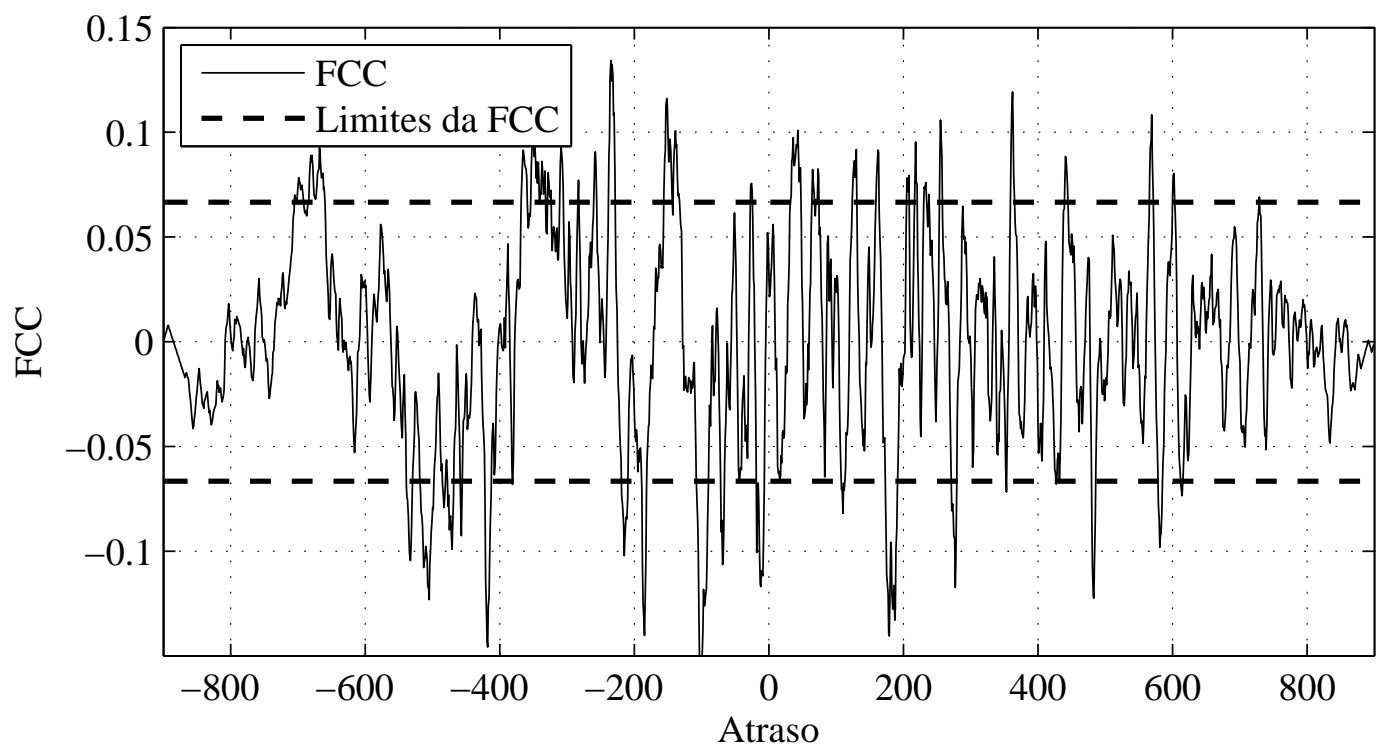

Fonte: Autor.

\subsubsection{Correlação de sinais de excitação}

Na literatura, o estudo das correlações entre os sinais de excitação para a identificação MIMO foi tratado inicialmente para sinais de teste PRBS. Davies (1970), Rivera e Jun (2000) usaram versões deslocadas de um sinal PRBS para reduzir a correlação cruzada entre as entradas. Assim, tendo uma sequência PRBS de comprimento $2047 \operatorname{com} T_{b}=1$, podem ser gerados quatro sinais idênticos, mas deslocados por 512 bits. Mesmo que esses sinais sejam idênticos, a correlação cruzada entre eles tende a ser zero, isto é, 1/2047 calculado a partir da Equação (3.2). Este valor é menor que o limite calculado pela Equação (5.4), $r_{\text {lim }}=0,0442$.

Na prática, existe uma grande dificuldade para gerar sinais completamente descorrelacionados. Essa dificuldade cresce quando se aumenta o tempo de bit nos sinais PRBS ou quando a probabilidade de não-chaveamento se aproxima de 1 nos sinais GBN. 
Como primeiro método para avaliar o efeito da correlação cruzada dos sinais de entrada propõe-se usar sinais de alta e baixa correlação dentro de um conjunto de sementes. Para isto, foi calculada a função de correlação cruzada com 60 atrasos, para garantir um tempo maior aos tempos mortos das dinâmicas das plantas a serem testadas.

Neste trabalho, as correlações cruzadas são calculadas sempre entre duas sequências que dão origem a vetores com 121 termos com valores de correlação $r$ para cada um dos 60 atrasos, incluído o valor de correlação no instante 0 . A escolha da menor e maior correlação se baseia no valor máximo dos 121 termos da FCC calculada. O registro do valor máximo de correlação e sua posição relativa dentro do vetor foi considerado importante para a interpretação dos resultados de identificação.

Para combinações entre três ou mais sequências, foi considerada ainda a média aritmética dos valores máximos da FCC de cada uma das combinações, resultando em um valor final $\bar{r}$. Assim, para um conjunto de três sequências, deve-se considerar o valor médio $\bar{r}$ obtido entre as sequências $u_{1}-u_{2}, u_{2}-u_{3}$ e $u_{3}-u_{1}$.

Tanto para combinações de sinais GBN como PRBS foi considerado um valor limite da FCC $\left|r_{\text {lim }}\right|=0,0667$. Este valor limiar foi calculado considerando $N=900$, comprimento do conjunto $Z_{N}$ usado para identificar os modelos das plantas apresentadas no Capítulo 4 .

Na Figura 5.2 se mostram os valores absolutos das correlações mínimas e máximas de duas sequências obtidas da pesquisa de 1000 sementes consecutivas a partir de 1 para sinais PRBS, este procedimento foi realizado variando $T_{b}$ de 1 a 44 . O mesmo é mostrado na Figura 5.3 para sinais GBN com $p$ variando de 0,5 a 0,99 .

Figura 5.2: Correlações cruzadas entre sequências PRBS.

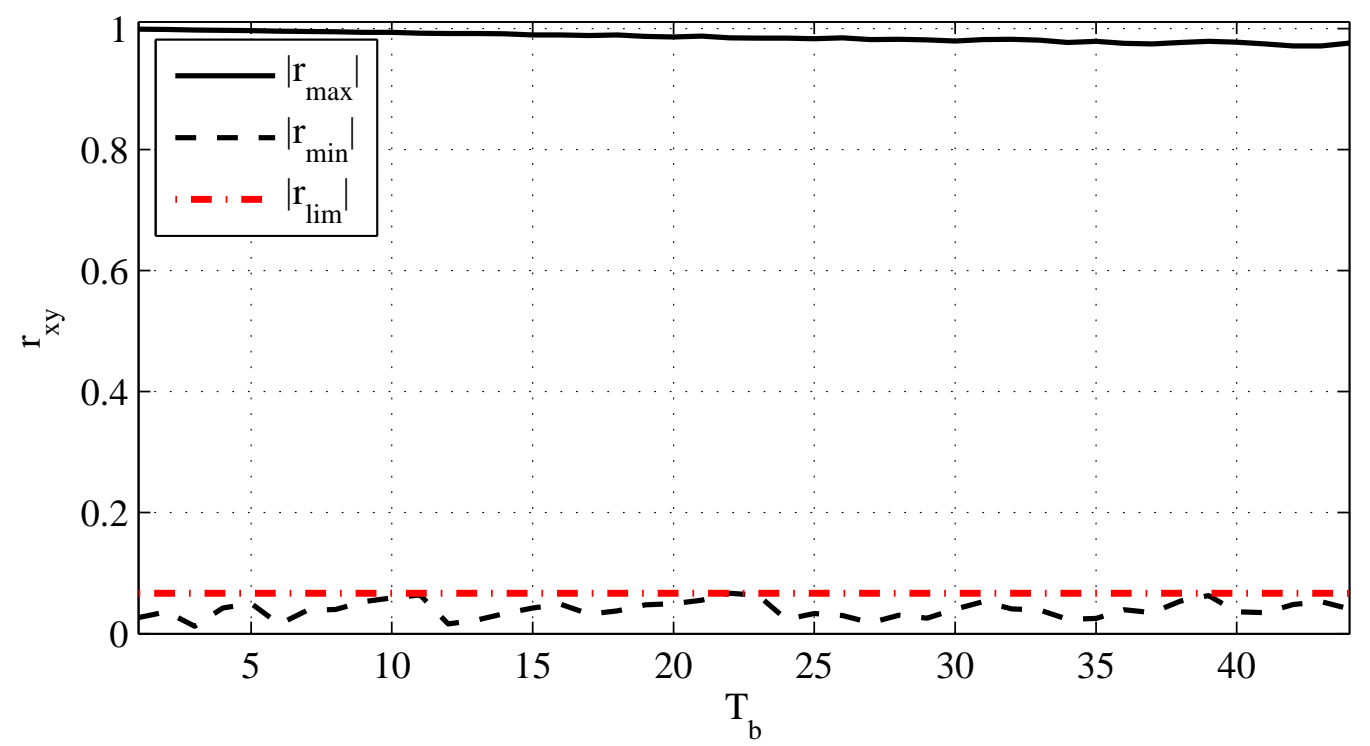

Fonte: Autor.

Para sinais PRBS, os menores valores de correlação ficaram em torno ao valor $\left|r_{\text {lim }}\right|=$ 0,0667 para todos os valores de $T_{b}$ usados, sem se perceber uma dependência com $T_{b}$.

Para as combinações de sinais PRBS de alta correlação verificou-se uma maior facilidade de se ter sinais correlacionados para os valores de $T_{b}$ usados, contendo valores de 
correlação quase unitários em algum ponto da sequência, o que significa que neste ponto os sinais estão seguramente correlacionados.

Um resultado similar ao obtido com sinais PRBS de baixa correlação foi observado usando sinais GBN, os menores valores das 1000 combinações de sinais GBN testadas ficaram em torno do valor $r_{\text {lim }}$.

Sinais GBN apresentam uma forma exponencial do valor de $\left|r_{\max }\right|$ em função de $p$, mas apenas a partir de uma probabilidade de não-chaveamento superior a 0,9 o valor cresce rapidamente. Para $p=0,99$ é atingido um valor perto de 0,7 , enquanto que os sinais PRBS atingem quase 1 para os tempos de bit testados.

Figura 5.3: Correlações cruzadas entre sequências GBN.

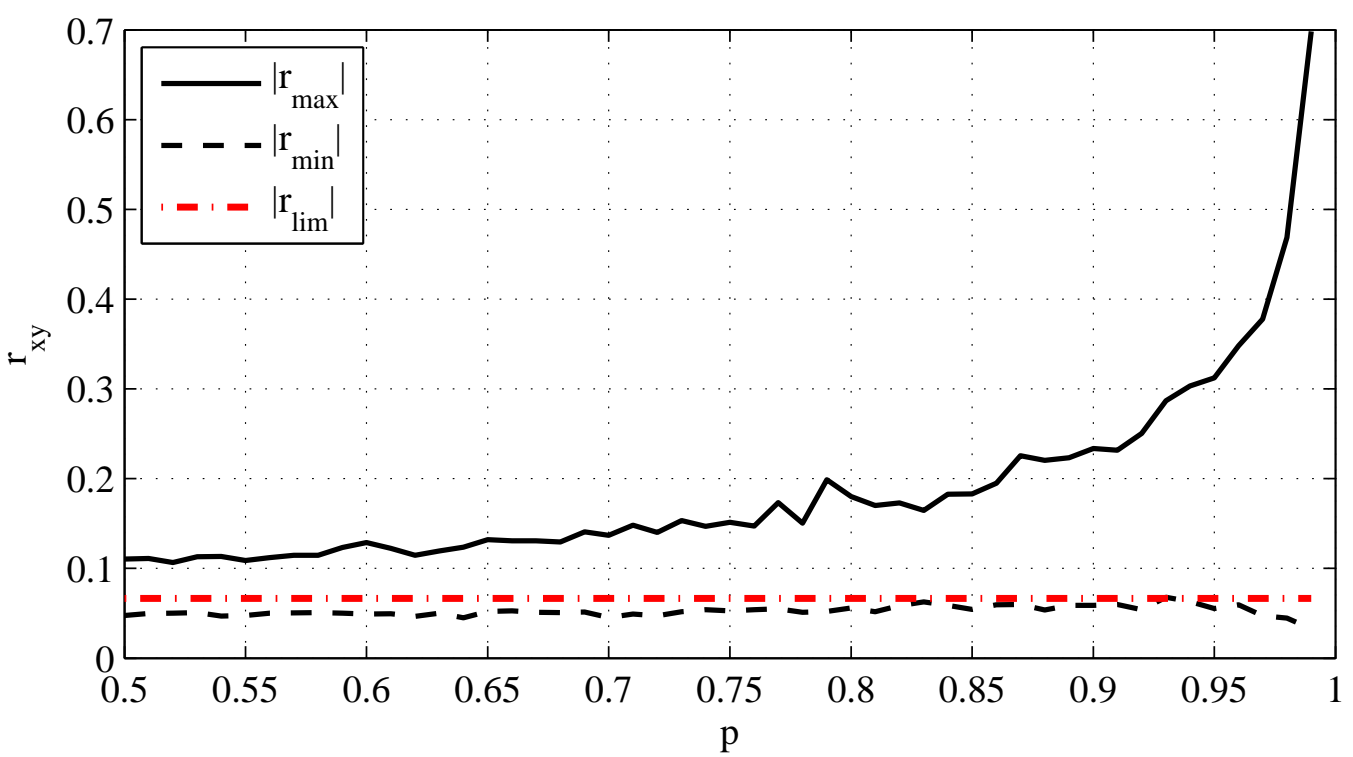

Fonte: Autor.

Na Figura 5.4 são mostradas as correlações cruzadas máximas de três combinações de sequências PRBS variando $T_{b}$ de 1 a 44 . Nos resultados pode ser observado que todos os valores de $|r|$ das combinações foram superiores ao valor $\left|r_{\text {lim }}\right|$. Para valores de $T_{b}$ entre 1 e 30 as três correlações cruzadas tiveram um valor próximo de 1. Esta característica não foi observada para valores de $T_{b}>30$, onde alguma das três correlações se afastou de 1 enquanto as outras duas se mantiveram com um valor perto deste.

Os resultados para as correlações cruzadas mínimas de três combinações de sequências PRBS são apresentados na Figura 5.5. Para os valores de $T_{b}$ usados é observado que os valores de $|r|$ das três combinações estiveram em torno de $\left|r_{\text {lim }}\right|$.

A Figura 5.6 mostra as correlações cruzadas máximas de três combinações de sequências GBN variando $p$ de 0,5 a 0,99 . Nos resultados pode ser observado que a maioria dos valores de $|r|$ das combinações foram superiores ao valor $\left|r_{\text {lim }}\right|$. Nas combinações de GBN ainda é observada a dependência das correlações cruzadas da probabilidade de não-chaveamento, apresentando valores próximos entre as três correlações e observando uma forma similar à observada na Figura 5.3.

Os resultados para as correlações cruzadas mínimas de três combinações de sequências 
Figura 5.4: Correlações cruzadas máximas entre três combinações de sequências PRBS.

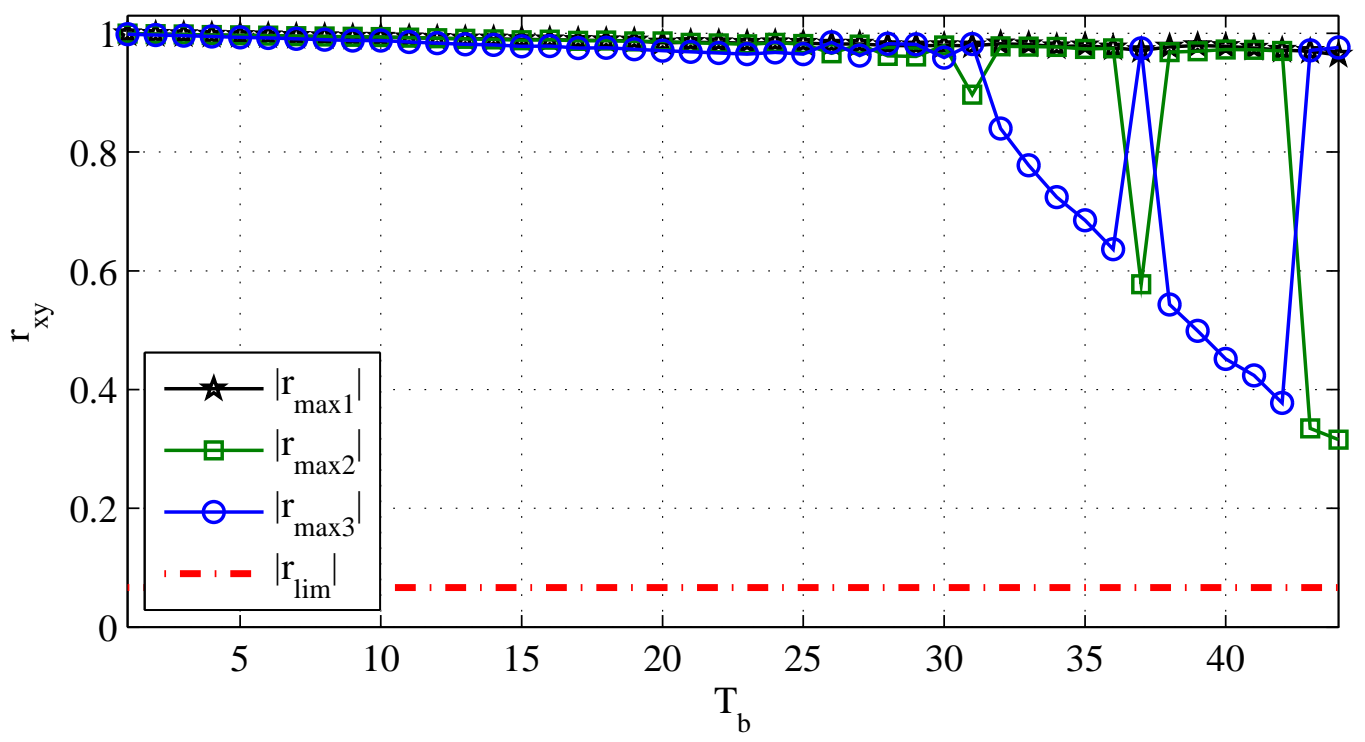

Fonte: Autor.

Figura 5.5: Correlações cruzadas mínimas entre três combinações de sequências PRBS.

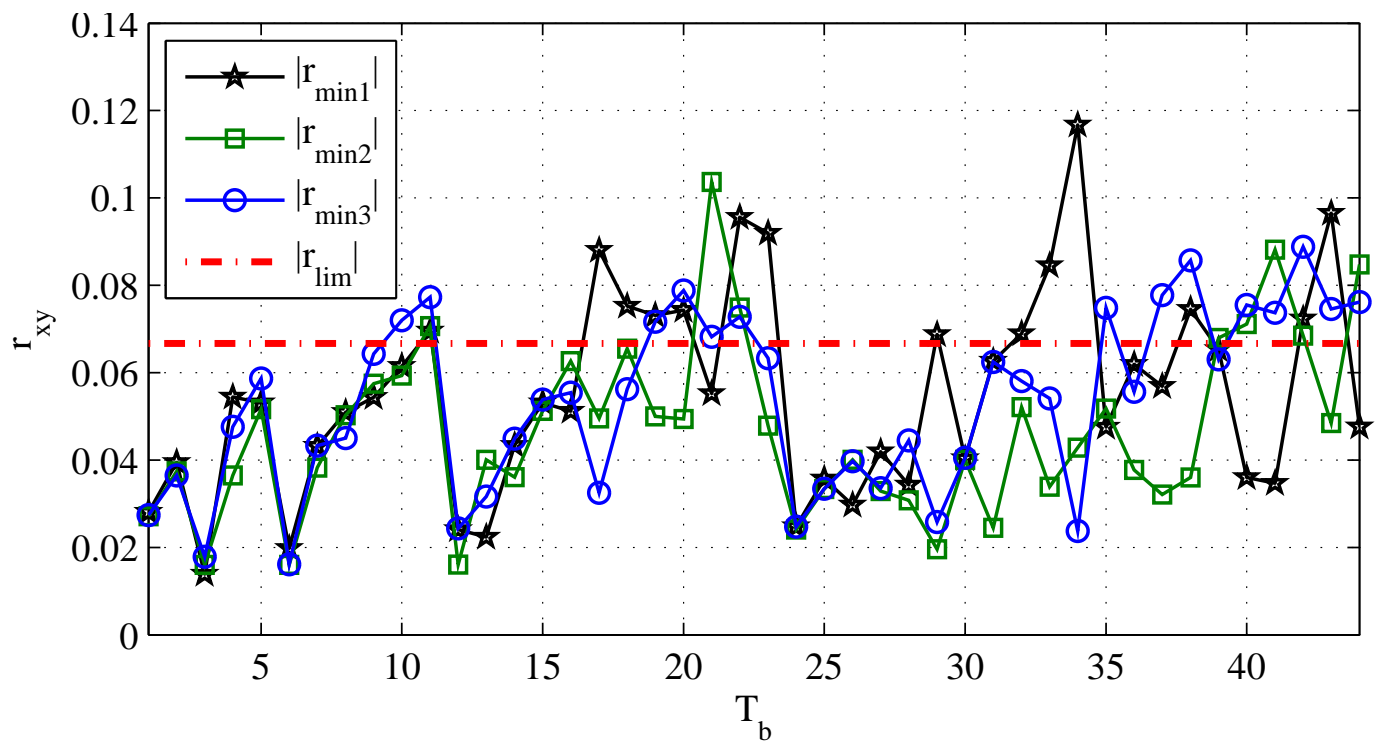

Fonte: Autor.

GBN são apresentados na Figura 5.7. Para valores de $p$ menores que 0,75 , a maioria dos valores de $|r|$ são inferiores a $\left|r_{\text {lim }}\right|$. Em contraste, para valores de $p \geq 0,75$ é observada uma maior dificuldade para encontrar combinações de sequências GBN com $|r|$ inferiores ao valor limiar, $\left|r_{\text {lim }}\right|$.

Para se determinar quais sinais entre PRBS ou GBN de menor correlação são os mais indicados para os processos de identificação MIMO e qual o grau de correlação que prejudica a identificação, uma seleção de combinações $2 \times 2$ e 3x3 de baixa correlação foi tomada para ensaios. Conjuntamente, optou-se também por realizar ensaios semelhantes, empregando-se combinações com alta correlação. 
Figura 5.6: Correlações cruzadas máximas entre três combinações de sequências GBN.

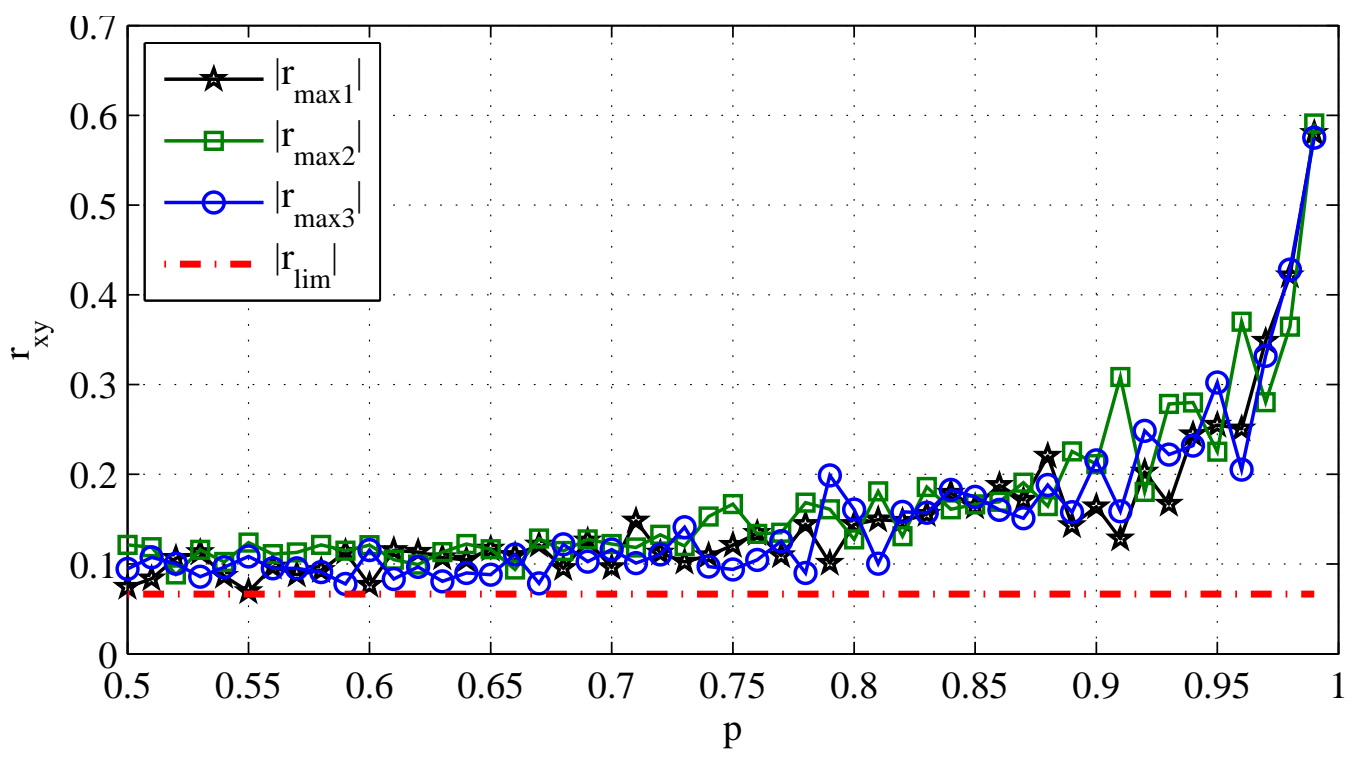

Fonte: Autor.

Figura 5.7: Correlações cruzadas mínimas entre três combinações de sequências GBN.

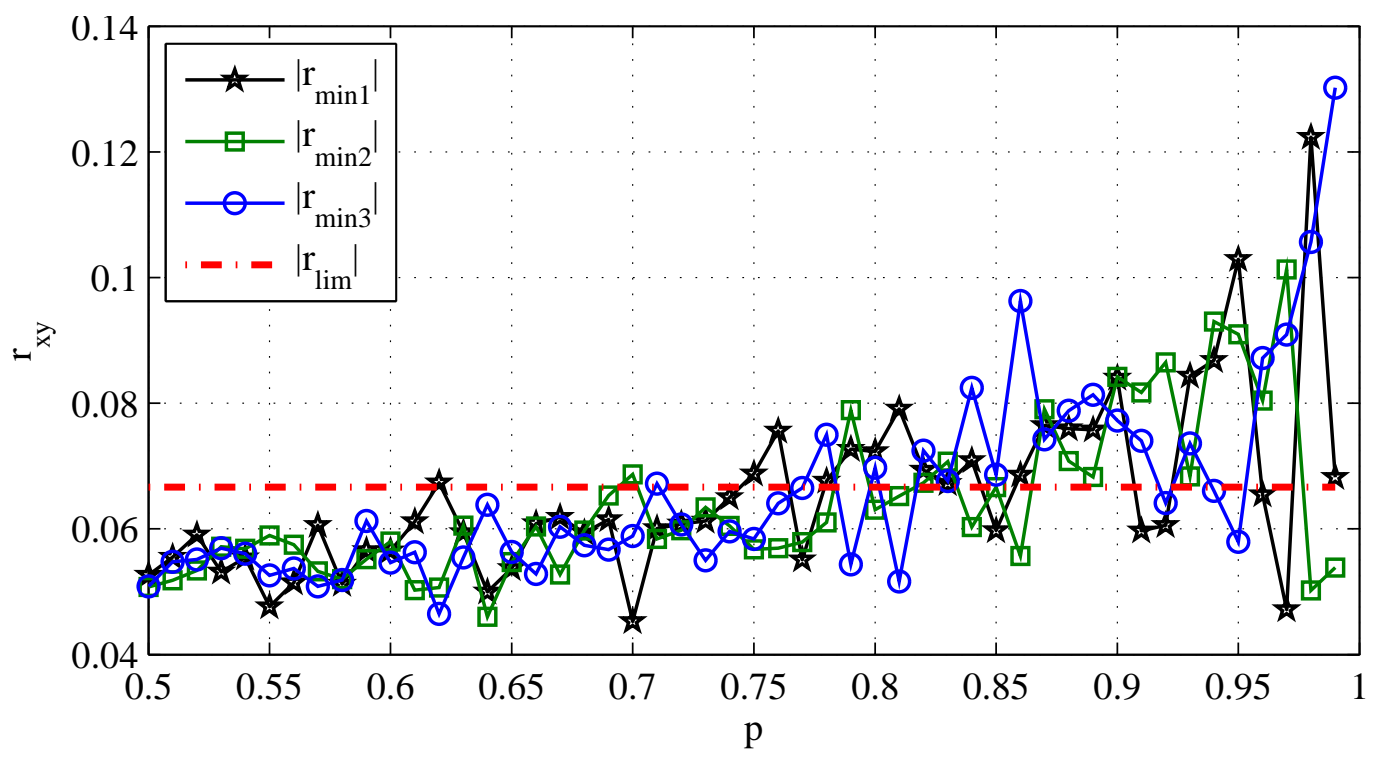

Fonte: Autor.

\subsection{Estudo de frequência}

No processo de identificação, o projeto das entradas desempenha um papel importante na excitação do processo (LJUNG, 1999; TULLEKEN, 1990).

A seleção da frequência dos sinais GBN e PRBS se faz mudando os valores $p$ e $T_{b}$, respectivamente. Segundo (AGUIRRE, 2007), o valor de $T_{b}$ deve ser relacionado com a menor constante de tempo. Isto ocorre basicamente porque se $T_{b}$ for muito grande, o sistema interpreta o sinal PRBS como um degrau, excitando o processo em uma região de frequências muito pequena. Por outro lado, se $T_{b}$ for pequeno, o processo não consegue responder a uma transição antes de chegar a seguinte. 
De (AGUIRRE, 2007) um resultado heurístico que normalmente fornece bons resultados sugere que $T_{b}$ seja escolhido conforme:

$$
\frac{\tau_{\min }}{10} \leq T_{b} \leq \frac{\tau_{\min }}{3}
$$

Em (RIVERA; JUN, 2000) o projeto de sinais PRBS, cuja orientação é baseada nas constantes de tempo é apresentado. Partindo de conhecimentos a priori dos sistemas, pode-se obter uma estimativa da banda de frequências adequada, na qual o sistema deve ser excitado, assim:

$$
\frac{1}{\beta_{s} \tau_{d o m}^{H}} \leq w \leq \frac{\alpha_{s}}{\tau_{d o m}^{L}}
$$

onde $\tau_{d o m}^{H}$ e $\tau_{d o m}^{L}$ são as constantes de tempo alta e baixa dominantes estimadas. O valor de $\alpha_{s}$ é selecionado para assegurar que o conteúdo de alta frequência esteja suficientemente disponível no sinal de entrada, este fator representa a proporção entre a velocidade da resposta em malha fechada em relação com a resposta em malha aberta. Por outra parte, $\beta_{s}$ é especificado para adequar a quantidade de informação de baixa frequência presente no sinal de entrada. Assim, $\beta_{s}$ representa o tempo de acomodação do processo, por exemplo, para $T_{95 \%}$ é usado $\beta_{s}=3$ e para $T_{99 \%}$ é usado $\beta_{s}=5$. (RIVERA; JUN, 2000)

A Equação (5.7) é usada para especificar as variáveis nos sinais PRBS, o tempo de bit, $T_{b}$, e o comprimento das sequências $N$ (RIVERA; JUN, 2000).

$$
T_{b} \leq \frac{2,8 \tau_{d o m}^{L}}{\alpha_{s}}, N=2^{n}-1 \geq \frac{2 \pi \beta_{s} \tau_{d o m}^{H}}{T_{b}}
$$

Lembrando que $N$ e $n$ são valores inteiros, enquanto $T_{b}$ é um inteiro múltiplo do tempo de amostragem $T$.

Aumentando $\alpha_{s}$ e $\beta_{s}$ aumenta-se a largura de banda de ênfase no sinal de entrada e aumenta a resolução do espectro do sinal de excitação.

Por outra parte, CHEN e YU (1997) sugerem uma forma de encontrar um valor ótimo para $p$, tal que a maior parte do espectro do sinal de entrada seja concentrado nas frequências de interesse, usando a Equação (5.8):

$$
p=\frac{1}{1+\sqrt{\tan \left(\frac{w_{L} T}{2}\right) \tan \left(\frac{w_{H} T}{2}\right)}}
$$

onde $w_{L}$ representa o limite inferior e $w_{H}$ corresponde ao limite superior da faixa de frequências de interesse.

Neste trabalho, primeiro são abordados estudos sobre os espectros de potência de sinais GBN e PRBS considerando casos práticos de geração destes sinais. Logo, combinações destes sinais são testadas com diferentes frequências para observar o efeito de $T_{b}$ e $p$ sobre a resposta dos modelos identificados. E finalmente, o estudo foi estendido manipulando-se individualmente os parâmetros $p$ e $T_{b}$ em cada sinal usado para se ter uma real percepção da influência de cada sinal nos modelos identificados. 


\subsubsection{Frequência dos sinais de excitação}

É comum que a informação de interesse dos sinais esteja codificada nos componentes senoidais que formam o sinal, devido à natureza oscilatória dos sinais usados, GBN e PRBS. Além da forma dos sinais no tempo, é relevante também a informação da frequência em amplitude e fase dos componentes senoidais. A informação pode ser obtida através do espectro de potência. A forma analítica do espectro de potência de sinais GBN vem dada pela Equação (3.6) (TULLEKEN, 1990), porém, levando-se em conta que a geração dos sinais GBN neste trabalho é feita sobre a plataforma do Matlab @ deve-se tecer algumas considerações.

Lembrando a teoria exposta no Capítulo 3, os sinais GBN são gerados a partir de uma sequência de ruído branco com uma distribuição uniforme. Consequentemente, os sinais de ruído branco são representados de uma melhor maneira conforme a quantidade de pontos do sinal aumenta, portanto é necessário estudar como varia o espectro de potência destes sinais para as diferentes sementes de geração.

Ao calcular o espectro de potência de sinais GBN com um comprimento $N=1500$, comprimento a ser usado para gerar os diferentes sinais neste trabalho, observa-se na Figura 5.8 a variação do espectro dos sinais gerados conforme a semente de geração do ruído binário muda.

Frequentemente, o espectro de potência de sinais é mostrado na unidade logarítmica decibel $(\mathrm{dB})$. Usando esta unidade de medida é fácil ver amplas faixas dinâmicas permitindo ver pequenos componentes do sinal (RANDALL; TECH, 1979). Uma característica importante que descreve o espectro de potência é a largura de banda, na prática refere-se à gama de frequências em que o espectro de potência do sinal é diferente de zero ou maior que um valor de limiar. O valor de limiar é muitas vezes definido em relação ao valor máximo, o valor mais comum é $3 \mathrm{~dB}$, que é o ponto em que a potência é a metade do seu valor máximo. Esta frequência é conhecida como $w_{3 d B}$ (STOICA; MOSES., 2005).

Na Figura 5.8 são apresentados também os espectros de potência dos sinais GBN em escala logarítmica, podendo ser observado que embora exista uma diferença no espectro de potência dos sinais GBN de diferentes sementes, estes sinais apresentam um comportamento similar nesta escala, isto é, possuem valores próximos de $w_{3 d B}$.

Visando analisar o efeito do comprimento dos sinais na análise espectral, foi calculado o espectro de potência dos sinais GBN com um comprimento aumentado para 10000 pontos. Na Figura 5.9 se observa que a resposta do espectro de potência dos sinais mudando as sementes é mais próxima uma da outra. Portanto é notável a importância da quantidade de pontos usados para gerar os sinais GBN. Na indústria é difícil realizar testes muito longos, sem esquecer que uma das principais vantagens de realizar uma identificação MIMO é diminuir o tempo empregado no experimento.

Para gerar sinais com espectros de potência mais próximos do valor analítico calculado com (3.6) foi imposto no código de geração uma característica de frequência de $3 \mathrm{~dB}, w_{3 d B}$, próxima da obtida a partir de (3.6). Com esta imposição se obtiveram os resultados observados na Figura 5.10. Impondo a frequência de $3 \mathrm{~dB}$ próxima da analítica também são obtidos resultados similares no ganho do espectro quando $w \rightarrow 0$ na escala logarítmica. Porém, para probabilidades de não-chaveamento maiores que 0,96 o algoritmo dificilmente gera um sinal com as características espectrais similares às calculadas analiticamente. 
Figura 5.8: Espectro de potência de sequências GBN com diferentes sementes e comprimento $N=1500, p=0,775$.
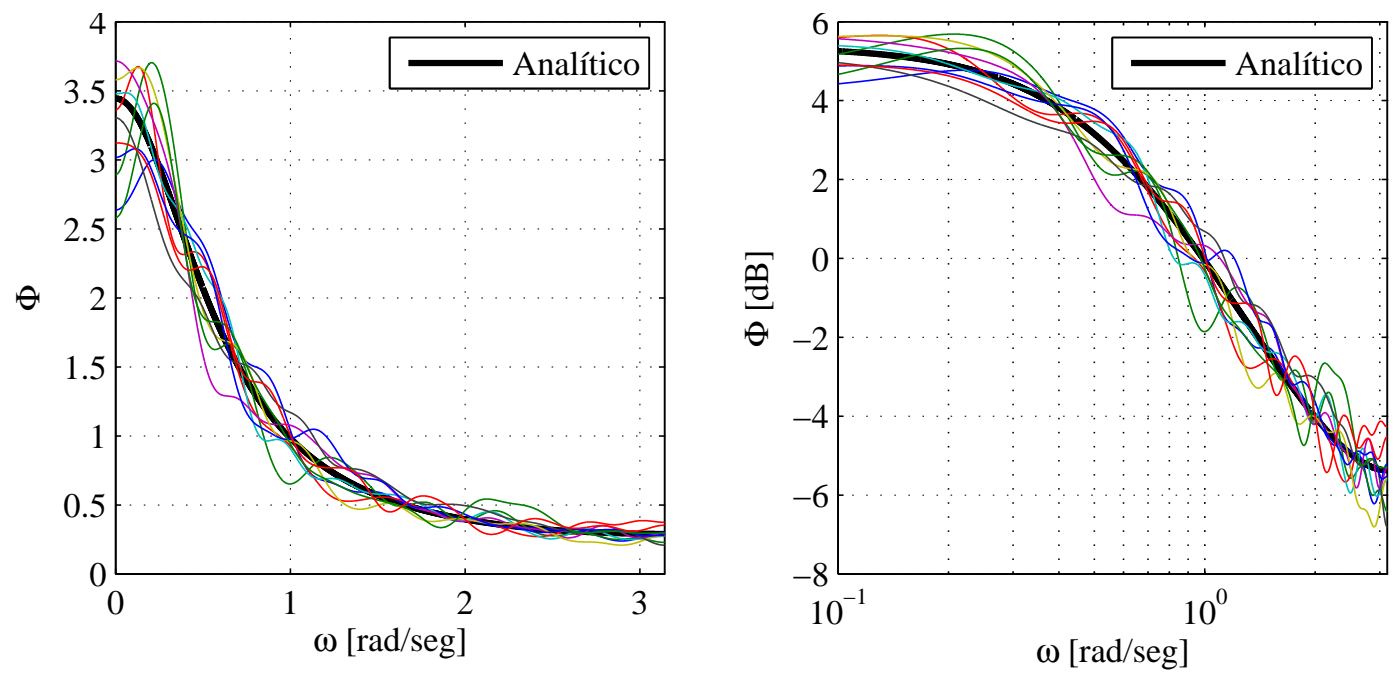

Fonte: Autor.

Figura 5.9: Espectro de potência de sequências GBN com diferentes sementes e comprimento $N=10000, p=0,775$.
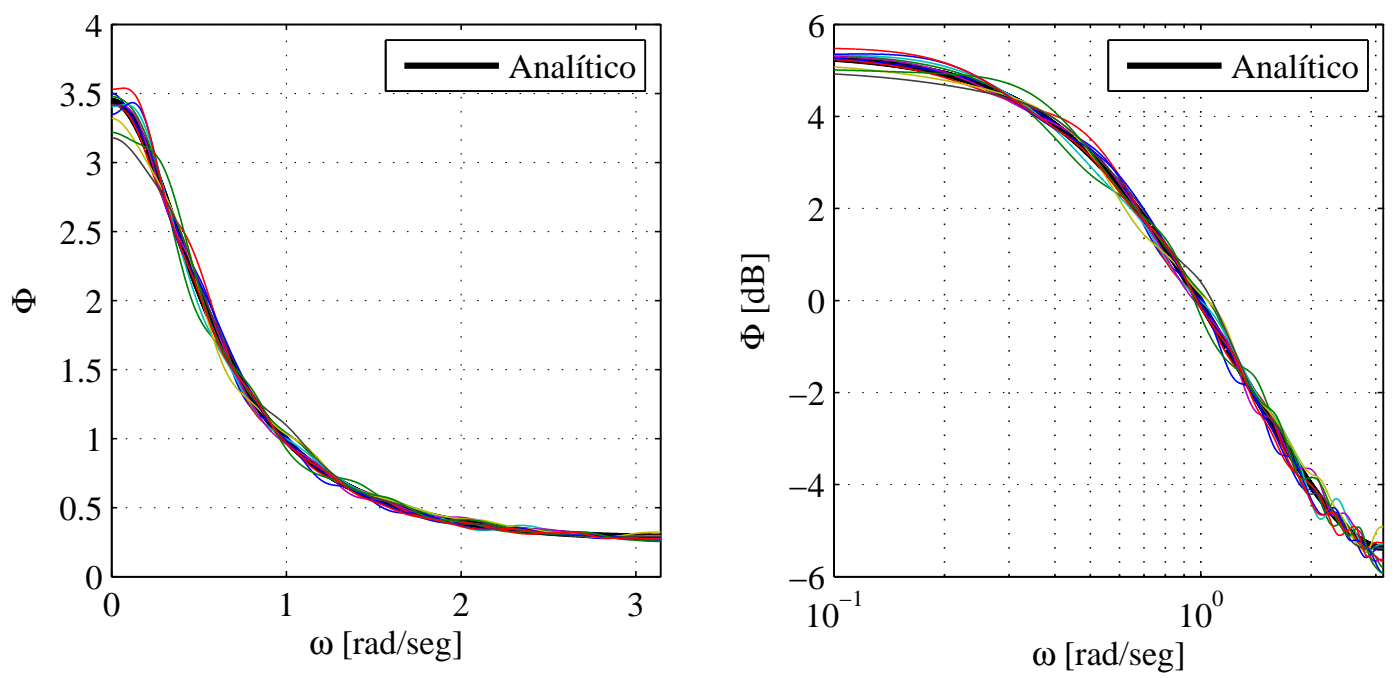

Fonte: Autor.

Um segundo teste empregando sinais GBN com um comprimento de 1500 pontos foi feito mudando-se a probabilidade de não chaveamento desde 0,5 até 0,998 . Em cada probabilidade de não-chaveamento foram gerados 1000 sinais e foram calculadas suas frequências de $3 \mathrm{~dB}$. Na Figura 5.11 são apresentados o valor médio das frequências de 3 dB dos 1000 sinais em cada probabilidade de não chaveamento, o seu valor máximo, seu valor mínimo e a função analítica obtida a partir de (3.6).

Na Figura 5.11 se observa que conforme a probabilidade de não-chaveamento é mais próxima de um, a brecha entre as frequências de $3 \mathrm{~dB}$ mínima e máxima se torna menor. Ainda assim, para uma certa probabilidade de não-chaveamento podem ser gerados sinais com características em frequência correspondentes à resposta analítica de outra probabilidade de não-chaveamento. Por outro lado, comparando-se a resposta analítica com a resposta média dos 1000 sinais, são observadas características similares na faixa 
Figura 5.10: Espectro de potência de sequências GBN com diferentes sementes e comprimento $N=1500, p=0,775$.
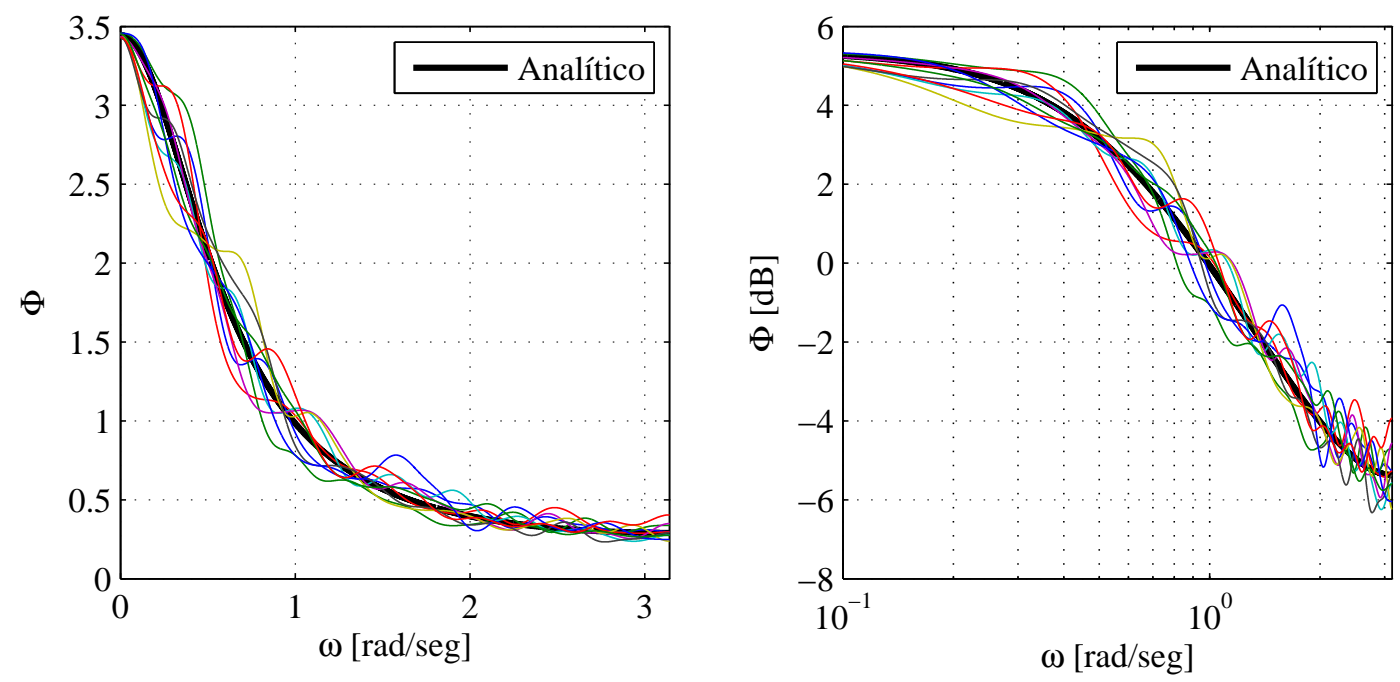

Fonte: Autor.

Figura 5.11: Frequência de 3 dB para sinais GBN com comprimento $N=1500$.

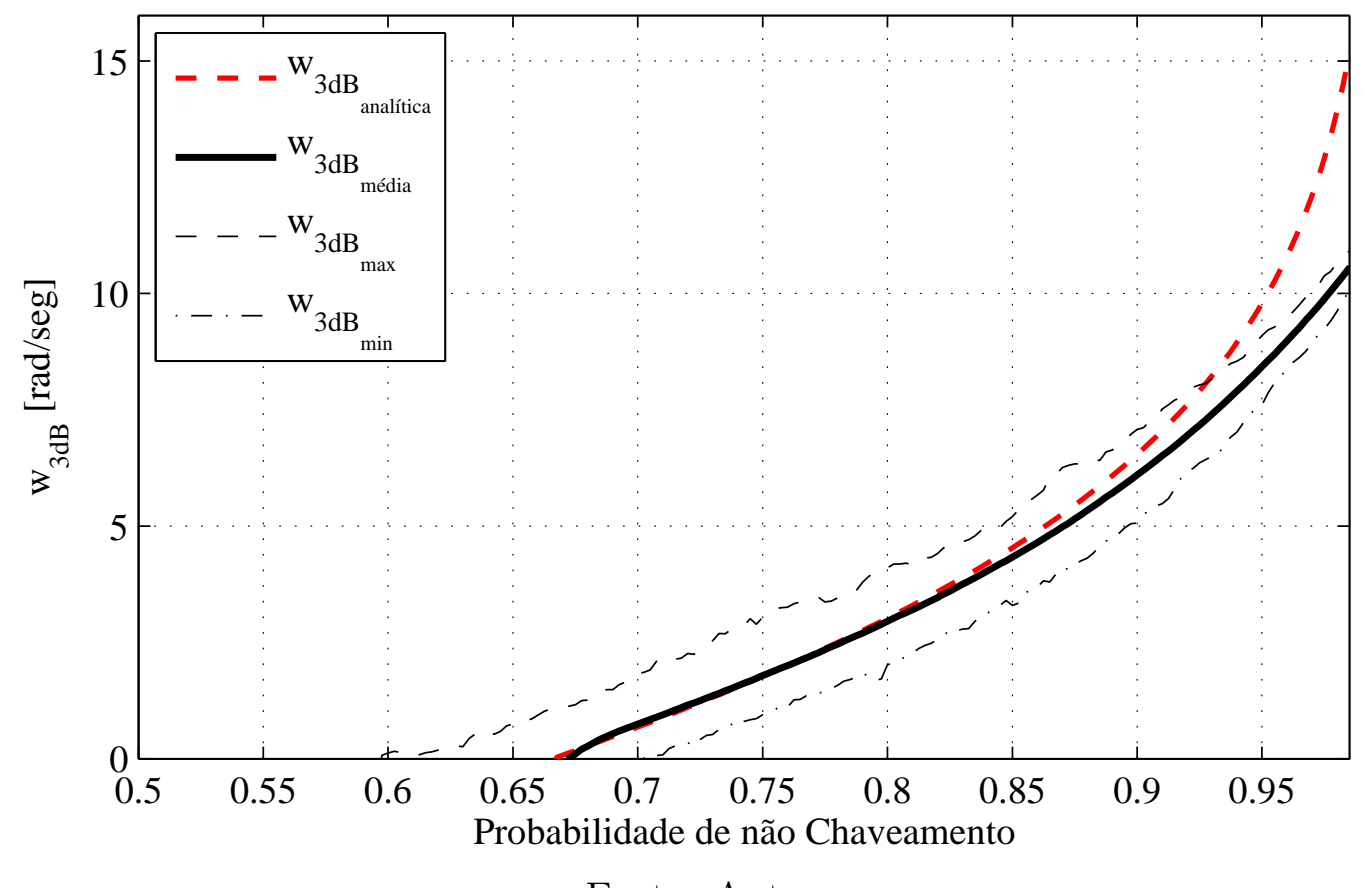

Fonte: Autor.

de $p=0,65$ a 0,85 , isto não é evidenciado para $p>0,85$ onde as duas curvas se afastam. Portanto, na hora de gerar os sinais GBN devem ser tomadas certas precauções para construir o sinal corretamente.

O estudo feito com sinais GBN foi realizado também com sinais PRBS. Na Figura 5.12 são apresentados os espectros de 10 sinais PRBS com 1500 pontos de comprimento e $T_{b}=4$. Neste caso os sinais PRBS apresentam algumas pequenas diferenças nos seus espectros de frequência. Isto acontece pela forma como são gerados os sinais PRBS, lembrando que mudar a semente de geração implica em um deslocamento do sinal gerado 
pela primeira semente. As pequenas diferenças entre as sementes ocorrem devido ao comprimento do sinal, já que com 1500 pontos não é gerado um sinal PRBS de máximo comprimento. Para este caso em particular, onde o comprimento do sinal é de 1500 e $T_{b}=4$, o sinal é construído a partir de uma sequência de máximo comprimento com $N=511$ e $T_{b}=4$, assim, o sinal formado possui 2044 pontos dos quais são tomados os primeiros 1500 .

Analisando-se a Figura 5.12 é observado que mesmo existindo pequenas diferenças no espectro de potência, as respostas em dB dos sinais são muito próximas, mantendo as mesmas características. O que representa na prática mais liberdade na geração de sinais PRBS fora do máximo comprimento considerando diferentes valores de $T_{b}$.

Figura 5.12: Espectro de sequências PRBS com diferentes sementes, comprimento $N=$ 1500 e $T_{b}=4$.
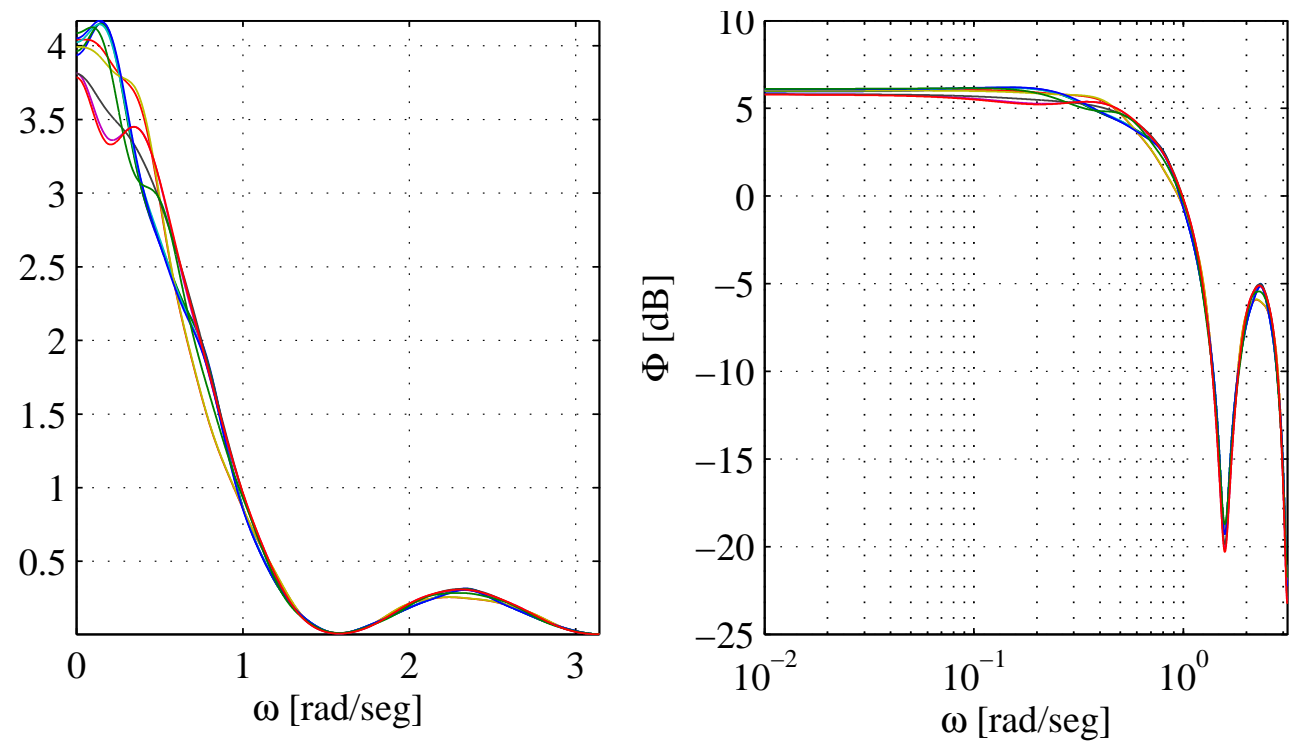

Fonte: Autor.

Na Figura 5.13 são apresentados os espectros dos mesmos 10 sinais PRBS usados na Figura 5.12, mas considerando agora os 2044 pontos de comprimento e $T_{b}=4$, ou seja o sinal de máximo comprimento. Neste caso, os espectros de frequência dos 10 sinais PRBS praticamente estão superpostos, o que retrata as características dos sinais de máximo comprimento.

O segundo teste empregando sinais PRBS foi feito com um comprimento de 5000 pontos, mudando-se o tempo de bit de 1 até 60 . Para cada tempo de bit foi gerada a quantidade de sinais possíveis de acordo com cada $T_{b}$ e foram calculadas suas frequências de 3 dB. Na Figura 5.14 são apresentados o valor médio das frequências de $3 \mathrm{~dB}$ dos sinais em cada probabilidade de não chaveamento, o seu valor máximo e o seu valor mínimo.

Segundo a Figura 5.14, os valores máximos e mínimos da frequência de 3 dB se afastam e se aproximam em várias oportunidades conforme varia $T_{b}$, isto ocorre quando os sinais gerados com um comprimento máximo a cada $T_{b}$ se aproximam do comprimento usado, $N=5000$. Também é observado que conforme o valor de $T_{b}$ aumenta, a faixa dos valores máximo e mínimo diminui, o que para efeitos práticos representa uma vantagem devido às baixas frequências que possuem as plantas industriais (SöDERSTRöM; STOICA, 1988; ZHU, 2001). 
Figura 5.13: Espectro de sequências GBN com diferentes sementes, comprimento $N=$ 2044 e $T_{b}=4$.
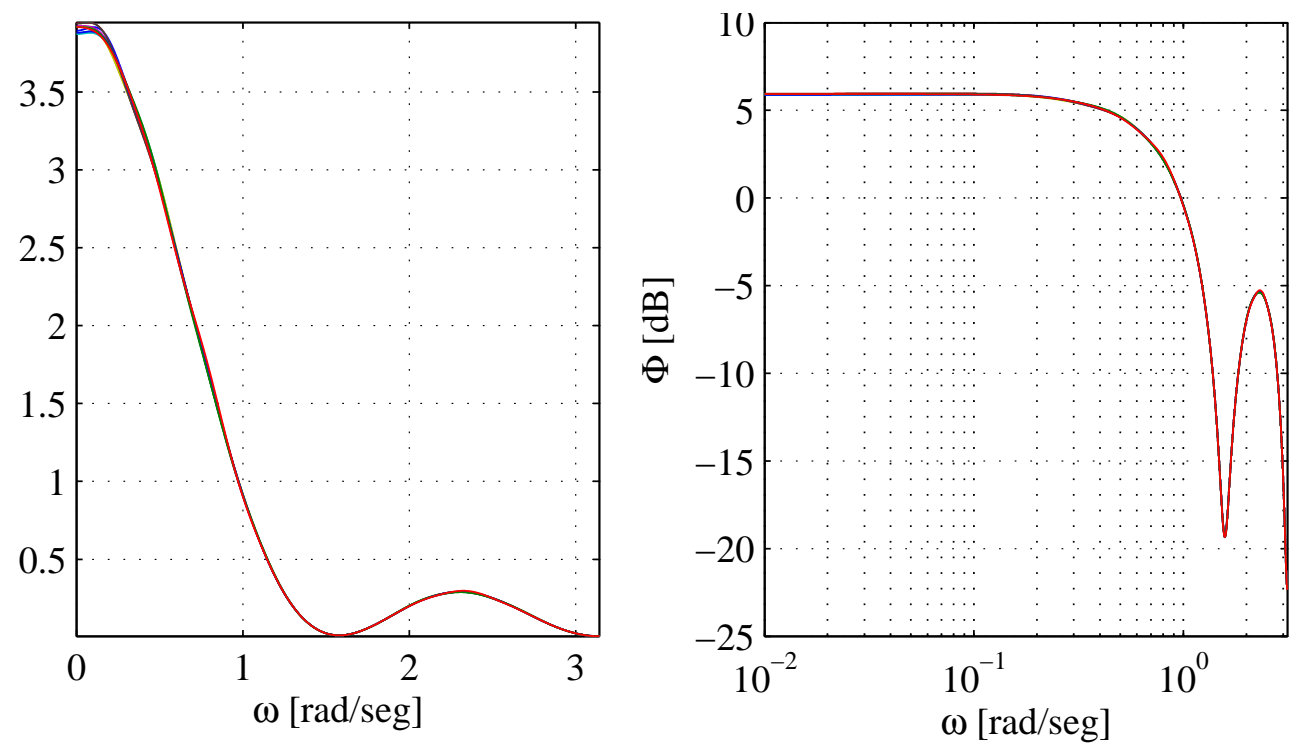

Fonte: Autor.

Figura 5.14: Frequência de $3 \mathrm{~dB}$ para sinais PRBS, comprimento $N=1500$.

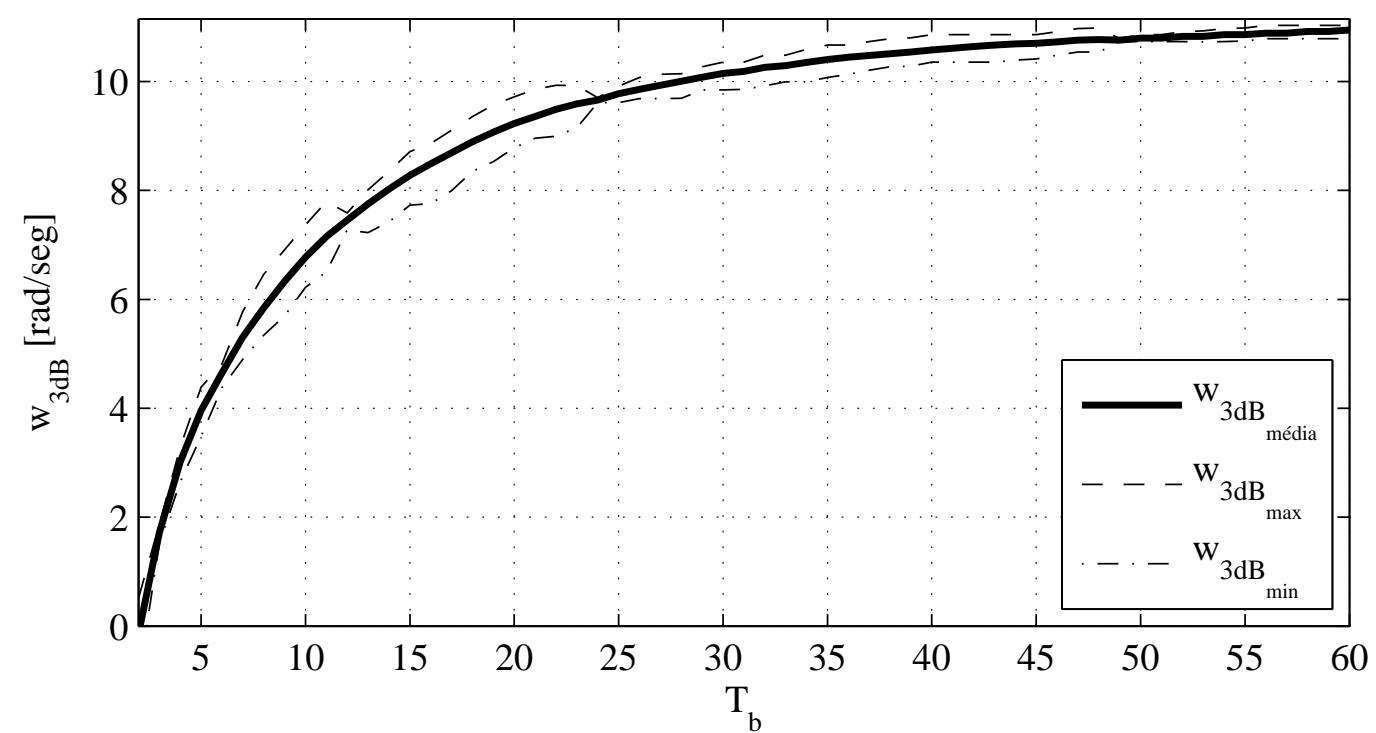

Fonte: Autor.

\subsection{Resumo}

O tema central deste capítulo foi o estudo das características de correlação cruzada e de frequência em sinais GBN e PRBS gerados no software MATLABß.

Os estudos de correlação cruzada foram feitos a partir do cálculo do coeficiente de Pearson, que calculado em diferentes pontos de deslocamento dos sinais geram a FCC. Foi estudada também a significância do coeficiente de correlação para poder afirmar, com uma certa probabilidade, que os sinais estão ou não correlacionados. Para isto foi obtida a expressão para considerar que dois sinais sejam descorrelacionados com um nível de significância de 5\% na Equação (5.4). 
Nos sinais GBN e PRBS foram calculadas as FCC de 1000 combinações de duas e três sequências extraindo o seu valor máximo. Isto foi feito em cada valor de $p$ e $T_{b}$, onde foram selecionados as sementes que geraram os maiores e menores valores de correlação cruzada. Analisando os valores máximos das 1000 combinações foi observado que para duas sequências GBN e PRBS:

- os valores mínimos se mantiveram próximos do valor de $\left|r_{1 i m}\right|$;

- os valores máximos de sequências PRS se mantiveram perto de 1 para todos os valores de $T_{b}$ testados;

- e, os valores máximos de sequências GBN apresentaram uma tendência exponencial em função de $p$.

Estas características foram observadas também nas combinações de três sequências. Porém, em alguns pontos de $p$ e $T_{b}$, os valores mínimos foram superiores que o valor limite, $\left|r_{1 \text { im }}\right|$.

Depois do estudo de correlações cruzadas foi feita uma revisão bibliográfica da seleção da frequência em sinais GBN e PRBS. Varias expressões são obtidas a partir de conhecimentos a priori dos processos para obter os valores adequados de $p$ e $T_{b}$. Mas, para ter um conhecimento real sobre o conteúdo de frequências foram abordados estudos a partir os espectros de potência de sinais GBN e PRBS considerando casos práticos de geração destes sinais.

Para sinais GBN foi observada a influência do comprimento do sinal gerado no espectro de potência. Para $N=1500$ foram encontradas diferencias nos espectros de potência dos sinais gerados com o espectro analítico obtido a partir de (3.6). Estas diferenças diminuíram usando um $N=10000$, portanto neste trabalho foi imposta uma restrição no código de geração de sinais GBN para obter sinais GBN com uma frequência de $3 \mathrm{~dB}$ próxima da calculada analiticamente. Este ajuste foi valido para valores de $p \leq 0,96$. Com estas considerações foi observada uma dependência exponencial da frequência de corte do espectro de potência em relação a probabilidade de não-chaveamento.

Os sinais PRBS apresentaram espectros de potência próximos independentemente da semente de geração usada. Quando os sinais gerados são de máximo comprimento, os espectros de potência a cada mudança da semente de geração foram praticamente iguais. Isto acontece devido a que a mudança de sementes em sinais PRBS representa deslocamentos do sinal original. Por sua vez, a frequência de $3 \mathrm{~dB}$ do espectro de potência deste tipo de sinais apresenta uma dependência similar a uma função raiz quadrada em relação ao tempo de bit. 


\section{Estudo de casos}

Neste capítulo são apresentadas e discutidas simulações de experimentos, identificações e validações realizadas nas plantas simuladas que foram descritas no capítulo 4. Vários testes para o estudo dos efeitos da correlação cuzada entre os sinais de excitação e a frequência dos sinais de excitação foram desenvolvidos ao longo do capítulo. Para comparar e avaliar os resultados da identificação foi usado o índice FIT baseado na raiz quadrada do erro médio quadrático normalizado (ARMSTRONG; COLLOPY, 1992):

$$
\operatorname{FIT}_{p}=\left(1-\frac{\sqrt{\sum_{i=0}^{N_{e}-1}\left(\hat{y}_{p}(i)-y_{p}(i)\right)^{2}}}{\sqrt{\sum_{i=0}^{N_{e}-1}\left(y_{p}(i)-\bar{y}_{p}\right)^{2}}}\right) \times 100[\%]
$$

onde $y_{p}(i)$ é a $p$-ésima saída medida, $\hat{y}_{p}(i)$ e $\bar{y}_{p}$ são a saída estimada e a média do sinal $y_{p}(i), N_{e}$ corresponde ao comprimento dos sinais $y_{p}$.

Os testes desenvolvidos começam com analise conjunta das frequências dos sinais de excitação e suas respectivas correlações cruzadas nas plantas em malha aberta. Após este estudo, foram analisadas as mesmas características independentemente expandindo o estudo para as configurações das plantas em malha fechada.

\subsection{Testes de correlação e frequência conjuntos}

Dois tipos de processo foram usados para verificar o efeito da correlação cruzada e da frequência dos sinais de entrada na identificação multivariável, o modelo do reator de polimerização e o modelo da coluna de destilação binária, expostos no Capítulo 4. Para a identificação dos modelos escolhidos, empregou-se sinais de entrada GBN e PRBS, escolhendo-se os de mínima e de máxima correlação entre as 1000 sementes consecutivas a partir de 1, mantendo-se o limite de 60 atrasos para garantir um tempo maior que os tempos mortos de cada dinâmica. Os ensaios foram feitos segundo um procedimento de Monte Carlo com 100 execuções para cada semente, alterando-se o ruído em cada execução e tomando-se como resultado final, a média aritmética dos 100 resultados obtidos.

Em plantas industrias dificilmente podem ser feitos projetos de identificação em malha aberta por questões de segurança e qualidade dos produtos finais. Portanto, além dos testes em malha aberta foram também analisadas as respostas do sistema em malha fechada, identificando tanto o modelo da planta como o modelo do processo em malha fechada, incluindo os controladores PI. 


\subsubsection{Resultados do Reator de Polimerização 2x2}

As simulações dos experimentos foram realizadas aplicando sinais de excitação GBN e PRBS nas entradas das variáveis manipuladas. O sistema foi simulado em torno de zero, com os sinais de entrada e setpoint variando entre $[-0,5 ; 0,5]$ (Figura 6.1), e, observandose as saídas do sistema (Figura 6.2).

A estrutura do modelo escolhida para a identificação foi a BJ, idêntica à obtida por discretização da Equação (6.2) para malha aberta, e à discretização da Equação (6.3) para malha fechada, com um tempo de amostragem $T=0,2$ horas,.

$$
\begin{aligned}
& y(z)=G(z) u(z)+G_{d}(z) d(z) \\
& G(z)=\left[\begin{array}{cc}
\frac{0,9797 z^{-2}}{1-0,9572 z^{-1}} & \frac{-1,22 z^{-3}}{1-0,8952 z^{-1}} \\
\frac{0,4121 z^{-2}}{1-0,9121 z^{-1}} & \frac{0,6096 z^{-3}}{1-0,8949 z^{-1}}
\end{array}\right] ; \quad G_{d}(z)=\left[\begin{array}{c}
\frac{-0,2393 z^{-3}}{1-0,9436 z^{-1}} \\
\frac{-0,05769 z^{-3}}{1-0,904 z^{-1}}
\end{array}\right] \\
& G(z)=\left[\begin{array}{l}
\frac{0,2519-1,611 z^{-1}+4,412 z^{-2}-6,706 z^{-3}+6,111 z^{-4}-3,338 z^{-5}+1,012 z^{-6}-0,1314^{-7}}{1-7,286 z^{-1}+23,24 z^{-2}-42,38 z^{-3}+48,35 z^{-4}-35,33 z^{-5}+16,15 z^{-6}-4,225 z-7+0,4839 z^{-8}} z^{-2} \\
\frac{0,09605-0,6354 z^{-1}+1,801 z^{-2}-2,834 z^{-3}+2,674 z^{-4}-1,513 z^{-5}+0,4754 z^{-6}-0,06398^{-7}}{1-7,286 z^{-1}+23,24 z^{-2}-42,38 z^{-3}+48,35 z^{-4}-35,33 z^{-5}+16,15 z^{-6}-4,225 z^{-7}+0,4839 z^{-8}} \\
z^{-2}
\end{array}\right. \\
& \frac{-0.1736+1.156 z^{-1}-3.296 z^{-2}+5.221 z^{-3}-4.96 z^{-4}+2.826 z^{-5}-0.894 z^{-6}+0.1212 z^{-7}}{1-7.286 z^{-1}+23.24 z^{-2}-42.38 z^{-3}+48.35 z^{-4}-35.33 z^{-5}+16.15 z^{-6}-4.225 z^{-7}+0.4839 z^{-8}} z^{-3} \\
& \left.\frac{0.1101-0.6868 z^{-1}+1.833 z^{-2}-2.711 z^{-3}+2.401 z^{-4}-1.272 z^{-5}+0.3737 z^{-6}-0.0469 z^{-7}}{1-7.286 z^{-1}+23.24 z^{-2}-42.38 z^{-3}+48.35 z^{-4}-35.33 z^{-5}+16.15 z^{-6}-4.225 z^{-7}+0.4839 z^{-8}} z^{-3}\right] \\
& G_{d}(z)=\left[\begin{array}{c}
\frac{-0,2393 z^{-3}}{1-0,9436 z^{-1}} \\
\frac{-0,05769 z^{-3}}{1-0,904 z^{-1}}
\end{array}\right]
\end{aligned}
$$

Na Figura 6.1 é apresentado um dos sinais GBN usados nas simulações que possui um comprimento $N=1500$ e probabilidade de não-chaveamento $p=0,93$. Enquanto a Figura 6.2 apresenta a resposta do Reator com uma condição de ruído correspondente a uma relação sinal-ruído (Signal to Noise Ratio - SNR) igual a 10 utilizando os sinais de excitação da Figura 6.1.

Cada simulação do experimento, isto é, identificação e validação, foi realizada com 100 iterações. O comprimento dos sinais GBN e PRBS utilizados foi $N=1500$, onde na etapa de identificação foram usados os primeiros 900 pontos e na etapa de validação cruzada foram tomados os restantes 600. Os ruídos de medição e as perturbações são tratados como processos estocásticos e vão mudando em cada iteração. Um cenário de ruído é usado para testar o modelo tanto em malha aberta como em malha fechada com SNR igual a 10.

As sementes utilizadas para as combinações de sinais GBN e PRBS de alta e baixa correlação foram tomadas a partir dos resultados apresentados nas figuras 5.2 e 5.3 e sintetizados junto com os valores de $r_{x y}(\tau)$ nas tabelas 6.1 e 6.2 . 
Figura 6.1: Sinais GBN para identificaçao do reator.
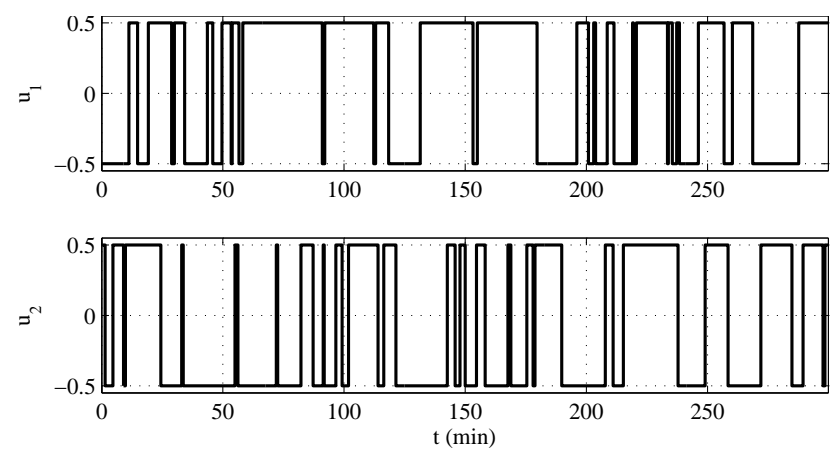

Fonte: Autor.

Figura 6.2: Resposta do sistema usando o sinal GBN da Figura 6.1.
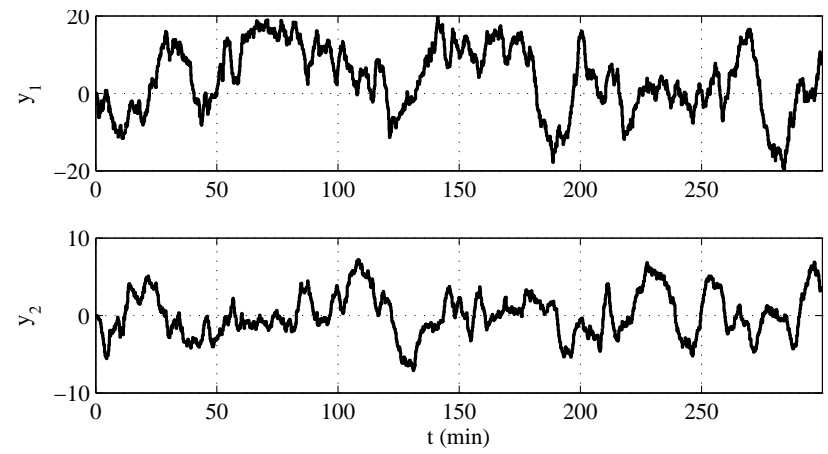

Fonte: Autor.

Tabela 6.1: Sementes de geração e características de correlação cruzada das combianções de sinais GBN.

\begin{tabular}{cccccccc}
\hline \multirow{2}{*}{ Corr. } & \multirow{2}{*}{ Característica } & \multicolumn{7}{c}{$p$} \\
\cline { 2 - 8 } & & 0,84 & 0,87 & 0,9 & 0,93 & 0,96 & 0,99 \\
\hline \multirow{3}{*}{ Baixa } & Semente & 281 & 499 & 594 & 755 & 665 & 786 \\
\cline { 2 - 8 } & $r_{u_{1} u_{2}}(\tau)$ & 0,0588 & 0,0599 & 0,0589 & 0,0677 & 0,0595 & 0,0327 \\
\cline { 2 - 8 } Alta & $\tau$ & -55 & -36 & -41 & -3 & -58 \\
\cline { 2 - 8 } & Semente & 144 & 695 & 395 & 619 & 541 & 864 \\
\cline { 2 - 8 } & $r_{u_{1} u_{2}}(\tau)$ & 0,1826 & 0,2257 & 0,2337 & 0,2869 & 0,3479 & 0,6983 \\
\cline { 2 - 8 } & $\tau$ & -44 & 10 & 3 & 31 & -28 & -5 \\
\hline
\end{tabular}

Tabela 6.2: Sementes de geração e características de correlação cruzada das combianções de sinais PRBS.

\begin{tabular}{cccccccc}
\hline \multirow{2}{*}{ Corr. } & \multirow{2}{*}{ Característica } & \multicolumn{7}{c}{$T_{b}$} \\
\cline { 2 - 8 } & & 2 & 3 & 4 & 8 & 12 & 44 \\
\hline \multirow{3}{*}{ Baixa } & Semente & 239 & 201 & 352 & 69 & 107 & 13 \\
\cline { 2 - 8 } & $r_{u_{1} u_{2}}(\tau)$ & 0,0359 & 0,0121 & 0,0425 & 0,0401 & 0,0160 & 0,0410 \\
\cline { 2 - 8 } Alta & $\tau$ & -16 & 18 & 20 & -54 & 12 & 28 \\
\cline { 2 - 8 } & Semente & 512 & 256 & 256 & 128 & 3 & 32 \\
\cline { 2 - 8 } & $r_{u_{1} u_{2}}(\tau)$ & 0,9987 & 0,9980 & 0,9973 & 0,9948 & 0,9920 & 0,9762 \\
\hline \multirow{2}{*}{$\tau$} & -2 & -3 & -4 & -8 & -12 & -44 \\
\hline
\end{tabular}


Os resultados em termos da média do índice FIT da validação cruzada do modelo identificado são apresentados na Tabela 6.3 para validação usando sinais GBN.

Tabela 6.3: Índices $\overline{F I T}$ obtidos da validação cruzada usando sinais GBN.

\begin{tabular}{|c|c|c|c|c|c|c|c|c|}
\hline \multirow{2}{*}{ ID } & \multirow{2}{*}{ Corr. } & \multirow{2}{*}{ Saída } & \multicolumn{6}{|c|}{$p$} \\
\hline & & & 0,84 & 0,87 & 0,9 & 0,93 & 0,96 & 0,99 \\
\hline \multirow{4}{*}{ Malha Aberta } & \multirow{2}{*}{ Baixa } & $y_{1}$ & 92,17 & 92,89 & 93,42 & 95,66 & 96,38 & 98,45 \\
\hline & & $y_{2}$ & 91,19 & 91,49 & 92,69 & 93,97 & 95,65 & 97,85 \\
\hline & \multirow{2}{*}{ Alta } & $y_{1}$ & 92,84 & 92,04 & 94,42 & 94,95 & 96,10 & 98,13 \\
\hline & & $y_{2}$ & 89,97 & 91,99 & 91,28 & 95,08 & 95,79 & 95,69 \\
\hline \multirow{4}{*}{$\begin{array}{l}\text { Malha Fechada } \\
\text { Modelo Completo }\end{array}$} & \multirow{2}{*}{ Baixa } & $y_{1}$ & 85,17 & 86,26 & 89,39 & 89,91 & 90,60 & 90,79 \\
\hline & & $y_{2}$ & 89,24 & 89,07 & 89,60 & 89,32 & 90,12 & 91,03 \\
\hline & \multirow{2}{*}{ Alta } & $y_{1}$ & 86,60 & 86,93 & 89,59 & 89,33 & 90,95 & 88,43 \\
\hline & & $y_{2}$ & 87,90 & 88,97 & 89,89 & 89,54 & 90,36 & 84,31 \\
\hline \multirow{4}{*}{$\begin{array}{l}\text { Malha Fechada } \\
\text { Modelo do Processo }\end{array}$} & \multirow{2}{*}{ Baixa } & $y_{1}$ & 81,48 & 80,99 & 84,08 & 83,60 & 86,36 & 85,14 \\
\hline & & $y_{2}$ & 87,67 & 87,29 & 89,05 & 88,54 & 89,89 & 90,51 \\
\hline & \multirow{2}{*}{ Alta } & $\overline{y_{1}}$ & 81,86 & 81,66 & 84,24 & 83,87 & 85,87 & 80,72 \\
\hline & & $y_{2}$ & 87,87 & 88,00 & 89,50 & 89,62 & 90,90 & 81,88 \\
\hline
\end{tabular}

Da Tabela 6.3 percebe-se que o valor de $p$ tem uma influência nos resultados obtidos, assim, os resultados foram melhorando conforme o valor de $p$ aumentou, encontrando-se os melhores resultados usando sinais GBN com $p=0,96$ e 0,99. Este comportamento foi observado identificando em malha aberta e malha fechada. A identificação direta do modelo da planta em malha fechada apresentou resultados piores aos obtidos em malha aberta com diferenças de ao redor de $10 \%$.

Os resultados dos indicadores $\overline{F I T}$ da validação cruzada calculados para cada uma das simulações com sinais PRBS são apresentados na Tabela 6.4.

Tabela 6.4: Índices $\overline{F I T}$ obtidos da validação cruzada usando sinais PRBS.

\begin{tabular}{|c|c|c|c|c|c|c|c|c|}
\hline \multirow{2}{*}{ ID } & \multirow{2}{*}{ Corr. } & \multirow{2}{*}{ Saída } & \multicolumn{6}{|c|}{$T_{b}$} \\
\hline & & & 2 & 3 & 4 & 8 & 12 & 44 \\
\hline \multirow{4}{*}{ Malha Aberta } & \multirow{2}{*}{ Baixa } & $y_{1}$ & 82,88 & 86,96 & 91,32 & 95,14 & 95,42 & 98,27 \\
\hline & & $y_{2}$ & 90,62 & 90,35 & 94,19 & 96,73 & 96,48 & 97,25 \\
\hline & \multirow{2}{*}{ Alta } & $y_{1}$ & 72,43 & 86,99 & 83,45 & 94,61 & 92,31 & 98,19 \\
\hline & & $y_{2}$ & 84,24 & 87,07 & 89,47 & 92,51 & 95,06 & 97,25 \\
\hline \multirow{4}{*}{$\begin{array}{l}\text { Malha Fechada } \\
\text { Modelo Completo }\end{array}$} & \multirow{2}{*}{ Baixa } & $y_{1}$ & 82,99 & 88,79 & 91,11 & 93,25 & 90,19 & 91,19 \\
\hline & & $y_{2}$ & 88,38 & 87,08 & 89,84 & 90,50 & 88,53 & 89,49 \\
\hline & \multirow{2}{*}{ Alta } & $y_{1}$ & 80,20 & 87,52 & 87,76 & 90,21 & 89,37 & 92,13 \\
\hline & & $y_{2}$ & 85,23 & 88,21 & 87,69 & 89,49 & 89,15 & 90,28 \\
\hline \multirow{4}{*}{$\begin{array}{l}\text { Malha Fechada } \\
\text { Modelo do Processo }\end{array}$} & \multirow{2}{*}{ Baixa } & $y_{1}$ & 83,22 & 87,53 & 83,88 & 89,42 & 85,86 & 83,55 \\
\hline & & $y_{2}$ & 86,38 & 88,52 & 90,08 & 90,69 & 90,81 & 90,25 \\
\hline & \multirow{2}{*}{ Alta } & $y_{1}$ & 74,60 & 79,80 & 81,21 & 82,60 & 85,19 & 86,38 \\
\hline & & $y_{2}$ & 82,37 & 85,51 & 87,09 & 88,62 & 90,21 & 91,07 \\
\hline
\end{tabular}

Na Tabela 6.4 é observado que com o aumento de $T_{b}$ os resultados foram melhorando usando sinais de alta correlação em malha aberta e fechada, obtendo-se os melhores re- 
sultados usando sinais PRBS com $T_{b}=44$, excetuando a identificação feita em malha fechada usando sinais de baixa correlação com os seus melhores valores $\overline{F I T}$ para $T_{b}=8$. Novamente foi observado que a identificação direta do modelo da planta em malha fechada apresentou resultados piores aos obtidos em malha aberta com diferenças de ao redor de $10 \%$. Finalmente, foi observado que maioria dos resultados obtidos usando sinais de baixa correlação apresentaram valores similares aos obtidos utilizando sinais de alta correlação.

Das Tabelas 6.3 e 6.4, nota-se que o uso de sinais de máxima e mínima correlação no modelo gerou resultados similares para ambos os sinais de excitação, PRBS e GBN. O uso de sinais correlacionados não afetou o processo de identificação.

\subsubsection{Resultados na Coluna de Destilação $3 \times 3$}

A estrutura do modelo escolhida para a identificação da coluna de destilação em malha aberta foi uma BJ (Box-Jenkins), idêntica à obtida por discretização da Equação (4.6) com um tempo de amostragem $T=0,5$ minutos, apresentada na Equação (6.4). Para a identificação do sistema em malha fechada foram usadas as ordens do modelo BJ apresentadas na Tabela 6.5, correspondentes com a discretização do modelo em malha fechada com um tempo de amostragem $T=0,5$ minutos.

$$
\begin{gathered}
y(z)=G(z) u(z)+G_{d}(z) d(z) \\
G(z)=\left[\begin{array}{ccc}
\frac{0,03825+0,009211 z^{-1}}{1-0,9281 z^{-1}} z^{-6} & \frac{-0,0343}{1-0,9438 z^{-1}} z^{-8} & \frac{-0,0002631}{1-0,9463 z^{-1}} z^{-3} \\
\frac{0,1583}{1-0,8574 z^{-1}} z^{-14} & \frac{-0,2246}{1-0,9048 z^{-1}} z^{-7} & \frac{-0,00049-0,00032 z^{-1}}{1-0,9319 z^{-1}} z^{-3} \\
\frac{-1,253-0,8103 z^{-1}}{1-0,9405 z^{-1}} z^{-19} & \frac{0,4219+1,649 z^{-1}}{1-0,9552 z^{-1}} z^{-19} & \frac{0,06534-0,06259 z^{-1}}{1-1,853 z^{-1}+0,8563 z^{-2}} z^{-3}
\end{array}\right] \\
G_{d}(z)=\left[\begin{array}{cc}
\frac{0,01085}{1-0,9225 z^{-1}} z^{-25} & \frac{-8,345 e-05+4,413 e-05 z^{-1}+3,704 e-05 z^{-2}}{1-1,905 z^{-1}+0,9068 z^{-2}} z^{-6} \\
\frac{0,03705}{1-0,9301 z^{-1}} z^{-22} & \frac{-5,746 e-05-0,0003451 z^{-1}+0,000391 z^{-2}}{1-1,879 z^{-1}+0,8829 z^{-2}} z^{-7} \\
\frac{-0,6401-0,1544 z^{-1}}{1-0,9312 z^{-1}} z^{-2} & \frac{0,01608+0,003891 z^{-1}}{1-0,9376 z^{-1}} z^{-6}
\end{array}\right]
\end{gathered}
$$

Tabela 6.5: Ordens utilizadas no modelo BJ para a identificação da coluna de destilação em malha fechada.

\begin{tabular}{cccccc}
\hline Saída & nb & nc & nd & nf & nk \\
\hline$y_{1}$ & {$\left[\begin{array}{lll}13 & 13 & 13\end{array}\right]$} & 2 & 2 & {$\left[\begin{array}{llll}13 & 13 & 13\end{array}\right]$} & {$\left[\begin{array}{lll}6 & 8 & 3\end{array}\right]$} \\
$y_{2}$ & {$\left[\begin{array}{lll}13 & 13 & 13\end{array}\right]$} & 2 & 2 & {$\left[\begin{array}{lll}13 & 13 & 13\end{array}\right]$} & {$\left[\begin{array}{llll}14 & 7 & 3\end{array}\right]$} \\
$y_{3}$ & {$\left[\begin{array}{llll}13 & 13 & 13\end{array}\right]$} & 1 & 1 & {$\left[\begin{array}{llll}13 & 13 & 13\end{array}\right]$} & {$\left[\begin{array}{llll}19 & 19 & 3\end{array}\right]$} \\
\hline
\end{tabular}

Na Figura 6.3 é apresentado uma combinação dos sinais GBN usada nas simulações feitas na coluna com um comprimento $N=1500$ e probabilidade de não-chaveamento $p=0,96$. Do mesmo modo, na Figura 6.4 é apresentada a resposta da coluna de destilação utilizando a combinação de sinais de entrada da Figura 6.3. 
Figura 6.3: Sinais GBN para identificaçao da coluna de destilação.
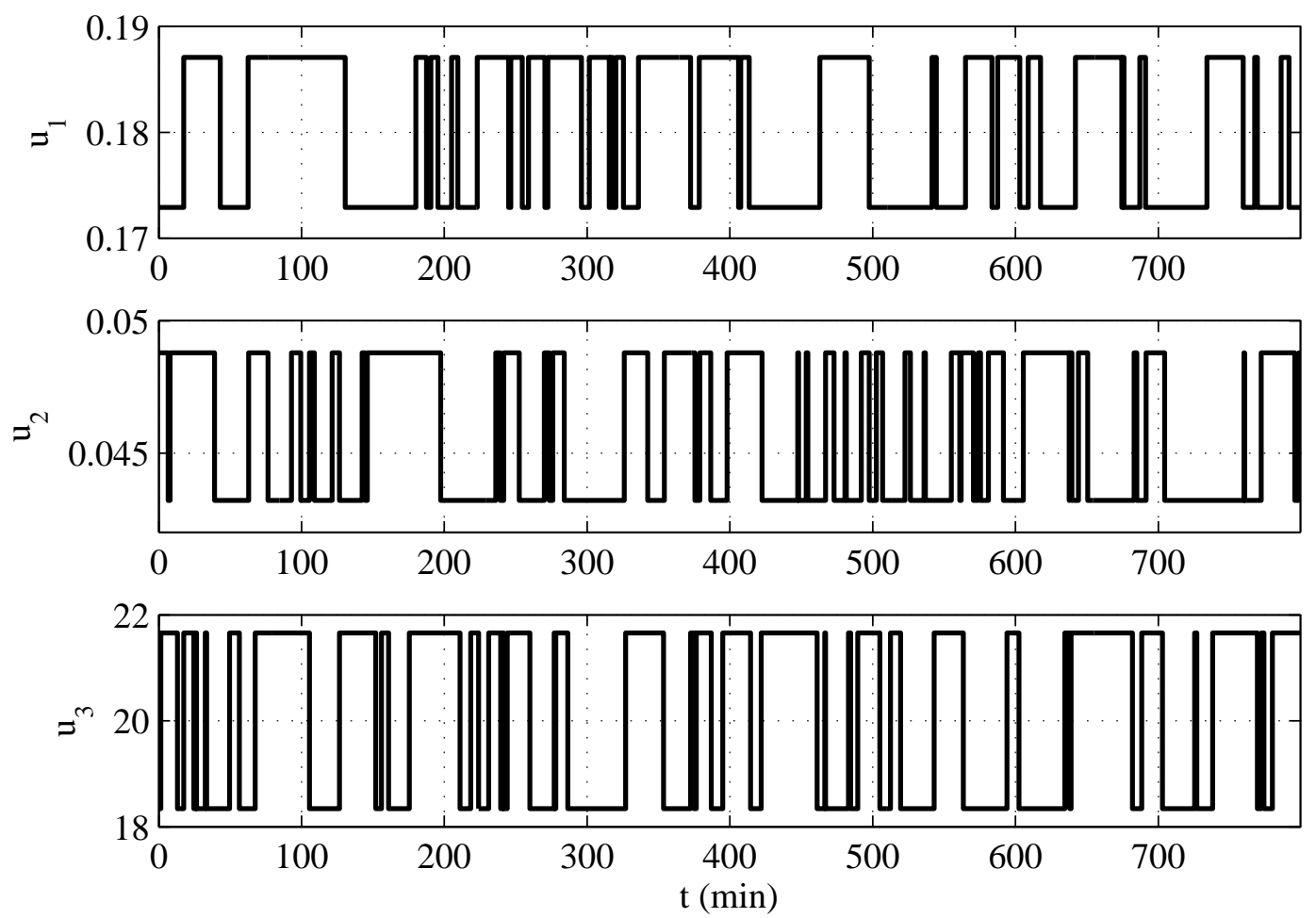

Fonte: Autor.

Figura 6.4: Resposta do sistema usando o sinal GBN da Figura 6.3.
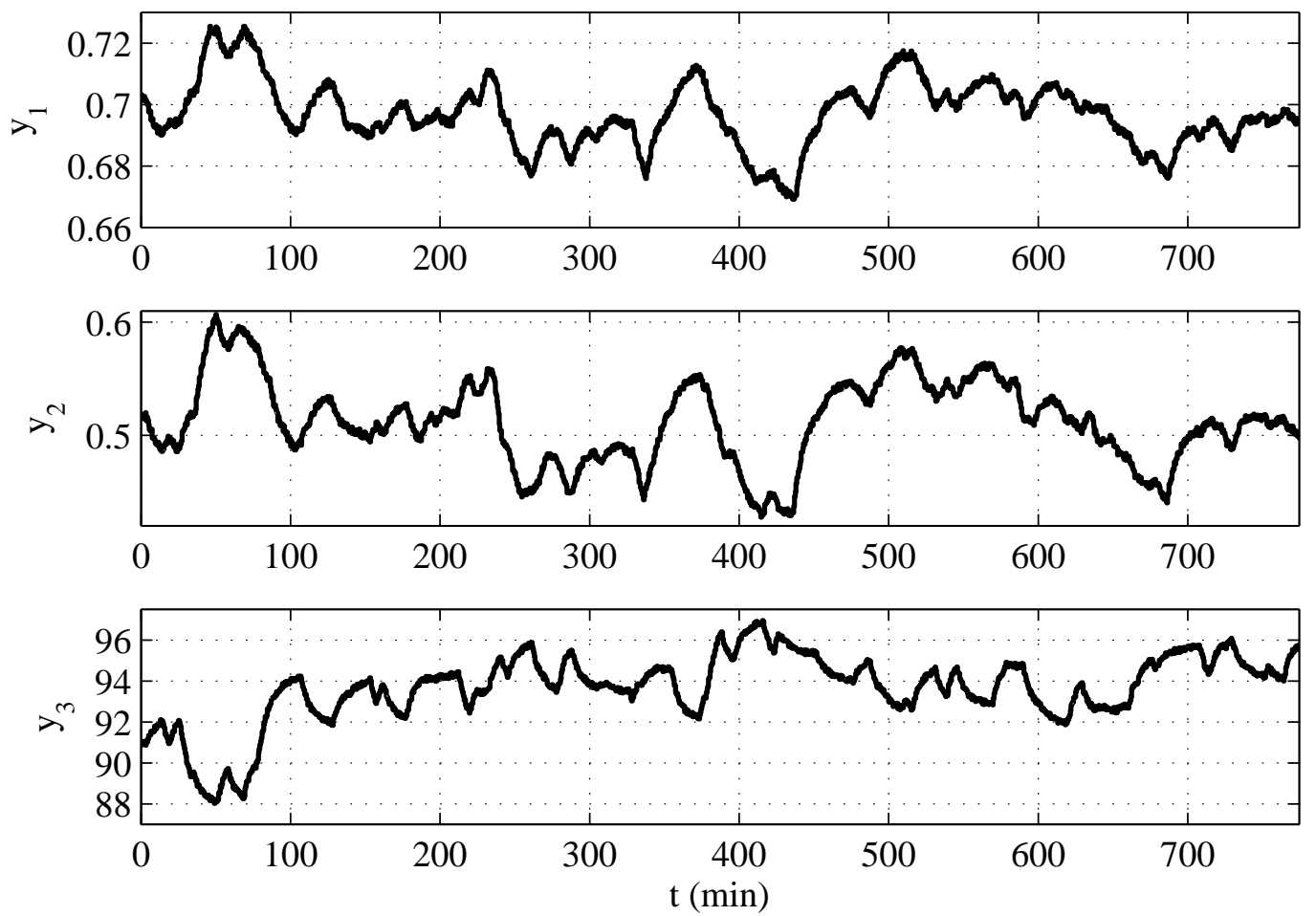

Fonte: Autor.

Cada simulação do experimento foi realizada com 100 iterações como feito no caso 
anterior. O comprimento dos sinais GBN e PRBS se manteve igual a $N=1500$. Os ruídos de medição e as perturbações são tratados como processos estocásticos e vão mudando em cada iteração. Os cenários de ruído são usados para testar o modelo segundo as condições apresentadas nas tabelas 4.2 e 4.3 .

As sementes utilizadas para as combinações de sinais GBN e PRBS de alta e baixa correlação foram tomadas a partir dos resultados apresentados nas figuras 5.2 e 5.3 e sintetizados junto com os valores de $r_{x y}(\tau)$ nas tabelas 6.6 e 6.7 .

Tabela 6.6: Sementes de geração e características de correlação cruzada das combianções de sinais GBN.

\begin{tabular}{cccccccc}
\hline \multirow{2}{*}{ Corr. } & \multirow{2}{*}{ Característica } & \multicolumn{7}{c}{$p$} \\
\cline { 2 - 8 } Baixa & 0,84 & 0,87 & 0,9 & 0,93 & 0,96 & 0,99 \\
\cline { 2 - 8 } & Sementes & $10-29$ & $39-90$ & $81-151$ & $54-105$ & $43-44$ & $19-94$ \\
\cline { 2 - 8 } & $r_{u_{1} u_{2}}\left(\tau_{1}\right)$ & 0,0708 & 0,0764 & 0,0839 & 0,0843 & 0,0654 & 0,0682 \\
\cline { 2 - 8 } & $\tau_{1}$ & 51 & 22 & -8 & 54 & 17 & -32 \\
\cline { 2 - 8 } & $r_{u_{2} u_{3}}\left(\tau_{2}\right)$ & 0,0602 & 0,0790 & 0,0842 & 0,0683 & 0,0804 & 0,0538 \\
\cline { 2 - 8 } Alta & $\tau_{2}$ & 46 & -60 & 20 & 17 & -14 & -59 \\
\cline { 2 - 8 } & $r_{u_{3} u_{1}}\left(\tau_{3}\right)$ & 0,0824 & 0,0742 & 0,0777 & 0,0736 & 0,0871 & 0,1302 \\
\cline { 2 - 8 } & $\tau_{3}$ & -60 & -41 & 40 & 45 & -56 & -8 \\
\cline { 2 - 8 } & Sementes & $99-145$ & $31-116$ & $63-88$ & $22-25$ & $25-123$ & $71-88$ \\
\cline { 2 - 8 } & $r_{u_{1} u_{2}}\left(\tau_{1}\right)$ & 0,1790 & 0,1714 & 0,1639 & 0,1668 & 0,2508 & 0,5799 \\
\cline { 2 - 7 } & $\tau_{1}$ & -11 & -35 & 42 & -43 & -45 & 48 \\
\cline { 2 - 7 } & $r_{u_{2} u_{3}}\left(\tau_{2}\right)$ & 0,1610 & 0,1906 & 0,2114 & 0,2785 & 0,3700 & 0,5909 \\
\cline { 2 - 7 } & $\tau_{2}$ & -2 & 2 & 48 & -13 & -52 & 0 \\
\cline { 2 - 7 } & $r_{u_{3} u_{1}}\left(\tau_{3}\right)$ & 0,1826 & 0,1512 & 0,2154 & 0,2221 & 0,2052 & 0,5751 \\
\hline$\tau_{3}$ & -44 & -52 & -2 & -21 & 9 & 60 \\
\hline
\end{tabular}

Tabela 6.7: Sementes de geração e características de correlação cruzada das combianções de sinais PRBS.

\begin{tabular}{|c|c|c|c|c|c|c|c|}
\hline \multirow{2}{*}{ Corr. } & \multirow{2}{*}{ Característica } & \multicolumn{6}{|c|}{$T b$} \\
\hline & & 2 & 3 & 4 & 8 & 12 & 44 \\
\hline \multirow{7}{*}{ Baixa } & Sementes & $47-80$ & $53-119$ & $30-86$ & $21-36$ & $77-102$ & $23-35$ \\
\hline & $r_{u_{1} u_{2}}\left(\tau_{1}\right)$ & 0,0394 & 0,0139 & 0,0544 & 0,0509 & 0,0240 & 0,0476 \\
\hline & $\tau_{1}$ & -23 & -18 & -18 & 43 & 12 & 21 \\
\hline & $r_{u_{2} u_{3}}\left(\tau_{2}\right)$ & 0,0373 & 0,0160 & 0,0364 & 0,0502 & 0,0160 & 0,0847 \\
\hline & $\tau_{2}$ & -40 & -24 & -46 & 36 & 52 & 38 \\
\hline & $r_{u_{3} u_{1}}\left(\tau_{3}\right)$ & 0,0364 & 0,0178 & 0,0476 & 0,0450 & 0,0243 & 0,0761 \\
\hline & $\tau_{3}$ & -20 & 0 & -4 & -54 & 36 & 38 \\
\hline \multirow{7}{*}{ Alta } & Sementes & $2-4$ & $2-4$ & $2-4$ & $3-7$ & $2-4$ & $2-32$ \\
\hline & $r_{u_{1} u_{2}}\left(\tau_{1}\right)$ & 0,9986 & 0,9980 & 0,9972 & 0,9947 & 0,9916 & 0,9635 \\
\hline & $\tau_{1}$ & 2 & 3 & 4 & 8 & 12 & 44 \\
\hline & $r_{u_{2} u_{3}}\left(\tau_{2}\right)$ & 0,9987 & 0,998 & 0,9973 & 0,9947 & 0,9916 & 0,3158 \\
\hline & $\tau_{2}$ & 2 & 3 & 4 & 8 & 12 & -60 \\
\hline & $r_{u_{3} u_{1}}\left(\tau_{3}\right)$ & 0,9973 & 0,9959 & 0,9945 & 0,9895 & 0,9832 & 0,9762 \\
\hline & $\tau_{3}$ & 4 & 6 & 8 & 16 & 24 & 44 \\
\hline
\end{tabular}


A Tabela 6.8 apresenta os resultados dos índices FIT médios, $\overline{F I T}$, para cada um dos testes em cada probabilidade de não-chaveamento usando sinais GBN. As respostas tanto dos sinais correlacionados como dos não-correlacionados são aproximadas, mas existe uma queda nos indicadores $\overline{F I T}$ usando sinais de alta correlação com $p=0,99$. Este efeito é atribuído à frequência usada já que se apresenta usando sinais de alta e baixa correlação.

Tabela 6.8: Resultados da validação cruzada usando sinais GBN.

\begin{tabular}{|c|c|c|c|c|c|c|c|c|}
\hline \multirow{2}{*}{ ID } & \multirow{2}{*}{ Corr. } & \multirow{2}{*}{ Saída } & \multicolumn{6}{|c|}{$p$} \\
\hline & & & 0,84 & 0,87 & 0,9 & 0,93 & 0,96 & 0,99 \\
\hline \multirow{6}{*}{ Malha Aberta } & \multirow{3}{*}{ Baixa } & $y_{1}$ & 54,74 & 64,56 & 77,60 & 61,74 & 82,28 & 74,11 \\
\hline & & $y_{2}$ & 61,21 & 65,93 & 76,74 & 70,72 & 83,87 & 76,68 \\
\hline & & $y_{3}$ & 65,12 & 70,31 & 71,15 & 66,98 & 75,94 & 72,61 \\
\hline & \multirow{3}{*}{ Alta } & $y_{1}$ & 62,77 & 52,96 & 76,27 & 51,49 & 69,38 & 58,64 \\
\hline & & $y_{2}$ & 60,04 & 64,88 & 76,59 & 67,74 & 82,10 & 70,29 \\
\hline & & $y_{3}$ & 67,01 & 63,96 & 70,12 & 69,45 & 74,04 & 72,97 \\
\hline \multirow{6}{*}{$\begin{array}{l}\text { Malha Fechada } \\
\text { Modelo Completo }\end{array}$} & \multirow{3}{*}{ Baixa } & $y_{1}$ & 85,04 & 88,03 & 85,76 & 79,79 & 84,65 & 84,41 \\
\hline & & $y_{2}$ & 68,80 & 78,61 & 79,74 & 77,97 & 72,48 & 76,44 \\
\hline & & $y_{3}$ & 81,31 & 82,96 & 85,46 & 79,43 & 85,93 & 86,39 \\
\hline & \multirow{3}{*}{ Alta } & $y_{1}$ & 83,88 & 87,70 & 84,36 & 85,67 & 88,34 & 87,76 \\
\hline & & $y_{2}$ & 75,37 & 77,61 & 79,64 & 78,82 & 82,05 & 73,80 \\
\hline & & $y_{3}$ & 79,04 & 83,10 & 82,39 & 84,09 & 82,43 & 84,13 \\
\hline \multirow{6}{*}{$\begin{array}{l}\text { Malha Fechada } \\
\text { Modelo do Processo }\end{array}$} & \multirow{3}{*}{ Baixa } & $y_{1}$ & 74,42 & 78,32 & 78,56 & 80,52 & 87,25 & 79,36 \\
\hline & & $y_{2}$ & 76,50 & 78,62 & 77,00 & 79,38 & 84,28 & 79,18 \\
\hline & & $y_{3}$ & 70,01 & 70,62 & 80,23 & 73,90 & 78,01 & 79,96 \\
\hline & \multirow{3}{*}{ Alta } & $y_{1}$ & 75,18 & 71,32 & 82,05 & 82,35 & 86,25 & 82,93 \\
\hline & & $y_{2}$ & 64,31 & 74,52 & 77,51 & 82,19 & 83,35 & 67,35 \\
\hline & & $y_{3}$ & 65,95 & 72,65 & 73,49 & 78,54 & 78,90 & 76,99 \\
\hline
\end{tabular}

Nos testes realizados com sinais GBN na coluna observa-se que os melhores resultados dos índices $\overline{F I T}$ foram alcançados na maioria dos casos com $p=0,96$. Os índices foram aumentando com o aumento de $p$, isto tanto para sinais correlacionados como para os não correlacionados em condições normais de operação.

Na Tabela 6.9 são apresentados os resultados dos índices FIT médios dos testes usando sinais PRBS. Nos resultados percebe-se que os índices $\overline{F I T}$ são próximos para todos os valores de $T_{b}$ identificando o processo em malha aberta. Em malha fechada os valores dos resultados usando sinais de alta e baixa correlação foram similares quando $T_{b} \leq 12$, mas existe uma queda nos $\overline{F I T}$ usando sinais PRBS de alta correlação com $T_{b}=44$, esta queda foi de ao redor de $10 \%$ identificando o processo diretamente usando o sinal $u(t)$.

Para os diferentes testes realizados conseguiu-se observar uma relação entre a qualidade da identificação e os tempos médios dos sinais de excitação. Os indicadores $\overline{F I T}$ atingem valores maiores para sinais com frequências menores, o que implica em probabilidades de não-chaveamento perto de 1 para sinais GBN e tempos de bit elevados para sinais PRBS. Em geral, os sinais correlacionados não apresentaram dificuldade na identificação de cada um dos sistemas. Porém, os pontos onde se perceberam quedas nos índices $\overline{F I T}$ foram usados sinais que apresentavam correlações perto de 1 e frequências muito baixas. 
Tabela 6.9: Resultados da validação cruzada usando sinais PRBS.

\begin{tabular}{|c|c|c|c|c|c|c|c|c|}
\hline \multirow{2}{*}{ ID } & \multirow{2}{*}{ Corr. } & \multirow{2}{*}{ Saída } & \multicolumn{6}{|c|}{$T_{b}$} \\
\hline & & & 2 & 3 & 4 & 8 & 12 & 44 \\
\hline \multirow{6}{*}{ Malha Aberta } & \multirow{3}{*}{ Baixa } & $y_{1}$ & 72,10 & 75,00 & 75,69 & 79,24 & 76,63 & 81,98 \\
\hline & & $y_{2}$ & 74,72 & 76,08 & 75,76 & 80,02 & 77,77 & 82,18 \\
\hline & & $y_{3}$ & 74,56 & 75,07 & 75,66 & 82,31 & 77,68 & 80,98 \\
\hline & \multirow{3}{*}{ Alta } & $y_{1}$ & 74,84 & 75,46 & 72,20 & 78,56 & 78,30 & 79,88 \\
\hline & & $y_{2}$ & 74,22 & 74,31 & 76,41 & 78,25 & 79,84 & 81,07 \\
\hline & & $y_{3}$ & 74,45 & 75,84 & 77,90 & 76,41 & 77,46 & 77,76 \\
\hline \multirow{6}{*}{$\begin{array}{l}\text { Malha Fechada } \\
\text { Modelo Completo }\end{array}$} & \multirow{3}{*}{ Baixa } & $y_{1}$ & 85,63 & 88,21 & 84,03 & 88,43 & 90,21 & 89,72 \\
\hline & & $y_{2}$ & 80,18 & 81,44 & 79,58 & 79,79 & 84,89 & 84,35 \\
\hline & & $y_{3}$ & 82,37 & 83,99 & 83,37 & 83,70 & 84,23 & 86,97 \\
\hline & \multirow{3}{*}{ Alta } & $y_{1}$ & 85,53 & 89,17 & 86,90 & 88,53 & 87,87 & 84,23 \\
\hline & & $y_{2}$ & 78,76 & 81,61 & 81,76 & 77,85 & 81,62 & 81,70 \\
\hline & & $y_{3}$ & 81,65 & 84,55 & 83,27 & 85,04 & 85,38 & 86,06 \\
\hline \multirow{6}{*}{$\begin{array}{l}\text { Malha Fechada } \\
\text { Modelo do Processo }\end{array}$} & \multirow{3}{*}{ Baixa } & $y_{1}$ & 75,62 & 78,31 & 76,35 & 77,46 & 80,26 & 89,52 \\
\hline & & $y_{2}$ & 75,33 & 76,96 & 77,14 & 76,99 & 79,80 & 83,39 \\
\hline & & $y_{3}$ & 76,36 & 75,42 & 77,56 & 75,68 & 79,62 & 86,93 \\
\hline & \multirow{3}{*}{ Alta } & $y_{1}$ & 76,16 & 79,11 & 80,20 & 79,04 & 81,97 & 74,92 \\
\hline & & $y_{2}$ & 74,97 & 76,52 & 76,77 & 78,67 & 79,40 & 74,59 \\
\hline & & $y_{3}$ & 76,49 & 75,31 & 77,71 & 77,63 & 80,28 & 76,13 \\
\hline
\end{tabular}

\subsection{Teste de frequências combinadas}

Na seção anterior observou-se que existe uma forte influência da frequência dos sinais de entrada na resposta do processo de identificação. Nesta seção é estudada uma abordagem diferente, na qual a frequência dos sinais de entrada varia individualmente e não conjuntamente como foi tratado no estudo anterior. Para evitar o efeito da correlação cruzada dos sinais, as combinações dos sinais foram geradas mantendo-se uma correlação inferior a $r_{x y}=0,25$ na FCC. Desta maneira é possível ter mais conhecimento sobre a verdadeira influência de cada um dos sinais sobre o processo de identificação de acordo com as características de frequência em cada sinal. As plantas testadas foram a mesmas usadas na seção anterior, de dimensões $2 \times 2$ e 3x3.

Nos testes realizados é usado também o índice FIT da validação da resposta ao pulso de cada função de transferência das plantas testadas, como apresentado na Figura 6.5. Estes dados são usados como parâmetro de comparação entre o modelo identificado e real, analisando-se individualmente cada função de transferência.

\subsubsection{Reator de Polimerização 2x2}

As simulações dos experimentos no reator de polimerização conservaram as características usadas nos testes da seção anterior. As amplitudes dos sinais de entrada, tanto a entrada em malha aberta e o set point em malha fechada, variam entre $[-0,5 ; 0,5]$ (Figura 6.1). A estrutura do modelo BJ segue a discretização da Equação (6.2) para malha 
Figura 6.5: Exemplo da resposta ao pulso de $y_{1} / u_{1}$ na coluna de destilação (fit $=91,06 \%$ ).

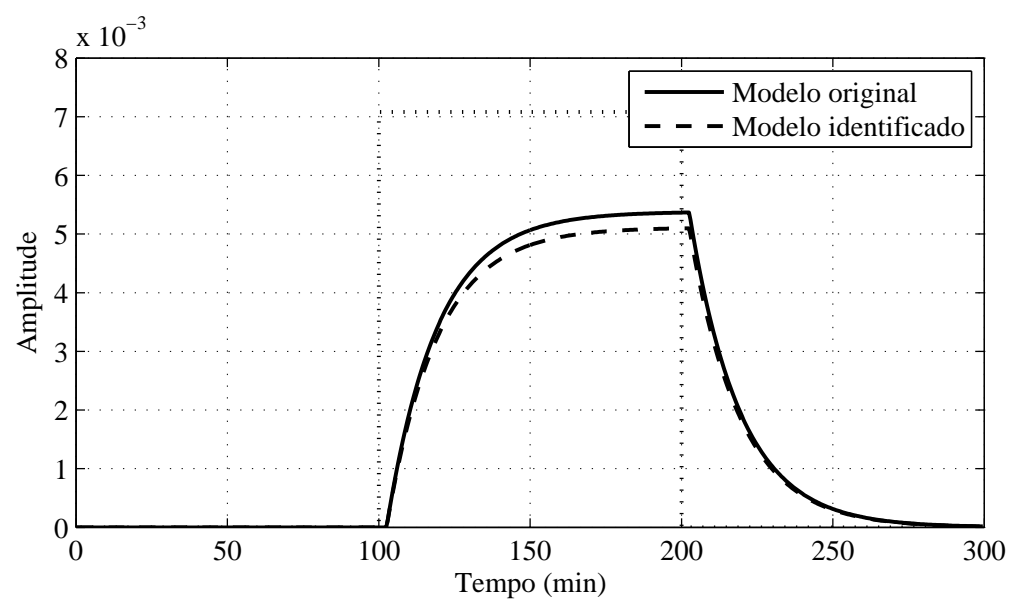

Fonte: Autor.

aberta e a discretização da Equação (6.3) para malha fechada. O cenário de ruído usado foi o correspondente a um $\mathrm{SNR}=10$, comum em vários processos industriais, e os testes de Monte Carlo foram reduzidos para 10 iterações devido ao tempo de computação dos resultados.

\subsubsection{Resultados em Malha aberta - GBN}

Na Figura 6.6 são apresentados os gráficos de como varia o índice $\overline{F I T}$ da validação cruzada para cada uma das saídas conforme as probabilidades $p_{1}$ e $p_{2}$ variam na faixa de $p=[0,50,998]$. Os resultados das validações cruzadas são apresentados individualmente para as saídas $y_{1}$ e $y_{2}$, mas para se ter um resultado conjunto foi usada a média geométrica dos resultados $\overline{F I T}_{y}=\sqrt{\overline{F I T}_{y_{1}} \overline{F I T}_{y_{2}}}$, estes resultados são apresentados na Figura 6.7.

Figura 6.6: $\overline{F I T}$ da validação cruzada das saídas $y_{1}$ e $y_{2}$ em função de $p_{1}$ e $p_{2}$.
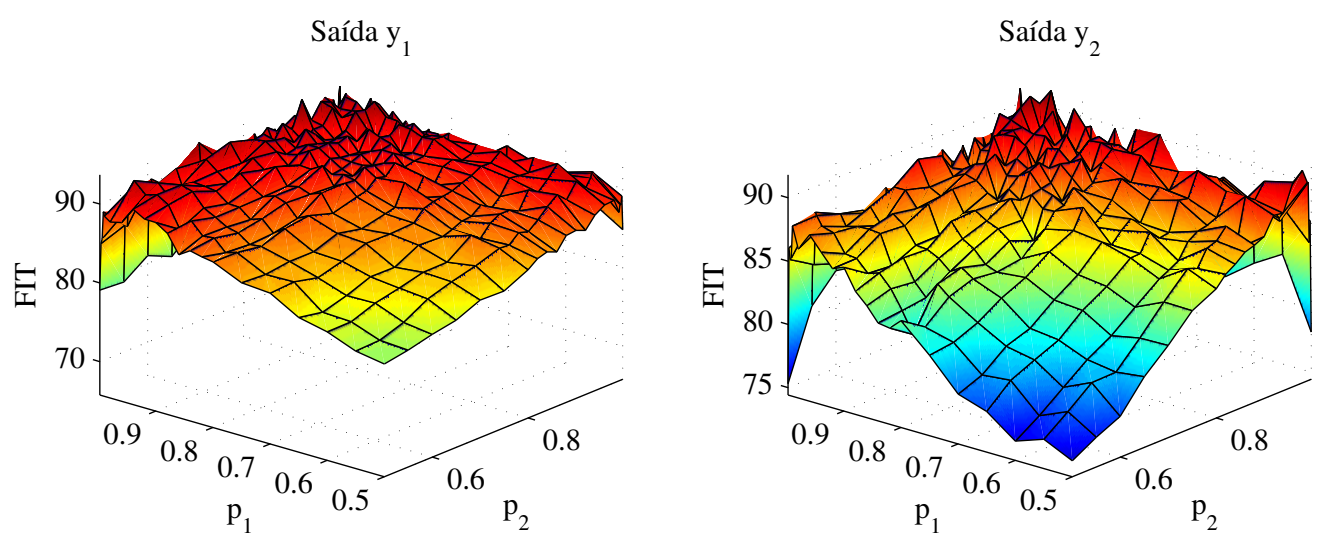

Fonte:

Autor.

Da Figura 6.6 pode ser observada uma influência das duas probabilidades de nãochaveamento nos valores dos índices $\overline{F I T}$ em cada saída. O valor máximo do índice $\overline{F I T}$ para a saída $y_{1}$ foi de $93,71 \%$ usando $p_{1}=0,98$ e $p_{2}=0,9$, e, para a saída $y_{2}$ foi de 91,91 $\%$ usando $p_{1}=0,94$ e $p_{2}=0,98$. 
Figura 6.7: Média geométrica, $\overline{F I T}_{y}$, entre as saídas $y_{1}$ e $y_{2}$.

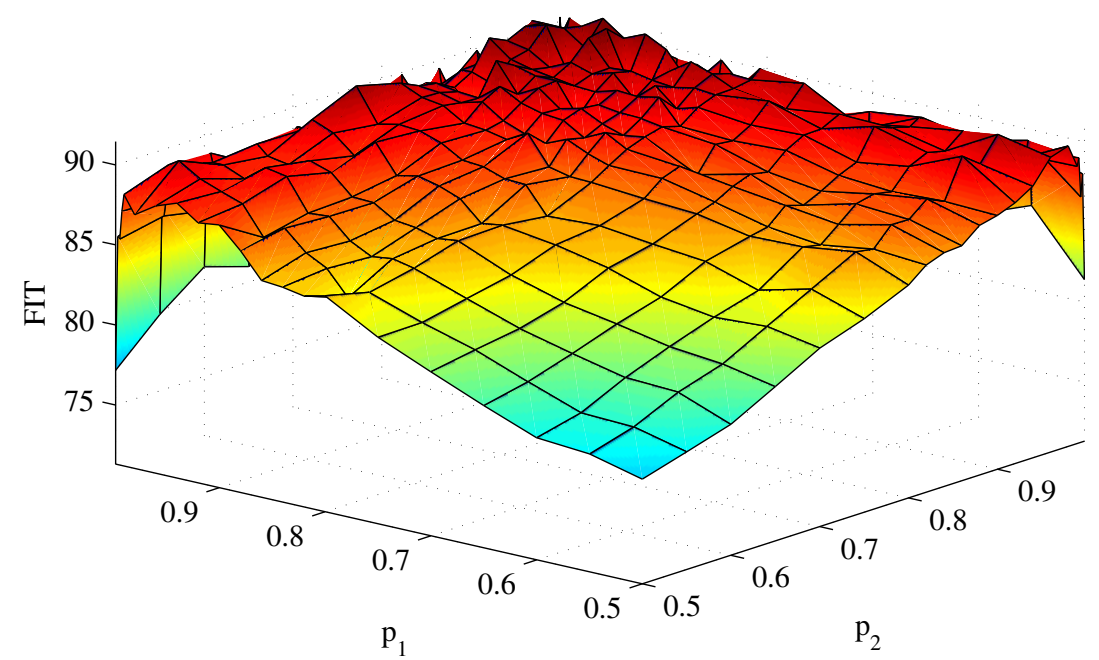

Fonte: Autor.

Dos resultados da Figura 6.7 foi obtido o máximo valor do $\overline{F I T}$ igual a 91,45\% usando $p_{1}=0,92$ e $p_{2}=0,96$, porém nos resultados pode ser observada uma região em que a identificação apresenta resultados similares ao ponto máximo do gráfico. Na Figura 6.8 é apresentado o contorno da média geométrica entre as saídas $y_{1}$ e $y_{2}$ em função de $p_{1}$ e $p_{2}$.

Figura 6.8: Contorno da média geométrica $\overline{F I T}_{y}$.

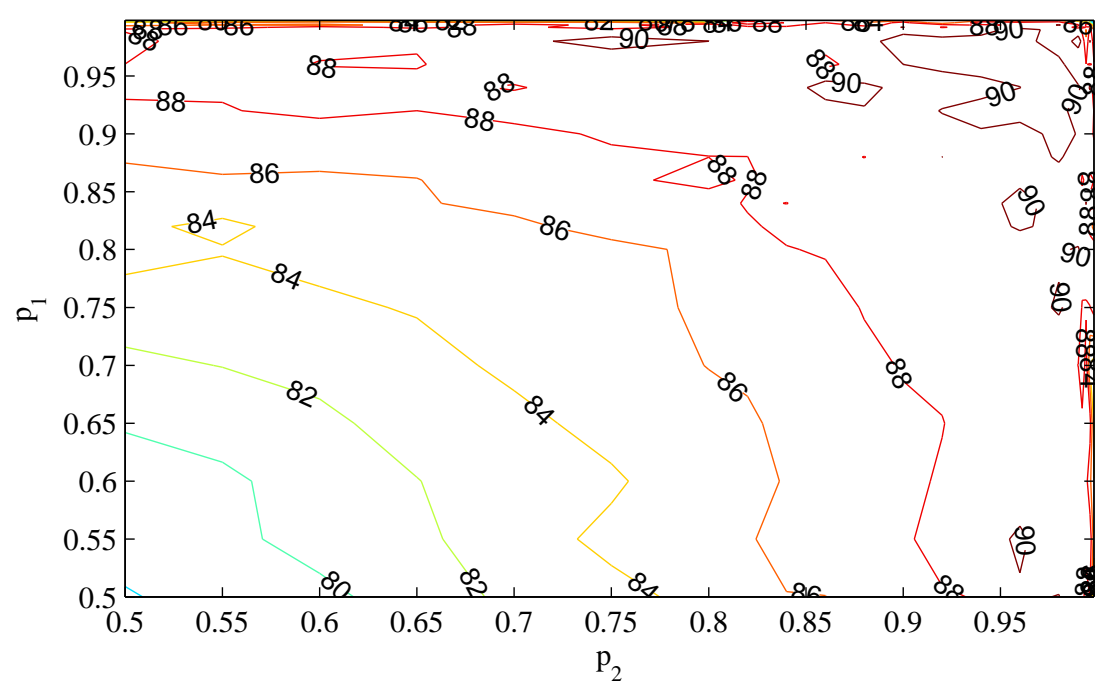

Fonte: Autor.

Na Figura 6.8 pode ser observado que existe uma região em que para valores de $p_{1} \geq 0,8 \wedge p_{2} \geq 0,85$ os resultados $\overline{F I T}$ são maiores ou iguais a $85 \%$, valores para os quais a identificação pode ser considerada satisfatória. Porém, existem algumas pequenas regiões com valores maiores que $90 \%$, entre elas, a região com uma maior área foi encontrada nas faixas de $0,9 \leq p_{1} \leq 0,99$ e $0,9 \leq p_{2} \leq 0,99$.

Após observar a influência da frequência de cada um dos sinais nos índices da validação cruzada dos sinais de saída $y_{1}$ e $y_{2}$, é analisado o efeito das probabilidades de 
não-chaveamento em cada uma das respostas da validação de $y_{i} / u_{i}$ com o sinal degrau, estes resultados são apresentados na Figura 6.9.

Figura 6.9: $\overline{F I T}$ da resposta ao degrau de $y_{i} / u_{i}$ em função de $p_{1}$ e $p_{2}$.
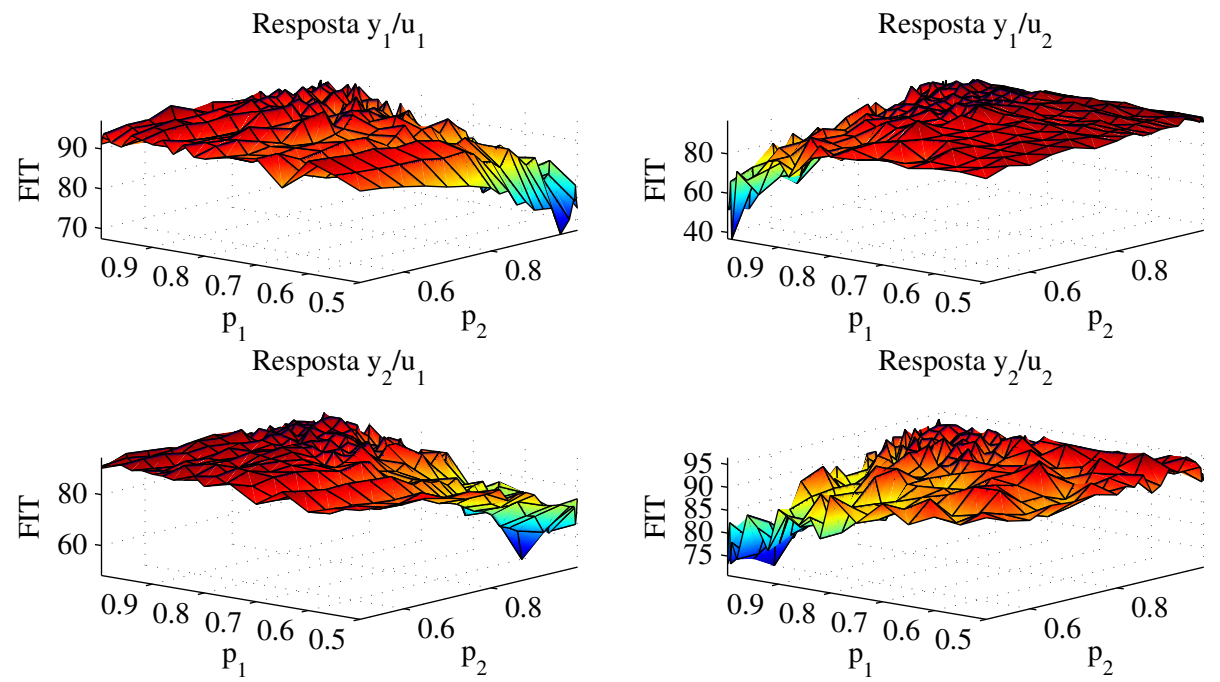

Fonte: Autor.

Da superfície plotada para cada $y_{i} / u_{i}$ os valores $\overline{F I T}$ vão crescendo com o aumento de cada probabilidade de não-chaveamento $p_{i}$ correspondente a cada entrada $u_{i}$ e a diminuição da probabilidade de não-chaveamento subsequente. Logo, para as respostas $y_{1} / u_{1}$ e $y_{2} / u_{1}$ os valores $\overline{F I T}$ tiveram seus valores mínimos quando $p_{1} \rightarrow 0,5$ e $p_{2} \rightarrow 1$, e, os seus valores máximos cresceram quando $p_{1} \rightarrow 1$ e $p_{2} \rightarrow 0,5$. Para observar o efeito conjunto nas respostas $y_{i} / u_{i}$ foi calculada a média geométrica entre todas as respostas

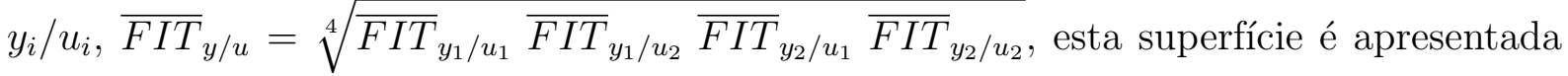
na Figura 6.10.

Figura 6.10: Superfície da média geométrica, $\overline{F I T}_{y / u}$ em função $p_{1}$ e $p_{2}$.

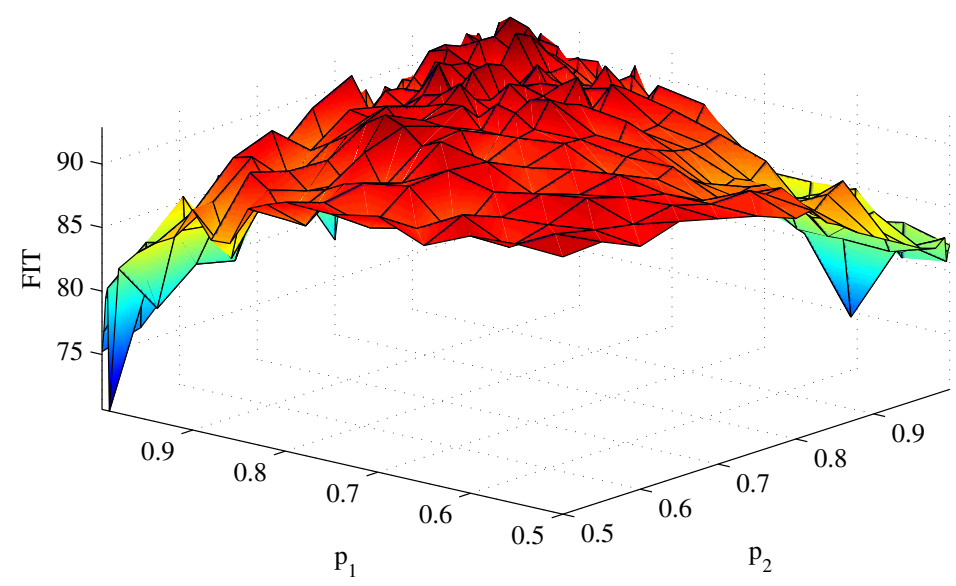

Fonte: Autor.

Da superfície apresentada na Figura 6.10 são observados que para a maioria dos pares de probabilidades $p_{1}$ e $p_{2}$, a média geométrica esteve ao redor de $90 \%$, excetuando os 
pontos em que $p_{1} \rightarrow 0,5 \wedge p_{2} \rightarrow 1$ e vice-versa. Do mesmo modo, o $\overline{F I T}_{y / u}$ foi aumentando enquanto $p_{1}$ tornou-se igual a $p_{2}$ e ao mesmo tempo quando $p_{1}$ e $p_{2}$ tenderam a 1 . Finalmente foi calculada a média geométrica tanto das respostas individuais das saídas de

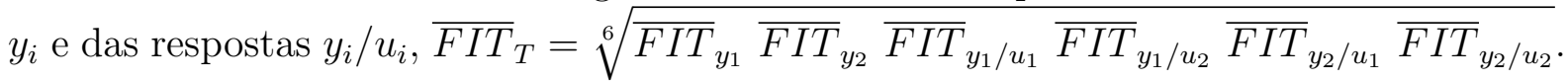

Figura 6.11: Superfície da média geométrica total, $\overline{F I T}_{T}$.

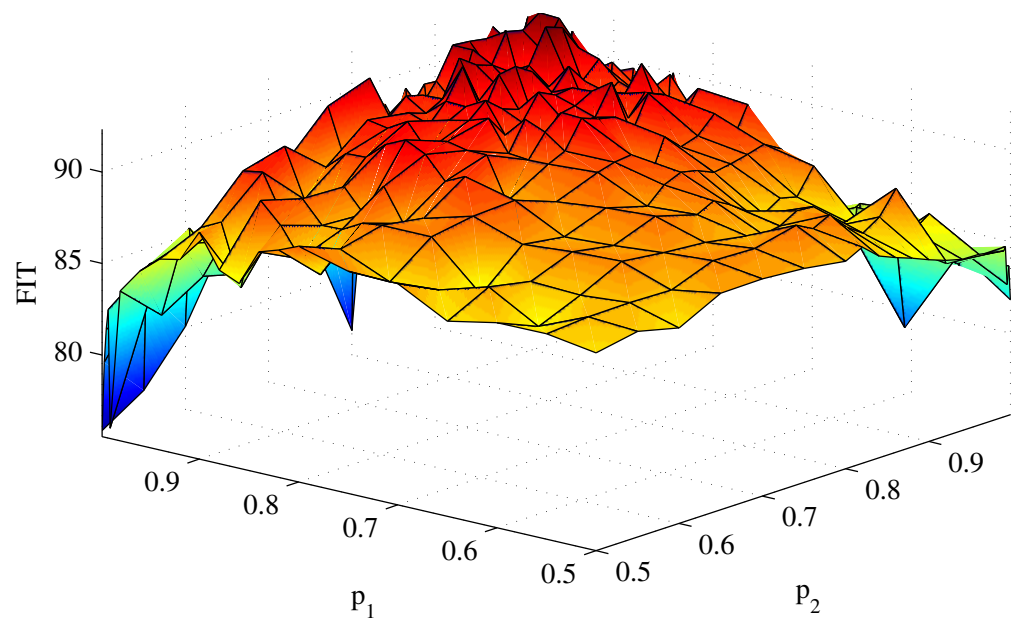

Fonte: Autor.

Do contorno da superfície apresentada na Figura 6.11 (Figura 6.12) pode ser observado que os pontos máximos da superfície acontecem em uma região de $p_{1} \geq 0,82$ e $p_{2}>0,82$, os picos apresentados na superfície se devem às descontinuidades dos pontos testados. $\mathrm{O}$ pico mais alto foi encontrado nos valores de $p_{1}=0,94$ e $p_{2}=0,92 \mathrm{com}$ um $\mathrm{FIT}=92,34 \%$, porém foram considerados os valores de $p_{i} \operatorname{com} \overline{F I T}_{T} \geq 91 \%$ e calculada a média das $p_{i}$, $\bar{p}_{1}=0,9339 \pm 0,0467$ e $\bar{p}_{2}=0,9292 \pm 0,0485$.

Figura 6.12: Contorno da média geométrica $\overline{F I T}_{T}$ da Figura 6.11.

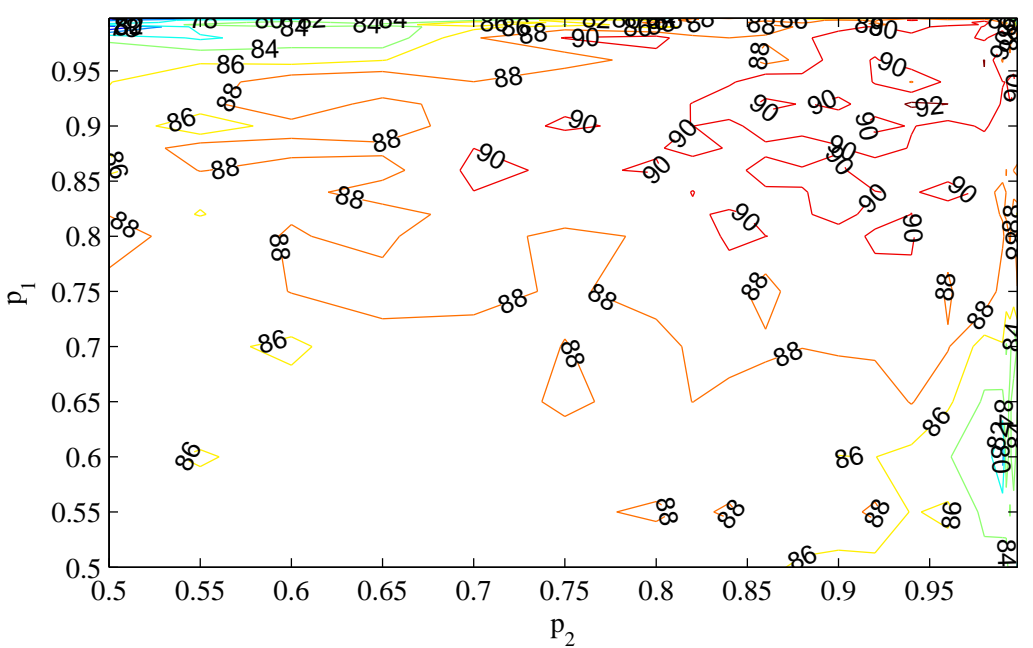

Fonte: Autor. 


\subsubsection{Resultados em Malha Fechada - GBN}

Os testes feitos em malha aberta foram implementados de igual maneira em malha fechada. Os experimentos foram desenvolvidos para analisar o efeito dos sinais de excitação no modelo identificado da planta em malha fechada e o modelo do processo identificado diretamente baseado no sinal de controle. Assim, é possível observar a região dos valores de $p_{1}$ e $p_{2}$ ótimos levando em conta o efeito do controlador em comparação com a obtida em malha aberta.

\section{Sistema em malha fechada - GBN}

Na Figura 6.13 são apresentados os resultados dos índices $\overline{F I T}$ da validação cruzada de cada uma das saídas $y_{i}$. Em comparação com a Figura 6.6 são observados menores valores para altas frequências e os maiores valores quando $p_{1}$ e $p_{2}$ estão próximos de 1, por isto, a inclinação das superfícies é mais acentuada nos resultados em malha fechada. Também é possível observar uma maior dependência dos resultados de cada saída $y_{i}$ com a frequência do setpoint correspondente, $S P_{i}$.

Figura 6.13: $\overline{F I T}$ da validação cruzada das saídas $y_{1}$ e $y_{2}$ em função de $p_{1}$ e $p_{2}$.
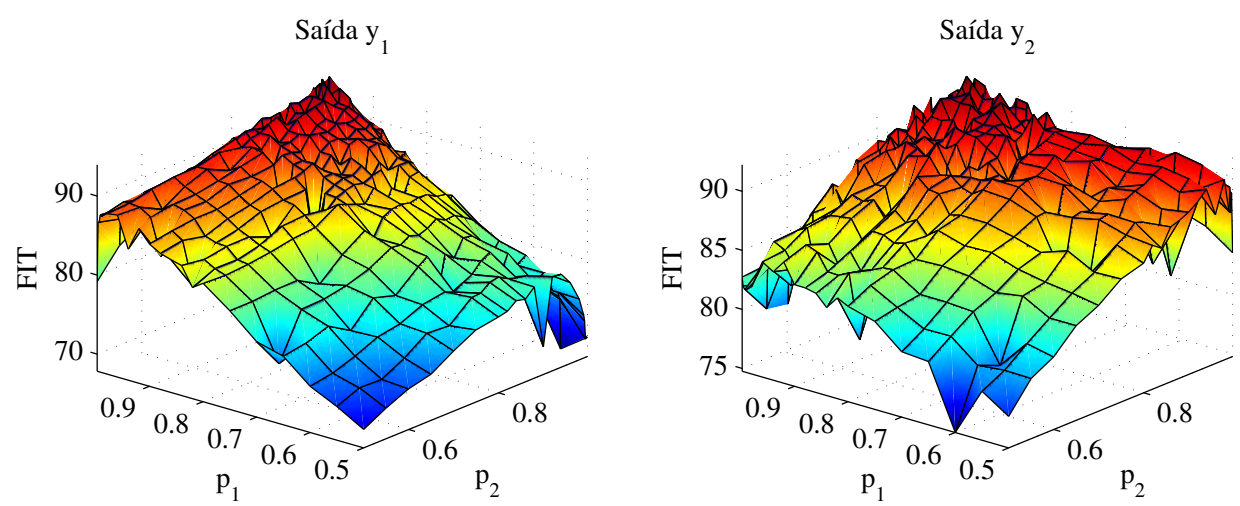

Fonte: Autor.

A Figura 6.14 apresenta o contorno da média geométrica dos índices FIT médios das saídas $y_{1}$ e $y_{2}$, na qual os maiores valores ocupam uma pequena região para valores de: $0,9 \leq p_{1} \leq 0,996$ e $0,94 \leq p_{2} \leq 0,996$.

Figura 6.14: Contorno da média geométrica $\overline{F I T}_{y}$ das saídas $y_{1}$ e $y_{2}$.

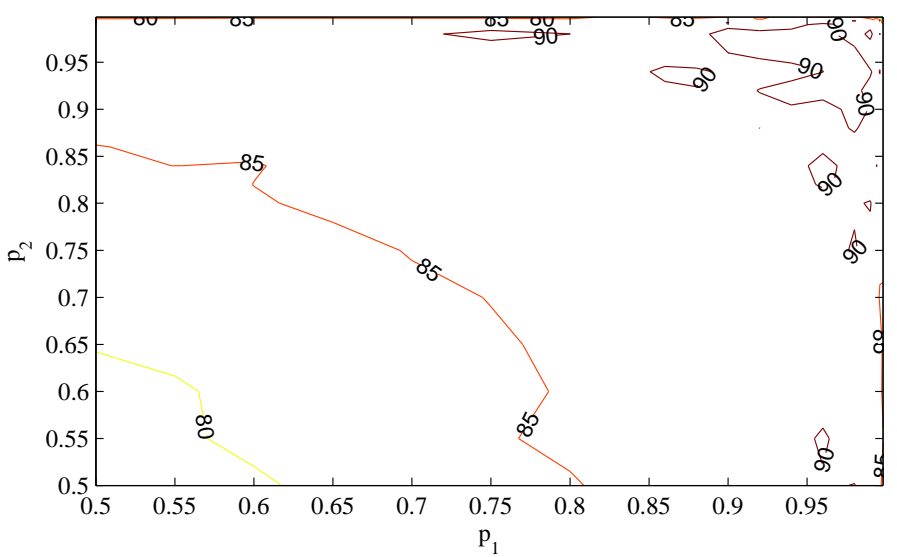

Fonte: Autor. 
Neste caso também são apresentados os resultados dos índices $\overline{F I T}$ da resposta ao degrau de cada par $y_{i} / u_{i}$ na Figura 6.15. Para cada par $y_{i} / S P_{i}$, os índices $\overline{F I T}$ vão crescendo com o aumento de cada probabilidade de não-chaveamento $p_{i}$ correspondente à entrada $S P_{i}$ respectiva, apesar do resultado ter uma certa semelhança com o apresentado em malha aberta, neste caso a dependência da frequência do sinal $S P_{i}$ no $\overline{F I T}_{y_{i} / S P_{i}}$ é mais acentuada, implicando em superfícies quase planas com inclinação similar ao longo de $p_{i \pm 1}$.

Figura 6.15: $\overline{F I T}$ das validações das respostas ao degrau de $y_{i} / u_{i}$.
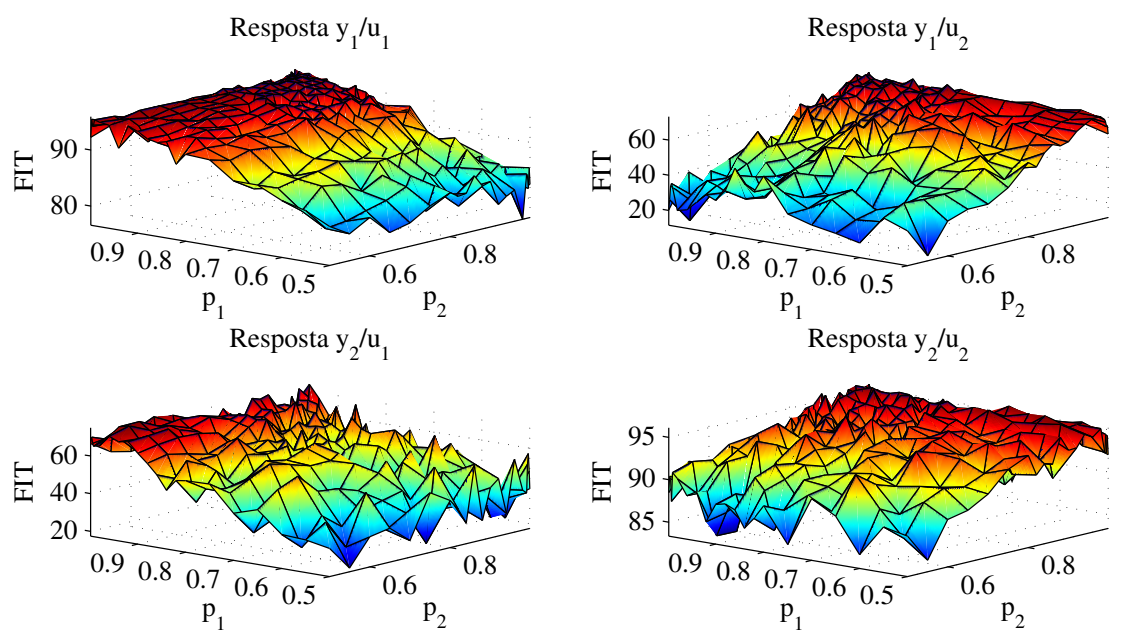

Fonte: Autor.

Também foi observado que, diferentemente do caso em malha aberta, surgem problemas para identificar as funções de transferência da diagonal secundária com valores próximos de $20 \%$ para valores de $p_{i}$ baixos e próximos de $60 \%$ quando $p_{i} \rightarrow 1$, isto ocorre pela ação do controlador, a qual tenta eliminar a interação entre as variáveis.

A Figura 6.16 apresenta os valores da média geométrica dos índices $\overline{F I T}$ das quatro respostas $y_{i} / S P_{i}$, onde os maiores valores se encontram para uma pequena região $0,88 \leq p_{1} \leq 0,98$ e $0,86 \leq p_{2} \leq 0,998$. Isto é diferente dos resultados em malha aberta, onde a região abarca uma grande parte dos pontos testados.

Figura 6.16: Média geométrica $\overline{F I T}_{y / u}$.

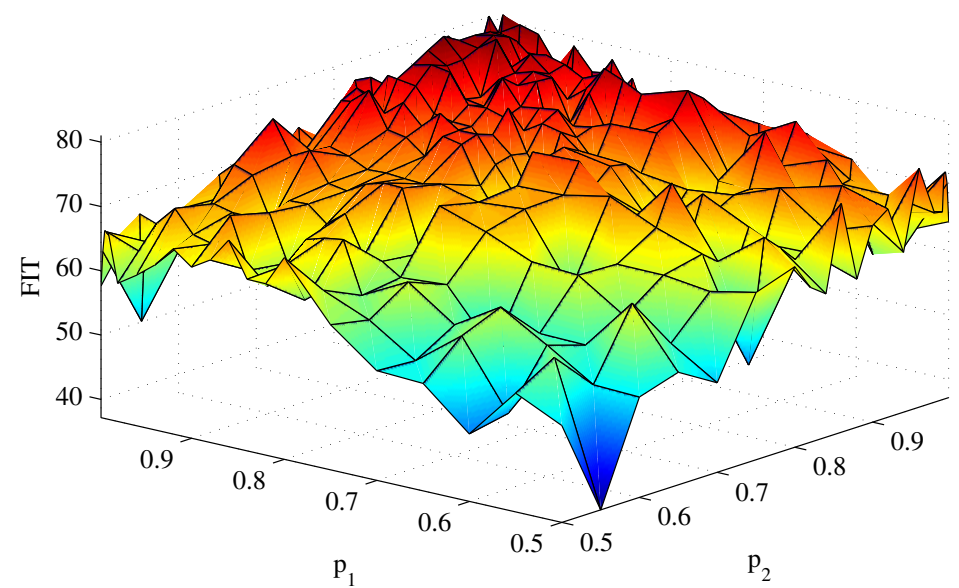

Fonte: Autor. 
Finalmente, é apresentada a superfície da média geométrica dos índices $\overline{F I T}$ das validações cruzadas das saídas e as validações das respostas ao degrau, $\overline{F I T}_{T}$ na Figura 6.17. Os resultados apresentam uma forma similar à apresentada na Figura 6.16 .

Figura 6.17: Média geométrica entre os FIT das respostas ao degrau e validação cruzada, $\overline{F I T}_{T}$.

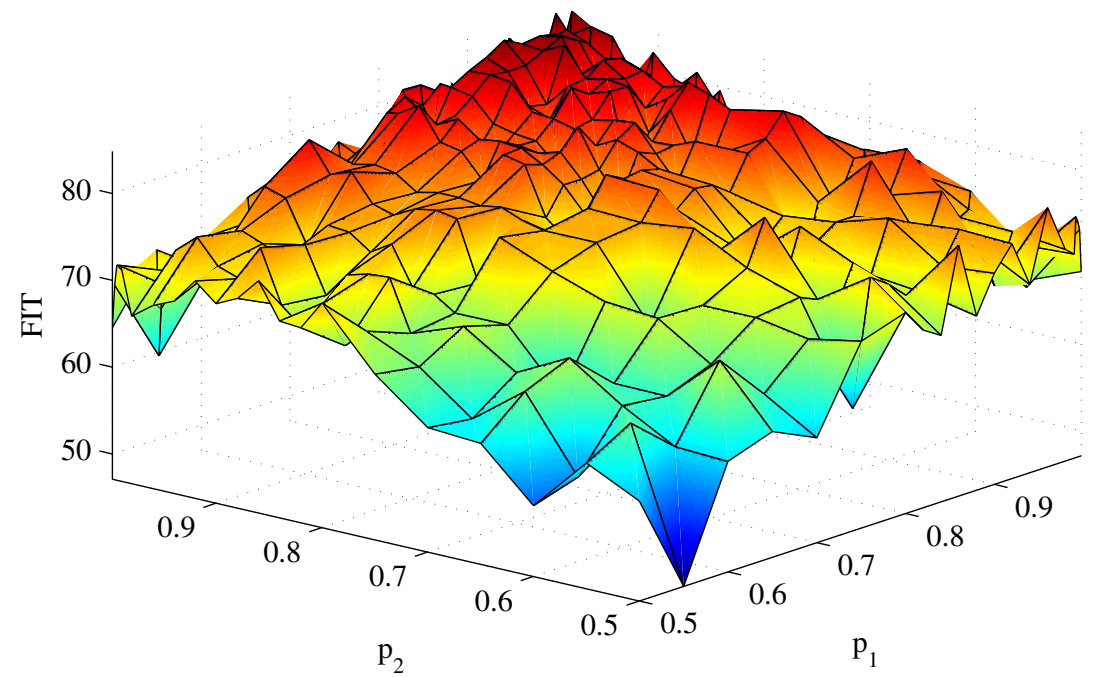

Fonte: Autor.

Em malha fechada os melhores resultados do $\overline{F I T}_{T}$ acontecem quando $p_{1}>0,86$ e $0,88<p_{2}<0,996$ com o ponto mais alto em $p_{1}=0,996$ e $p_{2}=0,98$ e um valor de $\overline{F I T}_{T}=84,856 \%$. Como pode ser observado na Figura 6.18, estes valores de $p_{i}$ são maiores que os obtidos em malha aberta. Também foram considerados os valores de $p_{i}$ com FIT $\geq 83 \%$ e calculada a média das $p_{i}, \bar{p}_{1}=0,9682 \pm 0,0190$ e $\bar{p}_{2}=0,969 \pm 0,0287$.

Figura 6.18: Contorno da superfície do $\overline{F I T}_{T}$ da Figura 6.17.

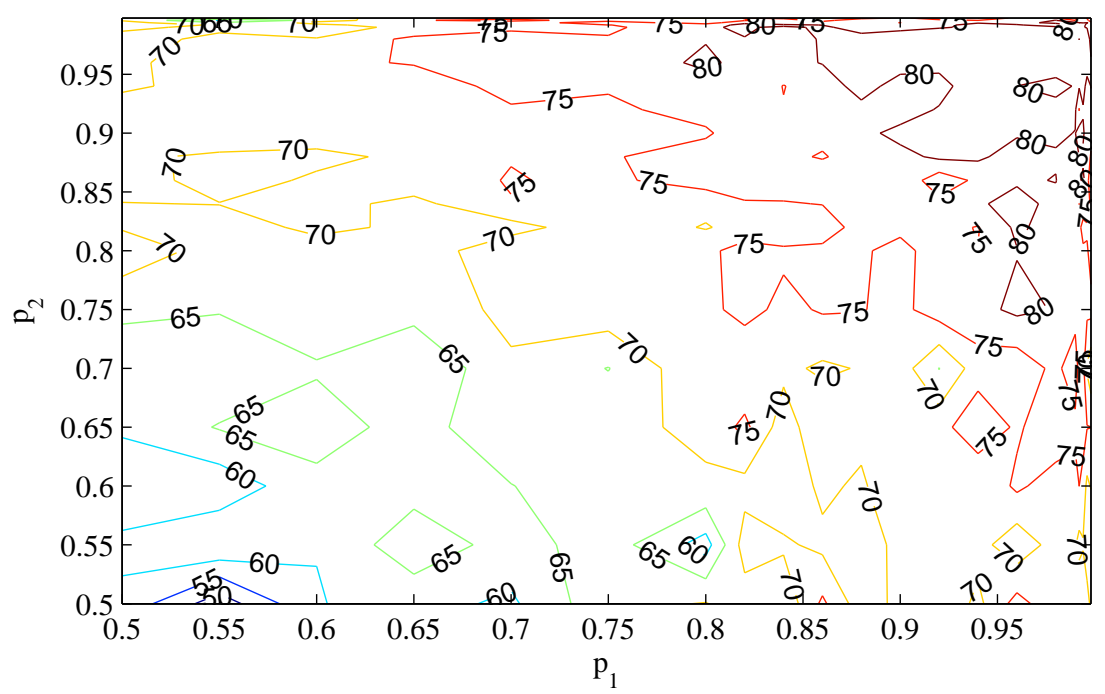

Fonte: Autor. 


\section{Identificação direta do processo - GBN}

O último caso analisado é a identificação direta do processo, a qual é feita usando o sinal de controle como a entrada do sistema. Esta análise é feita para observar a influência da frequência dos sinais de setpoint sobre a qualidade do modelo de processo identificado. Cabe lembrar que o sinal $u(t)$ é a saída do controlador PI.

Como exposto nos casos anteriores, são observadas as respostas dos índices $\overline{F I T}_{y_{i}}$ individuais das saídas $y_{i}$ (Figura 6.19), as respostas dos índices $\overline{F I T}_{y_{i} / u_{i}}$ (Figura 6.20 ) e a média geométrica $\overline{F I T}_{T}$ de todas as respostas (Figura 6.21).

Figura 6.19: $\overline{F I T}_{y_{i}}$ das validações cruzadas das saídas $y_{1}$ e $y_{2}$.
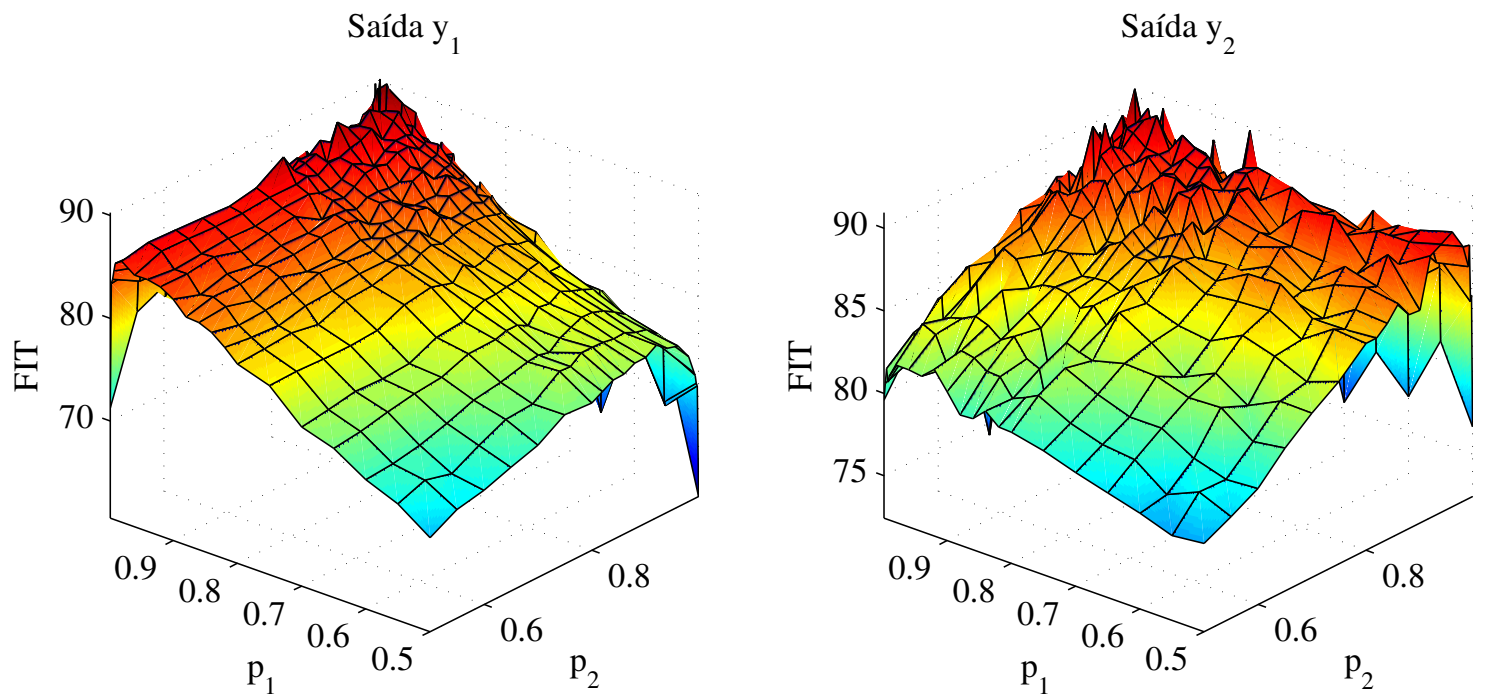

Fonte: Autor.

Figura 6.20: $\overline{F I T}_{y_{i} / u_{i}}$ da validação da resposta ao degrau.
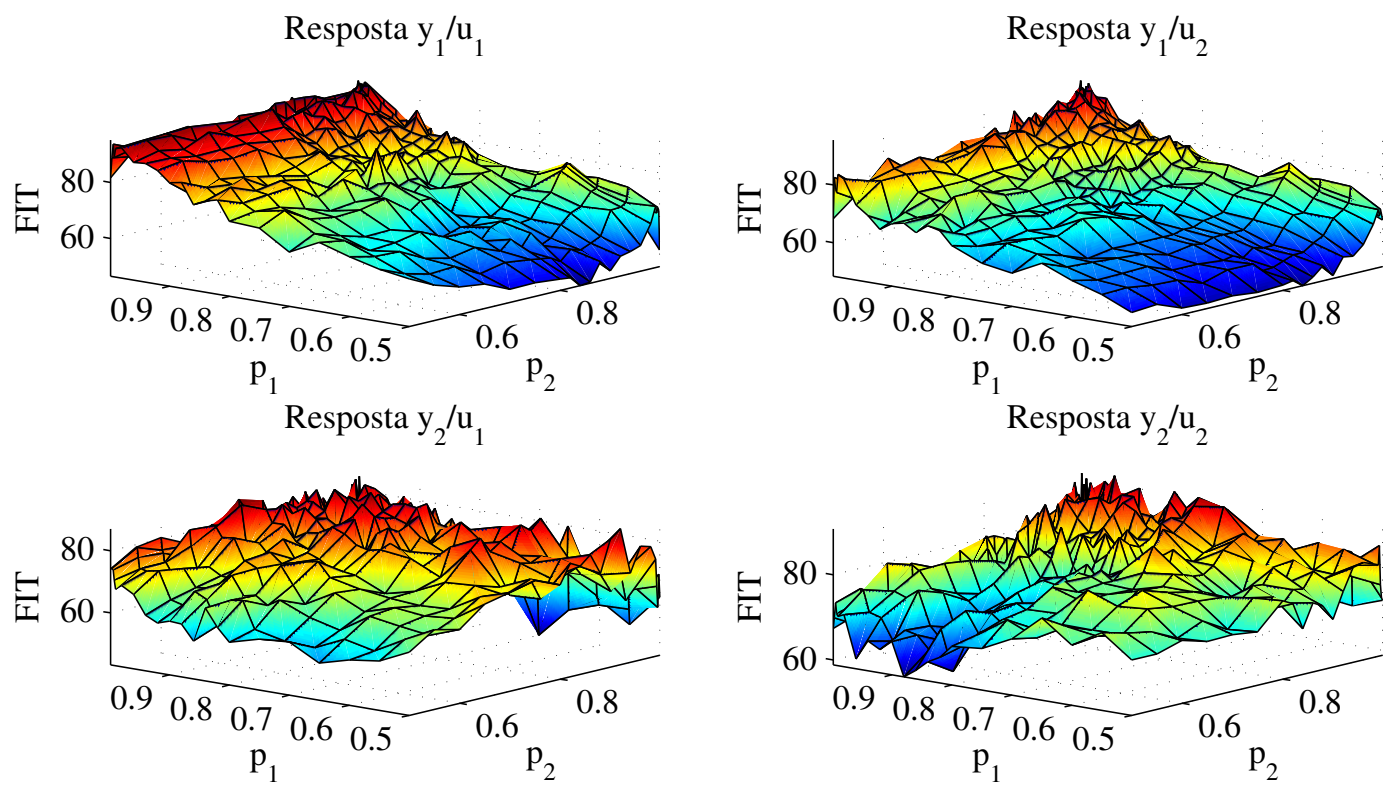

Fonte: Autor. 
Os resultados apresentados nas Figuras 6.19 e 6.20 são similares aos obtidos nas Figuras 6.13 e 6.15 . As superfícies possuem uma forma similar, com a pequena diferença de que as respostas $y_{i} / u_{i}$ da diagonal secundária foram melhor identificadas.

Figura 6.21: Média geométrica $\overline{F I T}_{T}$.

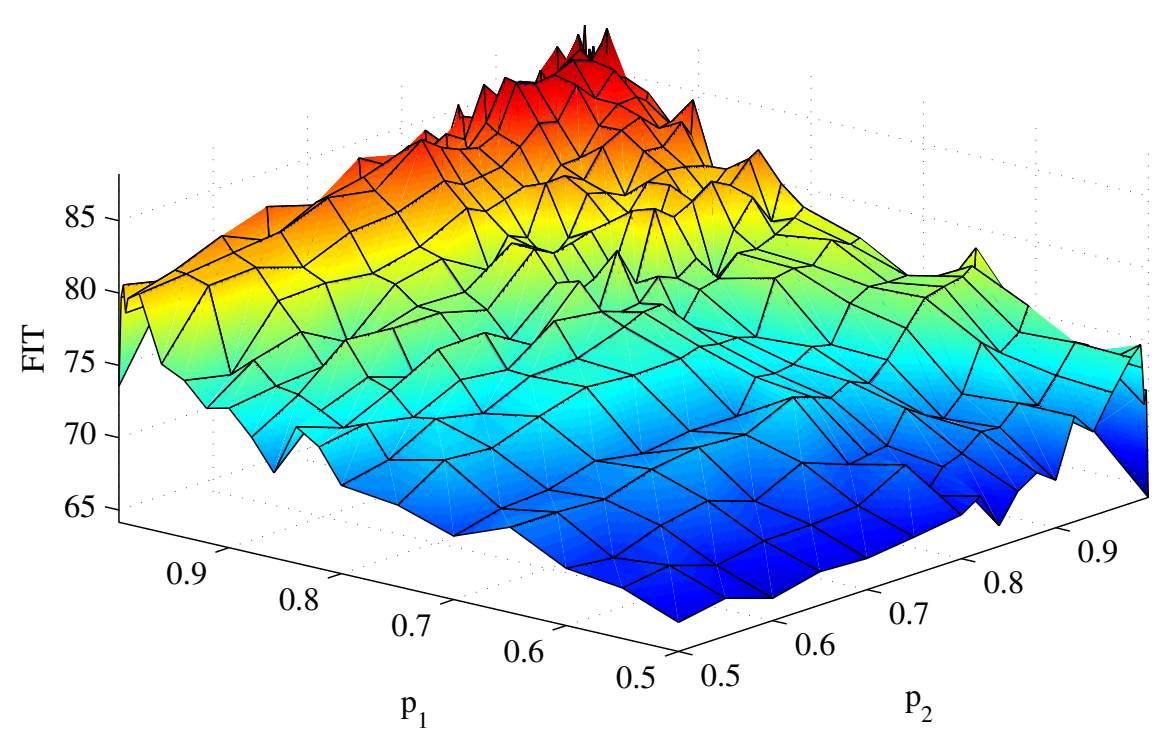

Fonte: Autor.

Da Figura 6.21 e 6.22 observa-se a região com os maiores índices $\overline{F I T}$, essa região esta delimitada por $0,94 \leq p_{1} \leq 0,994$ e $p_{2} \geq 0,88$. Esta região tem uma área menor, sobretudo pela diminuição da faixa de $p_{1}$. O ponto mais alto com um $\overline{F I T}=88,237 \%$ foi obtido para $p_{1}=0,994$ e $p_{2}=0,998$, estes valores de $p_{i}$ são maiores que os obtidos tanto na identificação em malha aberta como na identificação do processo em malha fechada. Considerando-se os valores de $p_{i}$ com FIT $\geq 86 \%$ foi calculada a média das $p_{i}$, com resultados $\bar{p}_{1}=0,9629 \pm 0,038$ e $\bar{p}_{2}=0,9887 \pm 0,0071$.

Figura 6.22: Contorno da média geométrica $\overline{F I T}_{T}$.

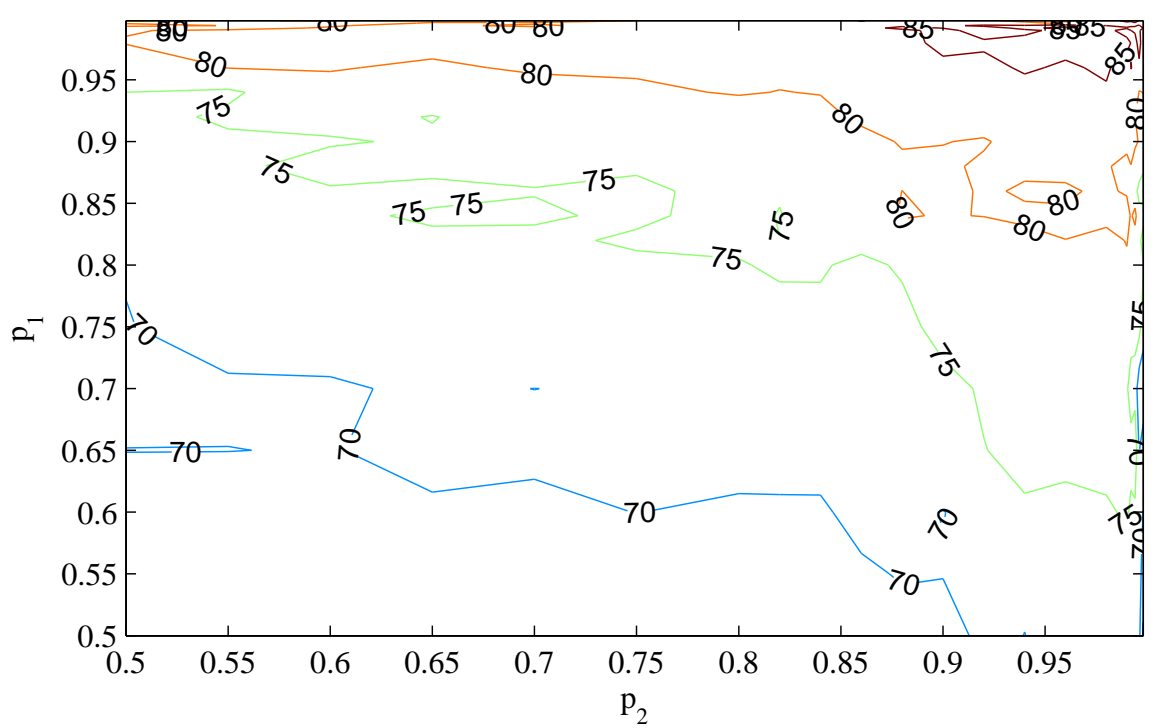

Fonte: Autor. 


\subsubsection{Forma analítica - GBN}

Para os sinais GBN pode ser calculado analaticamente o valor das probabilidades de não-chaveamento dos dois sinais de excitação baseado nas informações da planta, tanto em malha aberta como fechada, como é apresentado a seguir:

\section{Cálculos em malha aberta}

Considerando os valores de $\tau$ em malha aberta:

$$
\tau=\left[\begin{array}{ll}
4,572 & 1,807 \\
2,174 & 1,801
\end{array}\right]
$$

A análise dos valores de $\tau$ para cada $p_{i}$ deve ser feita por cada coluna a partir da Equação (5.6), com $\beta_{s}=5$ e $\alpha_{s}=1$. Assim, são obtidas as duas faixas de frequência:

$$
\begin{gathered}
w_{L}=0,0437 \leq w_{1} \leq 0,46=w_{H} \rightarrow p_{1} \\
w_{L}=0,1107 \leq w_{2} \leq 0.5552=w_{H} \rightarrow p_{2}
\end{gathered}
$$

com as faixas calculadas em (6.5) são obtidos os valores de $p_{1}$ e $p_{2}$, a partir da Equação (5.8):

$$
\begin{aligned}
& p_{1}=0,9860 \\
& p_{2}=0,9661
\end{aligned}
$$

Em (6.6) são observados valores maiores que os obtidos experimentalmente, embora façam parte da região dos pontos máximos com $p_{i} \approx \bar{p}_{i}+\sigma_{p_{i}}$.

\section{Cálculos em malha fechada}

Considerando os valores de $\tau$ em malha fechada:

$$
\tau=\left[\begin{array}{cc}
1,87 & 2,3 \\
2,3 & 1,64
\end{array}\right]
$$

Em malha fechada as dinâmicas de maior interesse são as pertencentes à diagonal principal, portanto, foram considerados apenas os valores da diagonal principal de $\tau$ para o cálculo de $p_{i}$. Considerando isto, são obtidas os valores de $w$ :

$$
\begin{aligned}
& w_{1}=0,1070 \rightarrow p_{1} \\
& w_{2}=0,1220 \rightarrow p_{2}
\end{aligned}
$$

Com os valores de $w$ obtidos em (6.7) são obtidos os valores de $p_{1}$ e $p_{2}$ a partir da Equação (5.8) modificada para um valor só de frequência (CHEN; YU, 1997):

$$
\begin{aligned}
& p_{1}=0,9894 \\
& p_{2}=0,9879
\end{aligned}
$$

Em (6.8) foram obtidos valores que fazem parte da faixa encontrada experimentalmente, tanto do modelo que inclui os controladores, como o modelo da planta, validando assim a forma analítica do cálculo das probabilidades de não-chaveamento para este sistema. 


\subsubsection{Resultados em Malha aberta - PRBS}

O estudo realizado com sinais GBN também foi desenvolvido para sinais PRBS usando as mesmas considerações de ruído, com um $\mathrm{SNR}=10$, e os tempos de bit $T_{b 1}$ e $T_{b 2}$ variando na faixa de [1 44] tempos de amostragem. Na Figura 6.23 são apresentados os gráficos do índice $\overline{F I T}$ das validações cruzadas para cada uma das saídas $y_{1}$ e $y_{2}$ em função dos tempos de bit. A média geométrica das saídas $y_{1}$ e $y_{2}$ também foi considerada e apresentada na Figura 6.24.

Figura 6.23: $\overline{F I T}$ das validações cruzadas dos saídas $y_{1}$ e $y_{2}$ em função de $T b_{1}$ e $T b_{2}$.

Saída $\mathrm{y}_{1}$

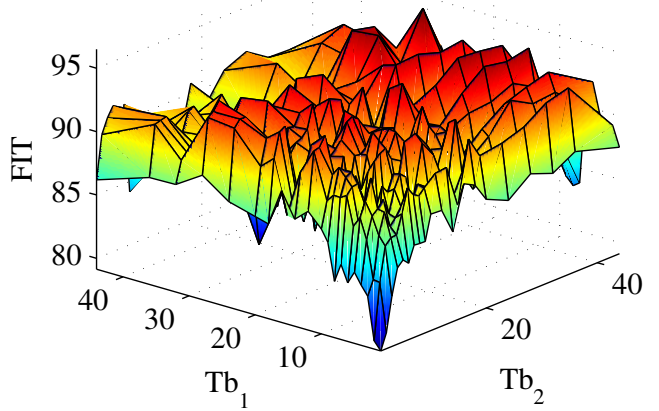

Fonte: Autor.

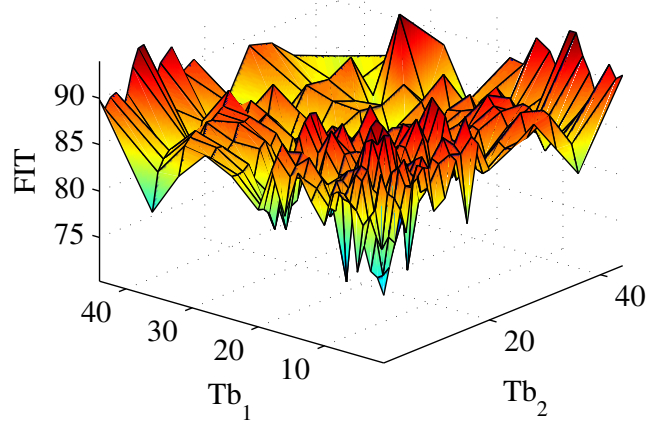

Saída $y_{2}$

Figura 6.24: Média geométrica $\overline{F I T}_{y}$ em função de $T b_{1}$ e $T b_{2}$.

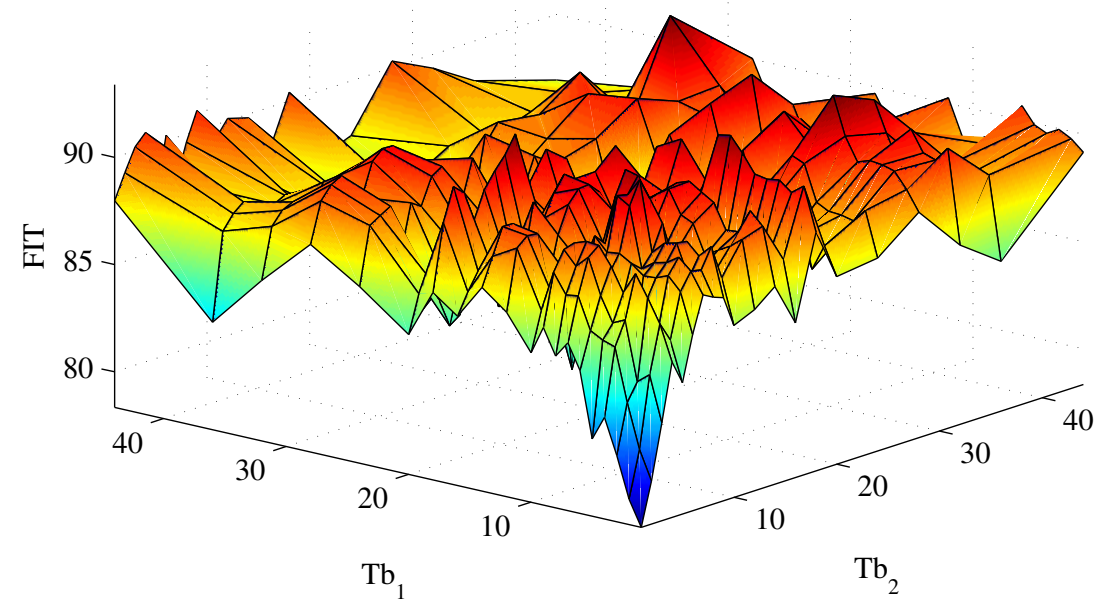

Fonte: Autor.

Da Figura 6.23 foi observado que para a saída $y_{1}$ os resultados são maiores que $85 \%$ a partir de $T_{b 1} \geq 3$ e $T_{b 2} \geq 3$, e, para $T_{b i} \geq 6$ os resultados estão perto de $90 \%$. Para os resultados da saída $y_{2}$ a partir de $T_{b 1} \geq 4$ e $T_{b 2} \geq 4$ o $\overline{F I T}$ foi maior que $85 \%$ e para $T_{b i} \geq 7$ os resultados oscilaram ao redor de $90 \%$.

Dos resultados da Figura 6.24 foi obtido o máximo valor do $\overline{F I T}_{y}$ igual a 93,38\% usando $T_{b 1}=8$ e $T_{b 2}=28$, porém nos resultados pode ser observada uma região em que 
a identificação apresenta resultados similares ao ponto máximo do gráfico. A partir de $T_{b 1} \geq 4$ e $T_{b 2} \geq 4$ os resultados são maiores que $85 \%$ e para $T_{b i} \geq 7$ os resultados estão perto de $90 \%$, valores para os quais a identificação pode ser considerada satisfatória.

Após observar a influência da frequência de cada um dos sinais nos índices da validação cruzada dos sinais de saída $y_{1}$ e $y_{2}$, foi observado o efeito de $T_{b}$ em cada uma das respostas $y_{i} / u_{i}$, estes resultados são apresentados na Figura 6.25.

Figura 6.25: $\overline{F I T}$ da validação da resposta ao degrau de $y_{1} / u_{1}, y_{1} / u_{2}, y_{2} / u_{1}$ e $y_{2} / u_{2}$.
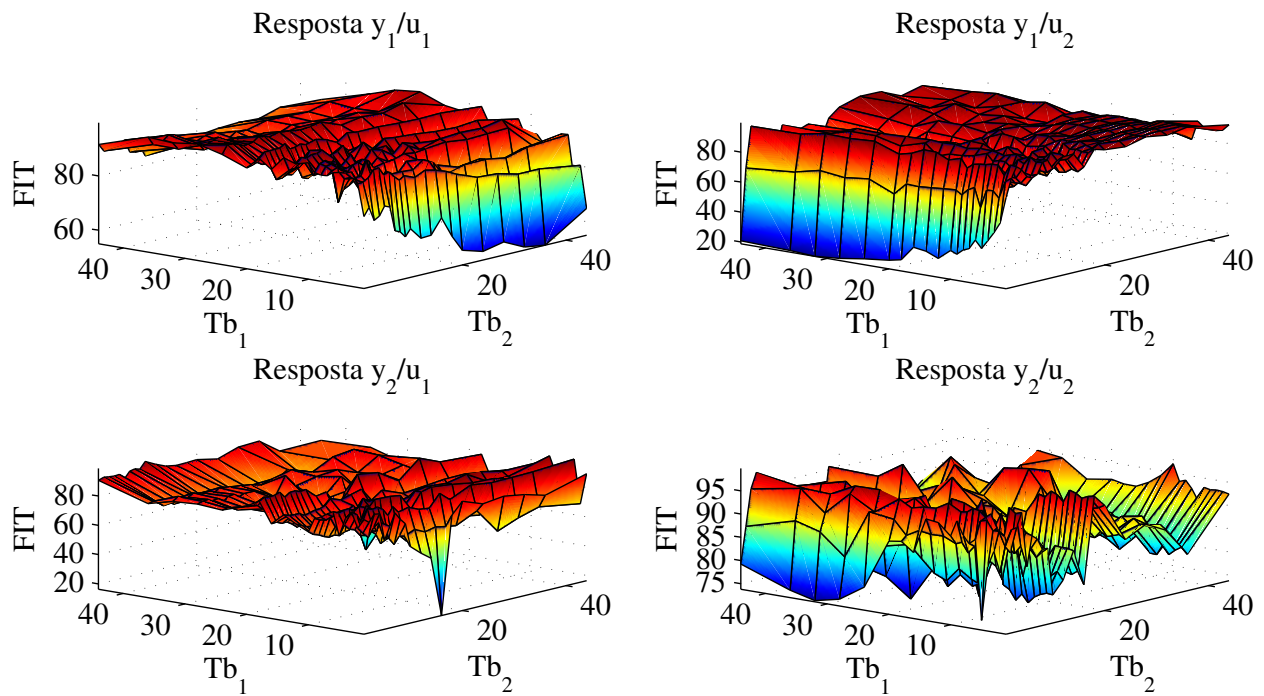

Fonte: Autor.

Da superfície plotada para cada $y_{i} / u_{i}$ os valores $\overline{F I T}$ vão crescendo com o aumento de cada tempo de bit $T_{b i}$ correspondente a cada entrada $u_{i}$. Neste caso, diferentemente dos resultados observados usando sinais GBN na Figura 6.9, as respostas $y_{i} / u_{i}$ variam mais em função da sua própria entrada. Para observar o efeito conjunto nas respostas $y_{i} / u_{i}$ foi calculada a média geométrica entre todas as respostas $y_{i} / u_{i}$, esta superfície é apresentada na Figura 6.26.

Figura 6.26: Média geométrica $\overline{F I T}_{y_{i} / u_{i}}$ em função de $T_{b 1}$ e $T_{b 2}$.

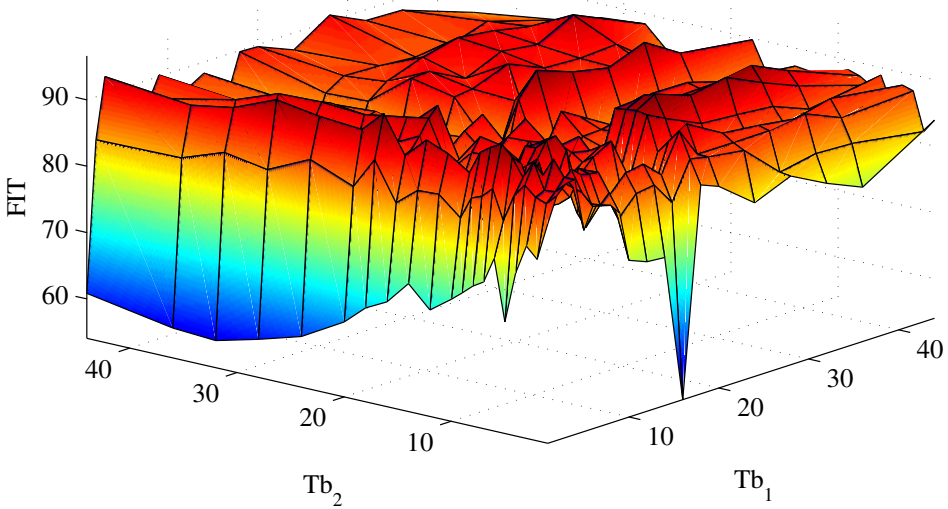

Fonte: Autor. 
Da superfície apresentada na Figura 6.26 observa-se que para a maioria dos pares $T_{b 1}$ e $T_{b 2}$ a média geométrica oscilou entre 85 e $90 \%$, excetuando os pontos em que $T_{b 1} \rightarrow 1$ e $T_{b 2} \rightarrow 1$. É observado também que $T_{b 2}$ afetou mais a média geométrica para valores próximos de 1, onde seus resultados foram os menores da superfície. Finalmente foi calculada a média geométrica total $\overline{F I T}_{T}$ dos índices de validação cruzada das saídas $y_{i}$ e das respostas ao degrau $y_{i} / u_{i}$.

Figura 6.27: Média geométrica $\overline{F I T}_{T}$.

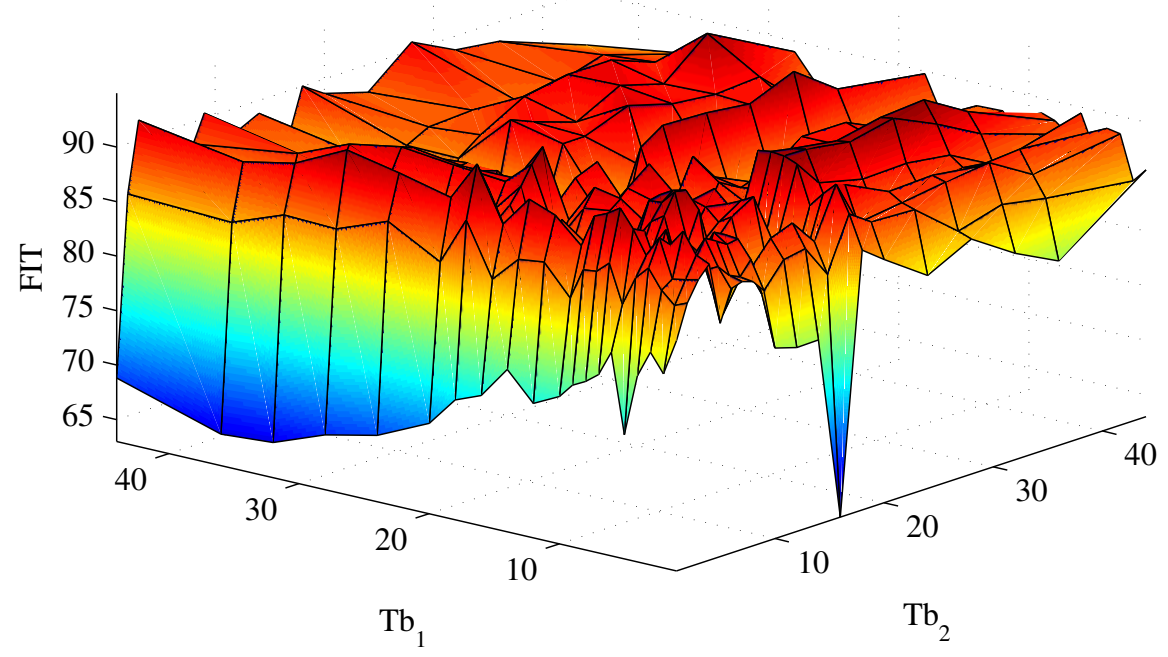

Fonte: Autor.

Da média geométrica de todas as respostas (Figura 6.27) pode ser observada uma forma similar à obtida na Figura 6.26, onde basicamente para valores de $T_{b 1}$ e $T_{b 2}$ maiores que 1 o $\overline{F I T}$ foi maior que $85 \%$, com valores de $T_{b i}$ maiores que 4 os resultados oscilaram entre 85 e 90\%. Portanto, é difícil definir uma área ótima, já que foram observadas pequenas regiões com $\overline{F I T}$ maiores que $90 \%$ em diferentes posições como observadona Figura 6.27.

\subsubsection{Resultados em Malha Fechada - PRBS}

\section{Sistema em malha fechada - PRBS}

Na Figura 6.28 são apresentados os resultados dos índices $\overline{F I T}$ da validação cruzada de cada uma das saídas $y_{i}$. Em comparação com a Figura 6.23 são observados melhores resultados. A inclinação das superfícies $y_{i}$ é mais acentuada quando $T_{b i}$ tende a 1, este efeito devido ao desacoplamento das variáveis. 
Figura 6.28: $\overline{F I T}$ da validação cruzada das saídas $y_{1}$ e $y_{2}$ mudando $T_{b 1}$ e $T_{b 2}$.
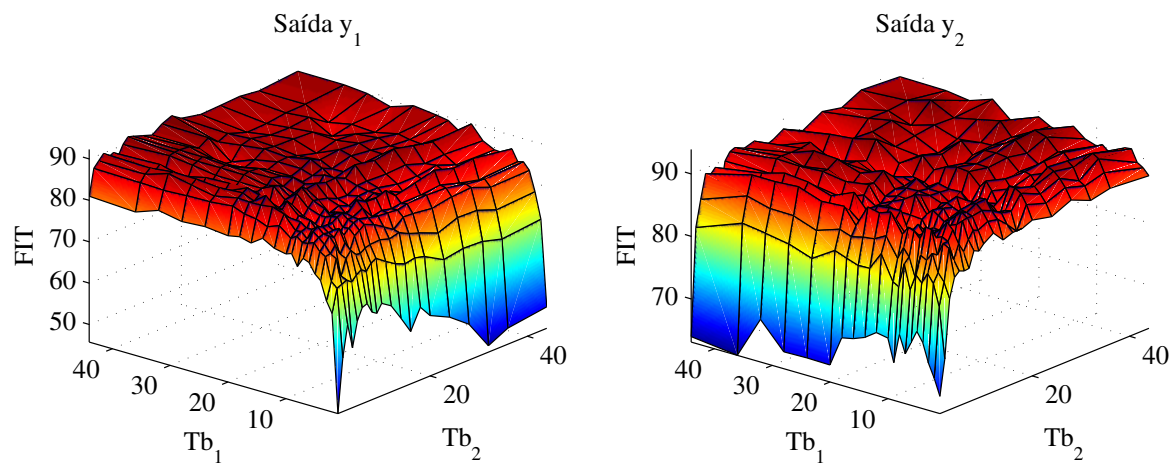

Fonte: Autor.

A Figura 6.29 apresenta o contorno da média geométrica do índice $\overline{F I T}$ das validações cruzadas das saídas $y_{1}$ e $y_{2}$ na qual para valores de $T_{b} \geq 4$ o $\overline{F I T}$ foi maior que $85 \%$, e para $T_{b 1} \geq 9$ e $T_{b 2} \geq 12$ os resultados foram maiores que $90 \%$.

Figura 6.29: Contorno da média geométrica $\overline{F I T}_{y}$ entre as validações cruzadas das saídas $y_{1}$ e $y_{2}$.

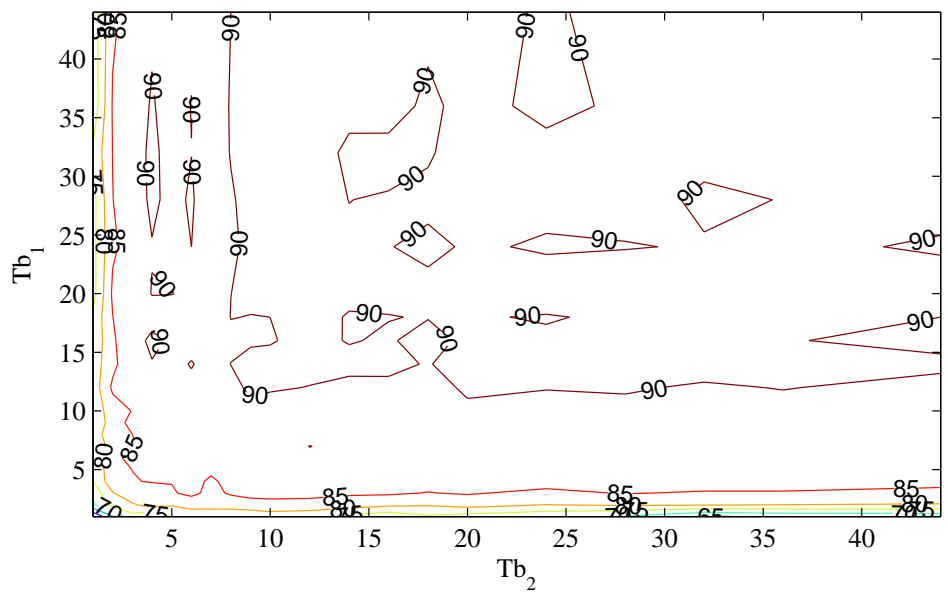

Fonte: Autor.

Neste caso também são apresentados os resultados dos índices $\overline{F I T}$ da validação da resposta ao degrau de cada par $y_{i} / u_{i}$ na Figura 6.30. Para cada par $y_{i} / S P_{i}$, os índices $\overline{F I T}$ vão crescendo com o aumento de cada tempo de bit $T_{b i}$ correspondente a cada setpoint $S P_{i}$, da mesma maneira que no caso da malha aberta. 
Figura 6.30: $\overline{F I T}$ da validação da resposta ao degrau de $y_{i} / S P_{i}$.
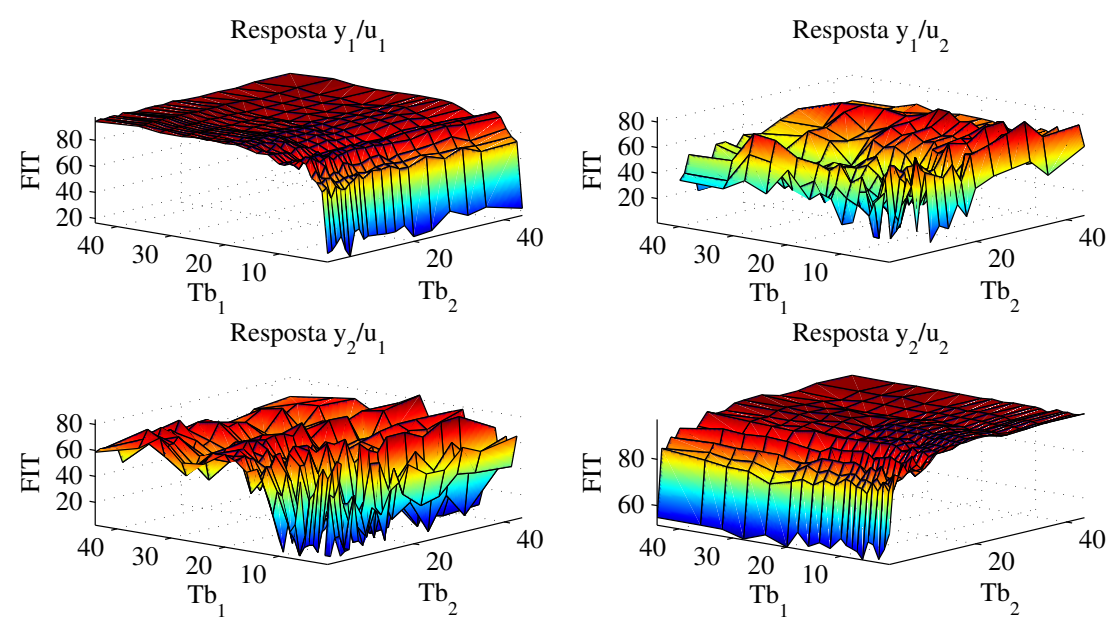

Fonte: Autor.

Também foi observado que diferentemente do caso em malha aberta e como foi observado usando sinais GBN, surgem problemas para identificar as funções de transferência da diagonal secundária com valores próximos de $20 \%$ para valores de $T_{b i}$ baixos e próximos de $60 \%$ para $T_{b i} \rightarrow 44$, lembrando que existe a ação do controlador, a qual tenta eliminar a interação entre as variáveis. Os valores obtidos nas superfícies da diagonal secundária foram similares aos obtidos usando sinais GBN, porém, nas respostas da diagonal principal foi observado que praticamente a resposta é dependente só da frequência do sinal de referência $S P_{i}$ associado a cada saída $y_{i}$, sem influência do outro sinal de referência.

A Figura 6.31 apresenta os valores da média geométrica $\overline{F I T}$ das quatro validações ao degrau $y_{i} / S P_{i}$, diferentemente dos resultados obtidos com sinais GBN, os maiores valores se encontram para uma região com $T_{b 1}$ e $T_{b 2}$ maiores que 20, diferentemente dos resultados em malha aberta onde existem várias regiões dispersas. Cabe dizer que a resposta da média geométrica $\overline{F I T}_{G}$ foi fortemente penalizada pelas respostas da diagonal secundária onde a identificação apresentou maior dificuldade.

Figura 6.31: Média geométrica $\overline{F I T}_{y_{i} / S P_{i}}$ das quatro validações ao degrau $y_{i} / S P_{i}$.

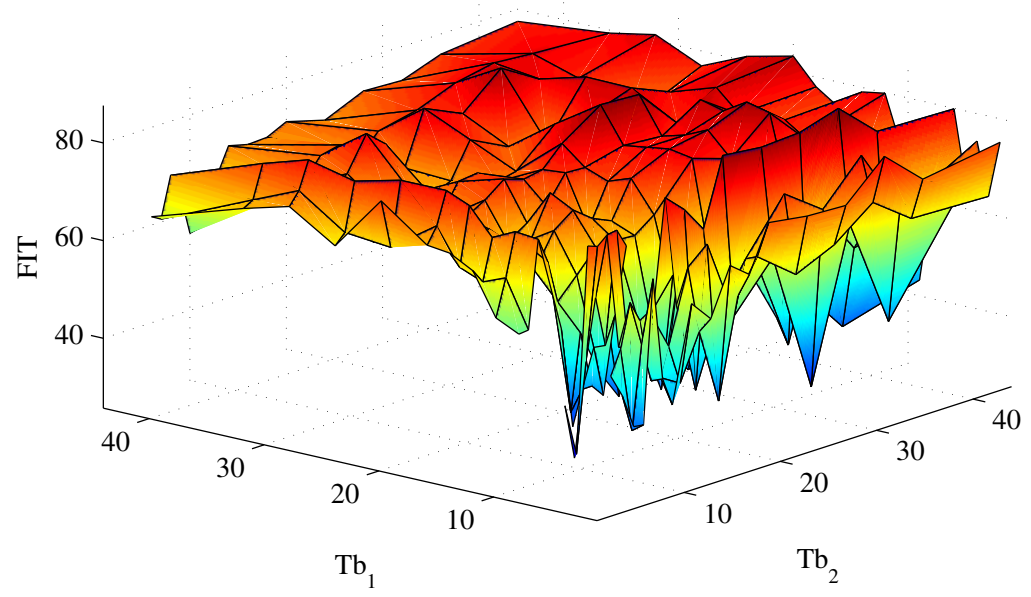

Fonte: Autor. 
Finalmente, foi calculada a média geométrica total, $\overline{F I T}_{T}$, das validações cruzadas das saídas $y_{i}$ e das respostas $y_{i} / S P_{i}$, essa superfície é plotada na Figura 6.32. Os resultados apresentam uma superfície quase igual à apresentada na Figura 6.31.

Figura 6.32: Média geométrica $\overline{F I T}_{T}$.

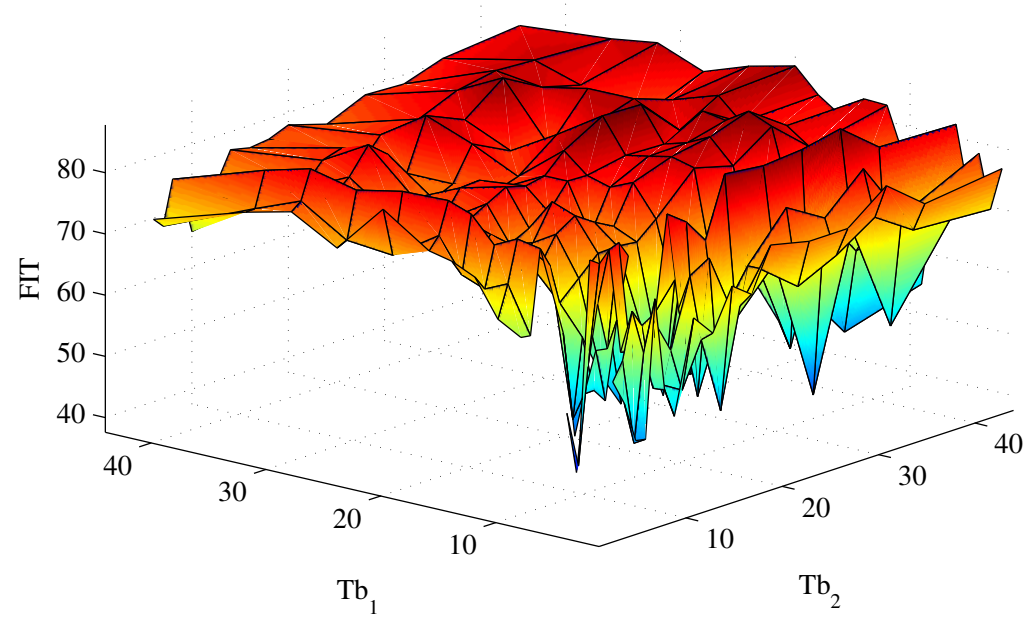

Fonte: Autor.

Em malha fechada os melhores resultados da média geométrica total acontecem em dois pontos, com tempos de bit $T_{b 1}=20$ e $T_{b 2}=24$ e $T_{b 1}=20$ e $T_{b 2}=28 \mathrm{com} \mathrm{um}$ $\overline{F I T}_{T} \approx 86,8 \%$. Ainda assim, existem outros pontos onde o resultado foi maior que $85 \%$, um deles em $T_{b 1}=28$ e $T_{b 2}=32$ e o outro em $T_{b 1}=32$ e $T_{b 2}=14$. Em geral, para $T_{b 1} \geq 20$ e $T_{b 2} \geq 14$ o resultado foi maior que $80 \%$. 


\section{Identificação direta do processo - PRBS}

Por último, o caso em que a identificação do sistema em malha fechada foi feita identificando com o sinal de controle como a entrada do sistema para obter o modelo da planta. Neste caso são apresentadas as mesmas respostas individuais para $\overline{F I T}_{y_{i}}$ (Figura 6.33), as respostas $\overline{F I T}_{y_{i} / u_{i}}$ (Figura 6.34) e a média geométrica de todas as respostas $\overline{F I T}_{T}$ (Figura 6.35).

Figura 6.33: Superfície de $\overline{F I T}_{y_{i}}$.
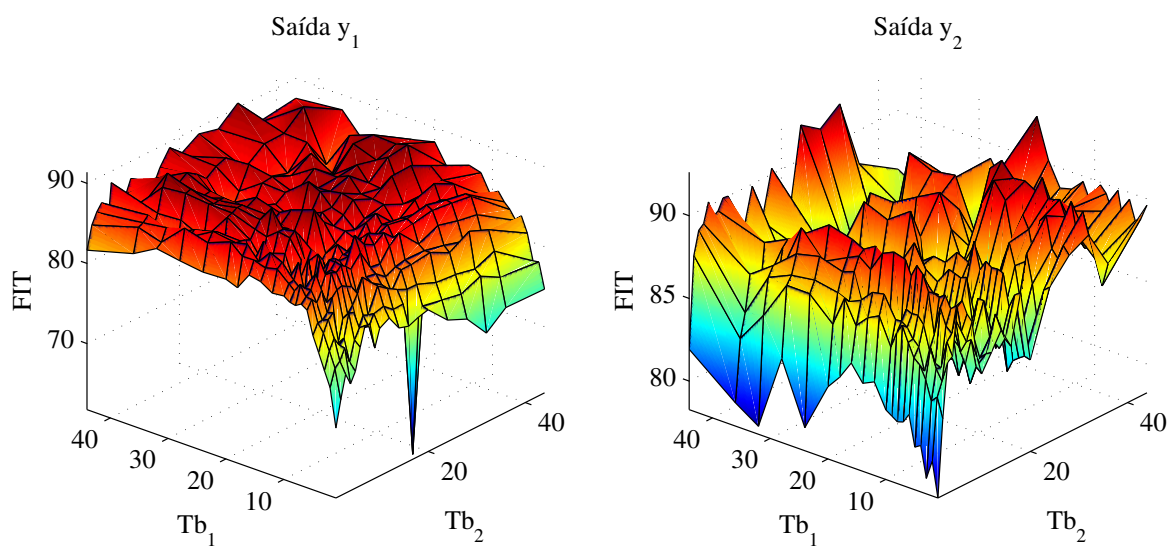

Fonte: Autor.

Figura 6.34: Superfície de $\overline{F I T}_{y_{i} / u_{i}}$.
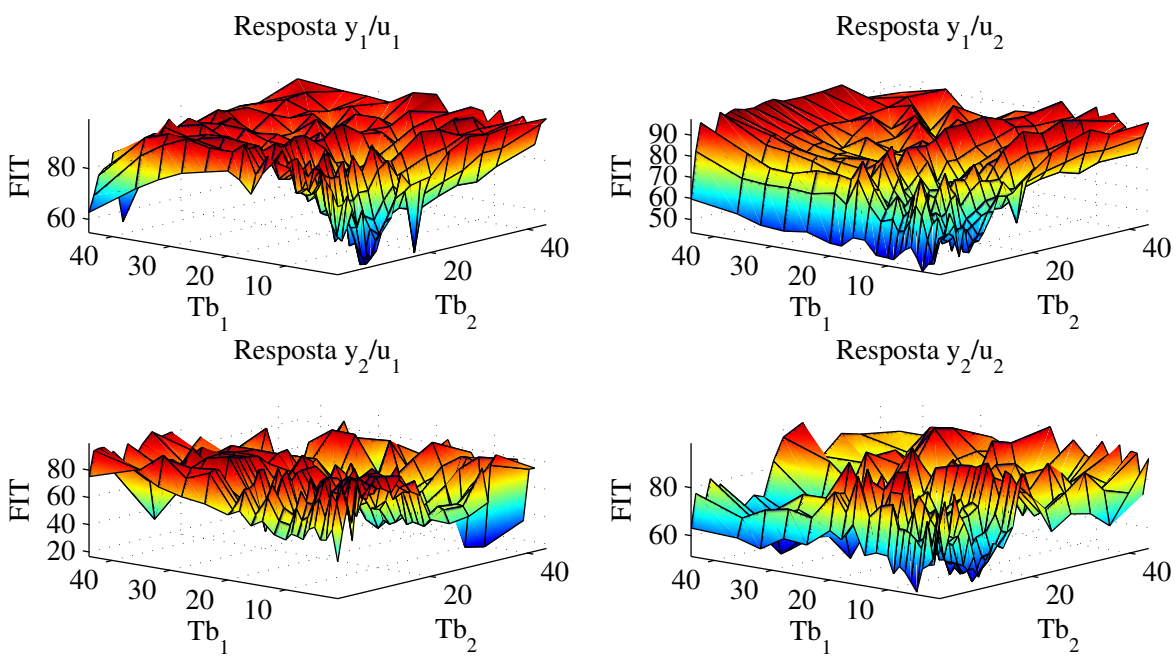

Fonte: Autor.

Os resultados apresentados nas Figuras 6.33 e 6.34 diferem um pouco dos obtidos nas Figuras 6.28 e 6.30, as superfícies correspondentes à saída $y_{1}$ apresentam uma forma similar, embora os pontos mínimos quando $T_{b 1} \rightarrow 1$ são maiores que os observados usando o sinal de referência para identificar o modelo em malha fechada. Com respeito à superfície correspondente à saída $y_{2}$ os resultados foram melhores identificando com o sinal de controle $u_{i}$ e também neste caso foi observado que o $\overline{F I T}$ diminui quando $T_{b 2}$ tende a 1 , porém, quando $T_{b 2}$ é maior ou igual a 4 , os valores são maiores que $85 \%$ mas estes oscilam entre este valor e $90 \%$, que a diferencia 
do observado na Figura 6.28, onde a superfície oscilava em torno de $90 \%$.

Por outro lado, deve ser ressaltado o fato de que as funções de transferência da diagonal secundária foram melhor identificadas, similar ao que havia ocorrido com sinais GBN, os $\overline{F I T}$ das funções de transferência da diagonal secundária foram próximos de $90 \%$.

Da Figura 6.35 são observadas duas regiões com os maiores índices FIT, essas regiões estão localizadas em: $\left[T_{b 1}=18, T_{b 2}=32\right]$ e a segunda ao redor dos pontos $\left[T_{b 1}=32, T_{b 2}=24\right]$ e $\left[T_{b 1}=36, T_{b 2}=28\right]$. Usando os pontos em que seus valores estiveram na faixa de $\overline{F I T}_{\text {max }}-3 \%$ foi calculada a média dos valores de $T_{b i}$, $\bar{T}_{b 1}=24 \pm 12$ e $\bar{T}_{b 2}=30 \pm 8$.

Figura 6.35: Média geométrica $\overline{F I T}_{T}$.

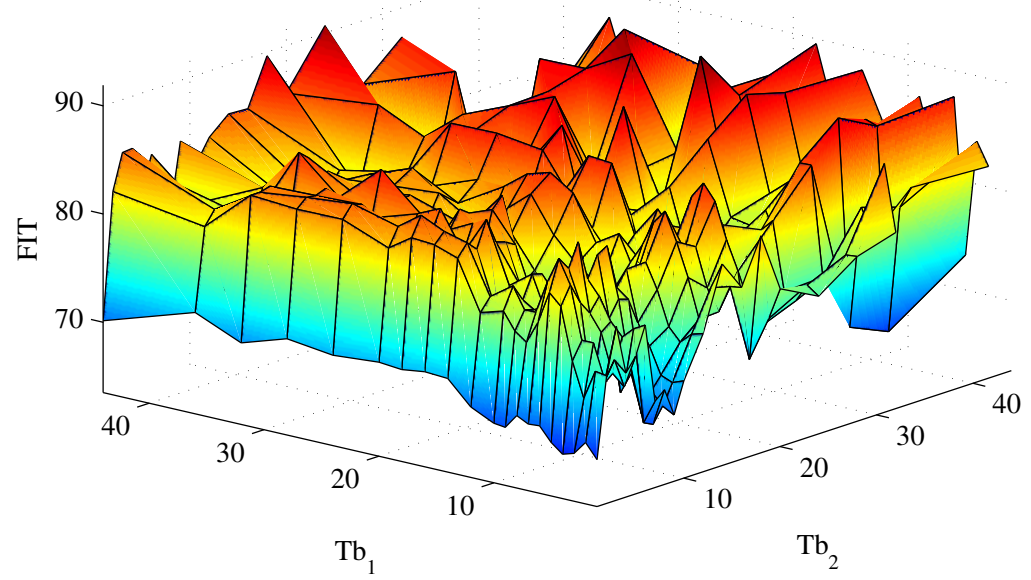

Fonte: Autor.

\subsubsection{Forma analítica - PRBS}

Para os sinais PRBS pode ser calculado analiticamente o valor dos tempos de bit dos dois sinais de excitação baseado nas informações da planta. Neste caso, diferentemente do caso com sinais GBN, não é necessário calcular a faixa de frequências. Isto porque as Equações (5.5) (AGUIRRE, 2007) e (5.7) (RIVERA; JUN, 2000) não precisam da informação explícita das faixas de $w$.

\section{Cálculos em malha aberta}

Considerando os valores de $\tau$ em malha aberta:

$$
\tau=\left[\begin{array}{ll}
4,572 & 1,807 \\
2,174 & 1,801
\end{array}\right]
$$

A análise dos valores de $\tau$ para cada $T_{b i}$ feita por cada coluna e com valor de $\beta_{s}=5$ e $\alpha_{s}=1$, resultam os valores de $T_{b 1}$ e $T_{b 2}$ a partir da Equação (5.7): 


$$
\begin{aligned}
& T_{b 1}=6 \\
& T_{b 2}=5
\end{aligned}
$$

Em (6.9) são observados valores que tiveram bons resultados obtidos experimentalmente. Portanto, a Equação (5.6) foi validada neste tipo de processo em malha aberta.

\section{Cálculos em malha fechada}

Considerando os valores de $\tau$ em malha fechada:

$$
\tau=\left[\begin{array}{cc}
1,87 & 2,3 \\
2,3 & 1,64
\end{array}\right]
$$

com valor de $\beta_{s}=3$ e $\alpha_{s}=2$ são obtidos os valores de $T_{b 1}$ e $T_{b 2}$, a partir da Equação (5.7):

$$
\begin{aligned}
& T_{b 1}=3 \\
& T_{b 2}=3
\end{aligned}
$$

Em (6.10) foram obtidos valores muito menores que os obtidos experimentalmente, isto pode ser atribuído a penalização feita pela dificuldade apresentada para identificar as funções de transferência da diagonal secundária.

A Equação (5.5) não foi usada neste processo devido a que os valores mínimos dos $\tau_{i}$ foram menores que 3 , portanto todos os resultados das faixas de $T_{b}$, tanto em malha aberta como em malha fechada, possuem como limite máximo um valor inferior a 1. 


\subsubsection{Coluna de Destilação}

As simulações dos experimentos conservaram as características usadas nos testes da seção anterior. As amplitudes dos sinais de entrada e setpoint correspondem a $\pm 4 \%$, $\pm 3 \%$ e $\pm 9 \%$ das restrições apresentadas na Tabela (4.2) (Figura 6.3), e a estrutura do modelo BJ seguindo a discretização da Equação (6.4) para malha aberta e a discretização correspondente para malha fechada com as ordens apresentadas na Tabela 6.5.

As condições operacionais e de perturbação da planta foram as mesmas usadas em (OGUNNAIKE et al., 1983), apresentadas na Tabela 4.3. Dos testes realizados na coluna de destilação serão apresentadas as médias geométricas totais das respostas, tal como no caso do reator de polimerização.

Os testes feitos para os diferentes valores de $p_{i}$ não consideraram o teste de Monte Carlo, mas foram testados uma vez em cada ponto. Isto devido ao grande tempo de computação consumido dada a maior complexidade do sistema em comparação com o reator de polimerização.

\subsubsection{Resultados em Malha aberta - GBN}

Na Figura 6.36 são apresentados os valores de $p_{i}$ da média geométrica dos valores FIT da validação cruzada das saídas $y_{1}, y_{2}$ e $y_{3}$, distribuídos em três faixas, como resultado da identificação em malha aberta da coluna de destilação. A maior resposta é obtida para os valores de $p_{1}=0,992, p_{2}=0,96$ e $p_{3}=0,992 \mathrm{com}$ um valor da média geométrica igual a $89,77 \%$. As faixas foram escolhidas partindo do valor máximo de 89,77\% e descendo de 5 em $5 \%$.

Figura 6.36: Resultados da média geométrica dos índices FIT da validação cruzada das saídas.

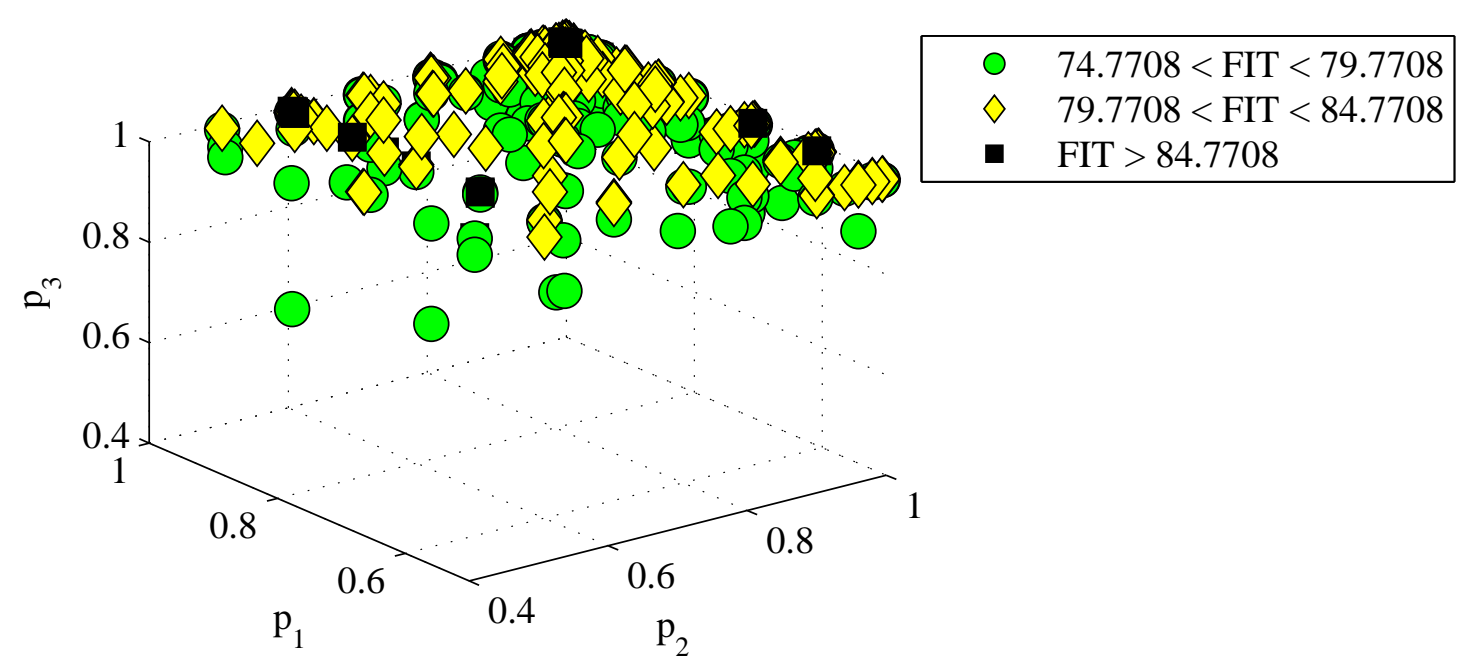

Fonte: Autor.

Cabe observar que a maioria dos pontos apresentados na Figura 6.36 estão concentrados para valores perto de 1 nas três probabilidades de não-chaveamento dos sinais de excitação, incluindo o valor máximo. 
Neste caso testado também é calculada a média geométrica total das validações cruzadas das saídas $y_{i}$ e as respostas individuais ao degrau $y_{i} / u_{i}$ como foi feito nos testes no reator de polimerização. Da média geométrica total os pontos mais altos encontrados são os apresentados na Tabela 6.10.

Tabela 6.10: Maiores $p_{i}$ encontradas na média geométrica de $\overline{F I T}_{T}$ em malha aberta

\begin{tabular}{cccc}
\hline$p_{1}$ & $p_{2}$ & $p_{3}$ & Média Geométrica \\
\hline 0,96 & 0,995 & 0,9 & $47,49 \%$ \\
0,94 & 0,96 & 0,994 & $50,82 \%$ \\
0,98 & 0,995 & 0,98 & $51,79 \%$ \\
\hline
\end{tabular}

Os testes em malha aberta com valores da média geométrica total positivos foram unicamente os apresentados na Tabela 6.10, isto ocorre pela dificuldade para identificar a planta. Esta dificuldade se deve às amplitudes utilizadas nas entradas do sistema, que foram restringidas para manter as saídas nas faixas de operação da planta.

\subsubsection{Resultados em Malha fechada - GBN}

\section{Sistema em malha fechada - GBN}

Na Figura 6.37 são apresentados os valores de $p_{i}$ da média geométrica dos valores FIT das validações cruzadas nas saídas $y_{1}, y_{2}$ e $y_{3}$, distribuídos em três faixas como resultado da identificação em malha fechada da coluna de destilação. A melhor resposta é obtida para os valores de $p_{1}=0,94, p_{2}=0,98$ e $p_{3}=0,94 \mathrm{com}$ um valor da média geométrica igual a $91,45 \%$.

Figura 6.37: Resultados da média geométrica dos índices FIT das validações cruzadas nas saídas em malha fechada.

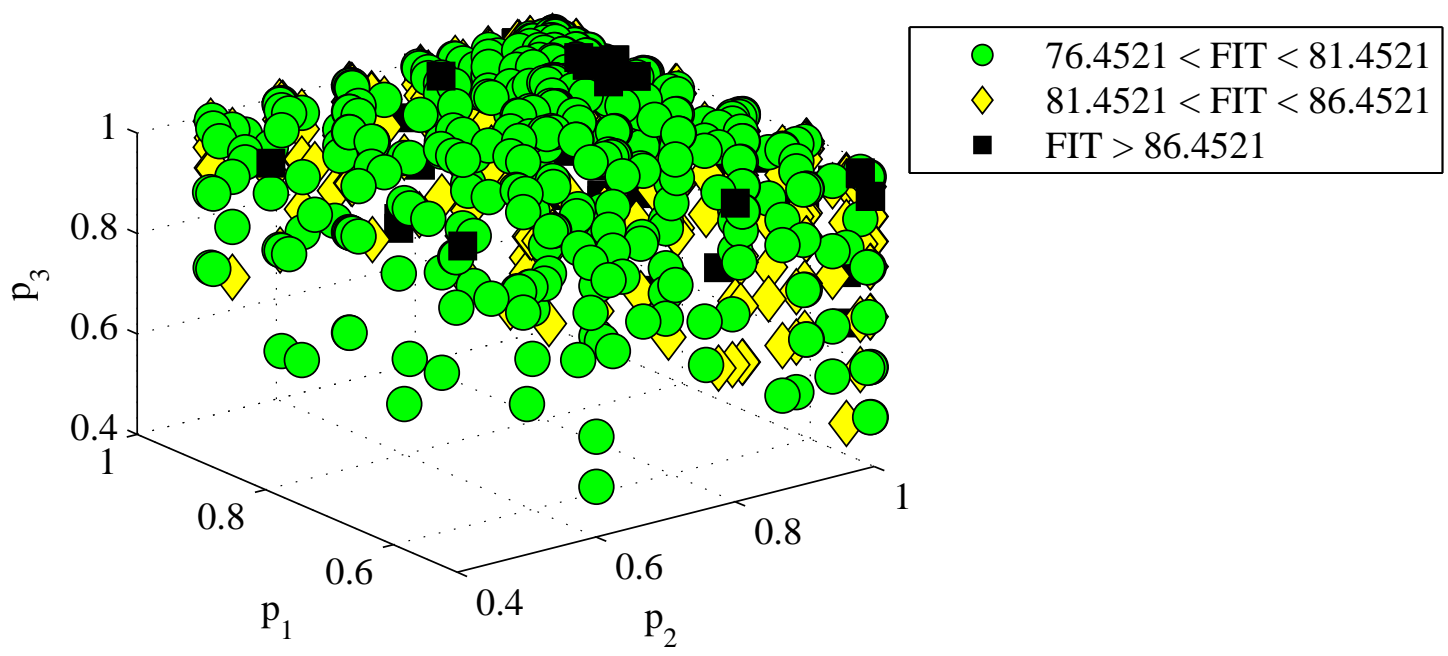

Fonte: Autor.

Na Figura 6.38 são apresentadas as 5 primeiras faixas das respostas em malha fechada identificando o sistema completo, incluindo os controladores. 
Figura 6.38: Resultados da média geométrica total em malha fechada usando sinais GBN.

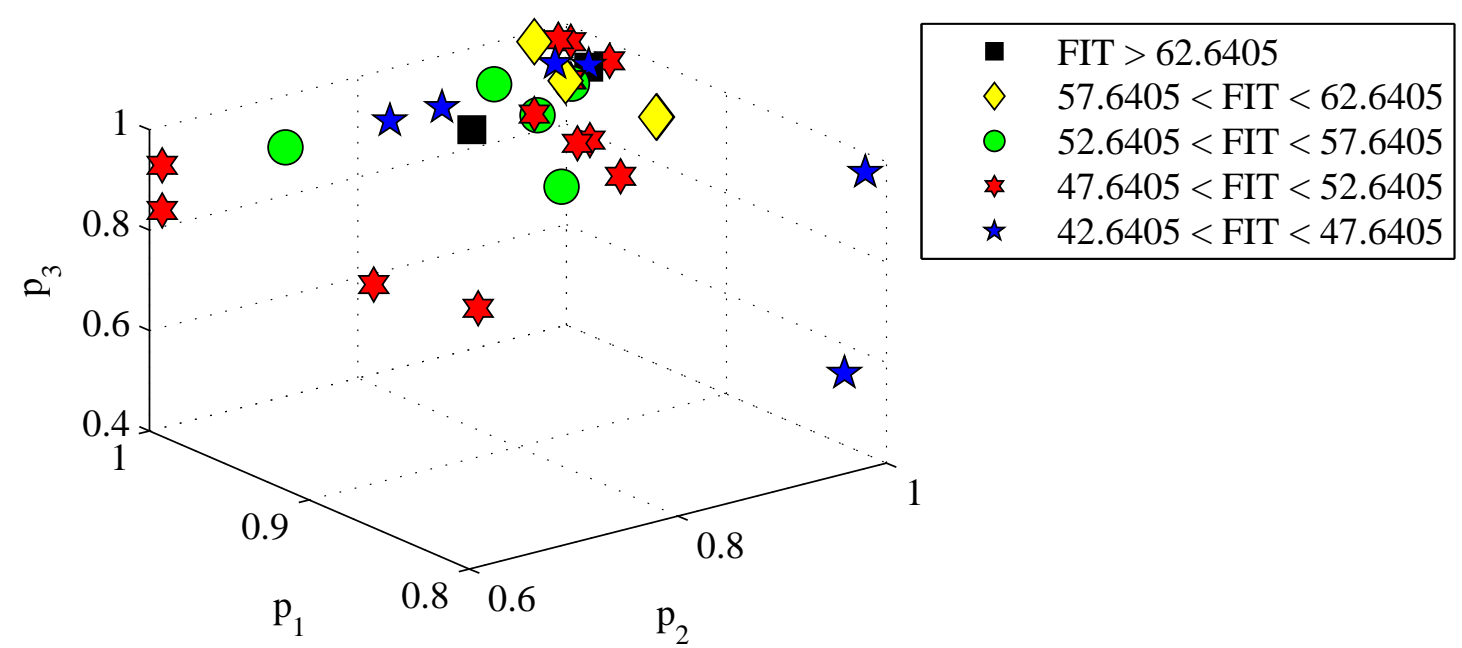

Fonte: Autor.

Dos resultados apresentados na Figura 6.38, é possível observar que para este processo os pontos obtidos se concentraram em valores altos de $p_{1}$ e $p_{2}$ e $p_{3}$, também são observados mais pontos que os apresentados na Tabela 6.10, isto se deve às amplitudes dos sinais de entrada para a identificação. O resultado máximo foi obtido para valores de $p_{1}=0,994, p_{2}=0,9$ e $p_{3}=0,85$ com um valor igual a $67,64 \%$. Porém, na primeira faixa também se encontra um outro ponto localizado em $p_{1}=0,96$, $p_{2}=0,96$ e $p_{3}=0,99$ com valor de $63,63 \%$.

\section{Identificação direta do processo - GBN}

Na Figura 6.39 são apresentados os valores de $p_{i}$ da média geométrica dos valores FIT das saídas $y_{1}, y_{2}$ e $y_{3}$, distribuídos em três faixas como resultado da identificação direta do processo em malha fechada. A maior resposta é obtida para os valores de $p_{1}=0,96, p_{2}=0,9$ e $p_{3}=0,96$ com um valor da média geométrica igual a 88,07\%.

Figura 6.39: Resultados da média geométrica dos índices FIT das saídas em malha fechada usando sinais GBN.

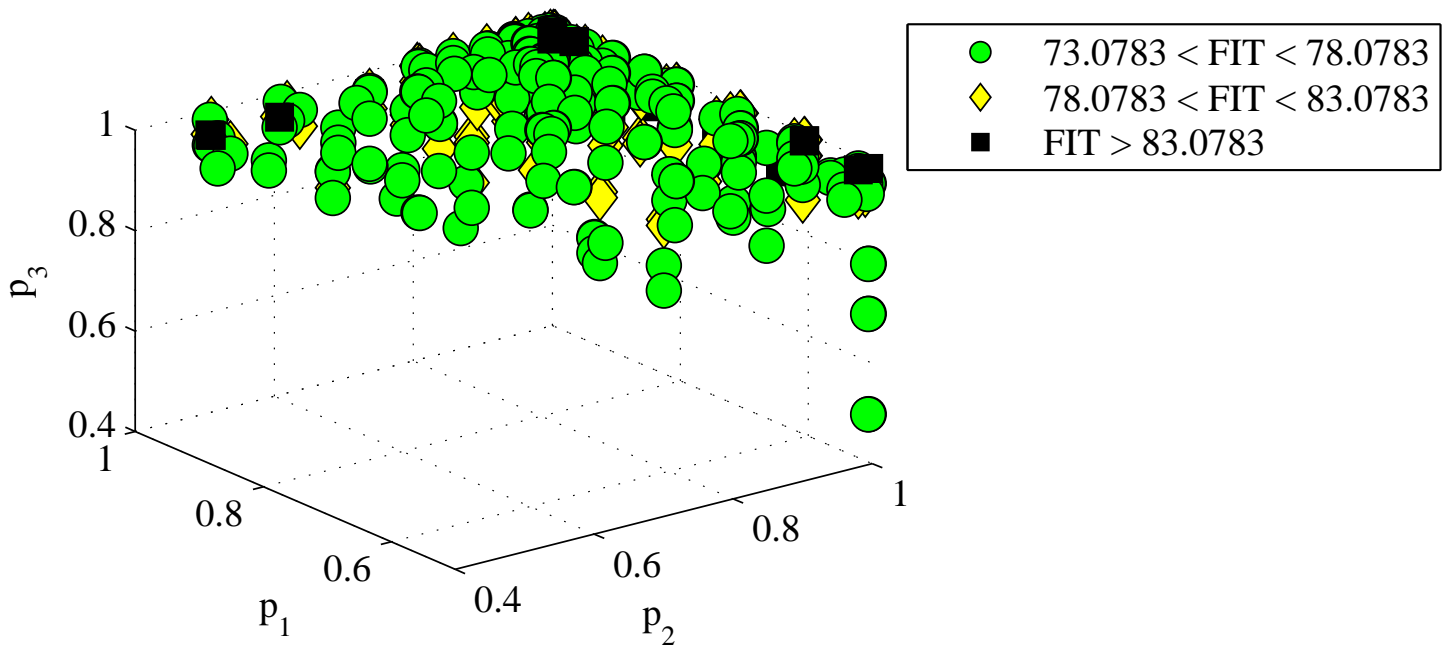

Fonte: Autor. 
Na Figura 6.40 são apresentadas as 5 primeiras faixas das respostas da identificação direta do processo em malha fechada .

Figura 6.40: Resultados da média geométrica total em malha fechada usando sinais GBN.

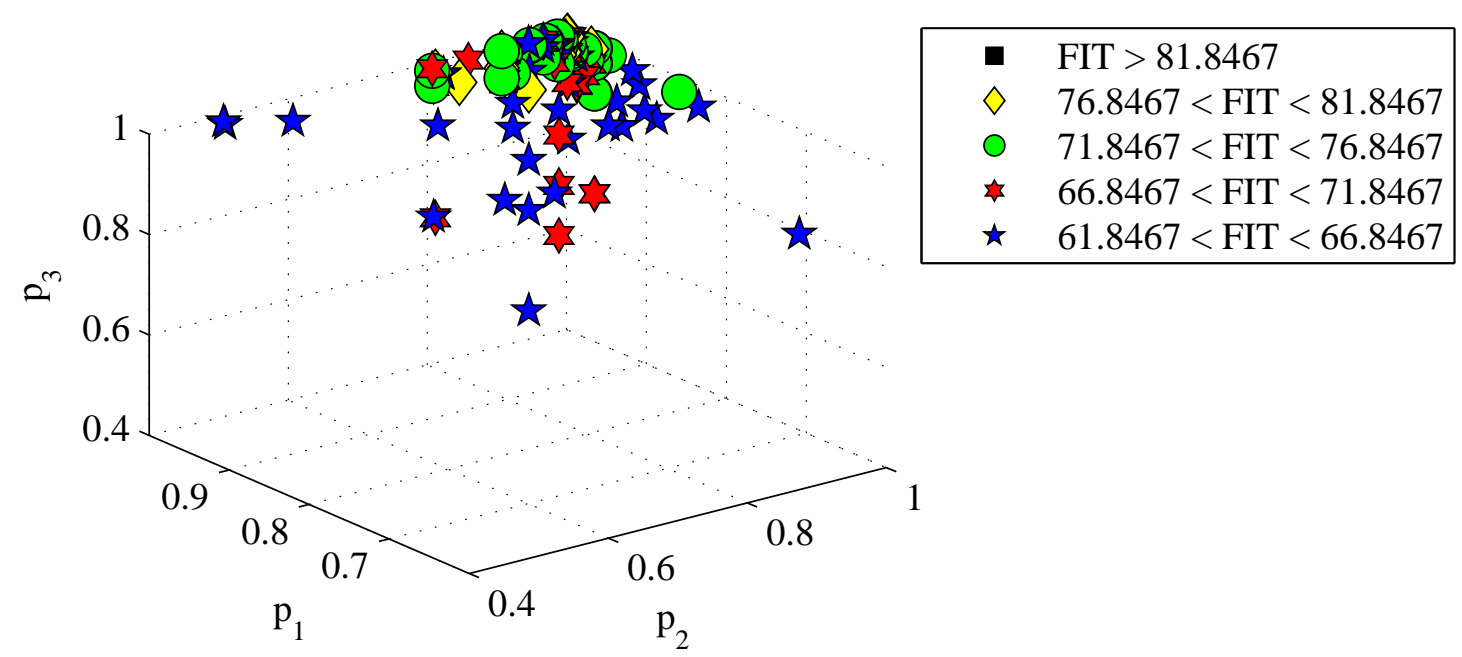

Fonte: Autor.

Dos resultados apresentados na Figura 6.40, é possível observar que para este processo os pontos obtidos se concentraram em valores altos de $p_{1}, p_{2}$ e $p_{3}$, onde novamente são observados mais pontos que os apresentados na Tabela 6.10. Os sinais de controle $u_{i}(t)$ apresentaram uma amplitude ao redor de 10 vezes maior que as amplitudes usadas na identificação em malha aberta. O resultado máximo foi obtido para valores de $p_{1}=0,992, p_{2}=0,9$ e $p_{3}=0,94$ com um valor de $86,84 \%$.

Da superfície da média geométrica total os pontos mais altos encontrados são os apresentados na Tabela 6.11.

Tabela 6.11: Maiores $p_{i}$ encontradas na média geométrica de $y_{i}$ e $y_{i} / u_{i}$ em malha fechada - identificação direta.

\begin{tabular}{cccc}
\hline$p_{1}$ & $p_{2}$ & $p_{3}$ & Média Geométrica \\
\hline 0,992 & 0,98 & 0,98 & $82,87 \%$ \\
0,994 & 0,98 & 0,96 & $84,24 \%$ \\
0,992 & 0,90 & 0,94 & $86,84 \%$ \\
\hline
\end{tabular}

\subsubsection{Forma analítica - GBN}

A faixa de frequências foi calculada a partir da Equação (5.6), com $\beta_{s}=5$ e $\alpha_{s}=1$.

\section{Cálculos em malha aberta}

Considerando os valores de $\tau$ em malha aberta:

$$
\tau=\left[\begin{array}{ccc}
6,7 & 8,64 & 9,06 \\
3,25 & 5 & 7,09 \\
8,15 & 10,9 & 15,2
\end{array}\right]
$$


A análise dos valores de $\tau$ para cada $p_{i}$ foi feito para cada coluna. Assim, são obtidas as duas faixas de frequência:

$$
\begin{aligned}
& w_{L}=0,0245 \leq w_{1} \leq 0,3077=w_{H} \rightarrow p_{1} \\
& w_{L}=0,0183 \leq w_{2} \leq 0,2000=w_{H} \rightarrow p_{2} \\
& w_{L}=0,0132 \leq w_{2} \leq 0,1410=w_{H} \rightarrow p_{3}
\end{aligned}
$$

Com as faixas calculadas em (6.11) são obtidos os valores de $p_{1}, p_{2}$ e $p_{3}$, a partir da Equação (5.8):

$$
\begin{aligned}
& p_{1}=0,9790 \\
& p_{2}=0,9851 \\
& p_{3}=0,9893
\end{aligned}
$$

Em (6.12) são observados valores dentro dos resultados experimentais fazendo parte da região dos pontos máximos encontrados.

\section{Cálculos em malha fechada}

Considerando os valores de $\tau$ em malha fechada:

$$
\tau=\left[\begin{array}{c}
8,05 \\
52,23 \\
11,09
\end{array}\right]
$$

Com o os valores da diagonal principal de $\tau$ são obtidas os valores de $p_{1}, p_{2}$ e $p_{3}$ a partir da Equação (5.8) modificada para um valor só de frequência (CHEN; YU, 1997):

$$
\begin{aligned}
& p_{1}=0,9938 \\
& p_{2}=0,9991 \\
& p_{3}=0,9955
\end{aligned}
$$

Pode ser observado que em (6.13) são obtidos valores de $p$ muito maiores que os obtidos experimentalmente.

\subsubsection{Resultados em Malha aberta - PRBS}

Na Figura 6.41 são apresentados os valores de $p_{i}$ da média geométrica dos valores FIT das validações cruzadas das saídas $y_{1}, y_{2}$ e $y_{3}$, distribuídos em três faixas como resultado da identificação em malha aberta da coluna de destilação usando sinais PRBS. A maior resposta é obtida para os valores de $T_{b 1}=8, T_{b 2}=4$ e $T_{b 3}=10$ com um valor da média geométrica igual a 81,04\%.

Neste caso novamente foi calculada a média geométrica das validações cruzadas nas saídas e das respostas ao degrau das funções de transferência individuais. Usando sinais GBN foi observada uma grande dificuldade para identificar as funções de transferência do sistema. Essa mesma dificuldade foi percebida usando sinais PRBS onde nenhum ponto testado apresentou valores positivos da média geométrica total das respostas. 
Figura 6.41: Resultados da média geométrica dos índices FIT das validações das saídas usando sinais PRBS.

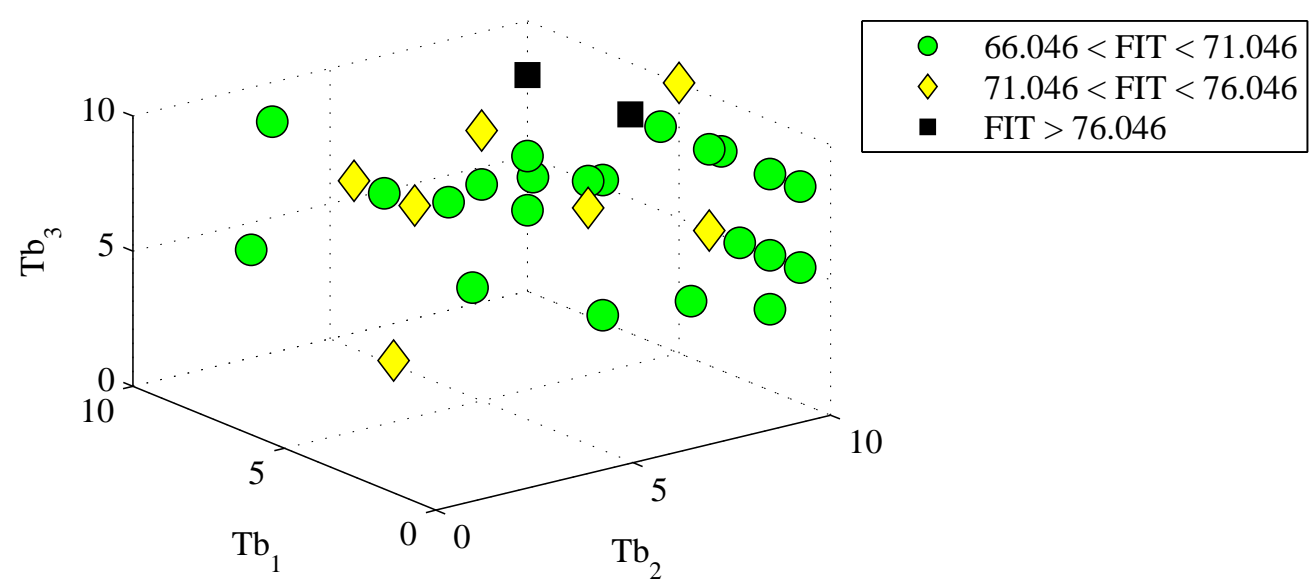

Fonte: Autor.

\subsubsection{Resultados em Malha fechada - PRBS}

\section{Sistema em malha fechada - PRBS}

Nas Figuras 6.42 e 6.43 são apresentados os pontos distribuídos nas faixas respectivas correspondentes às médias geométricas das saídas do processo e média geométrica total, resultados obtidos da identificação do processo em malha fechada. Os pontos máximos em cada gráfico ocorrem em $T_{b 1}=5, T_{b 2}=3$ e $T_{b 3}=10$ para a média das saídas do processo com um valor de $90,92 \%$, e para $T_{b 1}=2, T_{b 2}=10$ e $T_{b 3}=2$ para a média total com um valor de $48,89 \%$.

Figura 6.42: Resultados da média geométrica dos índices FIT das validações das saídas em malha fechada.

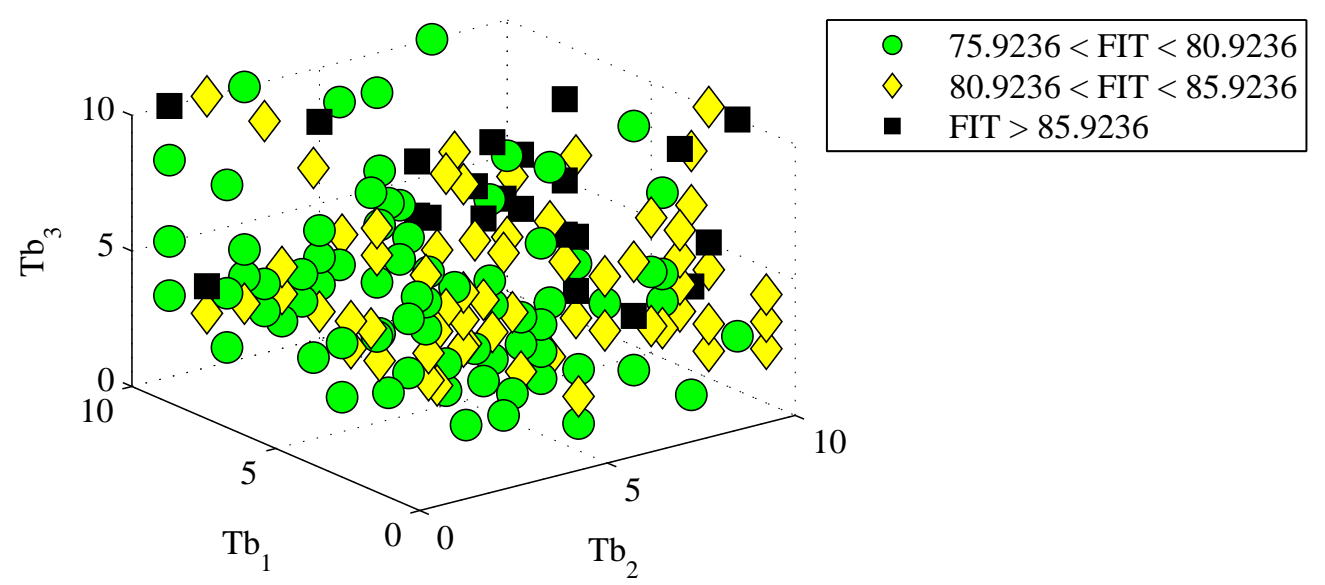

Fonte: Autor. 
Figura 6.43: Resultados da média geométrica total em malha fechada usando sinais PRBS.

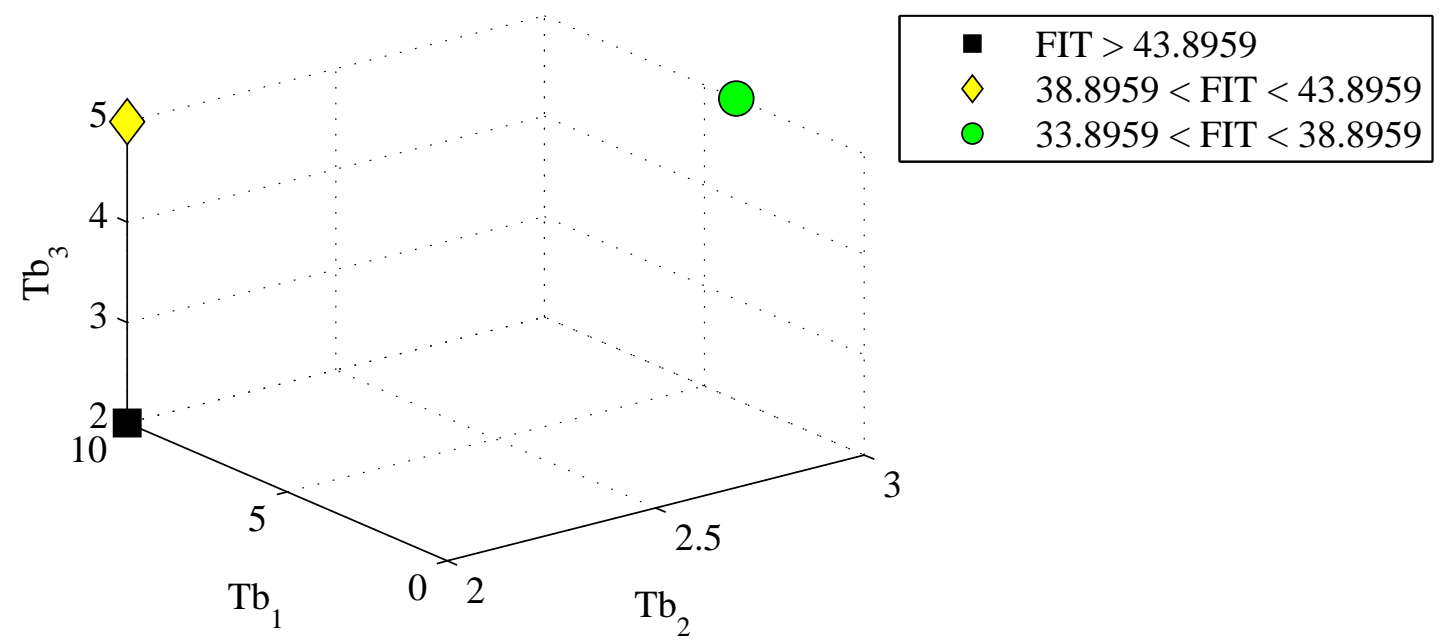

Fonte: Autor.

\section{Identificação direta do processo - PRBS}

Nas Figuras 6.44 e 6.45 são apresentados os pontos distribuídos nas faixas respectivas correspondentes às médias geométricas das saídas do processo e total, resultados obtidos da identificação direta da planta em malha fechada. Os pontos máximos em cada gráfico ocorrem em $T_{b 1}=10, T_{b 2}=10$ e $T_{b 3}=10$ para a média das saídas do processo com um valor de $83,92 \%$, e para $T_{b 1}=4, T_{b 2}=3$ e $T_{b 3}=3$ para a média total com um valor de $57,91 \%$.

Figura 6.44: Resultados da média geométrica dos índices $\overline{F I T}_{y}$ das saídas em malha fechada usando sinais PRBS.

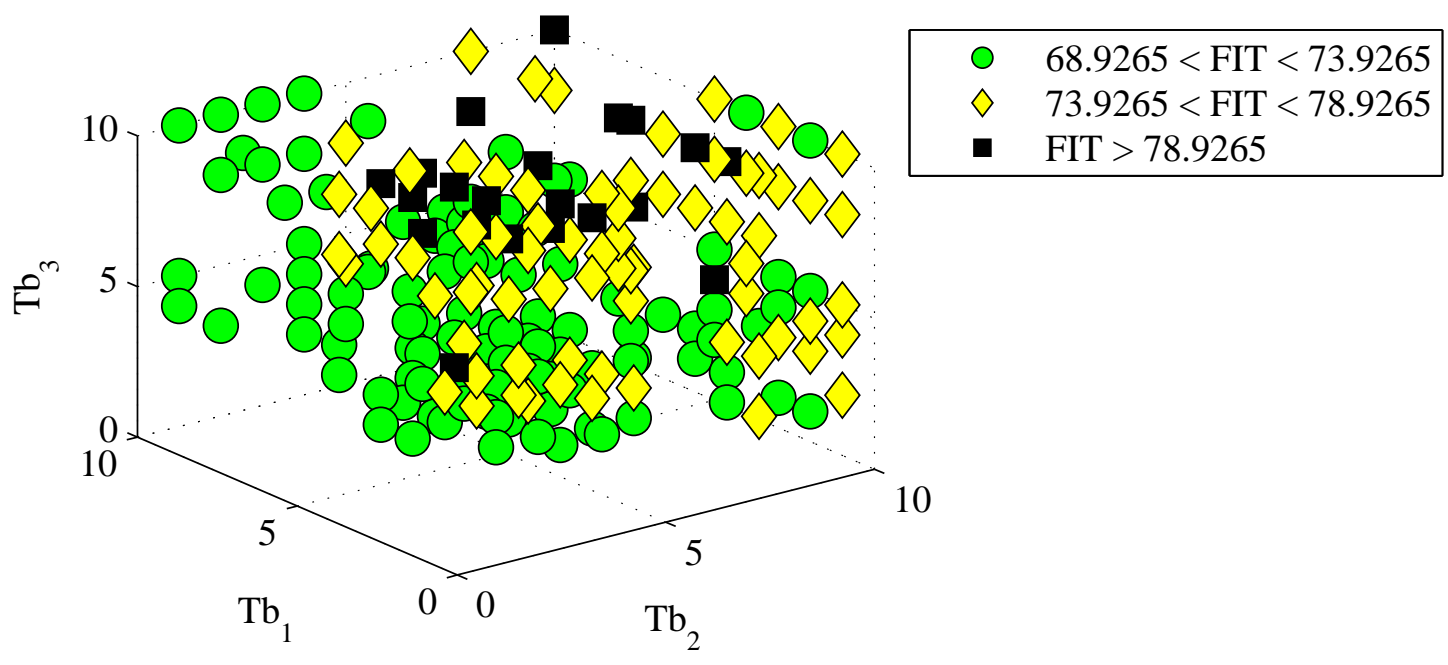

Fonte: Autor. 
Figura 6.45: Resultados da média geométrica total em malha fechada usando sinais PRBS.

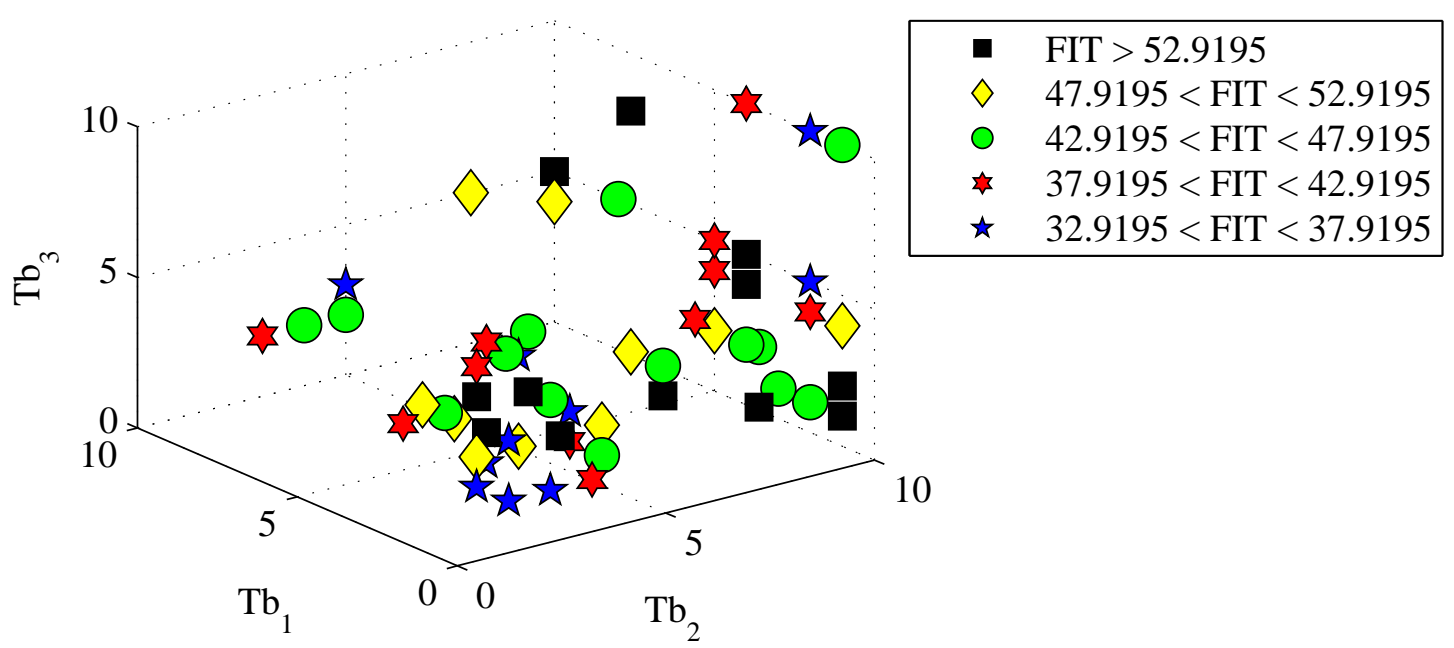

Fonte: Autor.

\subsubsection{Forma analítica - PRBS}

\section{Cálculos em malha aberta}

Considerando os valores de $\tau$ em malha aberta:

$$
\tau=\left[\begin{array}{ccc}
6,7 & 8,64 & 9,06 \\
3,25 & 5 & 7,09 \\
8,15 & 10,9 & 15,2
\end{array}\right]
$$

foram calculados os valores dos tempos de bit a partir de (5.7), proposta em (RIVERA; JUN, 2000):

$$
\begin{gathered}
T_{b 1}=9 \\
T_{b 2}=14 \\
T_{b 3}=20
\end{gathered}
$$

Também foram calculados os valores de $T_{b}$ a partir de (5.5), proposta em (AGUIRRE, 2007):

$$
\begin{aligned}
& T_{b 1}=1 \\
& T_{b 2}=1 \\
& T_{b 3}=2
\end{aligned}
$$

Em 6.14 são observados valores dentro dos resultados experimentais fazendo parte da região dos pontos máximos encontrados. Enquanto os valores obtidos em 6.15 não correspondem ao observado experimentalmente, isto ocorre pelos valores de $\tau_{\min }$ que são menores que 10 .

\section{Cálculos em malha fechada}

Considerando os valores de $\tau$ em malha fechada: 


$$
\tau=\left[\begin{array}{c}
8,05 \\
52,23 \\
11,09
\end{array}\right]
$$

A partir de $\tau$ são obtidas os valores de $T_{b 1}, T_{b 2}$ e $T_{b 3}$ usando a Equação (5.7):

$$
\begin{gathered}
T_{b 1}=24 \\
T_{b 2} \approx 150 \\
T_{b 3}=33
\end{gathered}
$$

e a partir da Equação (5.5):

$$
\begin{gathered}
1 \leq T_{b 1} \leq 2 \\
5 \leq T_{b 2} \leq 17 \\
1 \leq T_{b 3} \leq 3
\end{gathered}
$$

Usando a Equação (5.7) foram obtidos valores muito maiores que os observados experimentalmente. Por sua vez, usando a Equação (5.5) foram obtidos valores muito inferiores aos observados experimentalmente.

Os cálculos dos parâmetros $p$ e $T_{b}$ em malha fechada usando as equações encontradas na literatura apresentaram diferenças respeito dos valores obtidos experimentalmente na coluna de destilação.

\subsection{Testes de correlação}

Uma vez estudadas as frequências dos sinais de excitação individualmente, foi estudado o efeito das correlações independentemente. Assim, nestes testes serão considerados os pontos máximos da FCC dos sinais de excitação. Estas amplitudes serão comparadas com o valor limite $r_{\text {lim }}=0,0667$, calculado a partir de (5.4) usando $\mathrm{N}=900$, correspondente ao comprimento da seção do sinal usada para a identificação dos modelos.

Vários níveis de amplitude dos valores máximos da FCC usando 60 atrasos foram considerados para testar as plantas. Os níveis variam de $r_{x y}=[0,05-1]$ e em cada nível são geradas 100 combinações de sinais e aplicados na identificação dos sistemas em malha aberta e em malha fechada, cujos resultados fazem parte de um teste de Monte Carlo.

Na hora de implementar os testes com sinais PRBS apareceram certas dificuldades, daí a quantidade limitada de sementes de geração deste tipo de sinal, a qual se vê mais limitada a cada aumento de $T_{b}$, como visto nos resultados da seção anterior. Por esta razão foram implementados os testes unicamente usando sinais GBN. Porém, usando sinais GBN não foram atingidos níveis superiores a 0,85 em combinações de 2 sinais, e para combinações de 3 sinais conseguiu-se conjuntamente níveis máximos da FCC iguais a 0,75 . Os processos testados foram o reator de polimerização e a coluna de destilação. 


\subsubsection{Resultados do Reator de Polimerização}

As simulações no reator de polimerização para o estudo do efeito da correlação conservaram as características das amplitudes dos sinais de entrada e set point, variando entre [-0,5 0,5]. As probabilidades de não-chaveamento dos sinais GBN usados para o estudo foram $p_{1}=p_{2}=0,99$, mantendo o comprimento de 1500 pontos com seus primeiros 900 pontos usados para identificar os modelos e os seus restantes 600 usados na validação dos mesmos. Os experimentos de identificação estiveram sujeitos a uma condição de ruído $\mathrm{SNR}=10$ nas saídas $y_{1}$ e $y_{2}$.

Na Figura 6.46 são apresentados os resultados da média aritmética dos índices FIT da correlação cruzada das 100 iterações em cada ponto de correlação, isto identificando em malha aberta e em malha fechada.

Figura 6.46: Índices $\overline{F I T}$ da validacão cruzada em funcão da correlacão dos sinais de entrada
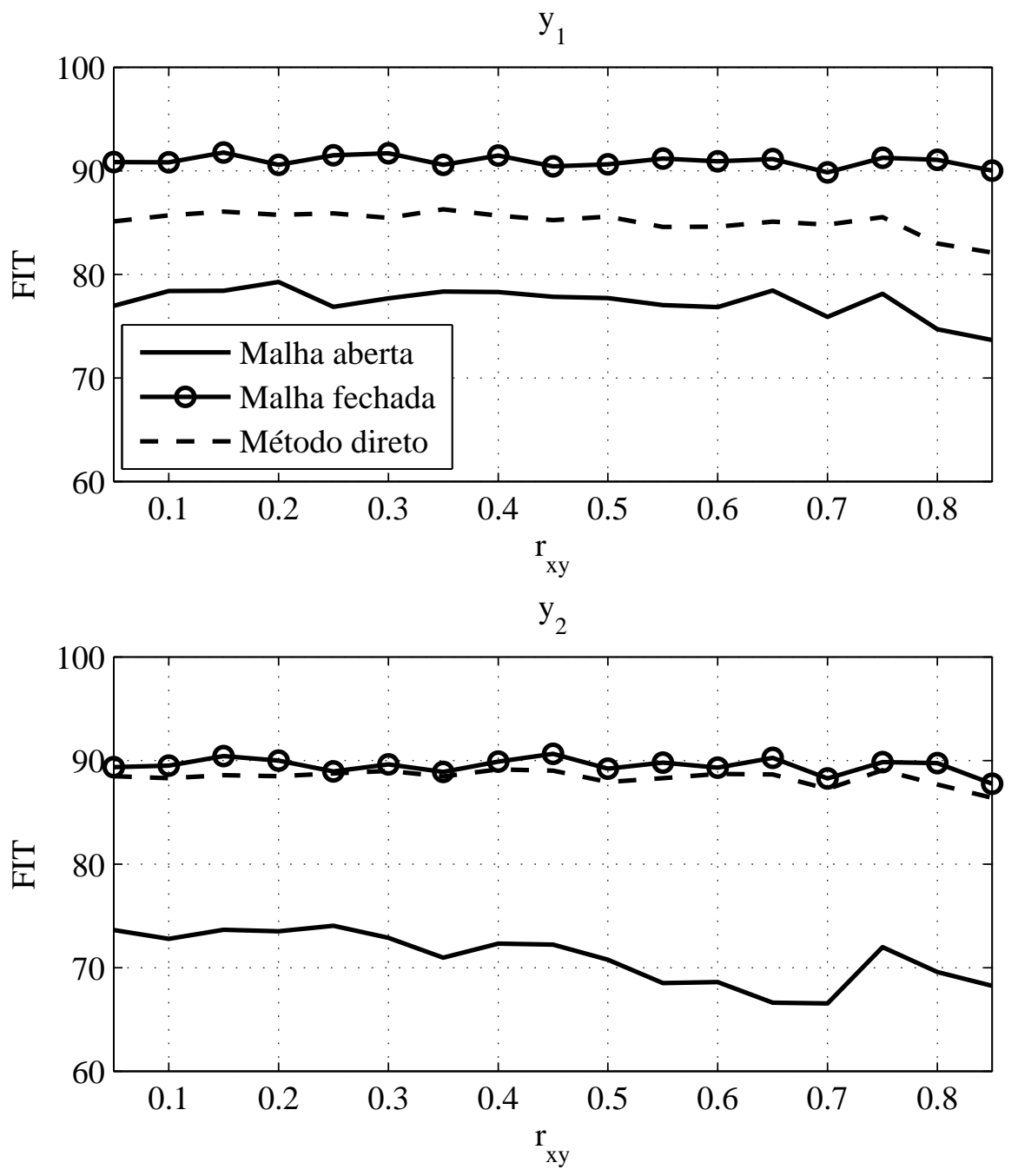

Fonte: Autor.

Nos resultados da Figura 6.46 é observado que os resultados dos $\overline{F I T}$ mantêm valores quase constantes ao longo das variações das correlações máximas. Aparentemente a correlação dos sinais não afeta os resultados da validação cruzada nas três configurações testadas, em malha aberta e malha fechada. No entanto, também foram analisadas as 
respostas ao degrau das funções de transferência em função da correlação máxima das combinações das entradas. Os resultados são apresentados na Figura 6.47.

Figura 6.47: Índices $\overline{F I T}$ da validacão da resposta ao degrau em funcão da correlacão
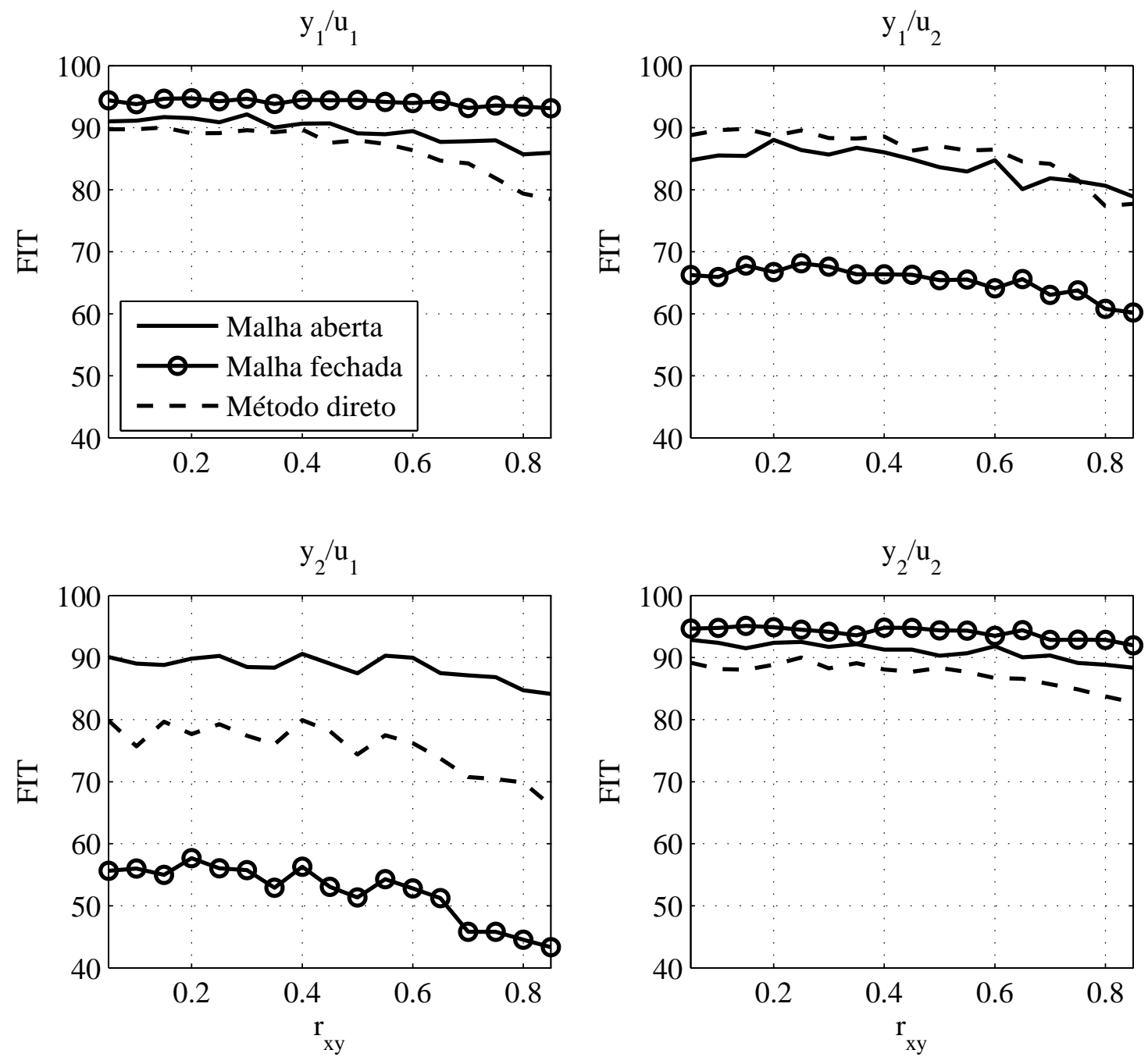

Fonte: Autor.

Analisando-se os resultados apresentados na Figura 6.47 é possível observar que para valores superiores a 0,4 da correlação entre os sinais de entrada, os resultados da validação cruzada da resposta ao degrau decrescem. Isto indica uma deterioração na identificação do modelo. Este fenômeno é observado tanto em malha aberta como fechada.

Os modelos identificados em malha aberta decresceram ao redor de $5 \%$ no seu valor $\overline{F I T}$ quando $r_{x y}$ foi igual a 0,85 nas quatro $y_{i} / u_{i}$. O que no modelo da planta identificado diretamente em malha fechada representou uma queda ao redor de $10 \%$ nas suas quatro componentes. Porém, as dinâmicas que mantiveram um valor quase constante no índice $\overline{F I T}$ foram as funções de transferência da diagonal principal do modelo identificado em malha fechada, onde o efeito da correlação neste modelo afetou unicamente as dinâmicas da diagonal secundária, caindo ao redor de 10 e $20 \%$ para $y_{1} / u_{2}$ e $y_{2} / u_{1}$, respectivamente. 


\subsubsection{Resultados da Coluna de Destilação}

O estudo das correlações foi implementado também na coluna de destilação para observar o efeito da correlação dos sinais de excitação em uma planta de maior dimensão que a do reator de polimerização. As amplitudes dos sinais de excitação foram as mesmas utilizadas em todos os testes anteriores. As entradas $u_{1}, u_{2}$ e $u_{3}$ correspondem a $\pm 4 \%$, $\pm 3 \%$,e $\pm 9 \%$ das restrições apresentadas na Tabela 4.2 , e os setpoint $S P_{1}, S P_{2}$ e $S P_{3}$ correspondem a $\pm 4 \%, \pm 3 \%, \mathrm{e} \pm 9 \%$ das restrições nas saídas $y_{i}$ apresentadas na Tabela 4.2 . Os cenários de ruído são usados para testar o modelo segundo as condições apresentadas nas tabelas 4.2 e 4.3 .

As variações de $r_{x y}$ foram mantidas iguais nas três possíveis combinações, isto é $r_{u_{1} u_{2}}=$ $r_{u_{2} u_{3}}=r_{u_{3} u_{1}}$, pois são gerados 3 sinais para excitar a coluna. As probabilidades de nãochaveamento dos sinais GBN usados para o estudo foram $p_{1}=p_{2}=p_{3}=0,992$. Devido aos altos valores de $p_{i}$, o valor inicial de $r_{x y}$ foi igual a 0,1 . Assim, dadas as diferentes restrições e considerações sobre o experimento na coluna de destilação, os testes de Monte Carlo foram diminuídos para 10 iterações evitando assim altos tempos de cômputo.

Na Figura 6.48 são apresentados os resultados da média aritmética dos índices FIT da correlação cruzada das 100 iterações em cada ponto de correlação, isto identificando o sistema em malha aberta e em malha fechada.

Figura 6.48: Índices $\overline{F I T}$ da validação cruzada em função da correlação dos sinais de entrada.
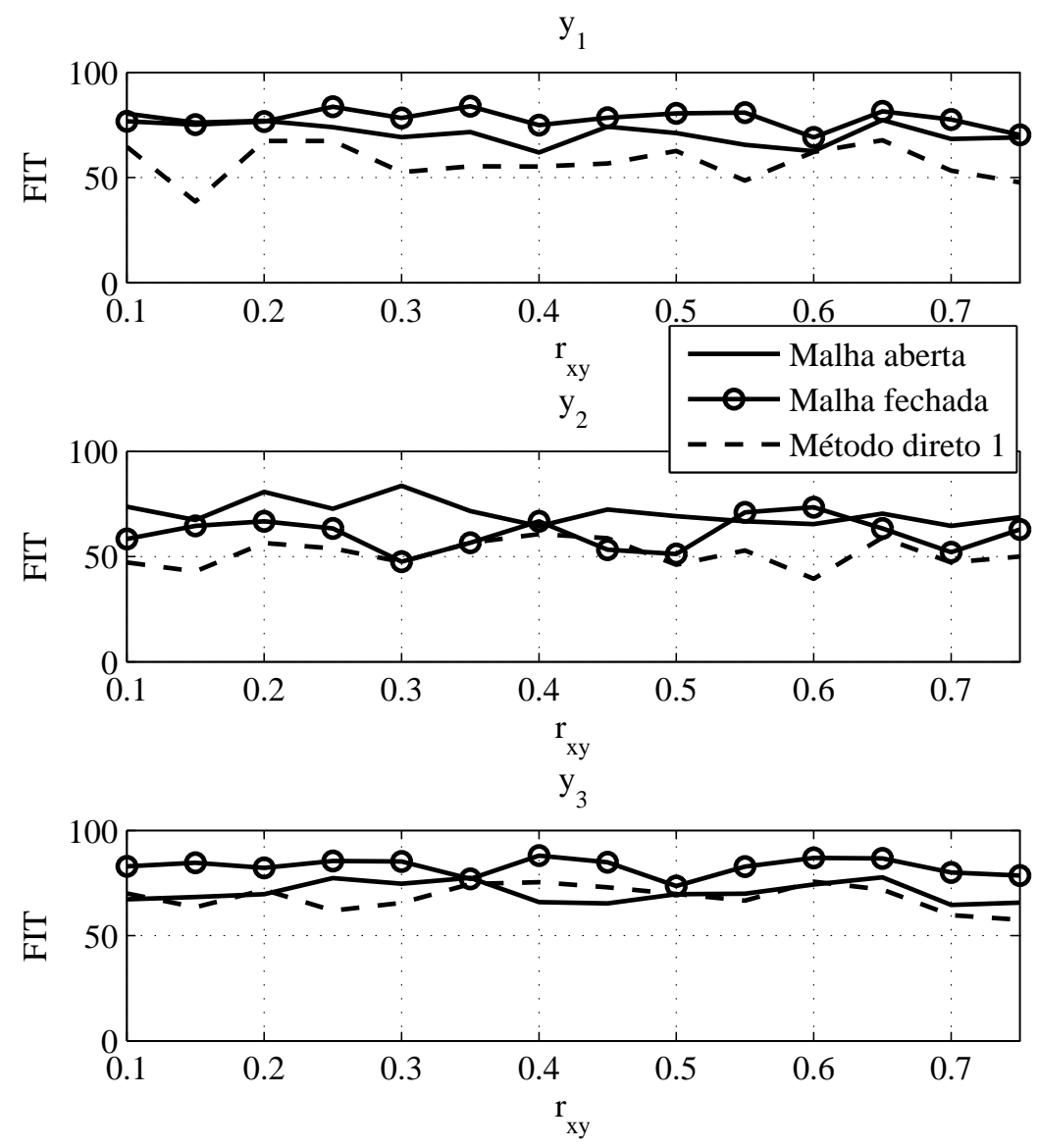

Fonte: Autor. 
Nos resultados da Figura 6.48 podem ser observadas características similares às obtidas no reator de polimerização. Embora neste caso as funções oscilam com a variação de $r_{x y}$, não foi percebida uma diminuição dos $\overline{F I T}$ atribuída ao aumento de $r_{x y}$. Contudo, são analisadas as respostas da validação ao degrau de cada função de transferência do modelo da coluna, conforme apresentado na Figura 6.49.

Figura 6.49: Índices $\overline{F I T}$ da validação da resposta ao degrau em função da correlação dos sinais de entrada.
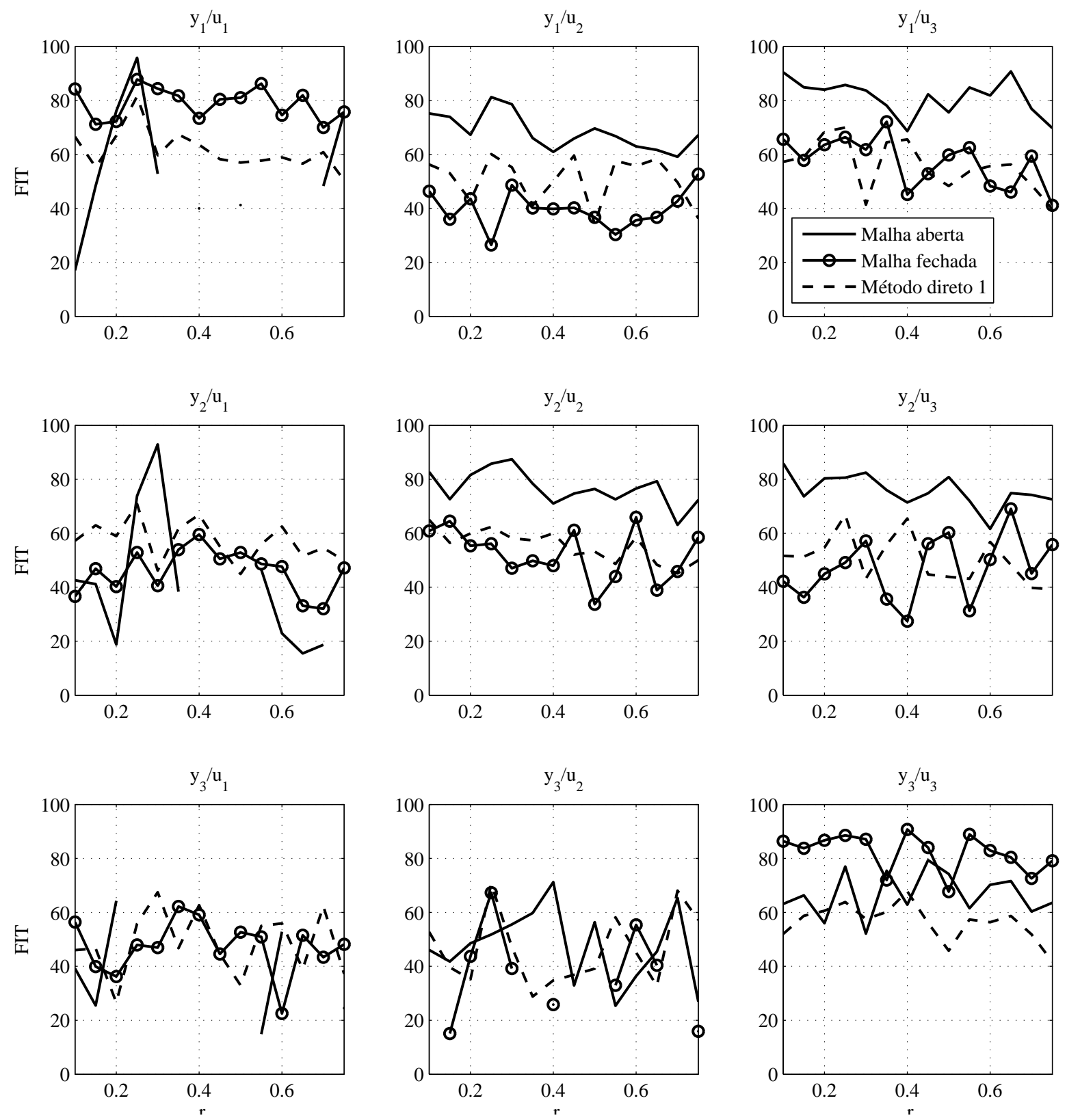

Fonte: Autor.

Das respostas da validação ao degrau de cada função de transferência a maioria das respostas oscilaram com a variação de $r_{x y}$, observando também a dificuldade para identificar certas funções de transferência. Em malha aberta as componentes dependentes das entradas $u_{1}$ foram mal identificadas em vários pontos, independentemente da amplitude de $r_{x y}$. Por sua vez, em malha fechada a componente $y_{3} / u_{2}$ apresentou também 
dificuldade para ser identificada sem dependência da amplitude de $r_{x y}$. E finalmente, é observado que para a identificação da processo diretamente em malha fechada todas as componentes do modelo foram identificadas.

Embora sejam apresentadas algumas oscilações em certas respostas das componentes $y_{i} / u_{i}$, nas respostas onde as oscilações foram menores apareceram algumas diminuições do seu valor médio. Estas variações foram de até $20 \%$ comparando seu valor em $r_{x y}=0,1$ e $r_{x y}=0,75$. Este caso é observado na componente $y_{1} / u_{3}$, para as três identificações.

Como comentário final, com respeito aos resultados obtidos nos dois processos testados, pôde ser observada alguma influência da correlação dos sinais sobre os modelos identificados. Mas, levando-se em conta que os processos foram testados com valores muito superiores ao limite $r_{\text {lim }}$, foi comprovado que usando estruturas BJ não é necessário cumprir a condição de sinais descorrelacionados. Porém, quando os sinais possuem um coeficiente de correlação perto do valor unitário a identificação se vê mais afetada.

\subsection{Método de dois passos para a identificação de plantas mal condicionadas}

As considerações das correlações cruzadas que possuem os sinais de excitação em experimentos de identificação são dependentes do tipo de planta a ser testada. Para plantas bem e medianamente mal condicionadas, foi observado que usar sinais com valores de $r_{x y}$ próximos valor unitário representaram algumas quedas nos índices de validação cruzada da resposta ao degrau. Porém, quando o processo é considerado mal condicionado, outras considerações sobre a correlação dos sinais de excitação devem ser levadas em conta.

Em Zhu e Stec (2006) e Zhu (2001) é proposto um método de dois passos para obter melhores resultados que os obtidos usando os métodos clássicos com sinais PRBS puros, em plantas mal condicionadas com duas entradas. No primeiro passo se realiza um teste com sinais de excitação binários não correlacionados, os quais fornecem uma excitação adequada para boas estimativas da direção de alto ganho. No segundo passo é realizado um novo teste usando sinais binários, mas conformados por uma primeira parte de alta amplitude e iguais para as duas entradas, e uma segunda parte de baixa amplitude e não correlacionados.

Existe uma relação entre as amplitudes, $\Gamma$, a qual segundo Zhu (2001) será no máximo o valor de $\gamma$. Na Figura 6.50 se apresenta um exemplo dos sinais de excitação descrito no método de dois passos. Com este tipo de sinais consegue-se excitar a direcionalidade de baixo ganho como se apresenta na Figura 6.51.

\subsubsection{Parametrização das simulações da Coluna de Alta Pureza}

Se realizaram testes na coluna de alta pureza com sinais puros e o proposto no método de dois passos. As simulações dos experimentos foram feitas com valores nominais em torno de zero, considerando três cenários de ruído, $\mathrm{SNR}=30,10$ e 3. As respostas apresentadas correspondem à média de 100 simulações de Monte Carlo, em que se mudaram os ruídos de medição e as perturbações em cada iteração. 
Figura 6.50: Exemplo de sinais utilizados no método de dois passos.
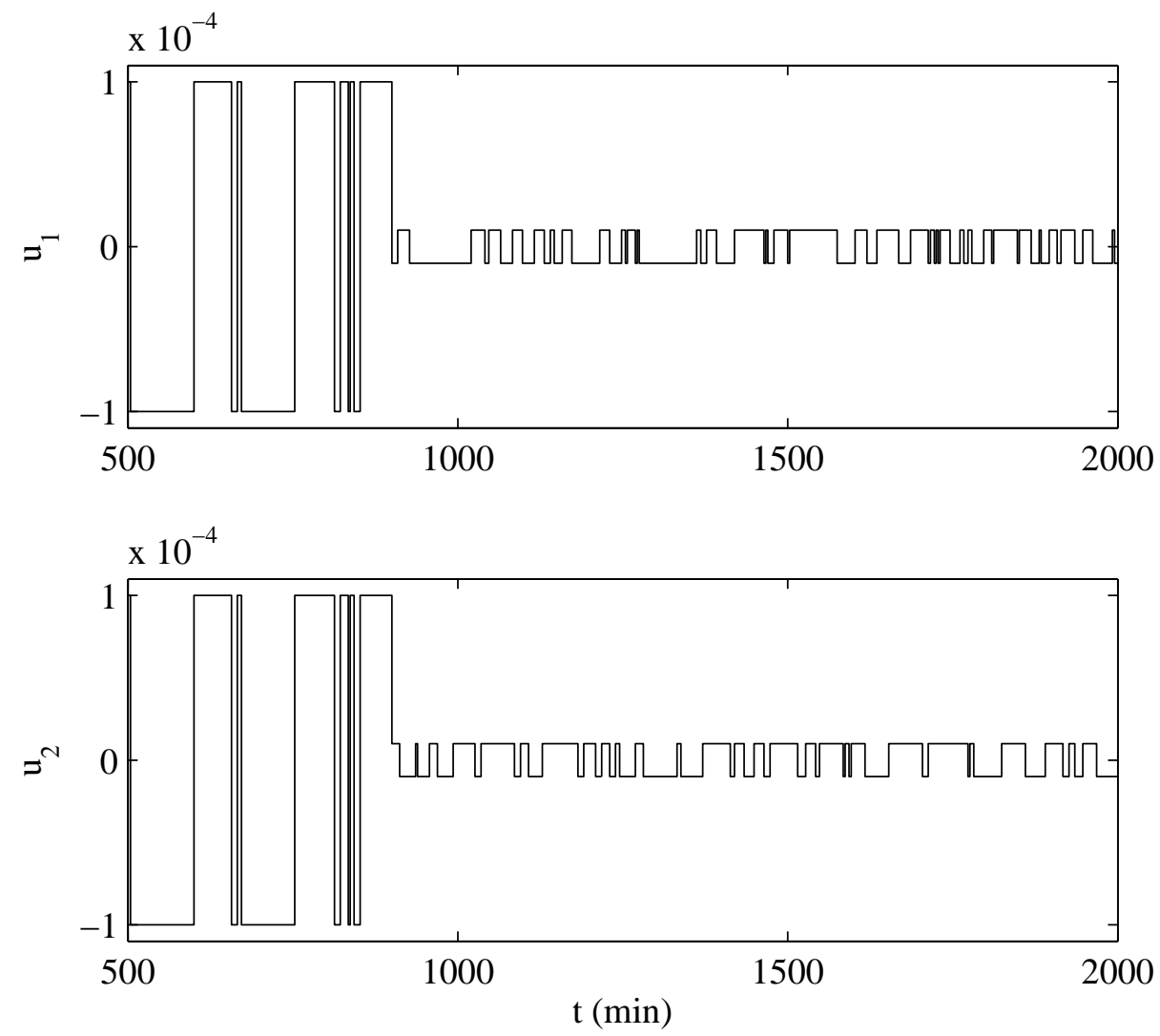

Fonte: Autor.

Figura 6.51: Plano de saídas $\left\{y_{1} ; y_{2}\right\}$ resultado de um teste com o método de dois passos no modelo $G(s)$.

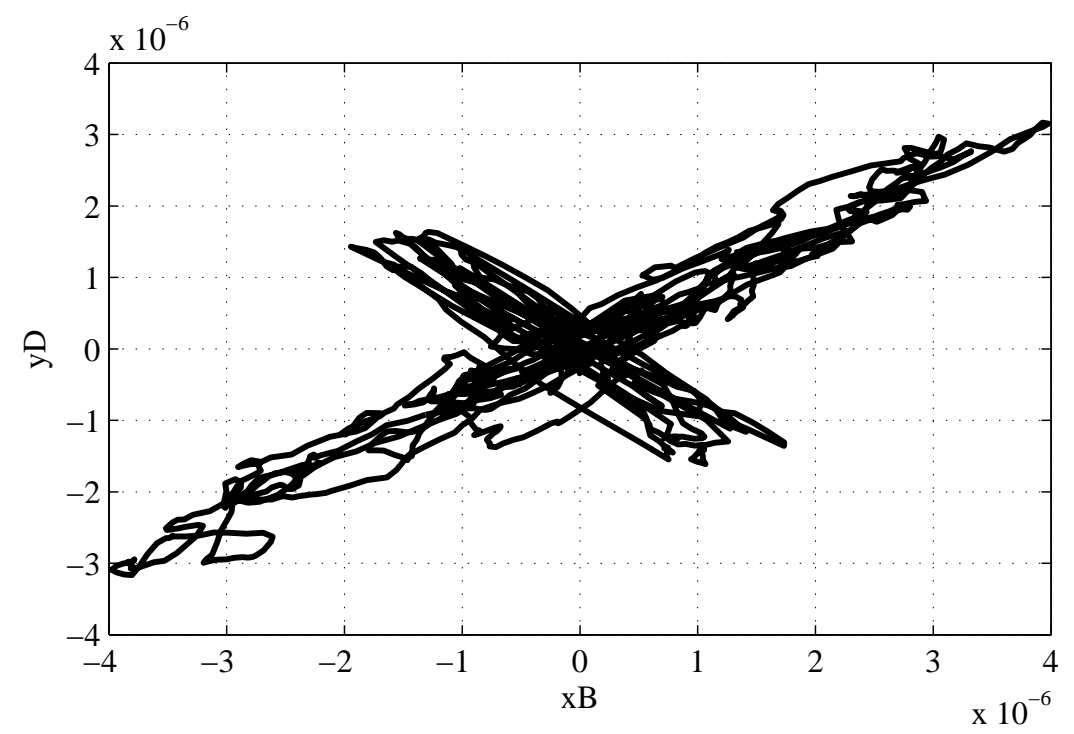

Fonte: Autor.

No caso dos sinais puros, foram usados os mesmos sinais gerados para identificar o reator de polimerização, com uma amplitude de 0,0001. Também estes sinais foram usados na parte não correlacionada dos sinais gerados, usando o método de dois passos 
mudando a sua amplitude de 0,0001 proporcionalmente ao fator $\Gamma$, o qual mudou seu valor conforme se variavam os valores de $p$ e $T_{b}$, em sinais GBN e PRBS respectivamente, como se apresenta na tabela 6.12.

Para as simulações com a planta $G(s)$ foi adotado um período de amostragem $T=1$ minuto. Os sinais construídos pelo método de dois passos têm um comprimento $N=1500$, onde os seus primeiros 300 pontos correspondem aos sinais iguais, para os quais usou-se $p$ de valor 0,88 no caso de sinais $\mathrm{GBN}$ e $T_{b}=8$ no caso de sinais PRBS. Este valor fixo foi próximo do calculado em (VAILLANT; KURAMOTO; GARCIA, 2013) baseado na largura de banda, segundo (CHEN; YU, 1997).

O ruído de medição é do tipo Gaussiano. As perturbações $v_{1}$ e $v_{2}$ são do tipo Gaussiano filtradas pela estrutura $G_{d}(s)=1 /(1+100 s)$, com $d_{1}$ e $d_{2}$ variando a cada 10 minutos.

Tabela 6.12: Valores de $\Gamma$ de acordo com $p$ e $T_{b}$.

\begin{tabular}{cc|c}
\hline$p$ & $T_{b}$ & $\Gamma$ \\
\hline 0,84 & 2 & 20 \\
0,87 & 3 & 20 \\
0,90 & 4 & 30 \\
0,93 & 8 & 30 \\
0,96 & 12 & 36 \\
0,96 & 44 & 36 \\
\hline
\end{tabular}

\subsubsection{Resultados usando Sinais Puros}

Nas tabelas 6.13 e 6.14 são apresentados os resultados da validação cruzada usando sinais GBN e PRBS puros na identificação da coluna de alta pureza.

Tabela 6.13: Resultados usando sinais GBN puros.

\begin{tabular}{ccccccccc}
\hline \multirow{2}{*}{ SNR } & \multirow{2}{*}{ Corr. } & \multirow{2}{*}{ Saída } & \multicolumn{7}{c}{$p$} \\
\cline { 3 - 9 } & & 0,84 & 0,87 & 0,9 & 0,93 & 0,96 & 0,99 \\
\hline \multirow{3}{*}{30} & \multirow{2}{*}{ Baixa } & $y_{1}$ & 69,45 & 72,44 & 73,04 & 74,76 & 78,25 & 67,90 \\
& & $y_{2}$ & 69,68 & 73,86 & 73,50 & 77,86 & 81,80 & 72,61 \\
\cline { 2 - 8 } & \multirow{2}{*}{ Alta } & $y_{1}$ & 63,91 & 72,57 & 73,28 & 68,23 & 69,15 & 70,68 \\
& & $y_{2}$ & 75,84 & 77,27 & 74,37 & 73,97 & 72,36 & 74,70 \\
\hline \multirow{3}{*}{10} & \multirow{2}{*}{ Baixa } & $y_{1}$ & 54,26 & 61,74 & 55,87 & 60,32 & 64,53 & 47,56 \\
& & $y_{2}$ & 60,22 & 66,95 & 62,09 & 65,41 & 69,86 & 55,10 \\
\cline { 3 - 9 } & \multirow{2}{*}{ Alta } & $y_{1}$ & 51,08 & 61,23 & 59,96 & 49,48 & 51,74 & 53,03 \\
& & $y_{2}$ & 66,09 & 67,60 & 65,08 & 57,44 & 57,50 & 59,38 \\
\hline \multirow{3}{*}{3} & \multirow{2}{*}{ Baixa } & $y_{1}$ & 32,25 & 41,99 & 30,97 & 39,27 & 43,35 & 21,06 \\
\cline { 2 - 8 } & & $y_{2}$ & 39,83 & 50,12 & 41,42 & 45,62 & 50,10 & 28,75 \\
\cline { 2 - 8 } & \multirow{2}{*}{ Alta } & $y_{1}$ & 37,30 & 42,37 & 40,00 & 26,96 & 28,95 & 28,88 \\
& & $y_{2}$ & 47,66 & 49,63 & 46,42 & 32,46 & 33,58 & 35,74 \\
\hline
\end{tabular}

Os resultados observados na Tabela 6.13 apresentam valores indicando bons ajustes e neste caso, não se percebem grandes diferenças quando a probabilidade de nãochaveamento vai se aproximando de 1 . De fato, no valor de $p=0,99$ nos sinais não- 
correlacionados se apresentou o menor valor comparado com as outras probabilidades de não-chaveamento.

Tabela 6.14: Resultados usando sinais PRBS puros.

\begin{tabular}{|c|c|c|c|c|c|c|c|c|}
\hline \multirow{2}{*}{ SNR } & \multirow{2}{*}{ Corr. } & \multirow{2}{*}{ Saída } & \multicolumn{6}{|c|}{$\overline{T_{b}}$} \\
\hline & & & 2 & 3 & 4 & 8 & 12 & 44 \\
\hline \multirow{4}{*}{30} & \multirow{2}{*}{ Baixa } & $y_{1}$ & 60,35 & 73,36 & 62,31 & 75,57 & 60,32 & 55,55 \\
\hline & & $y_{2}$ & 62,79 & 64,67 & 43,29 & 58,68 & 41,52 & 60,30 \\
\hline & \multirow{2}{*}{ Alta } & $y_{1}$ & 68,91 & 76,27 & 54,39 & 77,51 & 48,35 & 79,18 \\
\hline & & $y_{2}$ & 54,26 & 49,69 & 49,52 & 62,45 & 20,17 & 67,84 \\
\hline \multirow{4}{*}{10} & \multirow{2}{*}{ Baixa } & $y_{1}$ & 47,00 & 58,91 & 55,01 & 61,20 & 52,00 & 52,70 \\
\hline & & $y_{2}$ & 47,84 & 55,67 & 42,37 & 46,56 & 39,21 & 33,91 \\
\hline & \multirow{2}{*}{ Alta } & $y_{1}$ & 57,81 & 63,08 & 52,14 & 62,93 & 45,26 & 64,40 \\
\hline & & $y_{2}$ & 52,04 & 44,50 & 44,62 & 43,43 & 25,18 & 41,22 \\
\hline \multirow{4}{*}{3} & \multirow{2}{*}{ Baixa } & $y_{1}$ & 35,69 & 38,07 & 36,70 & 38,26 & 35,85 & 33,96 \\
\hline & & $y_{2}$ & 34,24 & 39,67 & 33,65 & 32,41 & 29,43 & 18,43 \\
\hline & \multirow{2}{*}{ Alta } & $y_{1}$ & 39,21 & 40,51 & 35,92 & 39,28 & 31,29 & 34,74 \\
\hline & & $y_{2}$ & 35,87 & 32,76 & 35,33 & 32,49 & 26,63 & 26,18 \\
\hline
\end{tabular}

Os resultados obtidos com sinais PRBS (tabela 6.14) apresentam um comportamento igual ao obtido com sinais GBN, mas neste caso cabe mencionar que em alguns casos os sinais correlacionados forneceram melhores índices FIT.

Na seguinte subseção se apresentam os resultados usando o método de dois passos e a validação do modelo obtido com sinais puros, utilizando os dados da resposta a sinais criados pelo método de dois passos para observar o desempenho do modelo ao excitar as duas direções da planta.

\subsubsection{Resultados do Método de 2 passos}

Nas tabelas 6.15 e 6.16 são apresentadas a média dos índices FIT das validações dos modelos identificados com os sinais gerados a partir do método de dois passos com sinais GBN e PRBS, respectivamente. Nas tabelas 6.17 e 6.18 são apresentados os resultados da validação cruzada dos modelos identificados na subseção anterior com os dados obtidos usando sinais gerados pelo método de dois passos.

Dos resultados apresentados nas tabelas 6.15 e 6.16, consegue-se observar resultados um pouco piores, mas similares aos obtidos nas tabelas 6.13 e 6.14. Nestes resultados usando sinais gerados pelo método de dois passos continuam se apresentando casos nos quais os sinais correlacionados geraram respostas melhores que as obtidas com sinais de mínima correlação.

Se observa que os resultados apresentados na Tabela 6.15, usando sinais GBN, não apresentam o comportamento observado nas plantas medianamente e bem condicionadas, onde a cada aumento de $p$ são obtidos melhores resultados. Neste caso os valores dos índices oscilam com o aumento de $p$. Já, usando sinais PRBS se observou este comportamento crescente até $T_{b}=8$, nos valores de $T_{b}=12$ e 44 os índices foram descendo. 
Tabela 6.15: Resultados usando sinais GBN mistos.

\begin{tabular}{ccccccccc}
\hline \multirow{2}{*}{ SNR } & \multirow{2}{*}{ Corr. } & \multirow{2}{*}{ Saída } & \multicolumn{7}{c}{$p$} \\
\cline { 3 - 9 } & & 0,84 & 0,87 & 0,9 & 0,93 & 0,96 & 0,99 \\
\hline \multirow{3}{*}{30} & \multirow{2}{*}{ Baixa } & $y_{1}$ & 60,35 & 73,36 & 62,31 & 75,57 & 60,32 & 55,55 \\
\cline { 2 - 8 } & & $y_{2}$ & 62,79 & 64,67 & 43,29 & 58,68 & 41,52 & 60,30 \\
\cline { 2 - 9 } & \multirow{2}{*}{ Alta } & $y_{1}$ & 68,91 & 76,27 & 54,39 & 77,51 & 48,35 & 79,18 \\
& & $y_{2}$ & 54,26 & 49,69 & 49,52 & 62,45 & 20,17 & 67,84 \\
\hline \multirow{3}{*}{10} & \multirow{2}{*}{ Baixa } & $y_{1}$ & 47,00 & 58,91 & 55,01 & 61,20 & 52,00 & 52,70 \\
& & $y_{2}$ & 47,84 & 55,67 & 42,37 & 46,56 & 39,21 & 33,91 \\
\cline { 3 - 9 } & \multirow{2}{*}{ Alta } & $y_{1}$ & 57,81 & 63,08 & 52,14 & 62,93 & 45,26 & 64,40 \\
& & $y_{2}$ & 52,04 & 44,50 & 44,62 & 43,43 & 25,18 & 41,22 \\
\hline \multirow{3}{*}{3} & \multirow{2}{*}{ Baixa } & $y_{1}$ & 35,69 & 38,07 & 36,70 & 38,26 & 35,85 & 33,96 \\
& & $y_{2}$ & 34,24 & 39,67 & 33,65 & 32,41 & 29,43 & 18,43 \\
\cline { 2 - 8 } & \multirow{2}{*}{ Alta } & $y_{1}$ & 39,21 & 40,51 & 35,92 & 39,28 & 31,29 & 34,74 \\
& & $y_{2}$ & 35,87 & 32,76 & 35,33 & 32,49 & 26,63 & 26,18 \\
\hline
\end{tabular}

Tabela 6.16: Resultados usando sinais PRBS mistos.

\begin{tabular}{ccccccccc}
\hline \multirow{2}{*}{ SNR } & \multirow{2}{*}{ Corr. } & \multirow{2}{*}{ Saída } & \multicolumn{7}{c}{$T_{b}$} \\
\cline { 3 - 9 } & & 2 & 3 & 4 & 8 & 12 & 44 \\
\hline \multirow{3}{*}{30} & \multirow{2}{*}{ Baixa } & $y_{1}$ & 45,96 & 50,84 & 60,07 & 67,28 & 58,74 & 76,81 \\
& & $y_{2}$ & 40,24 & 44,07 & 39,88 & 52,10 & 46,95 & 22,71 \\
\cline { 2 - 9 } & \multirow{2}{*}{ Alta } & $y_{1}$ & 52,89 & 67,27 & 66,26 & 70,62 & 64,97 & 72,82 \\
& & $y_{2}$ & 58,89 & 67,01 & 65,31 & 53,68 & 45,61 & 41,11 \\
\hline \multirow{3}{*}{10} & \multirow{2}{*}{ Baixa } & $y_{1}$ & 39,26 & 48,57 & 53,22 & 59,78 & 59,17 & 62,32 \\
& & $y_{2}$ & 37,04 & 42,47 & 38,27 & 37,63 & 36,76 & 20,99 \\
\cline { 2 - 9 } & \multirow{2}{*}{ Alta } & $y_{1}$ & 49,14 & 57,22 & 55,73 & 58,91 & 59,36 & 59,04 \\
& & $y_{2}$ & 48,99 & 59,26 & 57,31 & 48,25 & 38,24 & 40,25 \\
\hline \multirow{3}{*}{3} & \multirow{2}{*}{ Baixa } & $y_{1}$ & 33,42 & 36,38 & 39,07 & 41,60 & 41,12 & 39,23 \\
\cline { 2 - 9 } & & $y_{2}$ & 28,89 & 32,93 & 28,68 & 29,99 & 27,78 & 26,17 \\
\cline { 2 - 9 } & \multirow{2}{*}{ Alta } & $y_{1}$ & 34,59 & 39,08 & 38,87 & 40,15 & 40,19 & 39,62 \\
& & $y_{2}$ & 40,12 & 43,73 & 43,50 & 38,81 & 32,65 & 26,05 \\
\hline
\end{tabular}

Tabela 6.17: Resultados da validação do modelo obtido com sinais GBN puros usando sinais GBN mistos.

\begin{tabular}{ccccccccc}
\hline \multirow{2}{*}{ SNR } & \multirow{2}{*}{ Corr. } & \multirow{2}{*}{ Saída } & \multicolumn{7}{c}{$p$} \\
\cline { 3 - 9 } & & & 0,84 & 0,87 & 0,9 & 0,93 & 0,96 & 0,99 \\
\hline \multirow{3}{*}{30} & \multirow{2}{*}{ Baixa } & $y_{1}$ & 16,86 & 18,00 & 25,40 & 26,39 & 19,54 & 27,17 \\
\cline { 2 - 9 } & \multirow{2}{*}{ Alta } & $y_{2}$ & $-18,42$ & 23,40 & 20,23 & 39,14 & 37,68 & 37,86 \\
\hline \multirow{4}{*}{10} & $y_{1}$ & $-111,65$ & 9,54 & 32,35 & $-16,20$ & 17,52 & $-127,59$ \\
& \multirow{2}{*}{ Baixa } & $y_{2}$ & 27,67 & 43,64 & 35,77 & 4,48 & 23,82 & $-96,32$ \\
\cline { 3 - 9 } & \multirow{2}{*}{ Alta } & $y_{2}$ & $-28,50$ & $-20,64$ & $-33,67$ & $-13,67$ & $-26,50$ & $-23,55$ \\
& & $y_{1}$ & $-28,99$ & $-2,76$ & $-12,61$ & 2,26 & 0,25 & $-6,20$ \\
\hline \multirow{4}{*}{3} & \multirow{2}{*}{ Baixa } & $y_{2}$ & $-29,99$ & $-2,76$ & $-12,61$ & 2,26 & 0,25 & $-6,20$ \\
\cline { 3 - 9 } & & $y_{1}$ & $-117,38$ & $-58,79$ & $-50,23$ & $-132,40$ & $-89,72$ & $-383,46$ \\
& \multirow{2}{*}{ Alta } & $y_{2}$ & $-32,37$ & $-41,15$ & $-31,25$ & $-105,43$ & $-82,53$ & $-355,96$ \\
\hline & $y_{1}$ & $-96,20$ & $-76,27$ & $-117,91$ & $-68,58$ & $-93,73$ & $-137,36$ \\
& & $y_{2}$ & $-87,33$ & $-58,66$ & $-71,05$ & $-52,20$ & $-58,53$ & $-95,11$ \\
\hline
\end{tabular}


Tabela 6.18: Resultados da validação do modelo obtido com sinais PRBS puros usando sinais PRBS mistos.

\begin{tabular}{|c|c|c|c|c|c|c|c|c|}
\hline \multirow{2}{*}{ SNR } & \multirow{2}{*}{ Corr. } & \multirow{2}{*}{ Saída } & \multicolumn{6}{|c|}{$T_{b}$} \\
\hline & & & 2 & 3 & 4 & 8 & 12 & 44 \\
\hline \multirow{4}{*}{30} & \multirow{2}{*}{ Baixa } & $y_{1}$ & $-74,33$ & 7,19 & $-14,19$ & 10,30 & 13,02 & 44,65 \\
\hline & & $y_{2}$ & $-41,97$ & $-10,12$ & $-23,25$ & 23,06 & 26,72 & 56,07 \\
\hline & \multirow{2}{*}{ Alta } & $y_{1}$ & $-176,00$ & $-256,82$ & $-305,63$ & $-481,44$ & $-91,08$ & $-14,02$ \\
\hline & & $y_{2}$ & 9,00 & $-309,40$ & $-317,27$ & $-548,71$ & 7,31 & 10,20 \\
\hline \multirow{4}{*}{10} & \multirow{2}{*}{ Baixa } & $y_{1}$ & $-67,62$ & $-49,15$ & $-38,27$ & $-38,11$ & $-51,58$ & 14,33 \\
\hline & & $y_{2}$ & $-53,50$ & $-21,13$ & $-40,48$ & $-26,75$ & $-21,01$ & 29,56 \\
\hline & \multirow{2}{*}{ Alta } & $y_{1}$ & $-67,62$ & $-49,15$ & $-38,27$ & $-38,11$ & $-51,58$ & 14,33 \\
\hline & & $y_{2}$ & $-53,50$ & $-21,13$ & $-40,48$ & $-26,75$ & $-21,01$ & 29,56 \\
\hline \multirow{4}{*}{3} & \multirow{2}{*}{ Baixa } & $y_{1}$ & $-127,35$ & $-265,90$ & $-258,77$ & $-381,46$ & $-144,95$ & $-82,27$ \\
\hline & & $y_{2}$ & $-133,55$ & $-324,48$ & $-292,64$ & $-472,56$ & $-118,66$ & $-60,07$ \\
\hline & \multirow{2}{*}{ Alta } & $y_{1}$ & $-104,07$ & $-109,56$ & $-121,27$ & $-121,07$ & $-112,46$ & $-40,85$ \\
\hline & & $y_{2}$ & $-109,03$ & $-70,25$ & $-105,09$ & $-87,84$ & $-96,97$ & $-12,05$ \\
\hline
\end{tabular}

Finalmente, ao realizar a validação cruzada dos modelos obtidos com sinais puros usando os dados obtidos excitando com sinais criados com o método de dois passos, se obtêm os resultados apresentados nas tabelas 6.17 e 6.18. Estes resultados em sua maioria apresentam-se com valores negativos, fazendo referência à dificuldade dos modelos obtidos com sinais puros, com os quais se excita só a região de alto ganho para descrever as respostas de baixo ganho. Neste tipo de processo mal condicionado se faz necessário usar sinais completamente correlacionados e descorrelacionados para excitar o processo em todas as suas regiões de operação, tanto a de alto como a de baixo ganho.

\subsection{Resumo}

Neste capítulo foram feitos quatro testes de simulação aplicados nas plantas descritas no Capítulo 4. Os testes foram feitos para evidenciar a influência da correlação cruzada e frequência de cada um dos sinais GBN e PRBS a partir de testes de Monte-Carlo.

O primeiro teste foi implementado no reator de polimerização e na coluna de destilação $3 x 3$ em malha aberta e fechada. Foram usados os sinais de alta e baixa correlação obtidos no capítulo anterior. Nos resultados nas duas plantas se percebeu uma maior influência da frequência dos sinais sobre os resultados de validação cruzada, os índices FIT foram melhores a cada incremento de $p$ e $T_{b}$. Por sua vez, não foram percebidas diferenças significativas entre os resultados obtidos com sinais de alta e baixa correlação.

Um segundo teste foi desenvolvido manipulando a frequência dos sinais individualmente para ter mais conhecimento da influência de cada um dos sinais sobre o processo de identificação. As plantas testadas foram a mesmas usadas no teste anterior, de dimensões $2 \times 2$ e $3 \times 3$. Novamente foi observado que sinais possuem a maior potência em baixas frequências permitem obter modelos identificados mais próximos aos processos reais. Com este teste foi possível avaliar as expressões encontradas na bibliografia para o cálculo dos parâmetros $p$ e $T_{b}$. Usando as equações (5.7), (5.6) e (5.8) foram obtidos 
valores adequados para a identificação em malha aberta, porém, em malha fechada os resultados forneceram valores mais altos aos observados experimentalmente.

Depois de analisar o efeito das frequências individualmente, foram testadas as plantas para vários níveis de correlação cruzada dos sinais de entrada. Para a geração dos diferentes níveis de correlação foram usados unicamente sinais GBN devido à limitada quantidade de sementes de geração que possuem os sinais PRBS. A partir de um valor de correlação cruzada maior que 0,4 , as funções de transferência dos modelos identificados foram perdendo qualidade, sendo acentuada quando estes sinais de excitação possuem valores próximos de 1 na sua Função de Correlação Cruzada. Contudo, usando altos níveis de correlação cruzada nos sinais de excitação foi possível identificar modelos de processo apenas com algumas quedas nos resultados de validação em comparação com sinais que possuem baixa correlação.

Por fim, foi implementado o método de dois passos para identificar o modelo da coluna de alta pureza. Este método permitiu excitar o processo nas direções de baixo e alto ganho. Para isto, os sinais de excitação foram construídos usando uma primeira parte completamente correlacionada, e uma segunda parte com baixa correlação. 


\section{Aplicação em tempo real: Planta piloto de neutralização de $p H$}

Para observar o efeito da correlação e aplicar os resultados obtidos em frequência em plantas MIMO em tempo real, a planta piloto de neutralização de $\mathrm{pH}$ localizada no Laboratório de Controle de Processos Industriais (LCPI) foi usada. As diferentes combinações foram geradas para sinais GBN e PRBS, portanto foram identificados e validados diferentes modelos.

\subsection{Descrição do processo}

A planta piloto de neutralização de pH é uma representação em escala de uma planta de neutralização de pH encontrada na indústria. Assim, esta planta utiliza equipamentos e instrumentação industrial para ter uma aproximação com aplicações práticas. Na Figura 7.2 se apresenta o P\&ID da planta piloto vista na Figura 7.1.

Figura 7.1: Foto da planta piloto de neutralização de pH do LCPI.

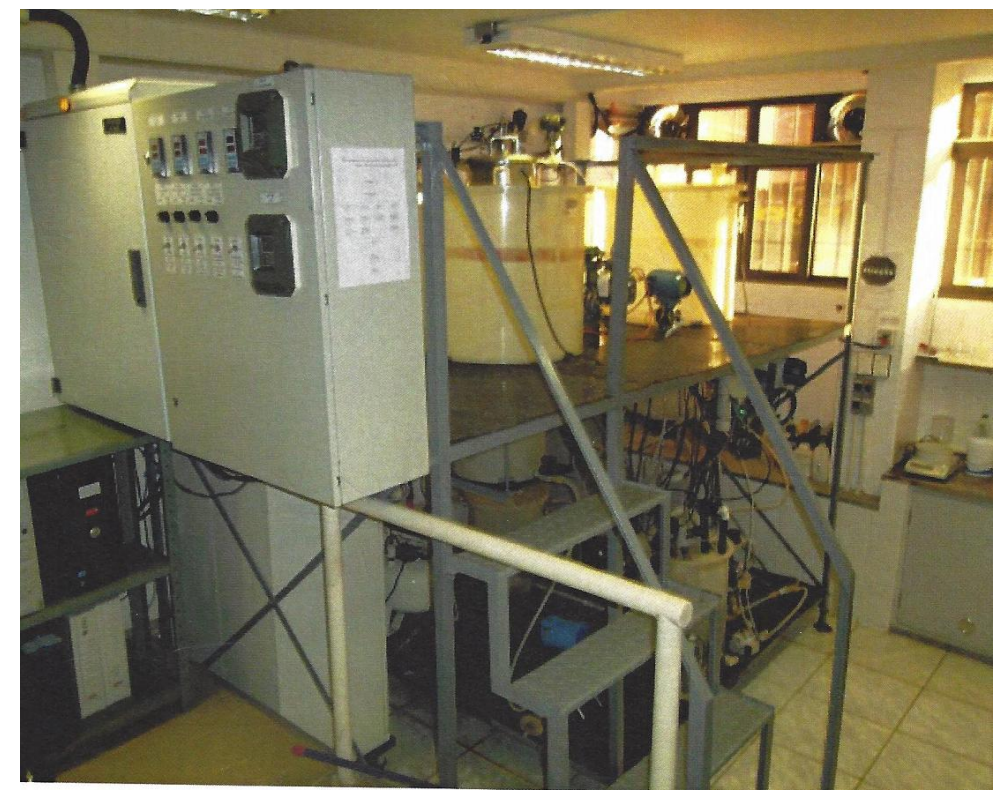

Fonte: Marques (2015). 
De acordo com o P\&ID mostrado na Figura 7.2, a planta piloto está composta por um tanque de ácido principal (TAP) onde uma solução de ácido clorídrico ( $\mathrm{HCl}$ ) é preparada. Esta solução é contida em um tanque intermediário (TAPI) para manter uma vazão constante na entrada do reator, o que é controlado por uma válvula manual. A vazão da solução de ácido é medida através do medidor de vazão (FIT-31).

Figura 7.2: P\&ID da planta de neutralização de pH.

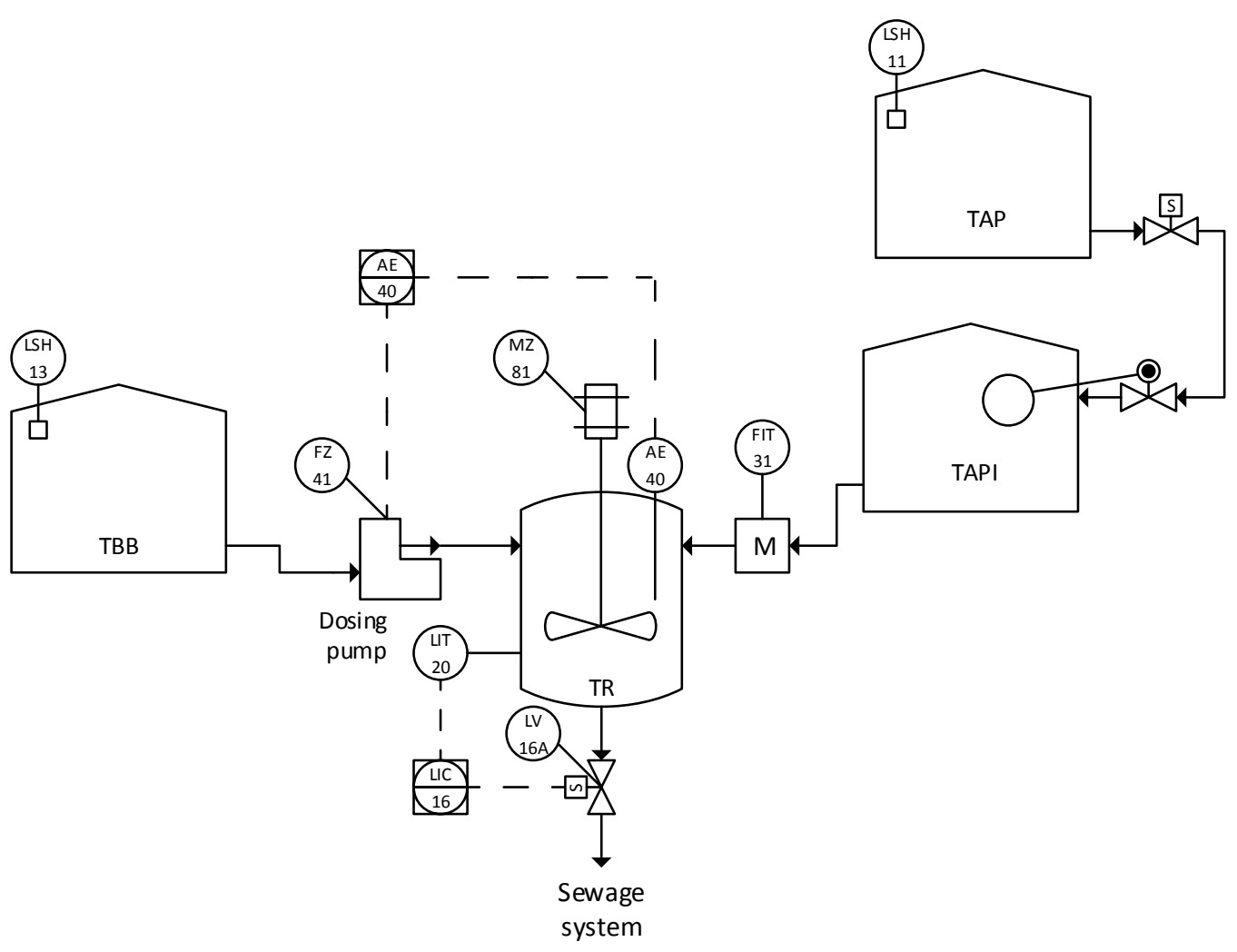

Fonte: Marques (2015).

O tanque de base (TBB) é usado para preparar a solução de hidróxido de sódio $(\mathrm{NaOH})$ com o fim de neutralizar a solução ácida bombeada pela bomba dosadora (FZ41).

Finalmente, a planta possui um tanque reator (TR) onde a neutralização é levada a cabo usando um agitador mecânico (MZ-81). Um sensor de pH (AE-40) mede o pH do TR. O controlador de pH (AIC-40) aumenta ou diminui a vazão de entrada da base para mantê-lo em um valor de setpoint. Além disso, um sensor de pressão diferencial (LT-20) mede o nível do TR, que é controlado pela válvula solenoide (LV-16A). O controlador de nível (LIC-16) mantém o nível do TR ao redor do 65\% do seu nível máximo. Deste modo, o TR é classificado como um tanque reator de agitação contínua.

Os controladores e a aquisição dos sinais são feitos com MATLAB ß. A comunicação entre o sistema de controle distribuído (SDCD) da planta e MATLAB @ ocorre por um servidor OPC (emphOLE for process control).

A Tabela 7.1 apresenta as principais características da planta de neutralização do LCPI. 
Tabela 7.1: Condições experimentais da planta de neutralização de pH.

\begin{tabular}{cc}
\hline Parâmetro & Valor \\
\hline Volume nominal do TR & $43 \mathrm{l}$ \\
Concentração de HCl no TAPI & $0,0056 \mathrm{~mol} / \mathrm{l}$ \\
Concentração de NaOH no TBB & $0,0047 \mathrm{~mol} / \mathrm{l}$ \\
Vazão máxima do TAPI ao TR & $50 \mathrm{l} / \mathrm{h}$ \\
Vazão máxima do TBB ao TR & $30 \mathrm{l} / \mathrm{h}$ \\
\hline
\end{tabular}

\subsection{Identificação em malha fechada}

Devido à instabilidade do processo, a identificação foi levada a cabo em malha fechada incluindo os controladores PID para as variáveis de $\mathrm{pH}$ e nível do TR.

Para a identificação dos modelos em malha fechada foram usados sinais GBN e PRBS, e foram selecionadas 3 combinações dos mesmos, a primeira delas com baixa correlação, a segunda com uma alta correlação e sementes de geração diferentes, e uma última usando a mesma semente e deslocando o sinal 10 atrasos, como é apresentado na Figura 7.3. Enquanto as duas primeiras combinações foram obtidas ao analisar a FCC mantendo o padrão de 60 atrasos usado neste trabalho, a última combinação de sinais foi gerada para realizar uma identificação em condições de máxima correlação nos sinais de excitação. Todos os sinais possuem um comprimento de 1500 amostras, usando as primeiras 900 para identificar o modelo e as últimas 600 para validar o mesmo.

Figura 7.3: Sinais deslocados para as entradas de nível e pH.

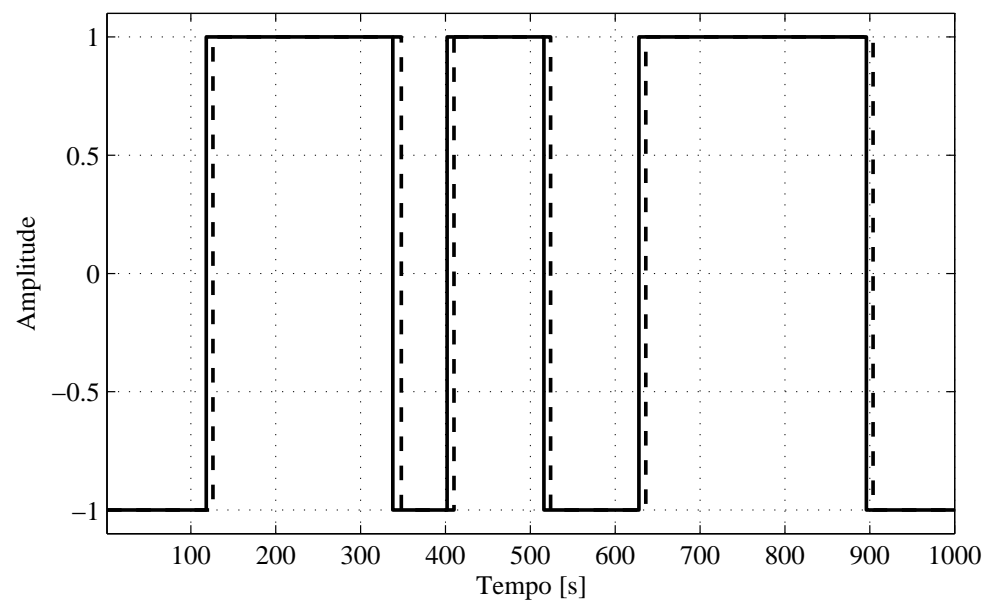

Fonte: Autor.

Na malha de nível, o estado estacionário foi de $65 \%$ e as variações na sua referência foram na faixa de $\pm 2,5 \%$, e a malha de $\mathrm{pH}$ possui um valor em estado estacionário de 7 e as variações na sua referência foram de 6,5 para 7,5 . As características de geração dos sinais para a identificação são apresentadas na Tabela 7.2.

Os valores de $p_{i}$ foram considerados menores que os obtidos usando a Equação (5.8), isto dada a dificuldade para gerar sinais com chaveamentos maiores que 2 usando pro- 
Tabela 7.2: Características de geração dos sinais para a identificação da planta piloto.

\begin{tabular}{ccc}
\hline Combinação & GBN & PRBS \\
\hline Baixa Corr. & $p_{1}=0,99$, sementes $=(274,991)$ & $T b_{1}=50$, sementes $=(19,20)$ \\
Alta Corr. & $p_{1}=0,99$, sementes $=(875,604)$ & $T b_{1}=50$, sementes $=(14,28)$ \\
Desloc. & $p_{1}=0,99$, semente $=274$ & $T b_{1}=100$, semente $=28$ \\
\hline
\end{tabular}

babilidades de não-chaveamento maiores que 0,996 . Por sua vez, os valores de $T_{b}$ foram calculados a partir de (5.5). Estes parâmetros foram calculados considerando as constantes de tempo do processo a partir de um pré-teste da planta usando a resposta ao pulso.

As estruturas usadas para a identificação foram ARX, ARMAX, OE e BJ, com as ordens e tempos mortos encontrados usando o algoritmo recursivo implementado em (GARCIA et al., 2004) como são mostrados nas Tabelas 7.3 e 7.4 .

Tabela 7.3: Ordens das estruturas usadas para a identificação da malha de nível

\begin{tabular}{|c|c|c|}
\hline Combinação & Modelo & Ordens \\
\hline \multirow{4}{*}{ Baixa Corr. } & ARX & $\mathbf{n a}=1 \mathbf{n b}=\left[\begin{array}{ll}1 & 1\end{array}\right] \mathbf{n} \mathbf{k}=\left[\begin{array}{ll}7 & 5\end{array}\right]$ \\
\hline & ARMAX & $\mathbf{n a}=4 \mathbf{n b}=\left[\begin{array}{ll}4 & 4\end{array}\right] \mathbf{n c}=4 \mathrm{nk}=\left[\begin{array}{ll}11 & 31\end{array}\right]$ \\
\hline & $\mathrm{OE}$ & $\mathbf{n} \mathbf{b}=\left[\begin{array}{ll}1 & 4\end{array}\right] \mathbf{n f}=\left[\begin{array}{ll}1 & 3\end{array}\right] \mathbf{n k}=\left[\begin{array}{ll}8 & 26\end{array}\right]$ \\
\hline & BJ & $\mathbf{n b}=\left[\begin{array}{ll}3 & 3\end{array}\right] \mathbf{n} \mathbf{c}=2 \mathbf{n d}=2 \mathbf{n f}=\left[\begin{array}{ll}3 & 3\end{array}\right] \mathbf{n} \mathbf{k}=\left[\begin{array}{ll}4 & 14\end{array}\right]$ \\
\hline \multirow{4}{*}{ Alta Corr. } & ARX & $\mathbf{n a}=3 \mathbf{n b}=\left[\begin{array}{ll}1 & 1\end{array}\right] \mathbf{n} \mathbf{k}=\left[\begin{array}{ll}6 & 20\end{array}\right]$ \\
\hline & ARMAX & $\mathbf{n a}=2 \mathbf{n b}=\left[\begin{array}{ll}1 & 1\end{array}\right] \mathbf{n} \mathbf{c}=1 \mathbf{n k}=\left[\begin{array}{ll}1 & 1\end{array}\right]$ \\
\hline & $\mathrm{OE}$ & $\mathrm{nb}=\left[\begin{array}{ll}4 & 1\end{array}\right] \mathbf{n f}=\left[\begin{array}{ll}3 & 4\end{array}\right] \mathbf{n k}=\left[\begin{array}{ll}6 & 1\end{array}\right]$ \\
\hline & BJ & $\mathbf{n b}=\left[\begin{array}{ll}4 & 1\end{array}\right] \mathbf{n} \mathbf{n}=3 \mathbf{n d}=4 \mathbf{n f}=\left[\begin{array}{ll}3 & 0\end{array}\right] \mathbf{n k}=\left[\begin{array}{ll}10 & 0\end{array}\right]$ \\
\hline \multirow{4}{*}{ Desloc. } & ARX & $\mathbf{n a}=1 \mathbf{n} \mathbf{b}=\left[\begin{array}{ll}1 & 1\end{array}\right] \mathbf{n} \mathbf{k}=\left[\begin{array}{ll}2 & 38\end{array}\right]$ \\
\hline & ARMAX & $\mathbf{n a}=1 \mathbf{n b}=\left[\begin{array}{ll}2 & 1\end{array}\right] \mathbf{n} \mathbf{c}=1 \mathbf{n k}=\left[\begin{array}{ll}3 & 0\end{array}\right]$ \\
\hline & $\mathrm{OE}$ & $\mathbf{n b}=\left[\begin{array}{ll}1 & 2\end{array}\right] \mathbf{n} \mathbf{f}=\left[\begin{array}{ll}1 & 1\end{array}\right] \mathbf{n k}=\left[\begin{array}{ll}1 & 1\end{array}\right]$ \\
\hline & BJ & $\mathbf{n b}=\left[\begin{array}{ll}2 & 1\end{array}\right] \mathbf{n} \mathbf{c}=3 \mathbf{n d}=3 \mathbf{n f}=\left[\begin{array}{ll}2 & 2\end{array}\right] \mathbf{n k}=\left[\begin{array}{ll}5 & 13\end{array}\right]$ \\
\hline
\end{tabular}

Tabela 7.4: Ordens das estruturas usadas para a identificação da da malha de pH

\begin{tabular}{|c|c|c|}
\hline Comb. & Modelo & Ordens \\
\hline \multirow{4}{*}{ Baixa Corr. } & ARX & $\mathbf{n a}=2 \mathbf{n b}=\left[\begin{array}{ll}1 & 1\end{array}\right] \mathbf{n k}=\left[\begin{array}{ll}25 & 4\end{array}\right]$ \\
\hline & ARMAX & $\mathbf{n a}=3 \mathbf{n b}=\left[\begin{array}{ll}3 & 1\end{array}\right] \mathbf{n} \mathbf{c}=1 \mathbf{n} \mathbf{n}=\left[\begin{array}{ll}1 & 1\end{array}\right]$ \\
\hline & $\mathrm{OE}$ & $\mathbf{n b}=\left[\begin{array}{ll}4 & 4\end{array}\right] \mathbf{n} \mathbf{f}=\left[\begin{array}{ll}4 & 4\end{array}\right] \mathbf{n k}=\left[\begin{array}{ll}1 & 1\end{array}\right]$ \\
\hline & BJ & $\mathbf{n b}=\left[\begin{array}{ll}1 & 4\end{array}\right] \mathbf{n} \mathbf{c}=4 \mathbf{n d}=1 \mathbf{n f}=\left[\begin{array}{ll}1 & 2\end{array}\right] \mathbf{n} \mathbf{k}=\left[\begin{array}{ll}1 & 1\end{array}\right]$ \\
\hline \multirow{4}{*}{ Alta Corr. } & ARX & $\mathbf{n a}=4 \mathbf{n b}=\left[\begin{array}{ll}1 & 3\end{array}\right] \mathbf{n k}=\left[\begin{array}{ll}0 & 4\end{array}\right]$ \\
\hline & ARMAX & $\mathbf{n} \mathbf{a}=1 \mathbf{n} \mathbf{b}=\left[\begin{array}{ll}2 & 3\end{array}\right] \mathbf{n} \mathbf{c}=1 \mathbf{n} \mathbf{k}=\left[\begin{array}{ll}39 & 3\end{array}\right]$ \\
\hline & $\mathrm{OE}$ & $\mathbf{n} \mathbf{b}=\left[\begin{array}{ll}1 & 1\end{array}\right] \mathbf{n} \mathbf{f}=\left[\begin{array}{ll}1 & 1\end{array}\right] \mathbf{n} \mathbf{k}=\left[\begin{array}{ll}1 & 1\end{array}\right]$ \\
\hline & BJ & $\mathbf{n b}=\left[\begin{array}{ll}1 & 1\end{array}\right] \mathbf{n} \mathbf{c}=1 \mathbf{n d}=1 \mathbf{n} \mathbf{f}=\left[\begin{array}{ll}1 & 1\end{array}\right] \mathbf{n} \mathbf{k}=\left[\begin{array}{ll}1 & 1\end{array}\right]$ \\
\hline \multirow{4}{*}{ Desloc. } & ARX & $\mathbf{n a}=1 \mathbf{n b}=\left[\begin{array}{ll}1 & 1\end{array}\right] \mathbf{n k}=\left[\begin{array}{ll}1 & 0\end{array}\right]$ \\
\hline & ARMAX & $\mathbf{n a}=1 \mathbf{n b}=\left[\begin{array}{ll}1 & 1\end{array}\right] \mathbf{n} \mathbf{c}=1 \mathbf{n k}=\left[\begin{array}{ll}1 & 1\end{array}\right]$ \\
\hline & $\mathrm{OE}$ & $\mathbf{n b}=\left[\begin{array}{ll}1 & 1\end{array}\right] \mathbf{n} \mathbf{f}=\left[\begin{array}{ll}1 & 1\end{array}\right] \mathbf{n k}=\left[\begin{array}{ll}1 & 1\end{array}\right]$ \\
\hline & BJ & $\mathbf{n b}=\left[\begin{array}{ll}1 & 1\end{array}\right] \mathbf{n} \mathbf{c}=1 \mathbf{n d}=1 \mathbf{n} \mathbf{f}=\left[\begin{array}{ll}0 & 2\end{array}\right] \mathbf{n} \mathbf{k}=\left[\begin{array}{ll}0 & 3\end{array}\right]$ \\
\hline
\end{tabular}


Uma série de validações foi feita para observar a qualidade dos modelos e para avaliar a influência da correlação na identificação usando as três diferentes condições dos sinais de entrada. Todas as validações usaram um horizonte infinito de predição, isto é, simulação livre do sistema.

\subsubsection{Resultados - Auto-validação}

A primeira validação feita foi a auto-validação, onde as saídas simuladas são comparadas com o conjunto de dados de identificação, os primeiros 900 pontos do experimento, como apresentado na Figura 7.4. Assim, as tabelas 7.5 e 7.6 mostram o índice FIT (\%) para a auto-validação usando sinais GBN e PRBS, respectivamente.

Figura 7.4: Auto-validação do modelo BJ usando sinais GBN de baixa correlação.

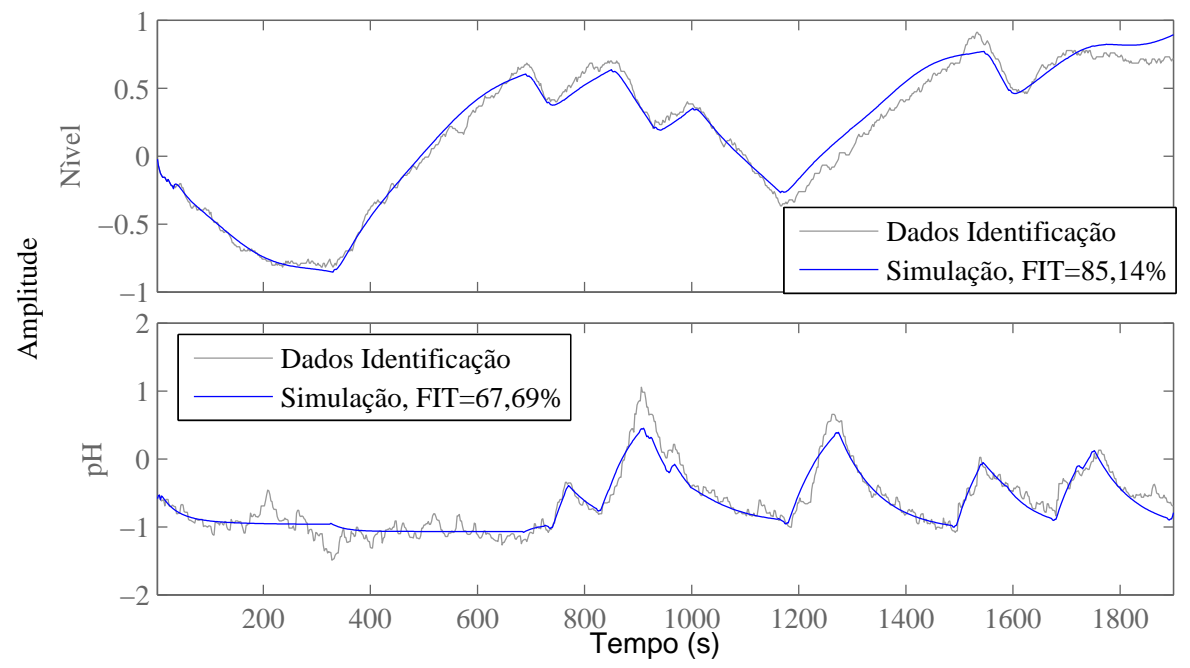

Fonte: Autor.

Tabela 7.5: Índice FIT (\%) da auto-validação para as três condições de correlação usando sinais GBN.

\begin{tabular}{cccccc}
\hline Combinação & Saída & ARX & ARMAX & OE & BJ \\
\hline \multirow{2}{*}{ Baixa Corr. } & Nível & 85,12 & 85,87 & 90,46 & 85,14 \\
& pH & 66,38 & 68,30 & 70,86 & 67,69 \\
Alta Corr. & Nível & 82,29 & 84,68 & 86,84 & 84,15 \\
& pH & 84,98 & 85,32 & 87,17 & 86,35 \\
Desloc. & Nível & 80,02 & 79,99 & 85,11 & 87,72 \\
& pH & 78,35 & 77,20 & 81,49 & 77,80 \\
\hline
\end{tabular}

Dos resultados da Tabela 7.5 pode ser observado que para todas as estruturas usadas e usando as três combinações de sinais os índices FIT atingiram valores muito bons. Usando a combinação de baixa correlação, os valores da auto-validação na saída de pH foram inferiores aos obtidos usando as combinações de alta correlação e os sinais deslocados. 
Tabela 7.6: Índice FIT (\%) da auto-validação para as três condições de correlação usando sinais PRBS.

\begin{tabular}{cccccc}
\hline Combinação & Saída & ARX & ARMAX & OE & BJ \\
\hline \multirow{2}{*}{ Baixa Corr. } & Nível & 72,66 & 75,31 & 81,40 & 73,00 \\
& pH & 77,22 & 78,56 & 82,28 & 76,39 \\
Alta Corr. & Nível & 68,62 & 63,07 & 89,60 & 64,54 \\
& pH & 58,88 & 55,74 & 73,80 & 75,92 \\
Desloc. & Nível & 50,26 & 76,45 & 87,76 & 81,48 \\
& pH & 52,78 & 75,30 & 79,80 & 80,43 \\
\hline
\end{tabular}

Por sua vez, dos resultados da Tabela 7.6 foi observado também que usando as três combinações de sinais os índices FIT foram muito bons. Neste caso, os índices da autovalidação na malha de $\mathrm{pH}$ foram melhores aos obtidos usando as combinações de alta correlação e os sinais deslocados.

\subsubsection{Resultados - Validação cruzada}

A primeira validação cruzada usa os últimos 600 pontos do experimento, como mostrado na Figura 7.5. As tabelas 7.7 e 7.8 mostram o índice FIT (\%) para a validação cruzada usando sinais GBN e PRBS, respectivamente.

Figura 7.5: Validação cruzada do modelo BJ usando sinais GBN de baixa correlação.

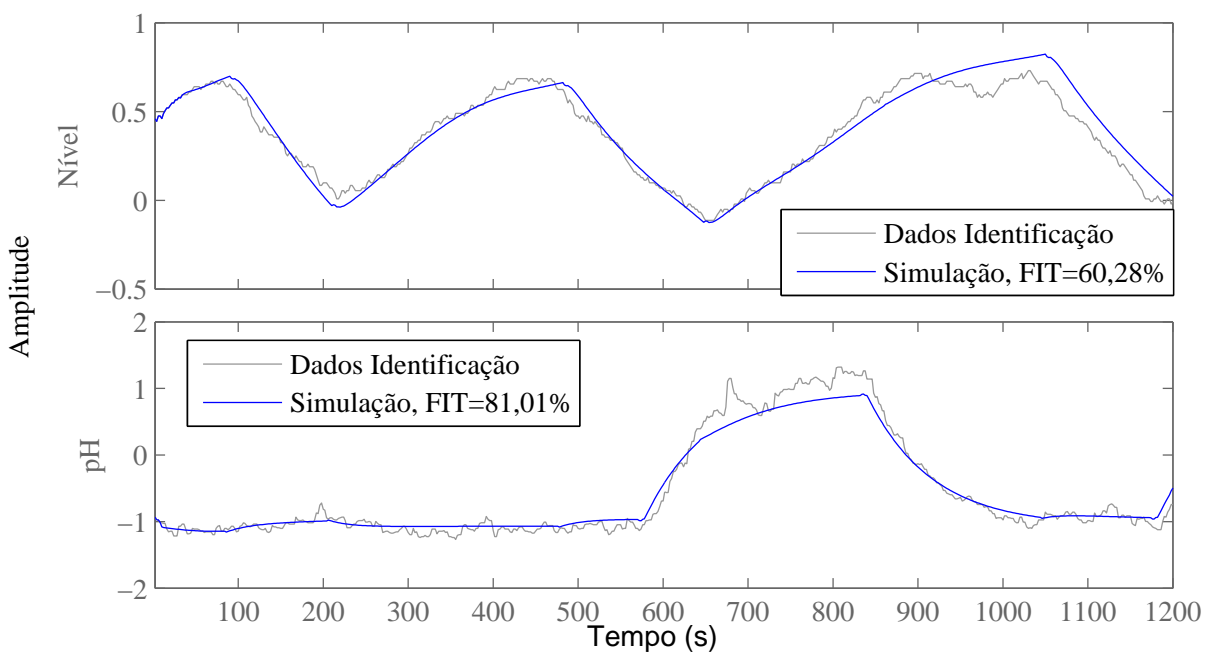

Fonte: Autor.

Os resultados mostrados na Tabela 7.7 não mostraram uma grande influência da correlação dos sinais GBN nos valores da validação cruzada para cada estrutura usada. Porém, os resultados mostrados na Tabela 7.8, usando sinais PRBS, mostraram uma influência da correlação dos sinais de alta correlação nos valores da validação cruzada nas estruturas ARX, ARMAX e mais fortemente na estrutura OE.

Os resultados da validação cruzada usando sinais GBN de baixa correlação foram melhores aos obtidos a partir da auto-validação, este efeito pode ser atribuído à pouca 
Tabela 7.7: Índice FIT (\%) da validação cruzada para as três condições de correlação usando sinais GBN.

\begin{tabular}{cccccc}
\hline Combinação & Saída & ARX & ARMAX & OE & BJ \\
\hline \multirow{2}{*}{ Baixa Corr. } & Nível & 61,86 & 57,63 & 67,61 & 70,28 \\
& pH & 80,54 & 82,32 & 86,01 & 81,01 \\
Alta Corr. & Nível & 71,55 & 65,62 & 79,59 & 70,71 \\
& pH & 79,76 & 79,31 & 70,11 & 72,50 \\
Desloc. & Nível & 52,59 & 48,49 & 81,25 & 83,89 \\
& pH & 64,66 & 72,34 & 81,02 & 75,73 \\
\hline
\end{tabular}

Tabela 7.8: Índice FIT (\%) da validação cruzada para as três condições de correlação usando sinais PRBS.

\begin{tabular}{cccccc}
\hline Combinação & Saída & ARX & ARMAX & OE & BJ \\
\hline \multirow{2}{*}{ Baixa Corr. } & Nível & 71,56 & 65,07 & 70,92 & 80,71 \\
& pH & 83,38 & 84,36 & 80,74 & 85,50 \\
Alta Corr. & Nível & 30,89 & 18,77 & $-9,77$ & 69,48 \\
& pH & 43,79 & 43,48 & 53,56 & 60,78 \\
Desloc. & Nível & 36,52 & 64,26 & 74,27 & 66,80 \\
& pH & 27,43 & 66,77 & 73,97 & 74,88 \\
\hline
\end{tabular}

variação que teve o sinal de referência de $\mathrm{pH}$ no conjunto de dados usado para a validação cruzada, como mostrado na Figura 7.5. Esta característica também foi observada no conjunto de dados usado para a validação cruzada usando sinais PRBS de baixa correlação.

Um conjunto de dados de pré-teste, usado para a obtenção dos valores das constantes de tempo foi usado para uma segunda validação cruzada. Os dados de pré-teste foram obtidos aplicando-se pulsos individuais em cada entrada para observar a característica individual de cada função de transferência como mostrado na Figura 7.6. Os resultados da validação dos modelos à resposta ao pulso são apresentados nas tabelas 7.9 e 7.10 usando sinais GBN e PRBS, respectivamente.

Figura 7.6: Validação cruzada da resposta ao degrau do modelo BJ usando sinais GBN de baixa correlação.

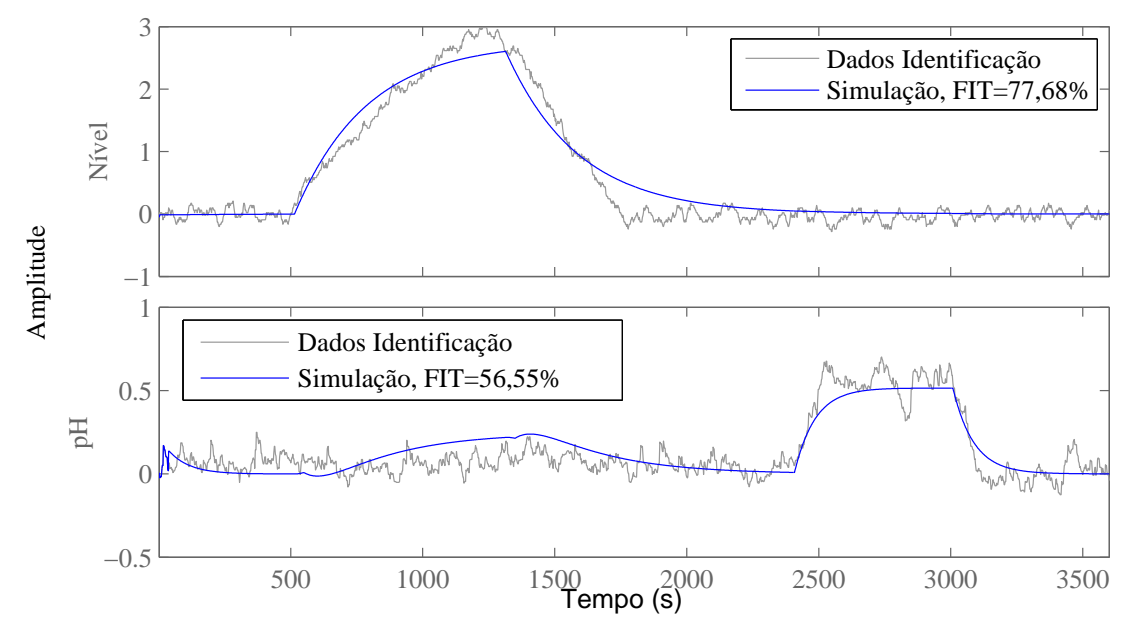

Fonte: Autor. 
Tabela 7.9: Índice FIT (\%) da validação cruzada da resposta ao degrau para as três condições de correlação usando sinais GBN.

\begin{tabular}{cccccc}
\hline Combinação & Saída & ARX & ARMAX & OE & BJ \\
\hline \multirow{2}{*}{ Baixa Corr. } & Nível & 77,75 & 78,76 & 61,66 & 79,45 \\
& pH & 59,47 & 59,88 & 57,45 & 52,94 \\
Alta Corr. & Nível & 77,47 & 76,89 & 64,46 & 78,69 \\
& pH & 59,77 & 59,07 & 31,92 & 35,17 \\
\multirow{2}{*}{ Desloc. } & Nível & 76,03 & 75,64 & $-770,85$ & 70,02 \\
& pH & $-76,24$ & $-47,21$ & $-151,87$ & 18,36 \\
\hline
\end{tabular}

Tabela 7.10: Índice FIT (\%) da validação cruzada da resposta ao degrau para as três condições de correlação usando sinais PRBS.

\begin{tabular}{cccccc}
\hline Combinação & Saída & ARX & ARMAX & OE & BJ \\
\hline \multirow{2}{*}{ Baixa Corr. } & Nível & 47,27 & 46,83 & 41,23 & 60,77 \\
& pH & 39,80 & 45,10 & 54,50 & 56,58 \\
Alta Corr. & Nível & $-81,26$ & $-1,43$ & $-84,03$ & 61,24 \\
& pH & $-26,28$ & 49,30 & 53,31 & 51,01 \\
Desloc. & Nível & $-22,65$ & $-1715,55$ & $-0,79$ & 16,38 \\
& pH & 14,37 & $-1091,55$ & 42,21 & 50,54 \\
\hline
\end{tabular}

Dos resultados apresentados na Tabela 7.9 pode ser observado que o uso dos sinais deslocados provocou uma identificação errada das funções de transferência correspondentes à diagonal do modelo da planta em malha fechada. A identificação insatisfatória foi caracterizada por valores negativos nos FIT das respostas. Porém, a identificação do sistema foi afetada para as estrutura OE e BJ usando sinais de alta correlação em comparação com os de baixa. Para as estruturas ARX e ARMAX duas combinações de baixa e alta correlação apresentaram índices muito similares.

Para sinais PRBS, se observou na Tabela 7.10 que a identificação foi insatisfatória usando sinais deslocados e inclusive usando sinais de alta correlação, exceto a identificação usando a estrutura BJ. Esta perda da capacidade de identificação usando sinais PRBS de alta correlação pode ser atribuída ao alto valor da FCC dos sinais, com seu valor de pico $r_{x y}=0,94412$ no atraso 50 .

\subsection{Identificação direta da planta em malha fechada}

Nos experimentos realizados para a identificação do processo em malha fechada foram salvos também os sinais de controle das saídas dos controladores PI usados. Isto com o fim de realizar uma identificação do modelo da planta usando diretamente o sinal de controle e as saídas. Novamente ass estruturas usadas para a identificação foram ARX, ARMAX, OE e BJ, com as ordens e tempos mortos encontrados usando o algoritmo recursivo implementado em (GARCIA et al., 2004) como são mostrados nas Tabelas 7.11 e 7.12 . 
Tabela 7.11: Ordens das estruturas usadas para a identificação da malha de nível

\begin{tabular}{|c|c|c|}
\hline Combinação & Modelo & Ordens \\
\hline \multirow{4}{*}{ Baixa Corr. } & ARX & $\mathbf{n a}=1 \mathbf{n b}=\left[\begin{array}{ll}0 & 1\end{array}\right] \mathbf{n} \mathbf{k}=\left[\begin{array}{ll}1 & 2\end{array}\right]$ \\
\hline & ARMAX & $\mathbf{n a}=2 \mathbf{n b}=\left[\begin{array}{ll}2 & 1\end{array}\right] \mathbf{n} \mathbf{c}=3 \mathbf{n k}=\left[\begin{array}{ll}19 & 22\end{array}\right]$ \\
\hline & $\mathrm{OE}$ & $\mathbf{n b}=\left[\begin{array}{ll}3 & 1\end{array}\right] \mathbf{n f}=\left[\begin{array}{ll}2 & 1\end{array}\right] \mathbf{n k}=\left[\begin{array}{ll}2 & 25\end{array}\right]$ \\
\hline & BJ & $\mathbf{n b}=\left[\begin{array}{ll}4 & 4\end{array}\right] \mathbf{n} \mathbf{c}=4 \mathbf{n d}=4 \mathbf{n f}=\left[\begin{array}{ll}4 & 4\end{array}\right] \mathbf{n k}=\left[\begin{array}{ll}1 & 1\end{array}\right]$ \\
\hline \multirow{4}{*}{ Aalta Corr. } & ARX & $\mathbf{n a}=2 \mathbf{n b}=\left[\begin{array}{ll}4 & 0\end{array}\right] \mathbf{n k}=\left[\begin{array}{ll}38 & 1\end{array}\right]$ \\
\hline & ARMAX & $\mathbf{n a}=1 \mathbf{n b}=\left[\begin{array}{ll}2 & 0\end{array}\right] \mathbf{n} \mathbf{c}=3 \mathbf{n k}=\left[\begin{array}{ll}38 & 1\end{array}\right]$ \\
\hline & $\mathrm{OE}$ & $\mathrm{nb}=\left[\begin{array}{ll}4 & 4\end{array}\right] \mathbf{n} \mathbf{f}=\left[\begin{array}{ll}4 & 4\end{array}\right] \mathbf{n} \mathbf{k}=\left[\begin{array}{ll}1 & 1\end{array}\right]$ \\
\hline & BJ & $\mathbf{n b}=\left[\begin{array}{ll}4 & 4\end{array}\right] \mathbf{n} \mathbf{c}=4 \mathbf{n d}=4 \mathbf{n f}=\left[\begin{array}{ll}4 & 4\end{array}\right] \mathbf{n k}=\left[\begin{array}{ll}1 & 1\end{array}\right]$ \\
\hline \multirow{4}{*}{ Desloc. } & ARX & $\mathbf{n a}=4 \mathbf{n b}=\left[\begin{array}{ll}4 & 4\end{array}\right] \mathbf{n k}=\left[\begin{array}{ll}41 & 16\end{array}\right]$ \\
\hline & ARMAX & $\mathbf{n a}=3 \mathbf{n b}=\left[\begin{array}{ll}2 & 2\end{array}\right] \mathbf{n} \mathbf{c}=1 \mathbf{n k}=\left[\begin{array}{ll}47 & 13\end{array}\right]$ \\
\hline & $\mathrm{OE}$ & $\mathbf{n b}=\left[\begin{array}{ll}4 & 4\end{array}\right] \mathbf{n f}=\left[\begin{array}{ll}4 & 4\end{array}\right] \mathbf{n} \mathbf{k}=\left[\begin{array}{ll}1 & 1\end{array}\right]$ \\
\hline & BJ & $\mathbf{n b}=\left[\begin{array}{ll}2 & 1\end{array}\right] \mathbf{n} \mathbf{c}=3 \mathbf{n d}=1 \mathbf{n f}=\left[\begin{array}{ll}4 & 4\end{array}\right] \mathbf{n} \mathbf{k}=\left[\begin{array}{ll}12 & 3\end{array}\right]$ \\
\hline
\end{tabular}

Tabela 7.12: Ordens das estruturas usadas para a identificação da da malha de pH

\begin{tabular}{ccc}
\hline Combinação & Modelo & Ordens \\
\hline & ARX & $\mathbf{n a}=2 \mathbf{n b}=\left[\begin{array}{ll}1 & 1\end{array}\right] \mathbf{n k}=\left[\begin{array}{ll}37 & 50\end{array}\right]$ \\
Baixa Corr. & ARMAX & $\mathbf{n a}=3 \mathbf{n b}=\left[\begin{array}{ll}3 & 2\end{array}\right] \mathbf{n} \mathbf{n}=1 \mathbf{n k}=\left[\begin{array}{ll}42 & 47\end{array}\right]$ \\
& OE & $\mathbf{n b}=\left[\begin{array}{ll}4 & 4\end{array}\right] \mathbf{n f}=\left[\begin{array}{ll}4 & 4\end{array}\right] \mathbf{n k}=\left[\begin{array}{ll}1 & 1\end{array}\right]$ \\
& BJ & $\mathbf{n b}=\left[\begin{array}{ll}4 & 4\end{array}\right] \mathbf{n} \mathbf{n}=4 \mathbf{n d}=4 \mathbf{n}=\left[\begin{array}{ll}4 & 4\end{array}\right] \mathbf{n k}=\left[\begin{array}{ll}28 & 1\end{array}\right]$ \\
\hline & ARX & $\mathbf{n a}=4 \mathbf{n b}=\left[\begin{array}{ll}1 & 2\end{array}\right] \mathbf{n k}=\left[\begin{array}{ll}23 & 48\end{array}\right]$ \\
Alta Corr. & ARMAX & $\mathbf{n a}=4 \mathbf{n b}=\left[\begin{array}{ll}2 & 4\end{array}\right] \mathbf{n c}=1 \mathbf{n k}=\left[\begin{array}{ll}21 & 44\end{array}\right]$ \\
& OE & $\mathbf{n b}=\left[\begin{array}{ll}4 & 3\end{array}\right] \mathbf{n f}=\left[\begin{array}{ll}4 & 2\end{array}\right] \mathbf{n k}=\left[\begin{array}{ll}35 & 4\end{array}\right]$ \\
& BJ & $\mathbf{n b}=\left[\begin{array}{ll}2 & 2\end{array}\right] \mathbf{n c}=2 \mathbf{n d}=2 \mathbf{n f}=\left[\begin{array}{ll}2 & 2\end{array}\right] \mathbf{n k}=\left[\begin{array}{ll}29 & 12\end{array}\right]$ \\
\hline & ARX & $\mathbf{n a}=1 \mathbf{n b}=\left[\begin{array}{ll}1 & 1\end{array}\right] \mathbf{n k}=\left[\begin{array}{ll}1 & 1\end{array}\right]$ \\
& ARMAX & $\mathbf{n a}=2 \mathbf{n b}=\left[\begin{array}{ll}3 & 3\end{array}\right] \mathbf{n c}=1 \mathbf{n k}=\left[\begin{array}{ll}10 & 2\end{array}\right]$ \\
Desloc. & OE & $\mathbf{n b}=\left[\begin{array}{ll}1 & 3\end{array}\right] \mathbf{n f}=\left[\begin{array}{ll}2 & 3\end{array}\right] \mathbf{n k}=\left[\begin{array}{ll}1 & 1\end{array}\right]$ \\
& BJ & $\mathbf{n b}=\left[\begin{array}{ll}4 & 4\end{array}\right] \mathbf{n c}=4 \mathbf{n d}=4 \mathbf{n f}=\left[\begin{array}{ll}4 & 4\end{array}\right] \mathbf{n k}=\left[\begin{array}{ll}1 & 1\end{array}\right]$ \\
\hline
\end{tabular}

Nas tabelas 7.13 e 7.14 são apresentados os resultados de auto-validação da identificação direta do modelo da planta usando sinais GBN e PRBS, respectivamente.

Tabela 7.13: Índice FIT (\%) da auto-validação para as três condições de correlação usando sinais GBN.

\begin{tabular}{cccccc}
\hline Combinação & Saída & ARX & ARMAX & OE & BJ \\
\hline \multirow{2}{*}{ Baixa Corr. } & Nível & 65,21 & 60,64 & 86,22 & 85,65 \\
& pH & 38,48 & 46,54 & 67,44 & 62,30 \\
Alta Corr. & Nível & 75,17 & 78,12 & 87,84 & 78,59 \\
& pH & 14,72 & 2,51 & 57,77 & 76,30 \\
Desloc. & Nível & 25,82 & 76,72 & 78,42 & 75,99 \\
& pH & 49,56 & 75,52 & 80,52 & 77,13 \\
\hline
\end{tabular}

No caso da identificação usando sinais GBN foram observadas algumas estruturas com maior dificuldade para identificar o modelo do processo. As estruturas ARX e ARMAX na 
combinação de alta correlação foram as que apresentaram índices FIT da auto-validação na saída de $\mathrm{pH}$ baixos, um valor baixo também foi obtido para a estrutura ARX na saída do nível identificado com sinais deslocados.

Tabela 7.14: Índice FIT (\%) da auto-validação para as três condições de correlação usando sinais PRBS.

\begin{tabular}{cccccc}
\hline Combinação & Saída & ARX & ARMAX & OE & BJ \\
\hline \multirow{2}{*}{ Baixa Corr. } & Nível & 55,88 & 57,56 & 74,82 & 69,15 \\
& pH & 46,78 & 43,80 & 26,47 & 71,49 \\
Alta Corr. & Nível & $-56,83$ & $-41,272$ & 74,40 & 68,09 \\
& pH & $-25,86$ & 26,63 & 84,36 & 60,73 \\
Desloc. & Nível & 57,09 & 65,92 & 62,46 & 85,95 \\
& pH & 65,49 & 75,00 & 59,10 & 81,09 \\
\hline
\end{tabular}

Os resultados utilizando sinais PRBS apresentaram uma característica similar à obtida usando sinais GBN como excitação, mas neste caso a dificuldade para identificar o modelo de processo usando estruturas ARX e ARMAX com sinais de alta correlação foi evidenciada nos valores negativos dos seus índices FIT.

Finalmente, as tabelas 7.15 e 7.16 apresentam os resultados da validação cruzada da identificação direta do modelo da planta usando sinais GBN e PRBS, respectivamente.

Tabela 7.15: Índice FIT (\%) da validação cruzada para as três condições de correlação usando sinais GBN.

\begin{tabular}{cccccc}
\hline Combinação & Saída & ARX & ARMAX & OE & BJ \\
\hline \multirow{2}{*}{ Baixa Corr. } & Nível & 13,22 & 24,93 & 5,40 & 74,19 \\
& pH & 59,53 & 60,85 & 68,96 & 64,70 \\
Alta Corr. & Nível & $-14,87$ & $-38,04$ & 43,12 & 75,63 \\
& pH & 38,76 & 39,58 & 40,34 & 75,47 \\
Desloc. & Nível & $-64,67$ & $-37,71$ & 78,15 & 49,67 \\
& pH & $-5,44$ & 15,34 & 68,58 & 71,36 \\
\hline
\end{tabular}

Nos resultados da validação cruzada dos modelos identificados usando sinais GBN se perceberam valores negativos nas estruturas que apresentaram dificuldade para identificar o modelo na auto-validação, como era de esperar. Porém, as estruturas ARX, ARMAX e OE apresentaram valores muito inferiores aos obtidos na auto-validação, enquanto outras estruturas como a BJ usando sinais de alta correlação e OE para sinais deslocados apresentaram índices FIT satisfatórios, próximos dos obtidos na auto-validação.

Nos resultados apresentados na tabela 7.16 são observados resultados similares aos obtidos usando sinais GBN. Os valores negativos na auto-validação para estruturas que apresentaram dificuldade para identificar o modelo apareceram novamente na validação cruzada, como era de esperar. Foram encontrados também índices satisfatórios nas estruturas BJ em todas as combinações dos sinais. 
Tabela 7.16: Índice FIT (\%) da validação cruzada para as três condições de correlação usando sinais PRBS.

\begin{tabular}{cccccc}
\hline Combinação & Saída & ARX & ARMAX & OE & BJ \\
\hline \multirow{2}{*}{ Baixa Corr. } & Nível & 41,65 & 45,16 & 56,04 & 69,04 \\
& pH & 33,20 & 30,51 & 62,05 & 78,74 \\
Alta Corr. & Nível & $-149,11$ & $-18,30$ & 64,91 & 78,57 \\
& pH & $-41,28$ & 5,09 & 8,70 & 81,11 \\
Desloc. & Nível & 57,80 & 15,55 & 40,96 & 74,54 \\
& pH & 70,53 & 68,43 & 38,18 & 76,35 \\
\hline
\end{tabular}

Nos testes realizados identificando o modelo da planta diretamente foram observados resultados satisfatórios usando estruturas BJ, sendo um pouco mais imunes à alta correlação presente nos sinais de excitação. Cabe lembrar que o sinal usado para identificar é o sinal de controle gerado pelo controlador PI, que não é propriamente o sinal pseudoaleatório, mas este sinal conserva as propriedades de correlação dos sinais originais, diferindo no sentido da correlação entre eles. Isto é apresentado na Figura 7.7.

Figura 7.7: FCC dos sinais de SP e as saídas do controlador.
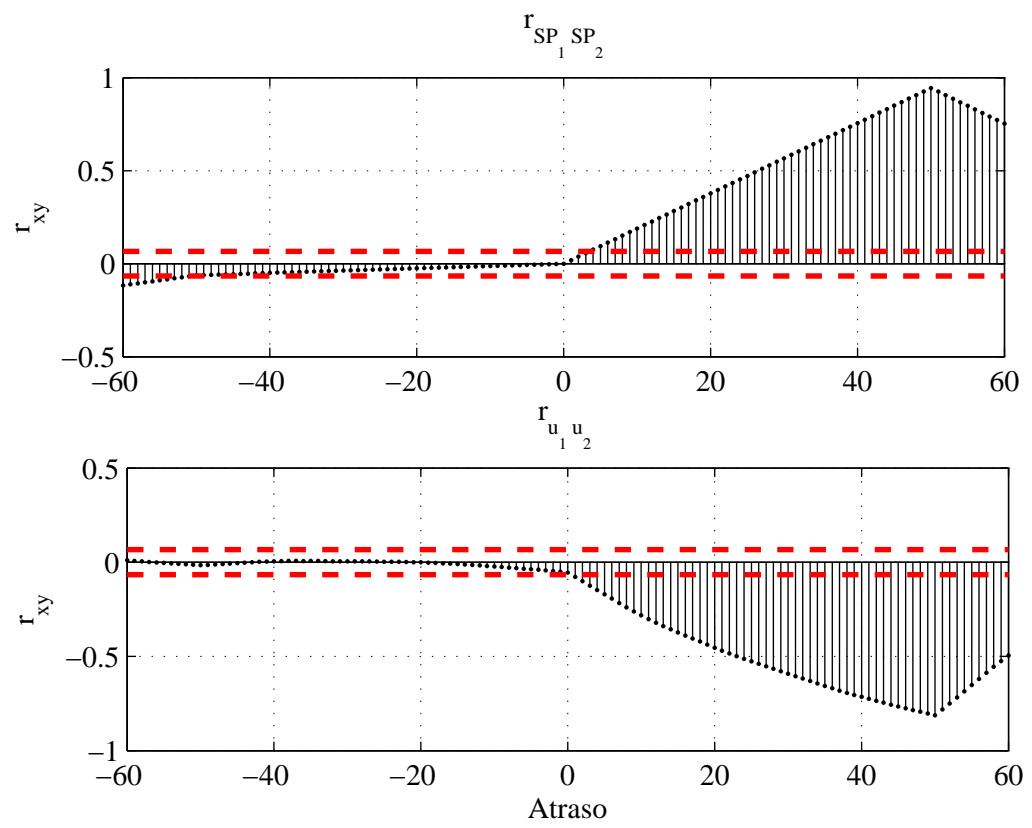

Fonte: Autor.

Finalmente ressalta-se que as combinações de sinais que menos problemas enfrentaram na hora de identificar o processo em malha fechada e o modelo da planta diretamente foram as de baixa correlação. Porém, seus valores máximos da FCC estiveram acima do limite $r_{\text {lim }}=0,0667$, calculado a partir de (5.4) usando $\mathrm{N}=900$. 


\subsection{Resumo}

Neste último capítulo foram testados os sinais GBN e PRBS em três combinações de correlação, isto com o objetivo de analisar os resultados obtidos no capítulo anterior em uma aplicação em tempo real. A aplicação em tempo real escolhida foi uma planta de neutralização de pH de dimensão 2x2. O projeto de identificação foi feito em malha fechada usando sinais com baixa correlação, alta correlação, e uma última combinação de sinais usando a mesma semente e deslocando o sinal 10 atrasos.

No geral, os resultados de auto-validação e validação cruzada mostraram que para as estruturas BJ e OE foi possível identificar o modelo em malha fechada e o modelo de processo com bons resultados FIT, independente da combinação de baixa ou alta correlação cruzada. Também foi observado que o uso combinação de sinais de baixa correlação na identificação gerou modelos com resultados positivos do FIT em todas as validações das estruturas usadas. 


\section{Conclusões}

\subsection{Principais Conclusões}

No Capítulo referente ao projeto de sinais de excitação foram estudadas as características de correlação cruzada e de frequência a partir de uma abordagem prática na qual os sinais GBN e PRBS foram gerados a partir de implementação de códigos no software MATLABR. O estudo partiu do critério básico para definir a correlação entre dois sinais, o coeficiente de Pearson e a significância do mesmo para o calculo do limite máximo a ser atingido na FCC por sinais considerados descorrelacionados. Foi definida a média dos valores da função de correlação cruzada e com esta foi observada uma dependência quase linear da média das correlações cruzadas e os tempos de bit em sinais PRBS. Já os sinais GBN apresentaram uma dependência exponencial em relação à probabilidade de não-chaveamento.

Após o estudo de correlação cruzada em sinais GBN e PRBS, foi feito um estudo do espectro de potência modificando as sementes de geração dos sinais. Em sinais GBN foi observado que o espectro de frequência dos sinais apresentam uma característica mais próxima da obtida analiticamente conforme o comprimento do sinal aumenta. Portanto, nos códigos de geração de sinais GBN usados neste trabalho foi incluída uma restrição para obter sinais com frequências de corte do espectro de potência próximas das calculadas analiticamente para cada probabilidade de não-chaveamento. Este ajuste foi válido para valores de $p \leq 0,96$. Com estas considerações foi observada uma dependência exponencial da frequência de corte do espectro de potência em relação à probabilidade de não-chaveamento.

Os sinais PRBS apresentam espectros de potência próximos a cada mudança da semente de geração, chegando a ser praticamente iguais quando são usados sinais de máximo comprimento. Por sua vez, a frequência de $3 \mathrm{~dB}$ do espectro de potência apresenta uma dependência similar a uma função raiz quadrada.

Baseado em testes de simulação em malha aberta e fechada realizados em plantas bem e medianamente condicionadas, tanto os sinais de excitação GBN como PRBS mostraram índices FIT melhores a cada incremento nos tempos médios de chaveamento, que em uma primeira observação da influência da frequência dos sinais de excitação sobre os resultados de identificação, infere que o uso de sinais de menor frequência apresentam melhores modelos identificados. O estudo foi aumentado usando probabilidades de não-chaveamento e tempos de bit independentes para cada entrada e setpoint. Estes estudos avaliaram a 
aplicação das expressões encontradas na literatura para o cálculo da faixa de frequências que os sinais de excitação devem possuir, com valores de $p$ e $T_{b}$ adequados, para extrair a informação dinâmica dos processos em malha aberta. Em malha fechada os resultados analíticos foram maiores aos obtidos experimentalmente.

Os resultados de simulação em plantas bem e medianamente condicionadas indicam que os sinais correlacionados pouco afetam o processo de identificação. A partir de um valor de correlação cruzada maior que 0,4 , as funções de transferência dos modelos identificados foram perdendo qualidade, sendo acentuada quando estes sinais de excitação possuem valores próximos de 1 na sua Função de Correlação Cruzada. Estes casos são mais comuns de encontrar usando sinais do tipo PRBS, devido à forma como são gerados, onde basicamente o conjunto de sinais gerados para a identificação multivariável é o mesmo, mas deslocado no tempo. Isto quer indicar que na hora de usar sinais PRBS para identificação multivariável se devem tomar mais precauções para evitar as altas correlações entre os sinais gerados, o que em sinais GBN é mais difícil de acontecer.

As considerações de correlação entre os sinais de excitação foi levado ao caso das plantas mal condicionadas, onde conclui-se que para excitar este tipo de plantas em todas as suas regiões de operação, tanto a região de alto ganho como a de baixo, se faz necessário incluir sinais completamente correlacionados. Já que usando sinais de baixa correlação ou intermediária, se excita só a região de alto ganho e os modelos gerados não conseguem descrever a região de baixo ganho.

Finalmente, foram avaliadas três combinações de sinais GBN e PRBS em uma aplicação em tempo real de uma planta piloto de $\mathrm{pH}$. As combinações dos sinais foram de baixa correlação, alta correlação e uma terceira combinação de sinais deslocados por 10 amostras. Foram usadas as expressões encontradas na literatura para o cálculo dos parâmetros $p$ e $T_{b}$ a partir de informações dos dados de pré-teste da resposta ao pulso da planta. Os valores de $p$ e $T_{b}$ foram modificados para valores menores devido a considerações práticas. Os resultados mostraram que o uso de sinais de baixa correlação na identificação do sistema em malha fechada e da planta diretamente usando os sinais de controle, geraram melhores modelos identificados.

\subsection{Recomendações e trabalhos futuros}

A seguir são apresentadas algumas perspectivas de extensão deste trabalho:

- Os estudos de correlação realizados neste trabalho foram feitos em processos de dimensão $2 \times 2$ e $3 \times 3$. Por tal razão se poderia propor estudos em modelos com mais variáveis de entrada e saída, visando estudar o efeito da correlação cruzada em outras plantas de maior dimensão.

- No estudo de frequências foi observado que as formas analíticas do cálculo dos parâmetros $p$ e $T_{b}$ estiveram de acordo com os resultados experimentais em malha 
aberta. Em malha fechada o cálculo destes parâmetros usando as mesmas expressões resultaram em valores maiores aos obtidos experimentalmente, por esta razão na aplicação em tempo real na planta piloto de Neutralização de pH foram considerados menores aos obtidos analiticamente. Propõe-se portanto realizar novos estudos sobre a forma analítica de estimar a frequência adequada dos sinais de excitação para sistemas em malha fechada. 


\section{Referências Bibliográficas}

AGUIRRE, L. A. Introdução à identificação de sistemas: técnicas lineares e não-lineares aplicadas a sistemas reais. 3ra. ed. Belo Horizonte: Editora da Universidade Federal de Minas Gerais., 2007.

ANDERSEN, H.; KÜMMEL, M. Evaluating estimation of gain directionality, part 2: a case study of binary distillation. Journal of Process Control, v. 2, n. 2, p. 67-86, 1992.

ARMSTRONG, J.; COLLOPY, F. Error measures for generalizing about forecasting methods: Empirical comparisons. International Journal of Forecasting, v. 8, p. 69-80, 1992. ISSN 01692070.

BIRDSALL, T. G.; RISTENBAT, M. P. Introduction to linear shift register generated sequences. Technical Report No. 90. Univ. Mich. Research Inst., Ann Arbor, USA, 1958.

BRISTOL, E. On a new measure of interaction for multivariable process control. Automatic Control, IEEE Transactions on, v. 11, n. 1, p. 133-134, Jan 1966.

BROCKWELL, P. J.; DAVIS, R. A. Time Series: Theory and Methods. Second. New York, NY 10013, USA: Springer New York., 1991.

CHEN, J. K.; YU, C. C. Optimal input design using generalized binary sequence. Automatica, v. 33, n. 11, p. 2081-2084, 1997.

CHIEN, I.-L.; HUANG, H.-P.; YANG, J.-C. A Simple Multiloop Tuning Method for PID Controllers with No Proportional Kick. Industrial \& Engineering Chemistry Research, v. 38, p. 1456-1468, 1999. ISSN 0888-5885.

DARBY, M. L.; NIKOLAOU, M. MPC: Current practice and challenges. Control Engineering Practice, v. 20, p. 328-342, 2012. ISSN 09670661.

DAVIES, W. System identification for self-adaptive control. Wiley-interscience, London, 1970.

FORSSELL, U.; LJUNG, L. Closed-loop identification revisited. Automatica, v. 35, p. 1215 - 1241, 1999.

GARCIA, C. et al. Algorithms and methods for identification of multivariable plants. In: Proceedings of the 24th European Symposium on Computer Aided Process Engineering ESCAPE 24. [S.l.]: Elsevier, 2004. v. 1, p. $667-672$.

GEVERS, M. et al. Identification of multi-input systems: variance analysis and input design issues. Automatica, v. 42, n. 4, p. 559 - 572, 2006.

GOLOMB, S. W. Sequences with randomness properties. Baltimore 3, Maryland, U.S.A.: [s.n.], 1965. 
GOUGH, W. Advanced model predictive control, ch. 18, Brain Wave@: model predictive control for the process industries. [S.1.]: InTech, 2011. 393-418 p.

ISERMANN, R.; MÜNCHHOFF, M. Identification of dynamic systems -An introduction with applications. [S.l.]: Springer-Verlag, Berlin, Heidelberg., 2011.

KOUNG, C. W.; MACGREGOR, J. F. Design of identification experiments for robust control. a geometric approach for bivariate processes. Industrial $\mathscr{6}$ Eng. Chemistry Res., v. 32, n. 8, p. 1658-1666, Agosto 1993.

KREMELBERG, D. Practical Statistics: A Quick and Easy Guide to IBM® SPSS® Statistics, STATA, and Other Statistical Software. [S.l.]: SAGE Publications, 2010.

LITH, P. Some considerations for mpc performance sustainment. Presented at ISA EXPO 2009, 6-8 in Reliant Center, Houston, Tx, 2009.

LJUNG, L. System identification: theory for the user. 2nd. ed. Englewood Cliffs, New Jersey: [s.n.], 1999.

MARQUES, F. G. Modelagem de uma planta piloto de neutralização de pH utilizando a combinação das abordagens fenomenológica e empírica. Dissertação (Mestrado) Escola Politécnica da USP. Departamento de Telecomunicações e Controle., 2015.

MICCHI, A.; PANNOCCHIA, G. Comparison of input signals in subspace identification of multivariable ill-conditioned systems. Journal of Process Control, v. 18, n. 6, p. 582 593, 2008.

MORALES, C. S. Identificação e controle preditivo de uma planta piloto de Neutralização de $p H$. Dissertação (Mestrado) — Escola Politécnica da USP. Departamento de Telecomunicações e Controle., 2013.

OGUNNAIKE, B. A. et al. Advanced multivariable control of a pilot-plant distillation column. AIChE Journal, v. 29, p. 632-640, 1983.

RANDALL, R.; TECH, B. Frequency Analysis. 3rd. ed. [S.l.]: Bruël and Kjaer, 1979.

RIVERA, D.; JUN, K. An integrated identification and control design methodology for multivariable process system applications. Control Systems, IEEE, IEEE, v. 20, n. 3, p. 25-37, 2000.

RIVERA, D. et al. Plant friendly system identification: A challenge for the process industries. In: 13th International Symposium on System Identification (SYSID).

Rotterdam, The Netherlands: [s.n.], 2003. p. 917-922.

SEBORG, D. E. A perspective on advanced strategies for process control (revisited). Advances in Control, P.M. Frank (Ed.) Springer-Verlag, NY, v. 15, p. 103-134, 1999.

SKOGESTAD, S.; MORARI, M.; DOYLE, J. C. Robust control of ill-conditioned plants: High-purity distillation. Automatic Control, IEEE Transactions on, IEEE, v. 33, n. 12, p. 1092-1105, 1988.

SöDERSTRöM, T.; STOICA, P. (Ed.). System Identification. Upper Saddle River, NJ.: Prentice-Hall, Inc., 1988. ISBN 0-138-81236-5. 
STOICA, P.; MOSES., R. Spectral Analysis of Signals. 1st. ed. Upper Saddle River, New Jersey 07458: Prentice Hall, 2005.

TULLEKEN, H. J. A. F. Generalized binary noise test-signal concept for improved identification-experiment design. Automatica, v. 26, p. 37-49, 1990.

VAILlANT, O. R.; KURAMOTO, A. S. R.; GARCIA, C. Effectiveness of signal excitation design methods for identification of ill-conditioned and highly interactive processes. Industrial \& Engineering Chemistry Research, v. 52, n. 14, p. 5120-5135, 2013.

ZHU, Y. Multivariable process identification for mpc: the asymptotic method and its applications. Journal of Process Control, v. 8, p. 101-115, 1998.

ZHU, Y. Multivariable system identification for process control. [S.l.]: Elsevier, Pergamon, 2001.

ZHU, Y.; STEC, P. Simple control-relevant identification test methods for a class of ill-conditioned processes. Journal of Process Control, v. 16, n. 10, p. 1113 - 1120, 2006. 